RONALD DAUS

\section{Der epische Zyklus der Cangaceiros in der Volkspoesie Nordostbrasiliens}

COLLOQUIUM VERLAG

BERLIN
In der ersten Hälfte des 20. Jahrhunderts wurden Verserzählungen nordostbrasilianischer Volksdichter millionenfach in kleinen Heften, in „Folhetos“, veröffentlicht. Durch die sehr enge wirtschaftliche Abhängigkeit vom Publikum sahen sich die Autoren gezwungen, möglichst getreu die Einstellung der unteren Schichten der Bevölkerung zu ihrer Umwelt und zu ihrer Gesellschaft zu reproduzieren und dadurch über die traditionellen literarischen Vorlagen, die Portugal geliefert hatte, hinauszugehen.

Am Beispiel der thematisch autochthonen, ehemals brennend aktuellen und besonders zahlreichen Cangaceiro-Geschichten untersucht Ronald Daus, wie und mit welcher Absicht eine präexistente Ideologie den Prozeß der Umwandlung geschichtlicher Realität in Dichtung prägte. Es zeigt sich, daß die literarische "Symbol"-Gestalt des Cangaceiros, als Ausdruck siegreicher und allmächtiger „Rebellion ", nur deshalb von den Volksdichtern so stark herausgearbeitet werden konnte, weil ihr im Rahmen der gesamten epischen Poesie Nordostbrasiliens ein anderes, ebenso bedeutendes Symbol, das 



$(16)$ 


\section{B IB LI OTHECA IBERO-A MERICANA}

Veröffentlichungen des Ibero-Amerikanischen Instituts

Preußischer Kulturbesitz

Herausgegeben von Hans-Joachim Bock

Band 12 
BIBLIOTHECA IBERO-AMERICANA

RONALD DAUS

Der epischeZyklus

der Cangaceiros

in der Volkspoesie

Nordostbrasiliens 
In ihren Grundzügen wurde diese Arbeit 1965 in Brasilien geschrieben. Die Philosophische Fakultät der Universität Kiel nahm sie im Wintersemester 1966/67 als romanistische Dissertation an.

(C) 1969 Colloquium Verlag Otto H. Hess, Berlin Satz und Druck: Thormann \& Goetsch, Berlin

Schrift: Linotype Garamond

Buchausstattung: Georg Goedecker - Printed in Germany

D 8 
TE IL I

DIE VOLKSPOESIE

NORDOSTBRASILIENS UND

DER EPISCHE ZYKLUS DER CANGACEIROS 
Die brasilianische Volksliteratur - Sprichwörter, Rätsel, Lieder, epische Gedichte, Märchen und Erzählungen, dramatische Tänze - konzentriert sich auf drei große geographisch-kulturelle Regionen, auf Amazonien, Nordostbrasilien und Rio Grande do Sul. Jedes dieser Zentren besitzt eine Gattung der Folklore, die im Mittelpunkt des künstlerischen Interesses der jeweiligen Bevölkerung steht. So verdrängen in Amazonien die indianischen Märchen und Legenden andere Formen der Volksliteratur; Rio Grande do Sul ist die brasilianische Hochburg der Gaúcho-Dichtung. Typisch für Nordostbrasilien (im allgemeinen kurz „Nordeste“ genannt), das aus den Bundesstaaten Ceará, Piauí, Rio Grande do Norte, Paraíba do Norte, Pernambuco, Alagoas, Sergipe und Bahia besteht, ungefähr $1220000 \mathrm{qkm}$ umfaßt und über 20 Millionen Einwohner (1960) zählt ${ }^{1}$, ist die Cantoria, eine Literaturform, die in dieser Arbeit in einigen historischen, psychologischen, soziologischen und literaturwissenschaftichen Aspekten untersucht werden soll.

Dieses mit „Gesang“ nur unzutreffend ins Deutsche zu übersetzende Wort "Cantoria“ bezeichnet ein Genre der Volkspoesie, das in zwei Gruppen zerfällt, in die Cantoria repentista und in die epischen Gedichte.

Die „Cantoria repentista“ ist ein Streitgesang zwischen mehreren, meist zwei Personen, in dem jede ohne eine zu lange Denkpause eine Antwort auf die herausfordernden Verse des Partners zu finden hat. Die Strophen werden in der Regel improvisiert; oft verwenden die Sänger aber auch, wenn es in den Zusammenhang des behandelten Themas paßt, traditionelle auswendig gelernte Passagen. Dieser Disput - Desafio, $\mathrm{Pe}$ leja, Discussão genannt ${ }^{2}$ - endet, wenn einer der Gegner nicht mehr in der Lage ist, eine schnelle Erwiderung zu finden ${ }^{3}$. Abgehalten werden Desafios auf Wochenmärkten und Kirchweihfesten, zuweilen auch im Hause begüterter Nordestinos. Die Zuhörer bezahlen die Sänger je nach ihrer Schlagfertigkeit. Der Sieger erhält von den Anwesenden ein Extratrinkgeld. Diese Streitgesänge dauern oft Stunden, manchmal sogar Tage; und so wechselt man häufig das Versmaß und die Strophenform, um das Publikum nicht allzusehr zu langweilen, und natürlich auch, um 
durch eine verwickelte Metrik den Gegner durcheinanderzubringen; denn dieser ist gezwungen, auf die gleiche Weise zu antworten ${ }^{4}$. Zur Arbeit der Repentistas gehören außer den Desafios die "Glosas“, die ebenfalls improvisiert zu werden pflegen ${ }^{5}$.

Die einfachste und älteste Strophenform der Sänger ist die Quadra. Sie trifft man heutzutage nur noch selten an. Die "Quadra " besteht aus vier siebensilbigen Versen (redondilha maior) und folgt dem Reimschema b-a-c-a. In Portugal, und später auch in Brasilien, war sie die volkstümliche Strophenform par excellence und diente als Teil einer größeren Komposition oder als komplettes Gedicht üblicherweise zu einer knappen Darstellung eines Gefühlszustandes:

Tudo que é triste no mundo

queria que fôsse meu,

Só pra ver se tudo junto

Era mais triste do que eu... ${ }^{6}$

Ihre beherrschende Rolle in der Cantoria repentista verlor sie um $1870^{\gamma}$, als zwei andere Strophenformen aufkamen, die noch heute das Gros der Desafio-Texte ausmachen. Die wichtigste ist die Sextilha, eine Strophe aus sechs Versen, Reimschema b-a-c-a-d-a:

- Senhor Manuel Serrador,

Vamos entrar em questão:

Nós somos dois candidatos,

Estamos numa eleição!

Hoje aqui há de se ver

Quem tem maior votação ${ }^{8}$.

Auch sie ist wie die Quadra volkstümlicher Herkunft, gehört aber seit dem 15. Jahrhundert zum Repertoire der portugiesischen Kunstpoesie, vor allem als Glosa, wie man an vielen Beispielen des "Cancioneiro geral" und an den Redondilhas des Luís de Camões feststellen kann. Dasselbe gilt für die zweite wichtige Strophenform der nordostbrasilianischen Cantoria repentista, für die Setilha. Ihre sieben Verse gehorchen dem Reimschema b-a-c-a-d-d-a:

Às vêzes um rapaz solteiro

Vai à casa da querida,

O façanha vê-se ali

Quem oferece a comida,

Faz-se de sala e porão,

Fica pedindo oração,

E lá vai desgôsto na vida ${ }^{9}$.

Die - seltenere - portugiesische "Oitava“ heißt in Nordostbrasilien Oito pés a quadrão (Reimschema: a-a-a-b-b-c-c-a), die „Décima“ Dez 
pés a quadrão (Reimschema: a-b-b-a-a-c-c-d-d-c). Die letztere Strophenform entspricht der spanischen „Décima espinela“, die von Lope de Vega und seinen Zeitgenossen in der dramatischen Dichtung häufig benutzt wurde und die in der portugiesischen Literatur vor allem durch die Glosas des Bocage bekannt ist. Sie wird wie auch die Oitava von den Repentistas Nordostbrasiliens meist mit siebensilbigen Versen verwandt. Als Zehnsilber heißt sie Galope oder Martelo oder auch Martelo agalopado. Fünfsilbige Verse sind in Sextilhas, Setilhas und Décimas sehr selten, kommen aber vor.

In vielen Fällen begnügen sich die Sänger nicht damit, eine Strophe des Gegners mit einer anderen zu beantworten. Sie fallen dem Gegenüber ins Wort und übernehmen einen Vers, worauf ihnen im darauffolgenden geantwortet wird und sie nun wieder den nächsten zu dichten haben. Auf diese Weise entstanden neue, mehrere Strophen überlappende Reimschemata, wie zum Beispiel der beliebte Mouräo trocado:

$$
\begin{aligned}
& \text {... Sänger } A \text { : }-----p \\
& -----\mathrm{p}
\end{aligned}
$$

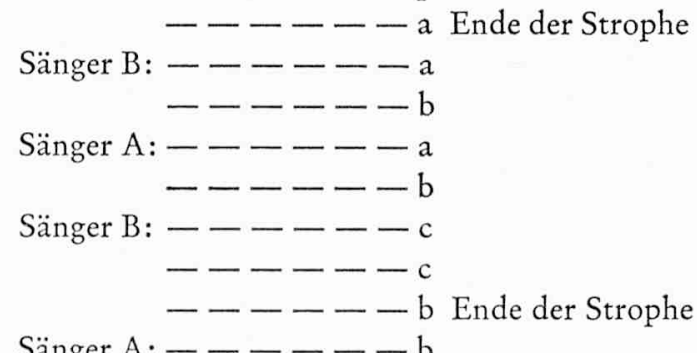$$
----- \text { - c..usw. }
$$

Diesen einfachen Metren, denen noch der Galope à beira-mar zugerechnet werden kann (es handelt sich um eine zehnsilbige Décima, deren zehnter Vers stets mit den Worten „beira do mar" enden muß) sowie die Gemedeira (eine Sextilha mit einem nach dem fünften Vers eingeschobenen „ai-ai, um ${ }^{10}$ ), schließen sich komplexere Metren an, wie die Toada alagoana (der erste, dritte, vierte, sechste und neunte Vers ist siebensilbig, der zweite, fünfte und achte dreisilbig; der letzte Vers muß immer "a toada alagoana" lauten; Reimschema: a-a-b-c-c-b-d-d-b") und der schwierige Gabinete, in dem vier-, sieben- und zwölfsilbige Verse in komplizierter, genau festgesetzter Reihenfolge miteinander abwechseln ${ }^{12}$. Ahnlich ineinandergeschachtelt, und ebenfalls von den nordostbrasilianischen Repentistas erfunden, ist die Parcela oder Carretilha (die Basis bilden fünfsilbige Verse ${ }^{13}$ ).

Die Quintilha und die noch von Leonardo Mota beschriebene Ligeira ${ }^{14}$ 
sind außer Brauch gekommen. Die „Gemedeira" und insbesondere der "Galope à beira-mar" haben ihnen den Rang abgelaufen.

Dieser Formenreichtum - teils der portugiesischen Volks- und Kunstpoesie entlehnt, teils selbst erfunden - ist das Ergebnis einer hundertjährigen Entwicklung, die auch jetzt noch nicht zum Abschluß gekommen $\mathrm{zu}$ sein scheint ${ }^{16}$.

Die Blütezeit der Cantoria repentista ist jedoch schon seit rund siebzig Jahren vorbei. Die letzten Jahre des 19. Jahrhunderts werden von den Sängern im allgemeinen als diejenige Epoche bezeichnet, in der die besten, schlichtesten und auch heute noch bekanntesten Desafios stattfanden. Die komplizierten formalen Kunstfertigkeiten begannen erst nach Romano da Mãe d'Água und Inácio da Catingueira ${ }^{17}$, als eine Art verzweifelter Rückzugsgefechte, zu Zeiten, als eine andere Form der Cantoria, die der epischen Gedichte ${ }^{18}$, immer mehr an Boden gewann.

Die ältesten Fragmente epischer Gedichte ${ }^{19}$, die uns von Folkloristen überliefert worden sind, stammen aus der Mitte des 19. Jahrhunderts sie wurden damals noch ausschließlich von Repentistas vorgetragen, dienten als Ergänzung eines Desafio ${ }^{20}$. Ihre überragende Stellung innerhalb der Volksliteratur Nordostbrasiliens aber errang die epische Volksdichtung erst, als diese Texte in kleinen Heftchen, in Folhetos, vom Format $12 \times 16 \mathrm{~cm}$, gedruckt wurden. Das älteste Folheto, das wir kennen, stammt aus dem Jahre 1902 und wurde von Francisco das Chagas Batista verfaßt; sein Titel ist Saudades do sertão ${ }^{21}$. Das verwandte Papier ist im allgemeinen sehr schlecht ${ }^{22}$, der Umfang der Heftchen beträgt üblicherweise, je nach Länge der Geschichte, acht, sechzehn, zweiunddreißig oder achtundvierzig Seiten, eine zwangsläufige Anpassung des Dichters an die Drucktechnik. In Brasilien wird diese gedruckte Volkspoesie in der Regel als "Literatura de cordel" bezeichnet, im Unterschied zur „Literatura oral“. Der Name kommt daher, daß die Folhetos auf den Wochenmärkten mit Wäscheklammern an Schnüren festgeheftet werden, um zum Verkauf anzureizen. Sicher wurde diese Bezeichnung aus Spanien (über Portugal) importiert, wo die Volksbücher schon im 16. Jahrhundert „libros de cordel“ genannt wurden ${ }^{23}$. Dieser bereits feststehende Gattungsbegriff hat sich dann auch in Brasilien durchgesetzt, als die Entwicklung der Volkspoesie des Nordostens den Stand erreichte, der den iberischen Volksbüchern entsprach.

Die Gedichte, die man als "Poesia épica“ innerhalb der Cantoria bezeichnet, sind in ihren ersten Zeiten (um 1850) ausschließlich in Quadras verfaßt worden ${ }^{24}$, bis sich um 1900 die siebensilbigen Sextilhas und 
Setilhas durchsetzten, diejenigen Strophenformen aus der Cantoria repentista also, die in der Einfachheit ihres Aufbaus (die drei Blankverse erleichtern den Fluß des Gedichtes beträchtlich) und durch die Lebendigkeit ihres Ausdrucks (eine Periode von sieben Silben entspricht etwa der üblichen Länge eines Sinnabschnittes in Prosatexten) am besten für lange Erzählungen geeignet sind - es gibt Texte mit über dreitausend Versen. Zu Sextilhas und Setilhas kamen später - um 1940 - die Décima (Reimschema: b-a-c-a-d-a-f-a-e-a), eingeführt durch José Pacheco.

Die zwei großen Meister der ersten zwanzig Jahre waren Francisco das Chagas Batista (1882-1930) und Leandro Gomes de Barros (18681918). Sie setzten die Maßstäbe, nach denen alle ihre Nachfolger anzutreten hatten. Sämtliche formalen Aspekte der epischen Volkspoesie Nordostbrasiliens sind von ihnen in endgültig gebliebener Weise ausgearbeitet worden und haben sich durch sie durchgesetz $\mathrm{t}^{25}$.

Die Tatsache, daß ihre epischen Gedichte als Folhetos gedruckt wurden, brachte als erste Konsequenz eine deutliche Veränderung des Stils gegenüber der Cantoria der Rezitatoren und Repentistas mit sich: man konnte auf die vielen epischen Formeln, die das unmittelbare Verständnis einer Rezitation erleichtern, wie zum Beispiel „nun gehe ich zu einem anderen Thema über", verzichten, man vermied überflüssige Interjektionen, die eine ganz bestimmte Stimmung erzeugen sollten, man sprach das Publikum nicht mehr mitten in der Geschichte an oder wiederholte nicht immer wieder dieselben, formelhaften Adjektive oder Appositionen, um eine Gestalt zu charakterisieren: auf all diese Hilfsmittel war der Volksdichter nicht mehr angewiesen, weil der Text stets nachlesbar war, weil stets einzelne Passagen wiederholt werden konnten. Wenn man einmal eine Figur vorgestellt oder eine Situation beschrieben hatte, brauchte man bei ihrer Wiederholung nicht immer wieder an sie zu erinnern. Selbstverständlich fehlen in den Folhetos auch die in der Cantoria repentista so beliebten Refrains; sie haben hier keine Funktion mehr, dienen nicht mehr als Gedächtnisstützen und erleichtern nicht mehr das Improvisieren. Die Spannung des Publikums wurde durch eine interessant erzählte, höhepunktreiche Geschichte aufrechterhalten, sie wurde nicht mehr dadurch erzeugt, daß man fortlaufend auf Kommendes hinwies, und dadurch erhöht, daß man vom Thema abschweifte; der epische Dichter, der für einen Leser arbeitet, kann mehr Geduld von seinem Publikum erwarten, braucht weniger eine Übermüdung zu befürchten, die bei einem Sänger bei aufmerksamem Zuhören zwangsläufig eintreten wird. 
Wie sehr die Volksdichter sich bewußt sind, daß ihre Texte gelesen werden müssen, beweist eine schon feststehende Formel, mit der sie einen Großteil ihrer Geschichten beginnen:

Leitores eu vou contar-vos ... $(13,1)^{26}$

O leitor deve lembrar-se... (100, 1).

Diese Verse zeigen, wie der Verfasser immer noch in einen unmittelbaren Kontakt zu seinem Publikum treten will, einen Kontakt, der sich aber nun nur auf die Einleitungsstrophen (und in einigen Fällen auf die Schlußverse) beschränkt. Nur hier spricht der Volksdichter seinen Leser an (oft in der archaischen Form der 2. Person Plural, wie in dem ersten Beispiel für einen Anfangsvers, das weiter oben zitiert wurde). Er will dem Leser einen Schlüssel für das Verständnis der Geschichte mit auf den Weg geben. So wird eine der ersten Strophen oft zu einer kurzen Skizzierung dessen, was zu erwarten ist, so führt sie in die Erzählung ein, wie zum Beispiel die ersten Verse der História da Imperatriz Porcina:

Nêsse romance se ver ${ }^{27}$

Quanto é vil a falsidade

Nunca triunfou na vida

Quem usasse da maldade

De acôrdo com sua ofensa

Terá êle a recompensa

Da sua perversidade. $(94,1-7)$

In ähnlicher Form wird dann eine Geschichte beendet - das lehrhafte Fazit wird gezogen (wie am Schluß des Folhetos Sacco e Vanzetti aos olbos do mundo):

Foi condenado à tragédia

Envolto em tremendo véu

Quando a inocência padece

E vai ao banco do réu

Seja na paz ou na guerra

Contra a justiça da terra

Vem a justiça do céu. (122, 393-399)

In der eigentlichen Erzählung tritt der Autor völlig zurück; die Handlung wird üblicherweise in leidenschaftsloser Form vorgetragen, mit knappen informativen Bemerkungen, mit genauer Beschreibung der angeblichen Ursprünge und der Auflösung einer Intrige. Nebenhandlungen fehlen. Es wird nicht zurückgeblendet oder vorgegriffen: jede Episode hat den Platz, der ihr chronologisch zusteht. Jede Strophe bildet einen Sinnkreis für sich, behandelt ein abgeschlossenes Thema ${ }^{28}$; jeder Vers ist ein geschlossener Satzabschnitt. Enjambements sind sehr selten. 
Schritt für Schritt, geradlinig, kommt man so der Lösung des beschriebenen Konfliktes näher. Die Meinung des Verfassers läßt sich nur durch gelegentliche schmückende Beiwörter für eine Person erschließen, wenn er zum Beispiel den Protagonisten „bom" nennt und den Antagonisten seines Helden ein "monstro “. Von der offensichtlichen Objektivität der Handlungsführung, von der Ausschaltung des Dichters, die in einem krassen Gegensatz zu den Desafio-Texten und den nichtgedruckten epischen Gedichten (bei manchen vorwiegend epischen ABCs zum Beispiel) steht, gibt die erste Strophe des sehr beliebten Folhetos Mariana e o capitão do navio einen Eindruck. In ihr wird dem Leser der Rahmen vorgestellt, in dem die Handlung ablaufen wird, in dem er seine eigene Position zu definieren hat:

Houve na ilha Nifon

Em um pôrto do Japão

Um homem chamado Alceu

$\mathrm{Da}$ cidade era Barão

Era rico em demasia

Mas tinha um mau coração. (106, 1-6)

Der allgemein übliche Gebrauch des Präteritums unterstreicht die durchkomponierte Abgeschlossenheit der Handlung, das Fehlen von Variationsmöglichkeiten. Anfang und Ende sind festgelegt, und so gehen die Folhetodichter nicht wie die Sänger ,in medias res“, sondern verknüpfen Beginn und Ausgang zu einer Einheit, zu einer folgerichtigen Steigerung; nicht Szenen werden geschildert, sondern ein Prozeß wird beschrieben $^{29}$. Da der Leser bei fast allen Geschichten weiß, wie sie ablaufen werden und wie sie ausgehen, da er sämtliche Kunstgriffe des Dichters kennt, darf die Erklärung für den außergewöhnlichen Erfolg der Folhetos sicher nicht allein im Ästhetischen gesucht werden.

Die epischen Gedichte, die in Folhetos veröffentlicht werden, entsprechen ausschließlich dem Typ von Gesängen, den Menéndez Pidal ${ }^{30}$ in bezug auf die hispanischen Romanzen "romances-cuento" genannt hat. Reine "romances-diálogo“, die sicher aus einem Wechselgesang entstanden, sind nicht mehr vorzufinden. Die Bedeutung der mitunter häufigen Gespräche wird immer noch einmal vom Dichter zusammengefaßt und erläutert. Lyrische Elemente sind innerhalb der epischen Gedichte sehr selten und kommen zumeist in den ersten, im Plauder-oder feierlichen Ton gehaltenen Strophen vor. Bemerkenswert ist hier bei einigen Dichtern, daß sie ihre Geschichten durch eine Anrufung Gottes oder der Musen beginnen, wie zum Beispiel in O filho de Garcia:

Deus Grande Ser Incriado ... $(89,1)$

Wahrscheinlich sind dies Reminiszenzen aus der Lektüre klassischer 
portugiesischer Oden, worauf der sinnlose, auch vom Verfasser nicht verstandene Wortschwall hinweist, den die Volksdichter für das wesentliche Stilelement bei diesen Werken zu halten scheinen. Als lyrische Einschübe innerhalb der Erzählungen finden wir einige Male Gebete der Hauptpersonen und andere Male ihre Klageausbrüche. Beides ist wohl nicht Nachklang traditioneller Motive aus der gehobenen epischen Literatur, sondern eine selbständige Verbindung zwischen Stilelementen aus der Cantoria repentista und der epischen Poesia popular, zumal gerade Gebete und Klagen einen großen Platz in der improvisierten Volkspoesie einnehmen. Trotz allem ist nicht auszuschließen, daß die Volksdichter in diesem Punkte traditionellen europäischen Vorbildern folgen, wie zum Beispiel in dem achtstrophigen Abschied der Rosa de Milão von der ihr liebgewordenen Einsiedelei ${ }^{31}$.

Nicht nur die formale Ausarbeitung ist seit den Zeiten Chagas Batistas und Gomes de Barros' unverändert geblieben, sondern auch das Verlags- und Verkaufssystem der Folhetos. Einige wenige Dichter, die genügend Geld haben auftreiben können, drucken ihre eigenen Erzeugnisse und die ihrer Kollegen in Tipografias ${ }^{32}$. Die Verfasser werden mit einer Anzahl von Folhetos entlohnt (meist sind es fünfzig gedruckte Exemplare, die man für ein Manuskript erhält), die sie auf den Wochenmärkten verkaufen, zusammen mit Folbeteiros, Personen, die selbst keine Gedichte schreiben und ein reiches Sortiment aller Verlage zum Kauf anbieten. Zum Teil haben sie sich, wie zum Beispiel in Recife, feststehende Buden gebaut. Das geographische Zentrum der epischen Poesie Nordostbrasiliens ist - genau wie der geistige Mittelpunkt der Cantoria repentista - das Innere der Staaten Pernambuco und Paraíba do Norte, zum Teil auch deren Küste. Von hier aus strömen die Dichter zum Verkauf ihrer Folhetos in die anderen Staaten des Nordostens, nach Bahia, Alagoas und Sergipe im Süden, nach Rio Grande do Norte, dem Ceará und Piauí im Norden und Westen und sogar bis Maranhão, Pará und Amazonas. In Südbrasilien haben sie sich Stützpunkte in Rio de Janeiro und São Paulo errichtet ${ }^{33}$. Verlagszentren sind Recife und Juàzeiro do Norte; Salvador und Fortaleza spielen eine untergeordnete Rolle. Die Millionenauflagen der Folhetos, die dort gedruckt werden, erdrücken die Produktion von Heftchen im Innern des Landes (wo es zum Teil Auflagen von nur hundert Exemplaren gibt, mit einer Handpresse hergestellt) ${ }^{34}$. Um 1960 war die Folhetoproduktion weitgehend monopolisiert. Kurz danach begann die große Krise der gesamten gedruckten epischen Volkspoesie, Folge nicht nur der immer größeren Schwierigkeit besitzloser Dichter, einen Verleger für ihre Verse zu 
finden, auch nicht nur die Folge der allgemeinen brasilianischen Wirtschaftskrise, des erhöhten Papierpreises und des Siegeszuges des Rundfunks, sondern der um rund vierzig Jahre verspätete Widerhall veränderter ökonomischer und sozialer Ausgangspositionen der Sertanejos. Selbst João José da Silva aus Recife, der größte Verleger, mußte seine Druckerei aufgeben ${ }^{35}$.

Der große Aufschwung der epischen Volksdichtung Anfang des 20. Jahrhunderts brachte als unmittelbare Konsequenz eine Arbeitsteilung zwischen Dichtern und Sängern mit sich. In den Anfängen der Cantoria (und zum Teil noch heute bei besonders begabten Sängern ${ }^{36}$ ) beherrschte man beide $Z$ weige, konnte improvisieren, vortragen und die Texte von Erzählungen selbst verfassen. Heute gibt es Spezialisten für Desafios und daneben Dichter, die nicht mehr singen können und ihre Verse von anderen vortragen lassen müssen, wenn sie ihre Folhetos verkaufen wollen ${ }^{37}$. Rodolfo Cavalcante, ein Volksdichter aus Bahia, zieht als Promotor einer Berufsgenossenschaft der Poeten in seinem Organ $O$ Trovador eine bewußte Parallele zu dem Phänomen Troubadour-Spielmann aus dem europäischen Mittelalter. Für ihn ist es unter der Würde eines Dichters, seine Folhetotexte selbst zu singen, wenn es für so etwas spezialisierte Hilfskräfte gibt ${ }^{38}$. Dieses Beispiel zeigt - gleich ob die Argumente Cavalcantes gut fundiert sind oder nicht —, wie weit die beiden Zweige der Cantoria sich im Bewußtsein der Volkspoeten auseinanderentwickelt haben. Die Cantoria repentista hat ihre Führungsstellung verloren, sie, die am Beginn der nordostbrasilianischen Poesia popular stand und die formale Ausbildung der epischen Volksdichtung so stark bestimmte, ist heute zu einer verspielten Abart der Volksliteratur geworden, die nach Ansicht der Nordestinos nicht das gleiche Prestige besitzt wie die Literatura de $\operatorname{cordel}^{39}$. 
Wie konnte sich in Nordostbrasilien eine eigenständige epische Dichtung entwickeln, die vergleichbare Volksliteraturgattungen in den anderen Regionen der brasilianischen Folklore weit in den Schatten stellt, und warum liegt der Beginn ihres Aufstiegs in der Mitte des vorigen Jahrhunderts?

Seit den ersten Jahrzehnten nach der Entdeckung Brasiliens war es der Nordosten, der im Mittelpunkt des Interesses der Portugiesen stand. Die Zuckerrohrkultur machte ihn Ende des 16. Jahrhunderts zum beherrschenden Gebiet Portugiesisch-Amerikas. Eine starke Einwanderung und Kolonisation, besonders nach dem Verlust Indiens, sicherte den überwiegenden Einfluß der Portugiesen in der um etwa 1700 vollständig konstituierten Mischkultur. Neben der Kunstpoesie und der gelehrten Dichtung strömte auch die Volksliteratur der iberischen Halbinsel in beträchtlichem Maße nach Brasilien, zumeist mündlich in Form von Liedern, Romanzen ${ }^{40}$ und Erzählungen, in einigen Fällen aber auch durch portugiesische Volksbücher (vom Typ der - französischen - Cronicques $d u$ geant Gargantua ${ }^{41}$ ) und Folhetos übermittelt. Das Wort „Folheto" wird schon im 16. Jahrhundert in Portugal verwandt. Die kleinen Heftchen machten nicht nur aktuelle Ereignisse bekannt und erzählten traditionelle Geschichten, sondern sie standen auch im Dienst der zeitgenössischen gehobenen Literatur. Vergessen wir nicht, daß die Stücke Gil Vicentes, Baltasar Dias' und auch die Camões' zuerst in Folhetos erschienen ${ }^{42}$. Es ist bekannt, daß das spanische Amerika von "pliegos sueltos" überflutet wurde. Rodríguez Marín ${ }^{43}$ schreibt, daß man allein im Jahre 1600 über Mexiko 10000 Bögen der Geschichte "Pierres y Magalona“ nach Amerika exportierte. Diese Pliegos sueltos hatten auf der gesamten iberischen Halbinsel - es gab zu jener Zeit kaum Sprachschwierigkeiten zwischen Spaniern und Portugiesen - die Funktion, die die Folhetos heute in Nordostbrasilien haben ${ }^{44}$. Man kann als sicher annehmen, daß Ende des 18. Jahrhunderts die Grundlage des Themenarsenals in der Volksliteratur Nordostbrasiliens weitgehend mit der der Metropole übereinstimmte ${ }^{45}$.

Begierig wurde im Nordosten nicht nur aufgenommen, was aus Portugal kam, sondern es wurde auch weiterverarbeitet. Das gilt besonders für 
die Verbindungen, die $\mathrm{zu}$ den großen europäischen Sagenkreisen geknüpft worden waren. Noch heute finden sich in der Folhetoliteratur Nachklänge des Troja-Zyklus (Helena, a deusa de Tróia und wahrscheinlich auch História do capitão do navio), des Zyklus Karls des Großen (hier seien nur genannt Batalba de Carlos Magno com Malaco, Rei de Fez, O cavaleiro Roldão, Roldão no leão de ouro, $A$ prisão de Oliveiros, Oliveiros e Ferrabrás und Traições de Galaläo e a morte dos 12 pares de França $a^{46}$ ), der Geschichten über Roberto do Diabo ${ }^{47}$, über Bernardo de Cárpio. Daneben ging der Kern der überwiegend didaktischen iberischen Novellenliteratur fast vollständig auf die Volksdichtung Nordostbrasiliens über. Wie beim Conde Lucanor des D. Juan Manuel steht bei diesen traditionellen Themen die moralische Nutzanwendung im Mittelpunkt, wie zum Beispiel bei den auch in Brasilien überaus verbreiteten und beliebten Geschichten der "Imperatriz Porcina “48, der „Donzela Teodora“49, der „Martírios de Rosa de Milão“, der „Martírios da Genoveva“, der „Fugida da Princesa Beatriz com o Conde Pierre" und der "História de João de Calais " ${ }^{\text {. }}$. Die enge Beziehung zu der europäischen Volksdichtung wird durch die Wiederaufnahme solcher Stoffe offensichtlich, verstärkt noch durch das Eingehen auf die Strömungen, die im 16. Jahrhundert in Spanien und Portugal vor allem die Romanzendichtung beeinflußten, auf pastorale und ritterlich-amouröse Themen. Beide Richtungen sind in der epischen Volkspoesie Nordostbrasiliens auch heute noch stark vertreten. $\mathrm{Zu}$ ihnen kommen die Geschichten über eine Reihe pikaresker Helden hinzu, allen voran der berühmte Pedro Malazarte (oder Malasartes) ${ }^{51}$ und Luís de Camões, der in Brasilien zu einem Possenreißer und Rätselrater herabgesunken ist, als Reflex der Abneigung „arbeitender" Menschen gegenüber „nichtsnutzigen" Verseschreibern.

Sämtliche berühmten Romanzen aus Portugal sind auch in Brasilien bekanntgeworden. Fast der gesamte Romanceiro ging schon während des ersten Jahrhunderts der Besetzung auf die amerikanische Kolonie über. Er brachte das amouröse Element in die epische Dichtung, lenkte vom nur Moralhaften und Heldischen etwas ab, stellte eine Verbindung zwischen Erzählungen und Liedern her. In einigen Fällen lieferte er außer der Anregung, sich mit bis dahin im Epischen unbekannten Stimmungsbildern zu befassen, auch Stoffe, wie im Falle der Romanze „A noiva roubada", deren Folhetofassung von Leandro Gomes de Barros ein sehr großer Erfolg wurde. Im allgemeinen aber blieben Stoff und Romanzenform beieinander, trennten sich nicht. Die beliebtesten portugiesischen Romanzen in Brasilien, die noch im vorigen Jahrhundert gesungen wurden, waren die „Dona Infanta“, der von Almeida Garrett 
hochgelobte „Bernal Francês", der „D. Duarte e Dona Donzilha“, die „Dona Maria e D. Arico“, der „Conde Alberto“, der „D. Carlos de Montealbar" (in zwei Versionen), die „D. Branca“, „O casamento malogrado", „Iria a fidalga", „Flor do dia“, „A pastorinha“, „Florioso", "Juliana", „A flor de Alexandria“, „Branca Flor", „Xácara de Flores Bela" und viele andere mehr ${ }^{52}$. Heutzutage sind all diese Romanzen im Nordosten zum größten Teil in Vergessenheit geraten. Die epische Volkspoesie hat sie verdrängt, ist an ihre Stelle getreten: das Publikum erwartet heute eine zusammenhängende Geschichte mit vielen Episoden, nicht mehr nur eine kurze Andeutung einer Situation. Es erwartet die Lösung eines Konfliktes. Wurde die epische Funktion der Romanze von der erzählenden Volkspoesie abgelöst, so übernahmen der Côco ${ }^{53}$ und die Embolada weitgehend ihre lyrische und musikalische. Nur einige ganz wenige Romanzen haben sich halten können, wie zum Beispiel die „Nau Caterineta“.

Seit ungefähr 1830 läßt der direkte portugiesische Einfluß auf die nordostbrasilianische Volksliteratur spürbar nach. Die Unabhängigkeitserklärung Brasiliens hat die beiden Länder zwar geistig nicht völlig auseinandergebracht, aber doch eine gewisse Distanz geschaffen. Dazu kommt, daß durch das Aufblühen der romantischen Bewegung in Portugal und Brasilien (und vor allem durch die übermäßige Produktion von Folhetins - die nicht mit den volkstümlichen Folhetos verwechselt werden dürfen) in den Städten die dem breiten Volk fremde gehobene Dichtung popularisiert wurde und in großem Maße die Volksbücher ersetzte.

Die Speicherung auswärtigen Kulturgutes in Nordostbrasilien bekam keinen Zufluß mehr. Ein Gärungsprozeß setzte ein. Der Nordosten besann sich auf sich selbst, denn von den anderen Gebieten Brasiliens war keine geistige Befruchtung zu erwarten: der Nordosten hatte sich gegenüber den übrigen Regionen abgekapselt ${ }^{54}$. Geographische Gegebenheiten spielen bei dieser Isolierung eine große Rolle. Wir dürfen nie vergessen, daß der übliche Weg, um nach Recife zu kommen, der Seeweg war und daß so Portugal dem Nordestino näher lag als Santos, Rio Grande do Sul oder gar Argentinien. Der Landweg nach Amazonien wurde erst um 1950 erschlossen, der nach Süden war bis Anfang dieses Jahrhunderts durch die Caatinga-Barriere im südlichen Bahia abgeriegelt. Ein Carioca mußte das Schiff nehmen, um an die Nordostküste zu gelangen, und auch dann war es noch sehr schwierig, in das Innere vorzudringen. Es muß daran erinnert werden, daß die starke nationale Mobilität der Nordostbrasilianer, die heutzutage eines ihrer hervor- 
ragendsten Merkmale ist, erst um 1880 einsetzte, nach dem kurzen Zwischenspiel des Paraguay-Krieges (1865 bis 1870) ${ }^{55}$, zur Zeit des Kaffeeund Kautschuk-Booms, in ihrem Ausmaße verstärkt durch die katastrophale Dürrezeit von 1877 bis 1879 . So wanderten allein im Jahre 1878 im Ceará 120000 Personen aus (bei einer Gesamtbevölkerung von 800000 Einwohnern); noch im Jahre 1900 zogen 40000 Cearenses nach Amazonien ${ }^{56}$. Heute geht man zumeist nach Rio in die Bauwirtschaft oder nach São Paulo auf die Kaffeeplantagen. Kehrten diese Auswanderer in ihre Heimat zurück, so konnte man ein interessantes Phänomen beobachten. Sie hatten ihre Volkskultur (und das heißt in entscheidendem Maße, die beiden Varianten der Cantoria) in ihren Auswanderungsorten bekanntgemacht, hatten sie dort eingeführt, ließen sich aber nicht von der ortsansässigen Folklore beeinflussen. So brachten die Cearenses ihre epischen Gedichte nach Amazonas, propagierten nach ihrer Heimkehr aber keineswegs auch Elemente der dortigen Volksliteratur, die doch mit ihren Legenden eine sehr eigene und beeindruckende Note besitzt. Auch in der Fremde kapselten sich die Nordestinos.ab, nahmen den Sertão mit sich. Das größte Zugeständnis an die veränderten Ortsgegebenheiten war es, wenn sie ihre traditionellen Themen einmal in schematischer Form auf dortige Verhältnisse übertrugen (wenn zum Beispiel aus einem grausamen Zuckerrohrplantagen-Besitzer ein grausamer Kautschuk-Pflanzer wurde, wie in dem Folheto O Nero do Amazonas). Die bewährten Grundstrukturen ihrer Geschichten wurden nicht verändert.

Die Ablösung des Nordostens von der portugiesischen Volkskunst fiel in die Blütezeit der Cantoria repentista. Von ihr formal in starkem Maße beeinflußt, wurden die bekannten portugiesischen Themen in Versform gebracht (sie waren aus Portugal, mit Ausnahme der Romanzen, zumeist in der Prosaform übermittelt worden. Das einzige portugiesische Volksbuch, das ein traditionelles Thema behandelte und in Versen geschrieben war, ist die Imperatriz Porcina, die volkstümliche Fassung des Gedichtes von Baltasar Dias aus der zweiten Hälfte des 16. Jahrhunderts). Die Handlungsschemata, die sich auf eine Handvoll Prototypen reduzieren lassen, wurden nun von den Volksdichtern selbständig variiert und ergänzt. Neue Geschichten kamen auf, entweder mit dem vorhandenen Material in eine neue Anordnung gebracht oder durch Aufnahme lokaler Elemente.

Aus der portugiesischen Volksdichtung in Brasilien wurde eine nordostbrasilianische Volkspoesie mit durchaus eigenen Zügen, aus der portugiesischen „Literatura tradicional“ eine nordostbrasilianische „Literatura popular" ${ }^{65}$. 
Von der einmal von Portugal gezogenen Grundlinie aber ging man nicht $a b$. Neue Stoffe wurden nur dann behandelt, wenn sie den traditionellen Schemata entsprachen. So ließ man die von den Indianern und Negern stammende Literatur völlig beiseite (trotz der Rassenzugehörigkeit der Dichter und des Publikums zu diesen beiden Gruppen oder zu ihren Mischungen untereinander und mit Weißen!), bemächtigte sich aber verwendbarer gehobener Literatur, die zu jener Zeit, um 1860, zur Blütezeit einer volkstümelnden Romantik, besonders geeignet zur Umformung erschien. Die bekanntesten Romane José de Alencars, Iracema und O Guarani, wurden von den Volksdichtern "übersetzt", in Sextilhas und Setilhas gebracht. Das gleiche geschah natürlich mit einem Großteil der spätromantischen Folhetimliteratur und entsprechenden Werken aus Portugal (so zum Beispiel mit dem Amor de perdição von Camilo Castelo Branco, einem Roman, der in zwei Folhetobänden von João Martins de Ataíde nacherzählt worden ist) und Frankreich (es gibt Heftchen über die Dama das Camélias und O Corcunda de Notre Dame). Die Volksdichter wurden durch billige Volksausgaben von Märchen und Sagen fremder Völker auch mit Geschichten aus 1001 Nacht bekannt (Ali-Babá e os 40 ladrões; Aladim $e$ a princesa de Bagdá und História de Aladin ou a lâmpada maravilhosa), mit den Mythen der Griechen (O principe e o monstro Teseu, o berói do Labirinto) und der Jungfrau von Orléans, die es ihnen besonders angetan zu haben scheint - es gibt drei verschiedene Versionen der "Joana d'Arc" von drei verschiedenen Dichtern. Ja, sogar die neunte Novelle des zweiten Tages vom Decamerone Boccaccios existiert unter dem Namen Madame Guinevra in Sextilha-Form. Ihr Autor ist José Galdino da Silva Duda ${ }^{58}$. Seit den zwanziger Jahren dieses Jahrhunderts ist es üblich geworden, auch Filmsujets in Folhetos zu verwenden. Man hielt sich dabei an Streifen, die in ihrer Bewußtseinslage der des Sertãos entsprachen, an amerikanische Wildwest- und Abenteurerfilme mit Vorrang, wohl auch mal an Filme mit biblischen Stoffen wie "Sansão e Dalila“ (3 Versionen). In letzter Zeit dienen oft Produkte des brasilianischen "Cinema Novo" als Vorbilder; sie sind durch ihre - meist nordostbrasilianischen - Themen besonders geeignet: es sei als hervorstechendes Beispiel $O$ cangaceiro genannt.

Die epischen Gesänge im Nordosten lassen sich als regionale Subliteratur zu der brasilianischen gehobenen Literatur definieren. Sie wurde von denjenigen Schichten der Bevölkerung erschaffen, die von der "Literatura de arte" nicht erfaßt werden konnten und ihre Entwicklung nicht mitmachten, die sich von ihr nicht ansprechen ließen, weil sie sie 
nicht verstanden. Der Abstand zwischen den beiden Arten brasilianischer Literatur entspricht dem Bildungsgefälle innerhalb der Bevölkerung und daher natürlich dem primären sozialen Gefälle. Die Kunstliteratur gehört den Gebildeten und Reichen; Literatura de cordel ist die Literatur der armen Massen Nordostbrasiliens. 
Nach achtzig Jahren eines in ständiger Entwicklung befindlichen Zustandes, nach dem Ende des ersten bedeutenden ökonomischen $\mathrm{Zy}-$ klus, dem des Brasilholzes, nach einer Zeit, in der sich die portugiesischen Eroberer um nicht viel mehr kümmerten als darum, sichere Landeplätze für ihre Schiffe zu finden und Indianer einzufangen, die das schwere Brasilholz zu verladen hatten ${ }^{59}$, bildete sich Ende des 16. Jahrhunderts durch den Import der Zuckerrohr-Wirtschaft und den Beginn einer planmäßigen Kolonisation in der Sociedade açucareira, der „Zuckerrohr-Gesellschaft", die erste eigenständige Gesellschaft des portugiesischen Amerikas heraus. Ihre Struktur läßt sich folgendermaßen skizzieren $^{60}$ :

1. Die breite Basis wird von Sklaven gebildet (zuerst von Indianergefangenen, dann von eingeführten Negern).

2. Darüber stehen die Portugiesen (zu denen noch ein Großteil der Mestizen und Mulatten hinzuzurechnen ist), die kein Land besitzen und die ihren Lebensunterhalt durch selbständige oder Lohnarbeit verdienen müssen (Handwerker, Händler, Aufseher usw.).

3. Die herrschende Schicht ist die Aristokratie der "Senhores de engenho", unterstützt von den Kapitalisten der Metropole.

Diejenigen Portugiesen, denen es nicht gelungen war, in dieser Gesellschaft einen Platz zu finden, setzten auf eigene Faust, trotz aller königlichen Edikte, den Krieg gegen die Indianer fort. Die gesamte Küste Nordostbrasiliens war in einer Breite von $150 \mathrm{~km}$ fest in der Hand der Eroberer. Um 1560 schon begannen die portugiesischen Raubzüge ins Innere; mit Unterstïtzung des Gouverneurs Mem de Sá wurden die Caetés am São-Francisco-Fluß ausgerottet, während eines Feldzuges, der auch die Jesuitensiedlungen nicht verschonte. Das Abschlachten der Indianer hielt bis zum Beginn des 18. Jahrhunderts an. Krieg war über zweihundert Jahre hindurch die normale Situation im Sertão, im Inneren Nordostbrasiliens. Auf brutalste Weise wurde der Ceará erobert ${ }^{6 \mathbf{1}}$. Um 1700 war die Widerstandskraft der Indianer gebrochen ${ }^{62}$. Nur noch sehr selten versuchten sie, sich weiterhin dem Vordringen der Weißen entgegenzustemmen oder vielleicht sogar einen Gegenangriff $\mathrm{zu}$ wagen. Sie assimilierten sich. 
Schon zu Beginn der Eroberungszüge hatten die Weißen das Land unter sich aufgeteilt und, weil dort die Zuckerrohrpflanzungen nicht gediehen, eine neue Form der Landwirtschaft in den Sertão gebracht, die Viehzucht. Sie waren die ersten, die die Caatinga, dieses für undurchdringlich gehaltene Dornen- und Kaktusgestrüpp, ökonomisch nutzbar machten. Der Sertão wurde (schon im 17. Jahrhundert) zu einer Wirtschaftsregion, ohne die der schmale Küstenstreifen, wo man jedes Fleckchen Land für das Zuckerrohr verwandte, nicht lebensfähig gewesen wäre. Der Sertão wurde die Fleischkammer des Nordostens und stellte die Ochsengespanne, die unbedingt für den Transport des Zuckers zu den Häfen gebraucht wurden. Die gesicherte wirtschaftliche Grundlage ließ eine Abart der Sociedade açucareira entstehen, die Gesellschaft des Sertãos, die Sociedade sertaneja. Es ist eine Gesellschaft, die, üblicherweise nicht sklavenhaltend, in horizontaler Richtung nicht so deutlich ausgeprägt ist wie die Zuckerrohr-Gesellschaft: ihre Konturen sind fließender, ständig in Bewegung. Die Grundstruktur jedoch ist noch starrer ausgebildet. Die Sociedade sertaneja ist eine von Adeligen ${ }^{63}$ beherrschte Gesellschaft mit stark ausgeprägten autoritären Zügen, die - vorhandene - demokratische Strömungen zu bedeutungslosen, nur um der Tradition willen aufrechterhaltenen Floskeln werden läßt. Man kann drei Klassen voneinander unterscheiden:

1. Die große Mehrheit der Bevölkerung (etwa 80 Prozent) ist besitzlos und muß sich deshalb in den Dienst der beiden anderen Gruppen stellen. $\mathrm{Zu}$ dieser Schicht gehören die wenigen überlebenden Indianer und ein sehr großer Teil der Mestizen. Es kann innerhalb dieser Klasse ein starker Zug zum Nomadismus festgestellt werden ${ }^{64}$.

2. Es gibt eine kleine Mittelschicht, die sich aus Pächtern (auf Parzellen, die von den Latifundien abgetrennt werden), kleinen Grundbesitzern und Händlern zusammensetzt.

3. Der weitaus größte Teil des Landes gehört den aristokratischen Sesmeiros (den Leuten, die vom König eine „Sesmaria“, das Besitzrecht auf ein bestimmtes Stïck Land, erhalten haben). Sie sind die wirtschaftlichen und politischen Herren des Sertãos.

Diese Sociedade sertaneja hatte sich nach dem Sieg über die Indianer, den Feind, der aus dem Inneren des Landes kam, zu genau der Zeit endgültig konstituiert, als auch die Sociedade açucareira durch die $\mathrm{Ab}-$ wehr des äußeren Feindes, der Franzosen und der Holländer, in ihrer Struktur nachdrücklich bestätigt wurde.

Den Resonanzboden der volkstümlichen Poesia épica bilden die beiden unteren Schichten der Bevölkerung des Sertãos und - in individueller 
Parallele zur sozialen Stufenleiter - die Kinder der Fazendeiros. Etwa 85 Prozent der nordostbrasilianischen Sertanejos gehören zum ansprechbaren Publikum der epischen Gedichte, das sind ungefähr zehn Millionen Menschen. Dazu kommt eine große Anzahl von Personen, die außerhalb des Sertãos, des Kerngebietes der Cantoria, lebt. Es sind insbesondere die Auswanderer, die jetzt in Südbrasilien wohnen, und diejenigen, die im Bereich der alten Sociedade açucareira bis zum Ende des letzten Jahrhunderts Sklavenarbeit verrichteten und heute Landarbeiter sind. Im Sertão übernahmen die Volksdichter, die Folhetos schrieben, zu Beginn im wesentlichen das Publikum von ihren Kollegen aus der Cantoria repentista. In starkem Maße erweitert wurde dieser Grundstock durch die Möglichkeit, die gedruckten Exemplare der Gedichte bis in die letzten Winkel des Sertãos zu bringen; der Dichter brauchte nicht mehr, wie vorher, persönlich anwesend zu sein.

Ausnahmslos stammt der Volksdichter aus derselben Schicht wie sein Publikum. Er ist wahrhaftig noch das Sprachrohr seiner Klasse; und seine Interpretationen geben Aufschluß über den Bewußtseinsstand der Sertanejos. Er artikuliert eine kollektive Ideologie. Die Kongruenz zwischen Publikum und Autor ist noch nicht zerbrochen. Die Ubereinstimmung in den allgemeinen - und speziell den ästhetischen - Ansichten zwischen dem nordostbrasilianischen Volksdichter und der breiten Masse der Bevölkerung ist etwas Lebensnotwendiges für den Poeten. Besitzlos und in der Regel ohne andere Beschäftigung, ernährt er sich von seinen Gedichten. Er zieht von einem Ort zum anderen, zu den Hauptstädten des Nordostens, bis zum Amazonas, um seine Heftchen zu verkaufen und Geld für den Unterhalt seiner Familie zu verdienen. Er muß sich der Marktlage anpassen, darf in seinen Texten nicht frei von eigenen, vielleicht originellen Ideen ausgehen, sondern ist darauf angewiesen, dem Volk unter allen Umständen zu gefallen. An Bewährtes muß er sich halten, an Modelle, von denen er die Gewißheit hat, $\mathrm{d} a ß$ sie beim Publikum ankommen und daß der Verbraucher durch sie zum Kauf angereizt wird.

Zwangsläufig läßt sich eine sehr weitgehende stilistische und gedankliche Uniformität in der Gruppe von Gedichten feststellen, die ein gemeinsames Thema behandelt. Zumeist fehlen bei den einzelnen Volksdichtern, die ja auch oft anonym schreiben, individuelle Merkmale; oder nur sehr geringe Nuancen unterscheiden sie voneinander. Die Gesamtheit der Folhetos eines Zyklus hat den Anschein, als sei sie aus einem Guß gearbeitet ${ }^{65}$.

Doch so sehr groß die gemeinsame Basis von einfachem Sertanejo und 
Poeta popular auch ist - eines unterscheidet den Dichter von seinen Landsleuten: die Begabung, sich ausdrücken zu können. Der nordostbrasilianische Volksdichter fühlt sich so solidarisch mit der Schicht, aus der er stammt, mit deren Ideologie, daß er glaubt, sich für dieses Anderssein entschuldigen zu müssen. Er versucht sich dadurch zu rechtfertigen, daß er sagt, nicht um des Geldes willen übe er seine Kunst aus, auch nicht nur, um andere zu unterhalten, schon gar nicht, weil es ihm Spaß mache, sondern aus Pflichtgefühl. Er wolle Wissen vermitteln und erziehen, die Sertanejos durch Ratschläge in ihnen verständlicher Sprache auf das eigene Niveau emporheben. Der Folhetoverleger Manuel Camilo dos Santos aus Campina Grande schreibt auf das Rückblatt seiner Heftchen: „As poesias desta casa instrui, alegra e suavisa." An erster Stelle kommt das Belehren, dann erst das Vergnügen. Das ist das Alibi des Poeten für sein Ausscheren aus der Norm.

Dieses Wissen, das der Volksdichter vermitteln will, ist eine Aneinanderreihung von Einzeldaten aus den verschiedensten Gebieten. Enzyklopädisches, ungeordnetes Wissen wird von Kindern und Autodidakten aus niederen Schichten stets für das Erstrebenswerte angesehen. Diese Menschen spüren, daß sie innerhalb ihrer Gesellschaft zurückgesetzt sind; sie sehen den Erfolg anderer, und sie können ihn nur dadurch erklären, daß diese ein automatisch funktionierendes Erfolgsrezept haben, das sich anzueignen man sich bemühen muß. Die anderen wissen Dinge, die man selbst nicht versteht: man muß sie lernen; und so lernt man die Namen der Dinge, die andere besitzen. Sie benennen zu können, eröffnet die Möglichkeit, sie zu erhalten. Wenn der Sertanejo einen Menschen klug nennt, so meint er damit, dieser hat ein großes Vokabular (das läßt sich leicht auf die Repentistas beziehen), oder er kann exemplarische Geschichten erzählen (hier wird das einfache Benennen schon um die Fähigkeit, einen Prozeß geistig aufzunehmen, erweitert: die epischen Volksdichter tun dies).

Es ist verständlich, daß sich die Volksdichter daher als die Elite ihrer Schicht fühlen und von den Sertanejos als solche anerkannt werden. Die Dörfer und Städte, in denen Dichter leben, rühmen sich ihrer. Selbst die reichen Fazendeiros achten sie. Und es nimmt nicht wunder, daß in einer Gesellschaft, in der die Alphabetisierung der Bevölkerung schon weit fortgeschritten ist - und nicht zuletzt durch den Wunsch der Massen, Folhetos zu lesen - , der epische Volksdichter ein höheres Prestige genießen muß als der zumeist analphabetische Desafiosänger. Die Folhetoschreiber haben es verstanden, sich der Anhebung des Kulturniveaus im Sertão anzupassen. Sie geben ihren Lesern das Gefühl, ihre Bildung zu verbessern. Folhetos lesen zu können, ist ein Statussymbol ${ }^{66}$. 
Der Zyklus der Cangaceiros eignet sich in besonderem Maße als Ausgangspunkt einer Analyse der nordostbrasilianischen Volkspoesie: er ist autochthon, hat einen überwältigenden Erfolg bei den Sertanejos und ist in einer beträchtlichen Anzahl von Folhetos in der Form einer fingierten Autobiographie geschrieben.

Er beschreibt die Taten und Persönlichkeiten Antônio Silvinos und Lampiãos, der beiden berühmtesten Cangaceiroführer des Sertãos, geht also ein spezifisch nordostbrasilianisches Thema $a n^{67}$, das in seiner speziellen Form keinerlei Bezug zu traditionellen volksliterarischen Sujets des Portugals der Jahre 1400 bis 1800 hat. Durch die weitgehende Isolierung des Nordostens im 19. Jahrhundert dürften, zur Zeit der Herausbildung des Zyklus, nicht nur direkte iberische Einflüsse gefehlt haben (etwa durch Gedichte über den portugiesischen Räuber José Telhado oder den Spanier José María), sondern auch Beziehungen zu ähnlichen Phänomenen in anderen lateinamerikanischen Staaten, wie zum Beispiel in Mexiko oder den Río-de-la-Plata-Ländern. Der Austausch volksliterarischer Formen und Themen zwischen dem portugiesischen und spanischen Amerika war (mit Ausnahme von Rio Grande do Sul und Misiones) stets auf ein Minimum reduziert. Frei konnten die Volksdichter Nordostbrasiliens in selbständiger Arbeit ein für sie aktuelles Thema, den Cangaço, den Schemata anpassen, die ihnen als Grundlage bei der Abfassung neuer Varianten von traditionellen Sujets dienten. Sie erkannten die Ähnlichkeiten zwischen den geschichtlichen Ereignissen, die sich vor ihren Augen abspielten, und den Handlungsläufen beliebter, aus Europa importierter Heldengeschichten. Die historischen Daten, die ihnen über die Cangaceiros zur Verfügung standen, wurden in die fixierte Form der heroischen Erzählungen gezwängt (die zahlreichen und immer gleichen Rittergeschichten lieferten dazu ausreichendes Anschauungsmaterial). Es soll nun untersucht werden, wieweit die Protagonisten im Zyklus der Cangaceiros entpersönlicht wurden und in welchen Fällen es ihnen gelang, durch ein besonders starkes Image selbständig Maßstäbe zu setzen, neue Varianten in die heroischen Handlungsschemata einzuführen und diese ihren Nachfolgern aufzuzwingen ${ }^{68}$. Die wichtigste Aufgabe wird die Analyse 
und Interpretation des symbolischen Kerns der Cangaceiro-Figur sein.

Der Erfolg der Cangaceiro-Folhetos im Sertão war und ist immer noch enorm. Câmara Cascudo spricht von mehr als einhundertfünfzig Folhetos allein über Lampiãa $0^{69}$; die Auflagen der bekanntesten Heftchen aus dem Zyklus gehen in die Hunderttausende und werden seit Jahrzehnten laufend erneuert. Schon unter den ältesten Folhetos, die erhalten blieben, behandelte ein beträchtlicher Anteil Cangaceiro-Themen; und als Gustavo Barroso 1912 sein Buch Ao som da viola schrieb, in dem er die gesamte Volksdichtung Brasiliens in Zyklen einteilte, nannte er neben dem überwiegend lyrischen Zyklus der Vaqueiros als einzigen Eigenzyklus des Nordostens den der Cangaceiros ${ }^{70}$.

Durch eine formale Besonderheit unterscheidet sich der Zyklus der Cangaceiros von allen anderen Texten der Poesia épica Nordostbrasiliens: sehr häufig verwenden die Verfasser die 1. Person Singular bei der Erzählung der Ereignisse. Ursprünglich hatte dies zweifellos mit der Angst der Volksdichter vor Repressalien zu tun: lobten sie in objektiv erscheinender Form das Vorgehen des Cangaceiro, so mußten sie Racheakte der Polizei befürchten. Tadelten sie den Cangaceiro, so erging es ihnen nicht besser: dessen Freunde verfolgten sie ebenso hartnäckig. Aus dieser Zwickmühle retteten sie sich, indem sie ihre Texte in einer Form abfaßten, die sie nicht kompromittieren konnte: der Protagonist selbst erzählt seine Geschichte. Aber hierbei stellt sich eine psychologische Folgeerscheinung ein: beim Lesen oder Vortragen dieser Verse identifiziert man sich mit dem Helden ${ }^{71}$, erzählt von ihm zwangsläufig so, als handele es sich um die eigene Person. Derjenige wiederum, der einem Vorlesenden zuhört, verbindet mit der Gestalt des Cangaceiro notwendigerweise auch die seines Gegenübers. Das beim lauten Lesen übliche Gesten- und Betonungsspiel unterstützt diesen Identifizierungsprozeß. Kein anderer Zyklus der Volkspoesie Nordostbrasiliens hat daher einen so tiefgehenden Einfluß auf die Leser im Sertão wie der Zyklus der Cangaceiros. Er gibt Auskunft über die psychologischen Grundstrukturen im Verhalten der Sertanejos; er läßt Rückschlüsse zu über Wünsche und Frustrationen der überwältigenden Mehrheit der Bevölkerung Nordostbrasiliens.

Um den Zyklus der Cangaceiros eingehender untersuchen zu können, ist es notwendig, seinen Platz innerhalb der Poesia épica des Nord- 
ostens zu definieren und schrittweise seine Stellung in Beziehung zu anderen Stoffen zu klären.

In der Sekundärliteratur über die Volkspoesie Nordostbrasiliens gibt es zwei ernstzunehmende Versuche, Gedichte aus Folhetos zu klassifizieren. Ariano Suassuna teilt die epischen Texte in sechs verschiedene Zyklen ein $^{72}$, wobei das Kriterium der Zugehörigkeit eines Folheto zu einem bestimmten Zyklus das vorherrschende Handlungsmoment ist. Die Klassifizierung des Centro de Pesquisas da Casa de Rui Barbosa ${ }^{73}$ geht teils von der Definition des Protagonisten aus, teils aber auch vom Hauptthema des Textes. Sie bezieht sich dabei sowohl auf epische als auch auf nicht-epische Gedichte ${ }^{74}$.

Es erscheint ratsam, in den Grundzügen auf der Klassifizierung Suassunas aufzubauen, wobei sechs Große Zyklen in einundzwanzig Zyklen zu unterteilen $\sin ^{75}$ :

\section{A. GROSSER HEROISCHER ZYKLUS}

1. Zyklus der Cangaceiros

(z. B. Folhetos über Lampião und Antônio Silvino)

2. Zyklus der Valentes

(Folhetos über mutige, capangaähnliche Draufgänger)

3. Zyklus der berühmten Verbrecher

(z. B. Folhetos über Marreco und bekannte Pistoleiros)

4. Zyklus anderer Helden

(z. B. Folhetos über Roldão und Roberto do Diabo)

5. Zyklus der sozialen und wirtschaftlichen Satiren

(z. B. Folhetos über wirtschaftliche Ausbeutung und ungerechtfertigte Teuerung) ${ }^{76}$

B. GROSSER ZYKLUS DER ANTIHELDEN

1. Zyklus der pikaresken Antihelden (z. B. Folhetos über João Grilo, Camões und Cancão de Fogo)

2. Zyklus der nicht-pikaresken Antihelden (z. B. Folhetos über die Donzela Teodora und die Zigeunerin Rosilda) ${ }^{77}$

C. GROSSER ZYKLUS DER MARCHENHAFTEN GESCHICHTEN

1. Zyklus der phantastischen Geschichten und der Märchen (z. B. Folhetos über künstliche Pfaue, die Menschen transportieren, 
über Rotkäppchen, über Abenteuer von Riesen)

2. Zyklus der Geschichten über phantastische Phänomene (z. B. Folhetos über „bois misteriosos" und über Frauen, die Tiere zur Welt brachten)

3. Zyklus der utopischen Geschichten

(z. B. Folhetos über das Schlaraffenland ${ }^{78}$ )

D. GROSSER ZYKLUS DER LIEBESGESCHICHTEN

1. Zyklus der Liebesgeschichten unverheirateter Partner

(z. B. Folhetos über Liebende, die durch ihre Eltern getrennt werden, und über den Kampf Liebender gegen Mißgünstige)

2. Zyklus der Geschichten über die Treue eines Ehepartners (z. B. Folhetos über Genoveva und die Kaiserin Porcina)

3. Zyklus der unsittlichen Geschichten (zumeist homosexuelle Geschichten oder Ziegenbock-Parabeln)

E. GROSSER RELIGIOOSER ZYKLUS ${ }^{79}$

1. Zyklus des Padre Cícero

(Folhetos über das Wirken und die Predigten des cearensischen Fanatikerführers)

2. Zyklus der Geschichten über religiöse Ereignisse und Wunder

(Folhetos über Heiligenlegenden, über die Wunder, die ein Heiliger im Sertão vollbracht hat, über feierliche Prozessionen u. dergl.)

3. Zyklus der Predigten und religiösen Betrachtungen

(z. B. Folhetos über fiktive Predigten von Missionaren und über religiöse Ideen der jeweiligen Volksdichter)

4. Zyklus der Fabeln und der moralisierenden Geschichten

(z. B. Folhetos über Ratschläge erteilende Tiere, über exemplarische Geschichten, daß Unrecht nicht lohnt)

5. Zyklus der moralisierenden Satiren

(z. B. Folhetos über den neuzeitlichen Sittenverfall, über die Mode)

6. Zyklus des Teufels

(z. B. Folhetos über die Versuche des Teufels, sich Seelen verschreiben zu lassen und Gläubige zum Unglauben zu verführen)

7. Zyklus der Magie

(z. B. Folhetos über Hexen und Hexenmeister und über spiritistische Sitzungen)

8. Zyklus der Protestanten

(Folhetos, die den in den Sertão eindringenden Protestantismus abqualifizieren) 


\section{F. GROSSER ZYKLUS DER GESCHICHTEN}

UBER HISTORISCHE UND AKTUELLE EREIGNISSE (z. B. Folhetos über Gouverneurswahlen, fliegende Untertassen, Sputniks, Eisenbahnkatastrophen, Tod des Getúlio Vargas u. ä.)

Vor der ideologischen Einordnung des epischen Zyklus der Cangaceiros in den Rahmen dieser sechs Großen Zyklen der nordostbrasilianischen Volkspoesie sollen die Grundlagen dessen, was diese Texte beschreiben, erläutert werden, die Grundlagen des Cangaços. 


\section{DIE HISTORISCHE UND SOZIOLOGISCHE ENTWICKLUNG DES CANGAÇOS ${ }^{80}$}

Die ersten zweihundert Jahre der Kolonialgeschichte Nordostbrasiliens begründeten eine Tradition der Gewalt.

Führer der ersten Conquistadores-Haufen waren Adelige, die in der Sociedade açucareira noch keine Pfründe gefunden hatten und denen daher vom portugiesischen König willkürlich, ohne Eingehen auf die Besonderheiten der Region und ihrer Bewohner, Ländereien im Sertão zugesichert worden waren. Die frischernannten Besitzer zogen mit eigenen Truppen ins Innere des Landes und eroberten sich die ihnen zugeteilten Fazendas. Als schließlich der allen gemeinsame Feind, der Indianer, besiegt war, gedachten die Fazendeiros jedoch keineswegs, abzurüsten und ihre Privatstreitkräfte zu entlassen. Der Konflikt innerhalb der Sociedade sertaneja brach sofort aus, als der Druck von außen schwächer zu werden begann. Die Indianerkriege mündeten, ohne jede Unterbrechung, in Familienfebden ein. Weiterhin gehörten kriegerische Unternehmungen zum Alltag des Sertãos ${ }^{81}$.

Die größten Dynastien der Fazendeiros versuchten, ihre Einflußsphäre gegeneinander abzugrenzen. Die Nachbarn wurden überfallen, das Land wurde ihnen weggenommen. Es begann eine Neuverteilung des Besitzes unter den Mächtigsten des Sertãos. Anstoß zu einer Familienfehde gab im allgemeinen eine - objektiv meist bedeutungslose Grenzfrage; häufig diente als Vorwand für eine Aggression eine „Questão de honra" ${ }^{\text {82 }}$.

Beide gegnerischen Seiten versuchten, so viele Personen wie möglich in ihren Streit hineinzuziehen. Weite Gebiete wurden lahmgelegt ${ }^{83}$. Man bediente sich der politischen Maschinerie. Von Anbeginn an beschränkte sich das System der lokalen Verwaltung im Inneren Brasiliens auf das Spiel von nur zwei antagonistischen Kräften, auf Regierung und Opposition, die keineswegs von verschiedenen Ideologien ausgingen, sondern die nur Vertreter einer bestimmten Personengruppe waren. Der Kampf der beiden politischen Parteien um die Macht pflegte rücksichtslos geführt zu werden. Ein solches System eignete sich vorzüglich für die Parteinahme in einer Familienfehde. Dadurch, daß die Lokalpolitik mit der Landespolitik (mit der Politik der „Província“ oder später des „Estado“) zusammenhing und die Parteien auf dieser Ebene mit Begrif- 
fen arbeiteten, die wohl für die Hauptstädte angemessen, nicht aber für den Sertão maßgebend waren, wurde die Unterscheidung zwischen zwei Gegnern einer Familienfehde zu einer Unterscheidung zwischen Gut und Böse. Wer die Regierung hinter sich hatte, konnte auf die Unterstützung der Polizei und der Justiz rechnen, konnte den Feind zum Verbrecher und Rebellen gegen die Ordnung stempeln und ihn mit allen Mitteln des „Rechts" verfolgen. Kam einmal im Lande die Opposition an die Macht, so kehrten sich die Begriffe um. Der ehemalige Rebell wurde zum Vertreter der Ordnung, konnte über Polizei, Justiz und Recht verfügen. In der Sociedade sertaneja (und auch in der Sociedade açucareira) kann es keine objektiven Werte geben: eine solche Konzeption ist sinnlos für jemanden, der in dieser Gesellschaftsstruktur zu leben hat. Moralische Begriffe werden relativiert, zu Instrumenten beim opportunistischen Ausnützen politisch günstiger Situationen gemacht. Die Justiz im Sertão muß zwangsläufig eine parteiische Justiz $\operatorname{sein}^{84}$.

Die kämpfenden Truppen bei Familienfehden setzten sich stets aus drei verschiedenen Blöcken zusammen:

1. Das Oberkommando und die Unterbefehlsposten lagen in den Händen der Familienangehörigen oder der engen Freunde des Clans.

2. Die Mehrzahl der Kämpfenden rekrutierte sich aus den Angestellten der Fazendeiros und ihrer Freunde. Die Pächter, Vasallen ihres Führers, brauchten nur in dringenden Fällen einzugreifen und erhielten dann oft untergeordnete Befehlsposten.

In länger andauernden Fehden oder in Kämpfen von außergewöhnlich großen Ausmaßen reichte diese Gruppe nicht mehr aus (zumal sie auch für andere Dienste, wie für die Beschaffung von Lebensmitteln, benötigt wurde), und man löste sie als Kerntruppe durch Angehörige des dritten Blockes $a b$ :

Capangas übernahmen den Befehl über die Unterabteilungen der Truppe. Es waren Söldner, die ausschließlich für ihre Kriegsdienste angeworben wurden. Um Capangas zu bekommen, schützte man Verbrecher vor dem Zugriff der Justiz ${ }^{85}$ und setzte einen sehr guten Lohn aus.

Eine ausgewählte Anzahl von Capangas blieb auch in Friedenszeiten im Dienst der Fazendeiros, half bei der Beaufsichtigung der Arbeiter oder übernahm kleinere kriegerische Aufgaben ${ }^{86}$.

Die Macht eines Fazendeiros hing in hohem Maße davon ab, wieviel Capangas er unterhalten konnte ${ }^{87}$. Seine Position innerhalb seiner Gesellschaft und sein Kriegsglïck standen in enger Beziehung zu der Möglichkeit, in dringenden Fällen schnell genügend Geld für die Bezah- 
lung von Capangas aufzubringen. Dadurch entstand im Sertão Nordostbrasiliens ein festes Interdependenzverhältnis zwischen Fazendeiro und Capanga ${ }^{88}$.

Der Einfluß der Capangas wuchs jedoch so sehr an, daß es ihnen schließlich gelang, sich von ihren Herren loszulösen. Sie sahen es nicht mehr als ihre Hauptaufgabe an, im Dienste eines bestimmten Fazendeiros einen bestimmten Feind zu besiegen, sondern sie führten Krieg auf eigene Rechnung. Sie, die bisher Instrumente der Fazendeiros zur Erhaltung der Macht gewesen waren, machten sich unabhängig ${ }^{89}$. Aus $\mathrm{Ca}-$ pangas wurden Cangaceiros $^{90}$. Sie sind seit etwa 1850 zum festen Bestandteil der Gesellschaft des Sertãos geworden. Der Cangaço bietet den Sertanejos aus den unteren Schichten die Möglichkeit, zu Machtpositionen vorzudringen, die ihnen sonst verschlossen geblieben wären. Die Barrieren zwischen den Klassen werden durchstoßen: ein Cangaceiroführer gleicht in seiner Machtfülle einem reichen Fazendeiro.

Die Bedrohung der bisher alleinherrschenden Stellung der Fazendeiros führte dazu, daß sie nach einer Kraft suchten, die ein Gegengewicht zu den Cangaçobanden bilden konnte. Von dem Bereich außerhalb der Sociedade sertaneja wird die Polizei herbeigerufen. Ihren Offizieren gelingt es, nun ihrerseits, unter dem Vorwand, die Bevölkerung schützen zu müssen, einen Teil der Macht im Sertão an sich zu reißen. Das Gleichgewicht der politischen Machtverhältnisse im Inneren Nordostbrasiliens hängt von nun an davon $\mathrm{ab}$, inwieweit die Fazendeiros mit einer der beiden antagonistischen Kräfte, Polizei - Cangaço, zusammenarbeiten. In das starre System der Sociedade sertaneja ist Bewegung gekommen. Nicht nur in horizontaler, sondern auch in vertikaler Richtung ändert sich ihre Struktur. Die Polizei bringt Elemente aus anderen Gesellschaftsformen in den Sertão und ermöglicht außerdem, wie der Cangaço, den sozialen Aufstieg von Männern aus den unteren Schichten der Bevölkerung ${ }^{91}$.

Die Blütezeit der Cangaceiros ist folgerichtig der Beginn der Desintegration der Sociedade sertaneja geworden. Die Niederlage des Cangaços war gleichzeitig das Scheitern eines Versuches, die Gesellschaft mit ihren eigenen Krä̈ten von innen heraus umzuwälzen. Die Cangaceiros glaubten, sie seien in die Sociedade sertaneja integrierbar und die Grundstruktur dieser Gesellschaft müsse erhalten bleiben.

In Wirklichkeit aber waren gerade sie es, die den Anstoß zur Zersetzung der Sociedade sertaneja gaben. Dadurch, daß der Cangaço übermäßig stark geworden war, wurde eine Reaktion in den Gebieten außerhalb des Sertãos hervorgerufen (man befürchtete einen Übergriff 
auf Randregionen), eine Reaktion, die vorgab, den alten Herren, den Fazendeiros, zu Hilfe zu kommen, die sie aber ebenso entmachtete wie die Cangaceiros. Die bis zur „Revolution von 1930“ übliche Aufspaltung des Sertãos in zwei feindliche Lager - ein Antagonismus, der auf Polizei und Cangaço übergegangen war - differenzierte sich; die Sociedade sertaneja öffnete sich gegenüber Einflüssen aus der modernen, demokratisierten Gesellschaft, die in den Hauptstädten des Nordostens und in weiten Teilen des Südens zumindest in der Theorie dominierend geworden war. Die traditionelle Struktur zerbröckelte.

Die verschiedenen Phasen vom Aufstieg und Niedergang des Cangaços spiegeln sich in der sozialen Herkunft seiner Führer wider. Anfangs herrschten adelige Fazendeiros, die durch eine Niederlage in Familienfehden verarmt waren und mit ihren Capangas in den Cangaço übertraten. Ihr Einfluß ließ schnell nach. Um 1900 bildete sich eine neue Führerschicht heraus, deren Hauptvertreter Antônio Silvino und Lampião waren. Beide stammten aus der untersten Schicht der Sociedade sertaneja. Silvino („Regierungszeit“: 1895-1914) forcierte die Professionalisierung des Cangaços, führte militärische Disziplin ein ${ }^{92}$ und baute das System der Coiteiros und des Nachschubs aus. Lampião (1920 bis 1938) folgte dem Modell seines Vorgängers und übertraf es. Er führte den Cangaço um 1925 auf seinen Höhepunkt und hielt ihn kraft seiner Persönlichkeit am Leben, selbst als er sich nicht mehr den neuen Anforderungen einer veränderten Zeit stellte ${ }^{93}$. Sein Ende kann als Schlußpunkt der Geschichte der Cangaceiros angesehen werden. Die Episode mit Corisco, der seinen Chef Lampião nach dessen Tode rächte, ist nur noch ein Epilog. Corisco ist schon der Vertreter einer neuen Zeit, gehört nicht mehr in den Rahmen der traditionellen Sociedade sertaneja. Er war der Sohn eines reichen Fazendeiros und wurde zum Cangaceiro, weil ihm dieser Beruf mehr Macht gab als der seines Vaters. Die einzelnen Klassen sind nicht mehr auf vorausbestimmte Handlungsweisen und Funktionen fixiert ${ }^{94}$.

Dieser Abriß der historischen und soziologischen Entwicklung des adeligen Kriegers, der die Indianer bekämptte, zum Cangaceiro, der der untersten Schicht seiner Gesellschaft entstammt, ist nur als Herausstellung wesentlicher Etappen zu werten. Nicht immer ging in den vierhundert Jahren der neueren Geschichte des Sertãos die Evolution so geradlinig vor sich. Unabhängige Capangaführer zum Beispiel mag es auch schon zur Blütezeit der Familienfehden gegeben haben. Sie waren aber nicht typisch für ihre Epoche, verschwanden wieder und tauchten später in einer weitaus bedeutenderen Position erneut auf, zu einer Zeit, die ihrer geschichtlichen Funktion angemessener war. 


\section{DIE PSYCHOLOGISCHE BASIS \\ DER SERTANEJOS}

Bei der Betrachtung des Phänomens des Cangaços (und bei seiner Widerspiegelung in der Volksliteratur) darf neben der Untersuchung historischer und soziologischer Faktoren der psychologische Aspekt nicht vernachlässigt werden. Denn die Ideologie, die das Zusammenleben der Individuen innerhalb der Sociedade sertaneja regelte, Produkt dieser Gesellschaft, beeinflußt nun ihrerseits das Verhalten der Sertanejos und verändert es in einer Richtung, die durch eine ausschließlich soziologische Betrachtungsweise nicht verstanden werden kann. Der Sertanejo befindet sich nämlich auf einer Kulturstufe, in der das Interesse des Individuums für sich selbst bei weitem sein Interesse für Gemeinsamkeiten mit anderen übertriff. Für ihn ist bei der Beurteilung eines Ereignisses oder einer Tatsache derjenige Aspekt maßgebend, der ihn persönlich angeht.

Seine Privatideologie, die Postulierung eines ganz bestimmten Persönlichkeitsideals, das jedes Individuum für sich anstrebt, hat sich gleichzeitig mit den Normen für den Kontakt der einzelnen Klassen untereinander zur Zeit der Konstituierung der Sociedade sertaneja herausgebildet $^{95}$. Ihr Modell eines "idealen Sertanejos" ist typisch für eine, im wesentlichen aus Europa importierte, patriarchalische Gesellschaft ${ }^{96}$, denn es geht von der Existenz von Großfamilien aus. Der Familienvater ist verantwortlich für alle Verwandten und kann frei über sie verfügen. Gegen Verletzungen seiner Autorität schützt ihn theoretisch der Ebrenkodex des Sertãos, der genau die Einflußsphäre des einen Individuums von der des anderen abgrenzt, der das Recht auf Rache bei Verbrechen gegen den Besitz (Diebstahl), gegen das Leben (Mord) und gegen die sexuelle Integrität (Entehrung und Vergewaltigung der Frauen) verteidigt.

Der größte Wunsch eines Sertanejos ist es folgerichtig, sich von der Befehlsgewalt einer jeglichen Person unabhängig zu machen. Vorbild dafür war ihm ursprünglich das Bild des Vaters, das sich bei wachsender kritischer Urteilskraft ihm gegenüber bald auf die Vorgesetzten übertrug und schließlich, fast resignierend wegen ihrer Unantastbarkeit, auch abstrakte Begriffe, wie Gott, Kirche, Regierung, Vaterland u. ä., anvisieren konnte. 
Für die große Mehrheit der Sertanejos klafft ein erheblicher Unterschied zwischen Wunschvorstellung und Wirklichkeit. Ein Herrscher innerhalb seiner eigenen Familie konnte man wohl werden, war aber außerhalb von ihr der Willkür der Ubergeordneten ausgesetzt ${ }^{97}$. Der Sertanejo nimmt zu seiner Idealfigur daher eine ambivalente Position ein: er füllt sie aus und wird gleichzeitig ihr Objekt. Er herrscht und wird beherrscht. Das Ergebnis dieser Situation ist die dominierende sadomasochistische Komponente in seiner Mentalität, die hier stärker als in anderen Gesellschaften ausgeprägt ist ${ }^{98}$. Begünstigt wurde die Tatsache, daß sie im Sertão eine so erstaunlich große Rolle spielte, dadurch, $\mathrm{da} ß$ die moralischen Barrieren, die das friedliche Zusammenleben innerhalb einer Gesellschaft ermöglichen, äußerst niedrig angelegt waren und häufig durchbrochen werden konnten, ohne daß Sanktionen von den Ordnungshütern zu befürchten waren ${ }^{99}$. Vertreter beider Extreme des Sadomasochismus beeinflußten in hohem Maße die Geschichte des Sertãos; auf der einen Seite - und damit kommen wir zur wichtigsten psychologischen Dimension des Cangaços - standen die Cangaceiros, die sich keinerlei Beschränkungen ihrer Freiheit gefallen ließen und die auf radikale Weise das Ideal des herrschenden Menschen zu realisieren suchten; auf der anderen Seite, der masochistischen und passiven, standen die religiösen Fanatiker ${ }^{100}$. Während der Cangaceiro versucht, neue Wege zur Verbesserung seiner gegenwärtigen Situation $\mathrm{zu}$ finden ${ }^{101}$, greift der Fanatiker auf in seinem Kulturstadium schon uiberwundene Formen des menschlichen Zusammenlebens zurück. Der Cangaceiro ist progressiv, der Fanatiker regressiv, denn er reduziert die komplizierten Wechselbeziehungen zwischen den einzelnen Schichten der Sociedade sertaneja auf eine einzige Beziehung, auf die eines absoluten, einzigen Herrschers zur uniformen Masse. Die Fanatiker unterwerfen sich bedingungslos der höchsten Autorität, Gott, der ihrer Ansicht nach auf Erden von einem Boten vertreten wird, von ihrem Führer ${ }^{102}$.

Sowohl dem Cangaceiro als auch dem Fanatiker gelang es nicht, das psychologische Gleichgewicht auf die im Sertão übliche Art zu finden, nämlich durch die gleichmäßige Verteilung sadistischer und masochistischer Elemente. Eine Seite überwog bei ihnen in außergewöhnlichem Maße, so daß eine Einordnung in den normalen Rahmen der Sociedade sertaneja nicht mehr möglich war. Gemeinsam stellen sich Cangaceiros und Fanatiker - aus der Genesis des Sadomasochismus geht hervor, daß eine Tendenz in die andere umschlagen kann; so wurden sehr häufig aus Cangaceiros Fanatiker und aus Fanatikern Cangaceiros ${ }^{103}-$ den bestehenden Verhältnissen in ihrer Gesellschaft entgegen und bekämpfen sie. 
Sie sprengen ihre Gesellschaft, indem sie die in ihr herrschenden Tendenzen ins Aberwitzige übersteigern. So ist der Cangaceiro Teil der Sociedade sertaneja und steht gleichzeitig außerhalb ihres normalen Rahmens.

Folgerichtig haben auch die Sertanejos selbst ein zweideutiges Verhältnis zu ihren Cangaceiros: sie verehren und verfluchen sie. Sie identifizieren sich mit ihnen und lehnen es ab, etwas mit ihnen gemein zu haben. 
TEIL II DAS BILD DER CANGACEIROS

IN IHREM EPISCHEN ZYKLUS 


\section{ANTOONIO SILVINOS UND LAMPIÃOS LEBEN UND TATEN \\ IM EPISCHEN ZYKLUS DER CANGACEIROS}

\section{VORBEMERKUNG}

Die Beschränkung auf die gedruckte Volkspoesie bringt zwangsläufig eine Beschränkung auf die Zyklen Antônio Silvinos und Lampiãos mit sich. Das älteste Folheto über einen Cangaceiro wurde 1904 veröffentlicht - es ist $A$ vida de Antônio Silvino von Francisco das Chagas Batista -, zu einer Zeit, als die Vorgänger Silvinos schon fast vergessen waren und er unbestritten der populärste Cangaceiro im Sertão geworden war. Neben ihm gelang es keinem anderen, das Interesse der Sertanejos auf sich zu ziehen. Nur Antônio Silvino und seine Taten werden von den Volksdichtern beschrieben. Andere Cangaceiros finden nur Erwähnung, wenn sie sich zu ihm in Beziehung setzen lassen. Bis zum Jahre 1914 ist die Geschichte des Zyklus der Cangaceiros die des Zyklus Antônio Silvinos. Bis etwa 1925 werden, immer seltener, Folhetos über ihn geschrieben, bis dann der Aufstieg Lampiãos diesen jungen Cangaceiro zum neuen Helden der Sertanejos werden läßt. Auch neben Lampião brachte es kein einziger Cangaceiro zu ähnlichem Erfolg, und kein einziger erscheint in einem eigenen Sekundärzyklus. Wie einstmals bei Antônio Silvino, so konzentriert sich in den Jahren 1925 bis 1950 das Schaffen der Volksdichter auf Lampião. Nach dem Tode dieses Cangaceiros (1938) begann eine Neubewertung der Gestalt Silvinos; einen Nachfolger fanden Lampião und Antônio Silvino nicht.

$\mathrm{Um}$ in der folgenden Untersuchung lästige und zu umfangreiche Hinweise auf die Biographie der beiden berühmtesten Cangaceiros zu vermeiden, erscheint es ratsam, vorweg einen kurzen Abriß ihrer Lebensgeschichte zu geben. So kennt der Leser die behandelte Materie schon und findet sich schneller in ihr zurecht.

\section{ANTÔNIO SILVINO - Abriß seines Lebens}

Manuel Batista de Morais wurde 1875 in der pernambucanischen Stadt Afogados da Ingàzeira geboren. Sein Vater, Batistão, war ein stadtbekannter Schläger. Um 1895 wurde er von politischen Feinden ermordet, was seinen Sohn Manuel dazu veranlaßte, in die Bande des damals berühmtesten Cangaceiros, Silvino Aires, des „Einäugigen“, einzutreten. 
Nach dem Tode seines Chefs übernahm er selbst die Führung der Gruppe; zu Ehren des Verstorbenen nannte er sich Antônio Silvino.

Silvino pflegte seine Operationen sowohl im Sertão als auch im Zuckerrohrgebiet durchzuführen. Nie hatte er mehr als sechs Kameraden bei sich, um beweglich zu bleiben. Er überfiel Fazendas, raubte Postsäcke, ermordete politische Gegner und erpreßte reiche Händler. Dadurch, $\mathrm{d} a ß$ er die Armen schonte, daß er keinem seiner Kumpane erlaubte, sich gegenüber Frauen etwas herauszunehmen (es gibt eine Unzahl von Anekdoten über diese Ehrenhaftigkeit des Cangaceiros), bekam er die Fama eines „ehrlichen, guten Räubers", wurde von den Sertanejos mit dem legendären Dieb Dimas verglichen, der durch widrige Umstände zum Räuber geworden war, aber wegen seiner Herzensgüte als einer der beiden Schächer bei der Kreuzigung Jesu Verzeihung und Eingang ins Himmelreich erlangte. Bei den Polizeioffizieren und Politikern der Regierungspartei war Antônio Silvino weniger beliebt: er „beaufsichtigte" Wahlen, beeinflußte Gerichtsschöffen zugunsten seiner Schützlinge und kassierte Steuern. In einigen Munizipien des Innern hörte man nur auf Antônio Silvino.

1914 gelang es einem bislang unbekannten Offizier, Teófanes, den Cangaceiro zu überraschen und gefangenzunehmen. In einem Sensationsprozeß wurde er zu der Höchststrafe von dreißig Jahren Kerker verurteilt. Nach fünfundzwanzig Jahren begnadigte man ihn wegen guter Führung. Bis zu seinem Tode 1944 lebte er als Arbeiter in Minas Gerais bei seiner Tochter.

Antônio Silvino war der erste Cangaceiro, dessen persönlicher Ruhm bis in die letzten Winkel Brasiliens gelangte. Berichte über ihn füllten viele Spalten in der Presse Rios und São Paulos. Im Nordosten gelang es ihm sogar, anläßlich seines Prozesses von der gefährlichen weltpolitischen Situation in Europa abzulenken. Der Cangaceiro Antônio Silvino war der ganzen Nation zu einem Begriff geworden.

Die wichtigsten Abhandlungen über seine Lebensgeschichte sind $\mathrm{zu}$ finden in: Um sertanejo e o sertão von Ulysses Lins de Albuquerque; Serrote Prêto von Rodrigues de Carvalho und Heróis e bandidos von Gustavo Barroso.

\section{LAMPIAO - Abriß seines Lebens}

„No centro de Pernambuco / No Nordeste brasileiro / No ano de novecentos / A 12 de fevereiro / No têrmo de Vila Bela / Nasceu êsse cangaceiro", schreibt der Volksdichter José Cordeiro über Geburtsdatum und -ort des Virgulino Ferreira da Silva. Die Stadt Vila Bela heißt seit 1939 Serra Talhada. Schon als Siebzehnjähriger nahm Virgu- 
lino an kriegerischen Auseinandersetzungen teil, als Mitglied einer Capangatruppe. Nach dem Tode seines Vaters (er wurde von einer Polizeistreife ermordet) trat der Junge "endgültig" in den Cangaço ein, und zwar in die Bande des (adeligen) Sebastião Pereira. Nachdem sein Führer nach Mato Grosso ausgewandert war, übernahm Virgulino, etwa um 1922, die Gruppe, schon unter dem Namen,Lampião“. (Er konnte so schnell den Abzug seiner Flinte ziehen, daß er ununterbrochen im Feuerschein stand, wie eine große „Laterne“ leuchtete.) Er begann seine Karriere mit bis dahin unerhörten Taten, überfiel mit seinen Kameraden Städte, zum Beispiel Patos/Paraíba, und plünderte sie aus, überzog ganze Landstriche mit Terror. 1926 stand er auf dem Höhepunkt seiner Macht; er bezeichnete sich selbst als „König des Sertãos“. Mit seiner Truppe, die bis zu einer Stärke von vierhundert Cangaceiros anwuchs, kontrollierte er das Innere von sieben Staaten des Nordostens, Sergipe, Alagoas, Pernambuco, Paraíba do Norte, Rio Grande do Norte, Ceará und Bahia. Als sich in diesem Jahr die Coluna Prestes, die sozialrevolutionären Aufständischen, auf Nordostbrasilien zubewegte, verlieh der Caudilho von Juàzeiro (Ceará), der berühmte Padre Cícero, dem Cangaceiro, seinem Freund, zur Abwehr dieser Gefahr ein Hauptmannspatent der Polizei. Lampião dachte jedoch nicht daran, die Rebellen anzugreifen. Er nutzte die Ablenkung seiner "Kollegen“" von der Polizei dazu aus, seine Räubereien ungestraft fortzuführen.

Im Jahre 1927 wagte es der Cangaceiro sogar, die zweitgrößte Stadt des Staates Rio Grande do Norte, das Handelszentrum Mossoró (mit 30000 Einwohnern), anzugreifen, ein Versuch, der durch den Verteidigungswillen der Mossoroenses fehlschlug. Danach setzte ein Kesseltreiben gegen Lampião ein. Alle Staaten des Nordostens schlossen sich vertraglich zusammen, um den Cangaceiro endlich zu fangen. Er floh nach Bahia (1929), wo er sich ein Jahr lang ruhig verhielt. Dann aber begann er auch dort, seine Untaten fortzusetzen. Er überfiel die Stadt Queimadas.

In Bahia lernte Lampião Maria Déa, die Frau eines Schusters, kennen. Sie brannte mit ihm durch und begleitete ihn als "Maria Bonita“ bis zu seinem Tode. Sie ist die berühmteste Frau im Cangaço. Ihre Liebesgeschichte wurde von Rachel de Queiroz (Lampião, Rio 1954) dramatisiert und von mehreren Filmregisseuren aufgegriffen.

Die Zeit von 1930 bis 1938 bezeichnet den Niedergang des Cangaços. Politische Konsolidierung, Kulturkampagnen, Straßenbau, Entmachtung der Coronéis, alles zusammen machte den Cangaceiros den Garaus. Nur in immer wieder gewechselten Schlupfwinkeln konnte Lampião die Verfolgung durch Polizeitruppen, die „Macacos“, überleben. 
1938 schließlich fand ihn der alagoanische Polizeioffizier Bezerra in der Höhle von Angicos. Bei einem Überfall wurden sämtliche anwesenden Cangaceiros erschossen (einschließlich Maria Bonitas). Man schnitt ihnen die Köpfe ab und führte die halbverwesten, von Kugeln durchlöcherten Trophäen im Triumphzug nach Maceió. Sie können heute im EstácioLima-Museum von Salvador besichtigt werden.

Der Tod Lampiãos hatte ein Nachspiel: sein Freund Corisco rächte seinen Führer, indem er den Vaqueiros der Fazenda von Angicos ebenfalls die Köpfe abschnitt. Aber schon nach kurzer Zeit wurde auch er erschossen.

Der einäugige Lampião wurde schon zu seinen Lebzeiten zum Inbegriff des brutalen, rücksichtslosen, perversen und habgierigen Cangaceiro. Alles denkbar Schlechte soll sich in seiner Person zusammengefunden haben. Mit dämonischer Schläue gelang es ihm, seine Verfolger abzuschütteln und sie im richtigen Augenblick zu vernichten, wie in dem Massaker von Serrote Prêto, in dem er Polizeieinheiten aus Pernambuco und Paraíba sich gegenseitig aufreiben ließ, ohne daß die Kämpfenden merkten, daß sie die eigenen Leute umbrachten. Seine Verbrechen sind von himmelschreiender Grausamkeit. Daneben nun sein Hang zum Mystizismus, seine Liebe zu Maria Bonita, sein Hohn gegenüber den reichen Fazendeiros, sein Vertrauen zu dem heiligen Padre Cícero, seine romanesken Abenteuer (als er zum Beispiel der Baronesa von Água Branca die Schmuckstücke und Münzen aus der Kaiserzeit abnahm, mit denen sie sich zu schmücken pflegte). Er war ein guter Volksdichter, spielte Handharmonika und soll das durch den nach seinem Leben gedrehten Film O Cangaceiro berühmt gewordene Lied „Mulher rendeira" komponiert haben. (Das Lied wurde zuerst registriert von Mário de Andrade, Ensaio sôbre a música brasileira, S. 115-117.) Lampião war ein Mensch voller Widersprüche, mit manchen guten Eigenschaften und vielen abscheulichen. Im Gefecht ein Held, bei feigen Ubberfällen eine Bestie. Sein Bild ist zwiespältig wie die Stellung der Sertanejos zu ihm.

Einzelheiten über das Leben Lampiãos finden sich vor allem bei Rodrigues de Carvalho, Serrote Prêto; Luís Luna, Lampião e seus cabras; Nertan Macêdo, Capitão Virgulino Ferreira Lampião, und Optato Gueiros, Lampião. Eine kurze Darstellung der Karriere Lampiãos (allerdings mehr phantastisch als objektiv) gibt Câmara Cascudo in dem betreffenden Artikel seines Dicionário do folclore brasileiro, S. $416-418$. 
Dem Volksdichter darf es nicht nur darum gehen, Realität auf eine angemessene und ihn befriedigende künstlerische Weise darzustellen, den Cangaço volksliterarisch in den Griff zu bekommen; er muß zugleich frische Informationen liefern - und gefallen. Die Folhetos machen sensationelle Vorkommnisse bekannt, übersetzen die Meldungen der hauptstädtischen Presse in die Sprache der Bewohner des Sertãos ${ }^{104}$, und sie interpretieren sie so, wie das Publikum sie gern hören möchte, verändern sie daher auch des öfteren, geben ihnen eine neue Funktion.

Es sind drei Themenkreise, die besonders deutlich eine Diskrepanz zwischen Dichtung und Realität aufweisen, Themenkreise, die entweder nicht von Zeitungsschreibern behandelt wurden oder die so eindringlich sind, daß sie den Dichter reizen, eigene Spekulationen anzustellen. An erster Stelle steht hier die Jugend der Protagonisten, die erst in das Blickfeld der Verfasser geriet, als die Cangaceiros auf dem Höhepunkt ihrer Laufbahn standen. Dann kommt das Verhältnis der Cangaceirochefs zu ihren Kameraden und schließlich das Ende ihrer Karriere, Gefangennahme oder Tod. Bei Lampião muß noch seine Liebesgeschichte mit Maria Bonita erwähnt werden.

Beschreibt ein Volksdichter das Leben eines bekannten Cangaceiros und will er auch die Jugend des Helden in seinen Text miteinbeziehen, so gibt es dafür zwei traditionelle Möglichkeiten. Entweder macht der Protagonist keinerlei Entwicklung durch, ist er sich stets gleich, folgt sein Geschick einer einzigen, vorbestimmten Linie; oder sein späteres Schicksal ist die Folge nicht vorherbestimmbarer Umstände, ist das Ergebnis zufälliger Ereignisse. Die erste Alternative ist die weitaus häufigere und hat gegenüber der zweiten den Vorteil, ein künstlerisch geschlosseneres Bild von dem Protagonisten zu geben. Es entsteht kein Bruch zwischen der Zeit vor und nach dem Cangaço. Der Leser gewöhnt sich von Anfang an an die Eigenheiten des Helden. Die Dichter konnten hierbei auf eine gefestigte Tradition zurückgreifen und die Jugend des Cangaceiros nach den Schemata behandeln, nach denen die Jugend herausragender Menschen in anderen und älteren epischen Gedichten behandelt $\mathrm{zu}$ werden pflegte ${ }^{105}$.

Die Vorbereitung des Lesers auf die große Rolle, die der Protagonist später spielen wird, setzt im Zyklus Antônio Silvinos in drei verschiedenen Lebensphasen an: Geburt, frühe Kindheit, Jugend.

Bei der Beschreibung der Geburt des Cangaceiros weist der Dichter auf die Zeichen hin, die die Zukunft des Kindes vorhersehen lassen. Auch das Geburtsdatum wird in den Kreis unheimlicher Omina einbezogen: 

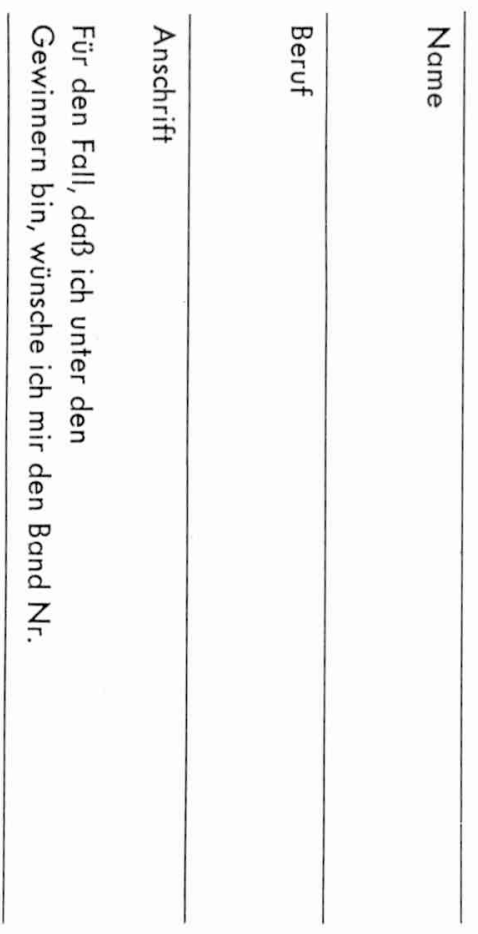

An den

COLLOQUIUM VERLAG

1 B ERLIN 45

Unter den Eichen 93 
Nasci em setenta e cinco

Num ano de inverno forte

No dia 2 de novembro

Aniversário da morte

Por isso o cruel destino

Deu-me de bandido a sorte. $(15,43-48)^{106}$

Nicht genug, daß der Junge am Allerseelentag geboren wird, noch andere Zeichen begleiten dieses Ereignis. Es findet in einer geheimnisvollen, seltsam düsteren Atmosphäre statt. Man erlebt ein schreckliches Gewitter. Am Körper des Neugeborenen zeigt sich der Abdruck eines Gewehres und auf seiner Handfläche der eines Dolches ${ }^{107}$, alles unheilverkündende Vorzeichen, die auch in anderen Zyklen der Volkspoesie nicht selten sind. Bei der Geburt des populären Pícaro João Grilo gab es sogar eine Mondfinsternis und einen Vulkanausbruch. Der Eindruck solcher Schilderungen auf den Leser wird vertieft durch die starke Neigung der Nordestinos zum Magisch-Ubersinnlichen. Aberglaube ist für sie noch nicht zum halbernsten Spiel geworden, er bestimmt ihr Leben tatsächlich. Die Geburt eines Cangaceiros mit unwiderlegbaren Zeichen zu begleiten, ihn in seinem späteren Leben mit Hexen und verwunschenen Tieren kämpfen zu lassen, das ist die beste Methode, um ihn strahlend über die Masse zu erheben. Das Übernatürliche großer Menschen erspart den durchschnittlichen das Gefühl der Minderwertigkeit aus eigenem Verschulden.

Als Knabe hat der Protagonist Abenteuer zu bestehen, die ihn auf seinen küntigen Beruf vorbereiten, die beweisen, daß er ihm gewachsen sein wird. Leandro Gomes de Barros schreibt über den frühreifen Antônio Silvino:

Em pequeno eu só brincava

Com menino muito mau

Eu nunca gostei de gaita

Nem carrinhos ou berimbau

Meus brinquedos eram espêtos

Ou espingardas de pau. $(22,121-126)$

Eu insultava cachorro

Até êle vir brigar

O cachorro vinha a mim

Querendo-me estrangular

Mas eu negava-lhe o corpo

Êle tinha que passar. $\quad(22,133-138)$ 
Der Kampf des Jungen mit dem wütenden Hund ist eine deutliche Parallele zu dem sehr bekannten, im Zyklus Silvinos mehrere Male beschriebenen Duell des Cangaceiros mit einem Jaguar ${ }^{108}$. Schon das Kind ist also ein Supermensch, ein Herkules:

Três anos e poucos mêses

Era que eu podia ter

A cascavel deu-me um bote

Vinha certa me morder

Peguei-a pela garganta

Soltei quando a vi morrer. $(22,31-36)$

Genaue, sehr niedrige Altersangaben gehören zum festen Bestandteil solcher Verse, die in dieser Form bereits zu Zeiten mündlich übertragener Literatur im Nordosten bekannt waren ${ }^{109}$.

Mit seinem phantasiereichen, immer etwas spöttischen Ton beschreibt Leandro die Taten des Knaben in genau dem gleichen Stil, wie er später die Abenteuer des Cangaceirochefs schildern wird.

Auf der dritten Stufe der Entwicklung Silvinos zum Banditen weitet sich diese bis dahin überwiegend stilistische regressive Projektion noch mehr auf die Handlungsführung aus. Im Alter von etwas mehr als zehn Jahren erlebt er schon genau das, was ihn später immer wieder im Cangaço erwarten wird. Die Volksdichter erzählen ausschließlich Parallelabenteuer zu künftigen Taten, deuten Motive an, die sie später ausführlicher wiederaufnehmen werden. So wird zum Beispiel Silvinos Vater laut Francisco das Chagas Batista ${ }^{110}$ von der Polizei gefangengenommen, aber dem Jungen gelingt es, ihn zu befreien. In späteren Versen werden die Leser erfahren, daß diese Episode nur die diesmal gut ausgegangene Variation desjenigen Ereignisses ist, das zum Eintritt Silvinos in den Cangaço führt.

Diese drei Phasen in der Jugend eines Protagonisten, der, wie alle wissen, später Cangaceiro werden wird, halten die Volksdichter auch im Zyklus Lampiãos ein. Hier herrscht ebenfalls die deterministische Orientierung vor. In einigen Texten - vergessen wir nicht, daß wir viel mehr Folhetos über Lampião als über Silvino besitzen und daß deshalb vielfältigere Meinungsäußerungen möglich sind - vertreten die Verfasser aber auch die entgegengesetzte Ansicht. Sie behaupten, daß Lampião ein Knabe wie jeder andere gewesen sei und daß man daher sein Schicksal nicht habe voraussehen können. Dadurch aber, daß sie diese Ansicht durch anschauliche Beispiele belegen wollen, erreichen die Verfasser genau das Gegenteil von dem, was sie postulieren. Durch die übertriebene Betonung der These, aus Virgulino hätte etwas anderes 
werden können, unterstreichen sie den Eindruck des Lesers, dem Jungen sei zwangsläufig ein außergewöhnliches Schicksal zugemessen. So berichten die Autoren davon, daß Lampião sogar habe studieren und daß er zum Priester habe geweiht werden sollen ${ }^{111}$. Im allgemeinen aber kann der Leser auch im Zyklus Lampiãos an exemplarischen außergewöhnlichen Abenteuern das künftige Geschick des Protagonisten erkennen; und er erwartet voller Ungeduld das Ereignis, das ihn zum Cangaceiro machen wird.

Nach Aussage der Volksdichter - die sich dadurch im Falle Lampiãos gegen die historische Realität stellen - ist dies die Ermordung des Vaters. Sie zwingt den Protagonisten dazu, in den Cangaço einzutreten; sie ist das entscheidende Erlebnis seines Lebens. Der Tod des Vaters wird ausführlich beschrieben, aber nicht mit seinen historischen Hintergrïnden, mit einer Charakterisierung der Situation, deren Kulminationspunkt er ist, sondern als innerer Konflikt des frischgebackenen Cangaceiros. Die Volksdichter fassen im allgemeinen den Eintritt in den Cangaço nicht als Resultat einer Unvereinbarkeit des Protagonisten mit dem ihm ungerecht erscheinenden System seiner Gesellschaft auf, sondern als bloße Folge seines Gehorsams gegenüber den Forderungen des Ehrenkodex. Die Autoren legen mehr Gewicht auf den persönlichen Charakter, den psychologischen Aspekt der Rache als auf deren gesellschaftliche Ursachen oder Konsequenzen.

Die Verpflichtung des Sertanejos, den Tod seines Vaters an den vermeintlichen Mördern zu rächen, ist außerordentlich stark und hat ihren Ursprung sicher in dem ambivalenten Verhältnis des Sohnes zum Vater. Die ersten rebellischen Gefühle des Jungen gegen die erste ihn unterdrückende Autorität werden verdrängt mit Hilfe der mächtigen Forderung, den Vater zu lieben und zu ehren. Diese verdrängten Gefühle kommen wieder zum Vorschein, wenn ihr ursprüngliches Ziel, die Vernichtung der väterlichen Autorität, erreicht ist; und der Konflikt zwischen ihnen und der immer noch bestehenden Vorschrift der Elternliebe äußert sich durch ein Schuldbewußtsein des Sohnes gegenüber dem Vater. Er fühlt sich mitschuldig an dessen Tode und nimmt die daraus folgenden Konsequenzen auf sich.

Daß das Verhältnis Sohn-Vater wirklich den Angelpunkt bei der Argumentation darüber darstellt, warum die Protagonisten Cangaceiros geworden sind, beweist die Tatsache, daß die Volksdichter vorher schon, als es darum ging, die Familie der beiden Cangaceiroführer vorzustellen, die Geschwister völlig außer acht ließen ${ }^{112}$. Alle die enge Beziehung der Cangaceiros zu ihren Vätern störenden Faktoren wurden aus- 
gemerzt. Tatsächlich existierende Konkurrenten wurden unterschlagen. Im Falle Lampiãos können wir außerdem das alles beherrschende Verhältnis des Sohnes zum Vater in seiner ganzen Bedeutung daran ermessen, daß kein einziger der Volksdichter es für nötig gehalten hat, auch den Tod der Mutter zu kommentieren, die ebenfalls von der Polizei ermordet worden ist. Alle konzentrieren sich ausschließlich auf den Vater.

Der Rachedurst des Sohnes läßt sich als ein Versuch interpretieren, seine eigene Schuld von sich abzustreifen, sie auf andere Personen zu projizieren, deren Vernichtung dann gleichzeitig die Vernichtung der eigenen Schuldgefühle mit sich bringt ${ }^{113}$. Logisch begründete Einwände gegen sein Vorgehen beeinflussen ihn nicht; der Rächer wägt das rechte Maß nicht ab, Schuld und Sühne des Täters stehen in keinem berechtigten Verhältnis zueinander.

Wie sich aus den Versen der Volksdichter ersehen läßt, kann sich die Projektion der Schuld auch von der realen Person des Mörders weg auf eine andere verschieben, ja kann sogar abstrakte Begriffe wie "Justiz" erreichen; alles wird von ihr einbezogen, wenn es nur irgendeine Möglichkeit der Assoziation zwischen dem Täter und dem nun ausgewählten Objekt der Rache gibt. So begnügt sich Antônio Silvino mit dem Tode einiger Verwandter des wahren Mörders.

Ist der Tod des Vaters gerächt, tatsächlich oder symbolisch, so verliert die ehemals so wichtig erscheinende Episode der Ermordung für den Rächer an Bedeutung: der Cangaceiro vergißt seinen Vater, vergißt, daß dessen Tod der Vorwand für den Eintritt in den Cangaço war, vergißt, von wo aus die Kausalkette seiner Verbrechen (die Rache fordert das Eingreifen der Polizei heraus; der Widerstand gegen die Polizei stellt einen außerhalb des normalen Rahmens der Gesellschaft) ihren Anfang genommen hat. Der Sohn ist nun von der engen Bindung zu seinem Vater befreit. Von ihm kann nichts mehr gefordert werden: der Vater bekam seine Genugtuung und verlor dadurch das Recht, weiterhin seinen Willen aufzuzwingen.

Eine Rechtfertigung der Cangaceiros pflegt stets von der moralisch positiven Bewertung ihrer Handlungsweise beim Tode des Vaters auszugehen. Das Mitleid, das man ihnen gegenüber empfindet, hat dazu geführt, daß sie zu Beginn ihrer Karriere stets in einem günstigen Lichte gesehen werden. Der Sertanejo bringt ihnen Sympathie entgegen, weil er ihre Konfliktsituation versteht und weil er selbst nicht weiß, wie sie hätten anders handeln können. Er ist bereit, ihr Vorgehen zu billigen, ihnen vieles zu verzeihen. Das Motiv „rächt Tod des Vaters und wird dadurch Cangaceiro" ist so repräsentativ für den Zyklus der Cangacei- 
ros geworden, daß Protagonisten aus anderen Zyklen der Volkspoesie, falls auch sie einmal den Tod ihres Vaters zu rächen haben, automatisch "Cangaceiros" genannt werden, selbst wenn sie allenfalls als mutige Draufgänger oder gar als Liebhaber zu klassifizieren wären ${ }^{114}$.

Ebenso gleichförmig wie die Beschreibung der Jugend Antônio Silvinos und Lampiãos ist die Darstellung ihrer Kämpfe und des Verhältnisses zu ihren Kameraden. Die Verfasser halten sich dabei an Schemata, die so simplifiziert sind, daß sie kaum auf geschichtliche Realitäten eingehen können.

In den Folhetos werden feindliche Einzelpersonen von den Cangaceiros stets in einem Duell besiegt ${ }^{115}$. Polizeitruppen lassen sich in einen Hinterhalt locken, wo sie Mann für Mann niedergemetzelt werden. Die einzige militärische Taktik ist die des Umzingelns, des "Cêrco". Das Gefecht wird im allgemeinen durch einen „Desafio“ eingeleitet. Die Führer der gegnerischen Truppen beschimpfen sich, stacheln sich gegenseitig zum Angriff auf, versuchen, den Gegner zu einer Unvorsichtigkeit zu verleiten, und verdecken ihre eigene Angst durch mutige Reden. Wird die Situation für den Cangaceiro gefährlich, so durchbricht er die feindlichen Reihen und flieht, schießt vielleicht auch einmal von hinten auf die Polizisten ${ }^{116}$.

Bei Berichten über Kämpfe gegen Polizeitruppen demonstrieren die Volksdichter ihre Sympathien gegenüber ihren Protagonisten vorsichtigerweise dadurch, daß sie deren Feinde scheinbar objektiv beschreiben, sie aber in ein ungünstiges Licht stellen. Manchmal berichten sie zwar über die Polizeitruppen wirklich wertfrei, meist aber unterlassen sie es nicht, sich über die Eindringlinge lustigzumachen und über ihre Gaunereien und ihre Feigheit zu schimpfen. Die Behauptung, Polizeisoldaten seien feige, wird zu einem in der Volkspoesie Nordostbrasiliens allgemein anerkannten Gemeinplatz, den man in vielen Texten bestätigt und zu dem man sich immer neue Variationen einfallen läßt. Die bitterste Satire auf die Polizei stammt von João Martins de Ataíde und heißt bezeichnenderweise $O$ que me disse um soldado que milagrosamente escapou da unha de Lampião. In ihr berichtet ein Polizist von seinen Verbrechen und schildert schließlich die Reaktion seiner Kameraden, als es zum Kampf mit Lampião kommt:

Logo nos primeiros tiros

Nosso povo esmoreceu

Cinco morreram na bala

E quarenta e quatro correu ... $(60,379-382)$ 
Bei Ataíde waren es sicher nicht nur seine Sympathien für Lampião, die ihn bewogen, die Polizei zu verunglimpfen, sondern er wußte als echter Sertanejo, daß diese Leute seiner Gesellschaft fremd waren und daß sie alles andere taten, als die Bewohner des Sertãos vor den Cangaceiros zu schützen. Die gefühlsmäßige Abneigung gegenüber den "fremden" Polizisten wird deutlich ausgesprochen in einer Strophe, in der Ataíde den Soldaten erzählen läßt, was ihm geschah, als er sich hatte anwerben lassen:

Os meus amigos de outrora

Gente que andava comigo

Não me procuravam mais

Dizendo ser um perigo

Deve ter muito cuidado

Que quem anda com soldado

Sempre procura inimigo. (60, 29-35)

Ein Vergleich zwischen den Polizeitruppen und den Cangaceirobanden fällt stets zugunsten der Banditen aus, ja, ihre Rollen verkehren sich; die Soldaten sind es, die stehlen, und die Cangaceiros müssen sie bestrafen ${ }^{117}$.

Gibt es bei der Beschreibung der wichtigsten Kämpfe noch einige, wenn auch sehr wenige verfolgbare Parallelen zu historischen Ereignissen und Fakten, so wurde die Schilderung des Verhältnisses der Cangaceirochefs zu ihren Kameraden zu einem literarischen Klischee, das mit keinerlei Nuancierungen auf reale Gegebenheiten eingeht. Die Gefährten spielen in den Versen der Volksdichter eine äußerst unwichtige Rolle. Stets sind es nur Antônio Silvino und Lampião, die kämpfen, die siegen, die handeln, die fliehen. In den Texten steht zwar, sie seien von Kameraden begleitet gewesen, aber nur selten erfährt der Leser Näheres über diese, und die wenigen Hinweise sind zumeist völlig nichtssagend. Die Machtstellung der Cangaceirochefs wird von den Dichtern so überschwenglich gepriesen, daß für andere Personen neben ihnen kein Platz mehr ist. Auch sie selbst scheinen ihre Kollegen wenig beachtet zu haben. Wenn sie einmal erzählen, jemand aus ihrer Gruppe sei getötet oder gefangen worden - denn nur dann wird das Vorhandensein anderer überhaupt erwähnt -, zeigen sie keinerlei Gemütsbewegung. Ist es ihnen gelungen, einer Umzingelung zu entfliehen, so kümmern sie sich nicht weiter um ihre Gefährten. Das Nichtbeachten der Kameraden ist bei den Texten über Antônio Silvino so erstaunlich, weil er immer nur von wenigen Leuten begleitet war und man demzufolge über genaue Kenntnisse hinsichtlich der Gefährten verfügt; und bei den Texten über Lampião, weil er Truppen von 
über vierhundert Mann hinter sich hatte und Unterführer zwangsläufig eine Rolle gespielt haben müssen. Wohl finden sich im Zyklus Lampiãos etwas häufigere Hinweise auf Gefolgsleute als im Zyklus Silvinos, aber die Volksdichter widmen sich diesen nicht in dem Ausmaße, das der historischen Situation entspräche. Der typisch infantile Totalitätsanspruch einer Wunschgestalt wird hier so deutlich wie sonst nirgends.

In beiden Zyklen begnügen sich die Verfasser damit, entweder nur Namen von Gefährten zu nennen oder jedem Namen eine Charakterisierung beizugeben, die nichts Individuelles aussagt und nur die Widerspiegelung der Eigenschaften des jeweiligen Chefs ist. Der Cangaceiroführer soll auf diese Weise um so höher in den Himmel gehoben werden. Sehr bekannt sind die Verse Leandros über Antônio Silvinos Gefährten, bei deren Schilderung auch nicht ein einziger Name genannt wird:

Eu tenho seis cangaceiros

Todos bem escolhidos

Tirados mesmo por mim

De grupos bem conhecidos

São seis leões muito fortes

Seis máquinas de fazer mortes

Seis fundições de gemidos.

O primeiro é um cabôclo

Sem dentes bôca de fole

A bala do rifle dêle

Acha tôda pedra mole

Êsse se vendo em perigo

Pega qualquer inimigo

$\mathrm{E}$ antes de matar engole.

O segundo é um mulato

De cabelo um tanto grosso

Tem cinqüenta e seis anos

E fôrça de um homem moço

Mata o inimigo sorrindo

Tira o fígado inda bolindo

Nem bota sal come ensosso. $(8,36-56)^{118}$

Es sind „Typen“, die hier dargestellt werden, keine Individuen. In 
demselben Text erscheinen später noch vier weitere Kameraden Antônio Silvinos, jeder ist dem anderen gleich, ein Unterschied liegt nur in ihrer Rassenzugehörigkeit: sie symbolisieren die verschiedenen Kreuzungen der Sertanejos.

Dieser Nachdruck, der auf das "Typische“ gelegt wird, dient zweifellos dazu, eine Identifizierung von Sertanejos und Cangaceiroführern zu schaffen oder doch zu erleichtern: die Gefährten sind Mittelsleute; sie sind so, wie jeder Sertanejo auch sein möchte: mutig bis zur Verwegenheit, treu und erfolgreich. Die Grausamkeiten, die sie begehen, wiegen nicht allzu schwer. Es handelt sich immer um mehrere Personen, im Zyklus Lampiãos sogar um sehr viele, das heißt: der Sertanejo, der sich mit ihnen identifiziert, steht nicht allein, er tut nur das, was andere vor und neben ihm ebenfalls tun. Ein Gefühl der Solidarität mit dem Cangaço wird auf diese Art hervorgerufen.

Selbst wenn es einigen sehr berühmten Kameraden Antônio Silvinos oder Lampiãos gelungen zu sein scheint, sich aus dem Zyklus ihrer Chefs zu lösen, muß man bei einer genauen Analyse der betreffenden Texte feststellen, daß keineswegs sie es sind, die im Mittelpunkt der Geschichte stehen. Stets entdeckt man im Hintergrund als riesige Gestalt, die nichts Ebenbürtiges kennt, Silvino oder Lampião als Kontrastfiguren (wie im Falle des Folhetos A prisão de Volta Sêca, in dem der sechzehnjährige Cangaceiro Volta Sêca Protagonist ist) oder als Personen, die die Eigenschaften der Protagonisten in noch größerem Ausmaße besitzen (wie in Morte de Tempestade aus dem Zyklus Antônio Silvinos).

Gehen die Volksdichter auf das Verhältnis der Cangaceiroführer zu ihren Kameraden ein, so tun sie es ausschließlich mit dem Ziel, den Wert der Persönlichkeit ihrer Protagonisten herauszustreichen, auf keinen Fall aber, um der historischen Funktion dieser Gefährten gerecht zu werden.

Der Wunsch, eine einheitliche, nicht wechselnde, stets gleich starke Persönlichkeit vorzustellen, liegt der Behandlung eines weiteren, in diesem Zyklus sehr bedeutsamen Themas zugrunde: der Schilderung der Episode, die den Abschluß der Cangaceirokarriere bildet.

Schon um 1904, in dem ältesten Folheto aus dem Zyklus der Cangaceiros, das erhalten blieb, setzte Francisco das Chagas Batista die Normen fest, nach denen ein Cangaceiro seine Karriere abzuschließen habe. In $A$ vida de Antônio Silvino stehen folgende Verse: 
Aos macacos do govêrno

$\mathrm{Eu}$ não pretendo entregar-me

Fugirei sempre das tropas

Porém se alguma cercar-me

Lutarei como um possesso

Até a vida faltar-me.

Meu rifle não mente fogo

Nem o meu punhal enverga

Dormindo ou embriagado

Inimigo não me enxerga

Porque Antônio Silvino

Morre mas não se entrega.

Então se eu cair ferido

Antes de alguém me prender

Eu me suicidarei

Pois antes quero morrer

De que nas mãos da polícia

Um só instante me ver.

Quero que o mundo diga

Que eu me suicidei

Porque hão de dizer também

Que como herói lutei

$\mathrm{E}$ que aos meus inimigos

Morri mas não me entreguei.

Saiba o mundo inteiro

Que é este o meu destino

Morrerei espedaçado

Sou de mim próprio assassino

Mas nenhum homem dirá:

- Prendi Antônio Silvino. (32, 151-180)

Mehrere Male hintereinander wiederholt der Verfasser dieselben Gedankengänge und gibt ihnen soviel Nachdruck wie möglich: da Silvinos Macht höher steht als die der Regierung (deren Repräsentant der Mann wäre, der den Cangaceiro gefangennehmen sollte), würde eine Niederlage Antônio Silvinos zwangsläufig sein Prestige vernichten und beweisen, daß die Sertanejos, die auf den Cangaceiro vertraut 
haben, einer Illusion erlegen sind. Silvino bleibt in einer eventuellen kritischen Situation nichts anderes übrig, als sich selbst zu töten, um so zu vermeiden, daß neben ihm ein Mensch erscheint, der ihm gleichwertig oder sogar überlegen ist. Der Nachdruck liegt in diesem Text nicht darauf, daß Silvino im Gefecht fällt, sondern daß er Selbstmord verübt. Helden kennen keinen Bezwinger.

Lampião nun starb wirklich im Kampfe, und die Tatsache, daß er sich nicht selbst töten konnte, spaltete die Volksdichter sofort nach dem Ereignis in zwei Lager. Die einen waren von dem Gefecht von Angi$\cos$ befriedigt und glaubten, daß der Cangaceiro "standesgemäß" gestorben sei. João Bernardo da Silva schmückte die Episode sogar noch etwas aus, gestaltete sie noch "traditioneller", ließ dem (in Wirklichkeit nur etwa zwanzig Minuten dauernden) Kampfe einige Desafios vorausgehen, beschrieb die Umzingelung eines Hauses und in der üblichen summarischen Form das Feuergefecht, bis dann schließlich der Cangaceiro, bis zum letzten Blutstropfen kämpfend, der Übermacht unterliegt. Die meisten Verfasser jedoch taten das, was Chagas Batista instinktiv vorhergesehen hatte, als er die Normen für den Tod eines Cangaceiros aufstellte: sie gingen zur Polizei über, sahen ein, daß der Cangaço den Streitkräften der Regierung unterlegen war, verzichteten auf eine Identifizierung mit Lampião und fanden als neues Objekt ihrer Bewunderung den siegreichen Polizeioffizier João Bezerra. Diese farblose Gestalt wurde zum Helden des Sertãos gestempelt, zu einem Manne, der mit noch größerer Machtfülle die Nachfolge Lampiãos antreten würde. Seinem Zufallserfolg gelang es, all die schwachen oder glücklosen Polizeioffiziere und -sergeanten zu rehabilitieren, die fast zwanzig Jahre lang vergebens versucht hatten, Lampião zu stellen. Erst viele Jahre später, etwa um 1950, hatte sich das Image des Cangaceiros von diesem Schlag erholt. Man begann, die Begleitumstände seines Todes zu vergessen (und vor allem auch den Namen des Bezerra, von dem nichts Ruhmreiches mehr zu berichten war), man identifizierte sich wieder mit Lampião, erkannte ihn als heldische Erscheinung an.

Sehr viel ungünstiger noch waren die Daten, mit denen sich die Volksdichter im Falle Silvinos bei der Beendigung seiner Karriere auseinandersetzen mußten. Ganz entgegen allen Voraussagen ließ der Cangaceiro sich doch gefangennehmen, eine Tatsache, die ihm die Sertanejos sehr übelnahmen und die von den Dichtern nur unter sehr großen Schwierigkeiten bemäntelt werden konnte. Am meisten wand sich Francisco das Chagas Batista, um die Handlungsweise seines Protagonisten zu rechtfertigen. Seine Verse werfen ein besonders klares Licht auf die Einstellung des Volksdichters zur Realität. Er sieht es 
als seine Berufspflicht an, dokumentarisch genau wirklich Vorgefallenes zu berichten, in der Form, in der es ihm bekannt geworden ist und von der er glaubt, daß es die authentische sei. Der Dichter weiß aber auch, daß es seinen Lesern nicht ausschließlich darum geht, Aktuelles $\mathrm{zu}$ erfahren oder sich über wahre Begebenheiten zu unterrichten; sie wollen so oft wie möglich an ein bestimmtes Thema erinnert werden, weil sie Assoziationen zwischen sich und diesem herstellen möchten, Assoziationen, die sie befriedigen. So soll durch seine Verse eine Identifizierung des Lesers mit dem Protagonisten möglichst nicht verhindert werden; es dürfen keine Schranken aufgerichtet werden, die die Beziehungen zwischen dem Dargestellten und denen, für die man es darstellt, zerstören.

Es lohnt sich, das Vorgehen Chagas Batistas in denjenigen Szenen seiner História completa de Antônio Silvino etwas eingehender zu analysieren, in denen von der Gefangennahme des Cangaceiros berichtet wird. Seine Verse lassen sich mit der wahrscheinlichen Quelle vergleichen; die Abweichungen können festgestellt werden.

Am 1. Dezember 1914 veröffentlichte das Jornal Pequeno aus Recife unter der Uberschrift „Declarações do alferes Teófanes“ die Aussagen des Polizeiführers, der Antônio Silvino zur Strecke gebracht hatte:

„No dia 28 de novembro de 1914 Antônio Silvino e quatro ou cinco companheiros jogavam cartas dentro de um cercado, debaixo dum juàzeiro, na Lagoa do Laje, Pernambuco... O alferes Teófanes Tôrres, da polícia pernambucana, que o procurara, teve notícias do seu paradeiro. Saíu-lhe no encalço com oito soldados. Avistou o bando dentro das cercas. Aproximou-se cautelosamente e mandou fazer fogo. Os bandidos ganharam umas abas de serrotas de onde responderam aos tiros. Silvino ficou atirando de frente no lugar onde estava. Uma bala extraviada dos que faziam fogo das serrotas feriu-o pelas costas, atravessando-lhe o tronco. Outro cangaceiro tombou também baleado. $\mathrm{E}$ os soldados, depois de baterem o matagal, recuaram. Joaquim Moura, o ferido, suicidou-se com um tiro no ouvido, para não cair vivo às mãos dos, macacos ${ }^{6}$. Antônio Silvino arrastou-se até uma casa próxima, a de Manuel Mendes, e mandou propor ao comandante da tropa a sua rendição."

Die Fortsetzung dieser Episode erzählt Gustavo Barroso in seinem Buch Heróis e bandidos ${ }^{119}$ : Drei Tage lang zögerte der Offizier, weil er einen Verrat befürchtete; dann nahm er den Vorschlag an und führte Antônio Silvino gefangen nach Recife.

Bevor Chagas Batista die Ereignisse des 28. November behandelt, bereitet er den Leser in einem Prolog darauf vor, daß etwas Schreck- 
liches mit dem Protagonisten geschehen wird. Von Anfang an versucht er zu verhindern, daß man in dem Alferes Teófanes einen Mann sieht, dessen Persönlichkeit die des Cangaceiro übertrifft. Die Gefangennahme Silvinos ist ein vom anonymen Schicksal vorbestimmtes Unglück. Der Volksdichter erzählt, wie Antônio Silvino vor dem fatalen Tage zwei Visionen hat, die ihm verkünden, daß das Ende seiner Laufbahn unabänderlich gekommen sei. Gegen sein Ausscheiden aus dem Cangaço könne er selbst nichts mehr unternehmen, sein Wille sei nicht mehr maßgebend. Die Atmosphäre, die diese Geschichte umgibt, ist unheimlich und unheildrohend. Die erste Vision hat der Cangaceiro, kurz nachdem ihn ein Pfarrer exkommuniziert hat, in der Nacht:

Eu estava em uma casa

Jogando bem descuidado

Quando apareceu-me um homem

Com um objeto embrulhado

e me disse: - Eis um presente

Que ali quase me assombrei. (12, 2017-2028)

Erguei a vista porém

Já o homem não avistei

Abri o pacote e dentro

um par de algemas achei

Fiquei tão impressionado

Que ali quase me assombrei. (12, 2017-2028)

Die Handschellen sind von dem Pfarrer herbeigehext worden. Einen Tag später hat Silvino eine weitere Vision. Ihm wird der Tod vorhergesagt. Er hatte einem Ochsen einen Kopfschuß gegeben. Danach war er fast fünfzig Kilometer gegangen, als er sich unter einem Baume ausruhte und plötzlich das Tier auf sich zukommen sah. In diesem Bild ist eine Inversion eingetreten: Antônio Silvino, der vom Töten lebt, ist nicht mehr fähig zu töten und muß deshalb sterben:

Quando eu vi aquela cena

Perdi logo a esperança

Conheci que minha vida

Estava numa balança

O urro do boi dizia:

- Meu sangue pede vingança. 

Conheci que aquêle boi
Da morte era o mensageiro
Quis atirar-lhe e meu rifle
Mentiu fogo, então ligeiro
Me retirei e não quis

Que o matasse um companheiro. $\quad(12,2053-2064)^{120}$

Das Gleichsetzen der Gefangennahme mit dem Tode läßt sich sicher dadurch erklären, daß in beiden Fällen ohne Unterschied das beendet wird, was das Image des Protagonisten definiert, seine Position als Chef einer Cangaceirobande ${ }^{121}$.

Den Beginn des letzten Gefechtes Antônio Silvinos beschreibt Chagas Batista genau so, wie wir ihn aus der Zeitung kennen; geringfügige Ausschmückungen verstärken die Anschaulichkeit der Schilderung:
Porém eu não quis voltar ${ }^{122}$
$\mathrm{Na}$ mesma noite cheguei
Em Alagoa da Laje
E no mato me ocultei
Debaixo dum juàzeiro
Quatro horas descansei.
Porém no dia vinte e oito
Melancólico me senti
Passei o dia jogando
Às cinco horas me vi
Pela polícia atacado
E ao fogo então resisti. (12, 2071-2082)

Nun folgt ein Detail, in dem der Dichter vom Zeitungsbericht abweicht und durch das er die Szene vorbereitet, in der Antônio Silvino verraten wird: der Chef bleibt laut História completa nicht dort, wo er sich zu Beginn des Kampfes befunden hat, sondern zieht sich gemeinsam mit seinen Gefährten auf die Anhöhe zurück, wo sie sich verschanzen. Nach einer weiteren Strophe, in der die Leser erfahren, daß der Cangaceiro unverständlicherweise bei dreißig Schuß nicht ein einziges Mal getroffen hat, beginnt die Beschreibung der entscheidenden Phase des Kampfes. Dabei wird nach dem Jornal Pequeno Antônio Silvino nur versehentlich, nach Chagas Batista aber absichtlich von einem seiner Gefährten angeschossen. Durch seine willkürliche Konstruktion erreicht der Volksdichter, daß in seinem Gedicht die traditionellen Feinde des 
Cangaceirochefs, die Polizeisoldaten, keinerlei Anteil an seiner Niederlage haben.

Chagas Batista sieht ein, daß seine Verratsthese sehr verwegen ist, und er versucht, sie dadurch zu rechtfertigen, daß er nun nachträglich erzählt, dieser verräterische Kamerad habe schon seit vier Jahren auf eine Gelegenheit gewartet, sich an seinem Chef zu rächen, da dieser damals angeblich seinen Vater verprügelt habe. Da Silvino also durch ein Mitglied seiner eigenen Bande zu Fall gebracht wird und da bekannt ist, daß alle Gefährten des Cangaceiros nur ein Abbild seiner eigenen Persönlichkeit darstellen, glaubt Francisco das Chagas Batista bewiesen zu haben, daß sein Protagonist sich durchaus an die traditionellen Handlungsschemata gehalten habe. Seine Gefangennahme kommt einem Selbstmord gleich. Daß er nur unfreiwillig vor der Schande, die Überlegenheit der Gegner anerkennen zu müssen, bewahrt bleibt, spielt für den Verfasser keine Rolle. Es gelingt Chagas Batista jedoch nicht, seinen Gedankengang in eine logische und überzeugende Form zu kleiden. Der Autor stellt seine Absicht, das Image des Cangaceiro zu retten, eindeutig über alle Forderungen nach Wahrscheinlichkeit der Darstellung.

Er sieht ein, daß es nicht ausreicht, den $\mathrm{Haß}$ des Verräters durch eine Tat Silvinos zu motivieren, die Jahre zurückliegt und von der kein Sertanejo glaubt, daß der Cangaceiro sie begangen haben könnte. So sucht der Dichter andere Wege, um die von ihm geschilderte Intrige plausibel zu machen. Drei Strophen lang richtet er seine Aufmerksamkeit ausschließlich auf das Ziel, den schlechten Charakter des verräterischen Gefährten Antônio Silvinos darzustellen. Der Cangaceiro wird nicht nur hinterrücks angeschossen, sondern auch noch bestohlen:

Levou-me todo o dinheiro

E um anel de brilhante

Levou-me um grande punhal

E um rifle muito importante

Não me pude defender

Porque estava agonizante. (12, 2113-2118)

Es folgt eine Szene, in der ein anderer Kamerad Silvinos so handelt, wie man es eigentlich von dem Chef selbst erwartet hätte: er begeht Selbstmord, um nicht in die Hände der Polizei zu fallen. Zum zweitenmal erscheint hier das Motiv des Selbstmordes, wieder ist es von Antônio Silvino weg auf einen Gefährten projiziert. Schon zu Anfang seiner Verse über das entscheidende Gefecht Silvinos mit der Polizei hat Chagas Batista erwähnt, daß ein Cangaceiro namens Joaquim Moura verwundet worden ist ${ }^{123}$. Diesen Vers nimmt er jetzt wieder auf, denn inzwischen ist auch Antônio Silvino verwundet, befindet sich also in 
der gleichen Situation wie sein Gefährte (ihre Identifizierung miteinander wird dadurch ausdrücklich unterstrichen):

... Olhei em redor e vi

Um homem no chão deitado

Era o amigo Joaquim Moura ${ }^{124}$

Que se achava baleado.

Chamei-o êle se sentou

E me disse: - Estou perdido

Mas não me entrego à polícia

Portanto eu me suicido

Deu um tiro na cabeça

Morreu sem dar gemido. $\quad(12,2127-2136)$

Aber auch diese Szene scheint dem Volksdichter nicht zur völligen Rechtfertigung des Cangaceirochefs auszureichen. Daß Antônio Silvino sich nicht selbst tötete, bleibt Chagas Batista im Grunde unverständlich. Er unternimmt einen dritten Versuch, die Gefangennahme so darzustellen, $\mathrm{da} ß$ der Cangaceiro der Tradition gerecht wird. Schrittweise nähert sich der Dichter der historischen Wahrheit, nähert sich der Darstellung im Jornal Pequeno. Zuerst hat er eine Geschichte erfunden, dann ein wirklich vorhandenes Detail ausgenutzt, nun berichtet er fast exakt, was wirklich geschah, muß aber ein klein wenig ergänzen, um das Image Antônio Silvinos zu erhalten. Er erzählt, daß der Cangaceiro habe Selbstmord begehen wollen, daß ihm die Mittel dazu jedoch gefehlt hätten. Irgend jemand (es wird nicht erläutert, wer es gewesen ist die gute Gelegenheit, den verräterischen Kameraden zu beschuldigen, wird nicht ausgenutzt, ihn hat der Dichter bereits vergessen) habe ihm das Gift abgenommen, das er für solche Zwecke bei sich zu tragen pflegte:

Quis eu também suicidar-me

Mas as armas não achei

$O$ veneno que eu trazia

Nos bolsos não encontrei ... $\quad(12,2137-2140)$

Alles, was Antônio Silvino hat tun können, ist von ihm versucht worden. Er unterwirft sich der Fatalität, ergibt sich. Seine Kapitulation ist nach Chagas Batista ein souveräner Akt. Die Polizisten werden nur als unbedeutende Werkzeuge des Schicksals aufgefaßt und gar nicht erst erwähnt: 
Sòmente à fatalidade

Devo esta situação

Pois todos sabem que eu era

Um indomável leão

E nem eu sei porque foi

Que me entreguei à prisão.

Não me prenderam entreguei-me

Porque fui impulsionado

Pelo destino talvez

Vi-me ferido e roubado

Vim morar nesta prisão

Cumprir a lei do meu fado. $\quad(12,2209-2220)$

Und noch einmal, in den letzten Versen seines Gedichtes, in einem Epilog, der das Leben Silvinos im Recifer Gefängnis behandelt, hält es der Verfasser für nötig, darauf hinzuweisen, daß der Cangaceiro auch jetzt noch habe Selbstmord verüben wollen und daß er zwar seinem Fatum, nicht aber den Menschen unterlegen sei. Ihnen gegenüber blieb er frei. So wird Antônio Silvino gleichzeitig als unabhängig und als zur Unterwerfung verpflichtet verstanden. Die dauernden Wiederholungen dieser Argumente scheinen zu beweisen, daß der Dichter selbst nicht vollständig an sie glaubt, daß er an seinem Helden irregeworden ist. Sein Versuch, die Dichtung mit der historischen Wahrheit abzustimmen, gleichzeitig wahrhaftig und ehrlich zu sein und den schon feststehenden Vorstellungen des Publikums zu entsprechen, scheiterte. $\mathrm{Er}$ ist gezwungen, die Wahrheit zu manipulieren, weiterhin ein Charakterbild des Helden zu zeichnen, das er selbst half aufzubauen, an das er in der fixierten Form gebunden ist.

Viel einfacher und psychologisch oberflächlicher und daher vom Formalen her gesehen künstlerisch befriedigender löst Leandro Gomes de Barros, der zweite große Volksdichter, der das Leben Antônio Silvinos beschrieb, das Problem der Gefangennahme. Er hält sich streng an die deterministische Linie, die er schon beachtete, als er die Jugend des Protagonisten schilderte. Für Leandro ist es nicht verwunderlich, daß Silvino so handelte: es war vorherbestimmt. Nicht ihn darf ein Vorwurf treffen, denn die alleinige Verantwortung tragen „Deus“, „Destino“, „Fortuna“, „Sorte“, „Sina“ und „Fado“. Das Image des Cangaceiros bleibt unangetastet, hat nichts von seiner Wirkung verloren. Antônio Silvino wurde das Opfer nicht beeinflußbarer höherer Mächte. Geschickt 
beendet Leandro sein Gedicht mit der Bemerkung, daß die Karriere des Cangaceiros nicht unter allen Umständen beendet sein müsse, vielleicht könne er entkommen und seine Machtstellung im Sertão wieder einnehmen.

Die Gefangennahme Antônio Silvinos und der Tod Lampiãos waren also zwei Ereignisse, die von den Volksdichtern nur mit großer Mühe in ein von ihnen vorweg konzipiertes Schema eingeordnet werden konnten. Kein Wunder, daß die Mehrzahl der Verfasser (und natürlich insbesondere die, die eine Generation später kamen und von der Aktualität der beiden Episoden nicht mehr angerührt wurden) es erst gar nicht versuchte und auf dieses Thema nicht eingeht. Sie findet eine Lösung, die im epischen Zyklus der Cangaceiros eine ganze Reihe von Beispielen hat: was dem Volksdichter nicht gefällt, was nicht in die Tradition dieser Folhetogruppe paßt, wird weggelassen.

Am deutlichsten läßt sich diese Haltung der Autoren bei der Liebesgeschichte Lampiãos und Maria Bonitas beobachten. Obwohl die Zeitungen in dem Zeitraum zwischen 1930 (als die beiden sich kennenlernten) und 1938 ausführlich über die Rolle Marias berichteten, erscheint sie in den Folhetos jener Zeit nur als unbedeutende Statistin und keineswegs, wie es der historischen Wirklichkeit entspräche, als wichtigste Figur der Bande neben Lampião. Einige konfuse Verse werden über sie geschrieben; die Volksdichter wissen nicht, was sie mit einer Frau im Cangaço anfangen sollen: den Fall gab es bisher noch nicht. Erst nachdem ihr Kopf nach Maceió gebracht worden und ihre Berühmtheit auf dem Höhepunkt angelangt war, beginnen einige Verfasser, sich mit ihr auseinanderzusetzen. Sie überlegen, ob Maria sich der Bande Lampiãos angeschlossen habe, weil sie von Natur aus eine Verbrecherin war, oder nur, weil sie den Cangaceiro liebte. Aber die Ratlosigkeit ihr gegenüber hält an, und die Volksdichter finden keine einheitliche Linie.

Erst Manuel Pereira Sobrinho, ein Verfasser, der die Geschichte Lampiãos möglichst genau erzählen wollte und dessen sehr bekanntes Folheto Verdadeira história de Lampião e Maria Bonita heißt, wagt es, wie der Titel ankïndigt, sich etwas ausführlicher mit Maria zu beschäftigen. Er erzählt in wertfreier Weise, wie Lampião sie kennenlernte, wie sehr sie sich liebten, wie sie füreinander sorgten.

Die Grundlage der Persönlichkeit Marias ist für ihn ihre Liebesbereitschaft, ein Charakterzug, der nicht motiviert zu werden braucht. Zum Cangaço hat sie kein besonderes Verhältnis, es ist ihr gleich, was für einen Beruf ihr Geliebter hat. Nicht verbrecherische Anlage war es, die 
sie in den Cangaço trieb. Sie steht am Rande, hat eine Beziehung zu den Cangaceiros nur dadurch, daß sie einen Lampião liebt. Manuel Pereira Sobrinho löst das Problem "Maria Bonita im Cangaço" dadurch, daß er auf einen anderen Zyklus in der Volkspoesie Nordostbrasiliens zurückgreift, auf den der Liebesgeschichten. Maria wird von ihm in genau der gleichen Art behandelt, wie es bei den Protagonistinnen der Liebesgeschichten der Fall ist. Der Dichter hat wieder festen Boden unter die Füße bekommen, kann wieder über Themen schreiben und Motive verwenden, die ihm aus traditionellen Texten bekannt sind ${ }^{125}$.

Das Einordnen der Gestalt Maria Bonitas in den Großen Zyklus der Liebesgeschichten stellt gleichzeitig den Versuch des Volksdichters dar, die Persönlichkeit Lampiãos in den Augen der Sertanejos aufzuwerten, von seinen schlechten Eigenschaften abzulenken. Die Hörer und Leser dieser Verse nähern sich dem Protagonisten in dem gleichen Maße, wie sie für den "Herói amoroso" der Liebesgeschichten eingenommen sind. Die vorgebrachte Behauptung, daß Lampião fähig gewesen sei zu lieben, läßt sich natürlich umkehren und macht aus dem Cangaceiro einen liebenswerten Menschen, vor allem, wenn man in dem Folheto die Verse zitiert, die von Lampião selbst gedichtet worden sein sollen und die ihn als empfindsamen Mann ausweisen ${ }^{126}$.

So weichen also auch beim Thema "Maria Bonita" die Volksdichter weit von der historischen Realität ab. Sie geben geschichtliche Ereignisse nur dann objektiv richtig wieder, wenn sie feststehenden Handlungsschemata entsprechen und somit in den meisten Fällen Wiederholungen altbekannter Fakten darstellen ${ }^{12 \tau}$. 


\section{ANTONNIO SILVINOS UND LAMPIAOS EIGENSCHAFTEN UND CHARAKTERE IM EPISCHEN ZYKLUS DER CANGACEIROS}

Die Verfasser machen keinen Unterschied zwischen Antônio Silvino und Lampião, wenn sie auf Eigenschaften der Cangaceiros zu sprechen kommen, die moralisch wertfrei sind. Die Basis ihrer Persönlichkeit ist stets die Tapferkeit; ihr verdanken sie ihren Erfolg; sie ist es, die ihnen ihre Machtstellung sichert. Um ihren Lesern zu beweisen, in welch hohem Maße die Cangaceiros sie besitzen, greifen die Volksdichter auf ein Motiv zurück, das auch in anderen Folhetogruppen des Großen Heroischen Zyklus zu diesem $Z$ weck verwandt wird: auf den „Kampf mit einem Jaguar". Bei der Beschreibung des Duells - die bekanntesten Verse stammen von Francisco das Chagas Batista und Leandro Gomes de Barros ${ }^{128}$ - vergessen die Autoren nicht, auch die Behendigkeit, die schnelle Auffassungsgabe, die Kraft und Ausdauer ihrer Protagonisten hervorzuheben - Qualitäten, die ein Cangaceiro sämtlich in sich vereint.

Warum steht die Tapferkeit in der Sociedade sertaneja in einem so hohen Ansehen? Zweifellos, weil man am Beispiel der Cangaceiros sieht, wie weit man es mit einer Eigenschaft, die jeder Sertanejo besitzt oder besitzen sollte, innerhalb dieser Gesellschaft bringen kann. Die Zugänglichkeit der Tugend Tapferkeit erweckt den Anschein, das Handicap, in einer der untersten Schichten geboren zu sein, lasse sich wettmachen.

Weit bedeutender jedoch bei der Beurteilung der Person Antônio Silvinos und Lampiãos durch die Volksdichter ist die Stellung der Cangaceiros zum Ehrenkodex des Sertãos, und hier wird konsequent zwischen Antônio Silvino und Lampião unterschieden.

Antônio Silvino ist, der historischen Realität entsprechend, der „ritterliche" Typ des Cangaceiros, ein Robin Hood, ein Schinderhannes. Wohl verletzt auch er die Vorschriften des Ehrenkodex der Sertanejos, aber in einer solchen Form, daß er sehr leicht gerechtfertigt werden kann. Stiehlt er, so nur bei Reichen, und zwar bei Reichen, die geizig sind. Sein Diebstahl ist ein erzieherischer Akt, kein Verbrechen; er begeht keinen Raub, um sich selbst zu bereichern, sondern um den Armen zu helfen. Daß er auch der Post und den Gemeindeverwaltungen Geld wegnimmt, kann von den Volksdichtern schon nicht mehr als Diebstahl 
interpretiert werden: es ist sein Recht, denn Antônio Silvino versteht sich als Gegenkraft zu den korrupten Regierungen in den Hauptstädten. Seine Handlungen sind Akte einer Anti-Justiz. Seine Übergriffe sind legitimiert durch die administrative Unfähigkeit seiner Gegner.

Auch im zweiten wichtigen Punkt des Ehrenkodex des Sertãos, in der Vorschrift, nicht zu töten, geht Silvino eigene Wege. Bringt er jemanden um, so in den meisten Fällen nur, weil dieser sich ohne Berechtigung gegen ihn gestellt hat. Im übrigen akzeptieren die Volksdichter mit größter Selbstverständlichkeit die Morde des Cangaceiros, ein Beweis für die Behauptung, daß gerade in diesem speziellen Falle die moralischen Barrieren für die Sertanejos sehr niedrig sind. Ein Menschenleben zählt nicht viel ${ }^{129}$.

Sehr konservativ aber verhält sich Antônio Silvino, wenn es um die Ehre der Frauen geht. Hier erlaubt er sich nichts, was vom Ehrenkodex verboten wird. Sein Respekt gegenüber den Frauen im Sertão ist sprichwörtlich geworden, und die Verfasser von Folhetos können den Cangaceiro deswegen nicht genug loben. Silvino hätte die Möglichkeit gehabt, die moralischen Vorschriften auch in diesem Punkte zu übertreten, aber er hat sich freiwillig an die Grenzen gehalten, die auch für jeden einfachen Sertanejo gelten. Diese Tatsache vor allem ist es, die Silvino in seinem epischen Zyklus zum uneingeschränkt positiven Helden werden ließ. Aus dem benachbarten Zyklus der Valentes nehmen die Volksdichter Handlungsschemata, um den Cangaceiro sogar in der Rolle eines „casamenteiro“, eines heiligmäßigen Ehestifters, zu zeigen. Diese Seite des Wirkens Antônio Silvinos blieb in der VolkspoetenGeneration, die der Zeit seiner Gefangennahme folgte, die einzige, die immer wieder von neuem aufgegriffen und variiert wurde. Seine Gefechte hatte man vergessen; sein Verhalten gegenüber den Frauen aber ist zu einem beständigen Grundzug seines Charakters geworden, besonders zu einer Zeit, in der die Handlungsweise Lampiãos größten Abscheu bei den Sertanejos hervorrief ${ }^{130}$.

Denn während es bei Antônio Silvino den Sertanejos nicht die geringste Mühe machte, sich bei allen Situationen, die ihnen die Volksdichter beschrieben, mit dem Cangaceiro zu identifizieren, war dies im Zyklus Lampiãos nur bei denjenigen Textstellen möglich, die nicht auf das Verhältnis dieses Banditen zu dem Ehrenkodex des Sertãos anspielten.

Die Taten Lampiãos wurden mit Empörung aufgenommen. Er verletzte nicht nur sämtliche moralischen Verbote, die für einen Sertanejo bestehen, sondern kümmerte sich auch nicht um eine Rechtfertigung seiner Handlungsweise. Er stahl, um Geld zu bekommen; er mordete, 
weil es ihm Spaß machte; und, das ist das Schlimmste, er vergewaltigte Mädchen, Ehefrauen und Witwen. Er machte in seiner Mordlust weder vor Kindern noch vor Greisen halt. Es gibt keinen Text über Lampião, in dem der Verfasser nicht über solche Verbrechen zu berichten wüßte. Die Züge des Cangaceiros durch die Staaten des Nordostens waren Züge des Grauens, waren eine ununterbrochene Kette von Gewalttaten, vor denen die heroischen Taten Lampiãos, der Angriff auf Mossoró etwa, verblassen sollten.

Für besonders interessant und nacherzählenswert hielten die Volksdichter die Sexualverbrechen des Cangaceiros ${ }^{131}$. Die starke moralische Verurteilung des Protagonisten bei solchen Episoden kann dem Sertanejo, der sich trotz allem mit einer Gestalt aus der beschriebenen Szene identifiziert, einen beträchtlichen Grad der Befriedigung vermitteln, denn das Umstoßen der Tabus und die daraus erfolgenden Gewissensbisse verstärken seine masochistischen Tendenzen. Ein Beispiel für deutlich sadistisch gefärbte Verbrechen Lampiãos sind die Verse Zé Vicentes aus dem Folheto Combate e morte de Lampião:

Uma vêz numa cidade ${ }^{132}$

Lampião apareceu

Cinco rapazes pegou

E de punhal abateu

Tirando o sangue de um dêles

Um de seus cabras bebeu.

Um rapaz que estava noivo

Num esteio êle amarrou

A noiva fêz ficar nua

Com ferro em brasa a marcou

$\mathrm{E}$ ao noivo desesperado

O criminoso castrou. $\quad(39,55-66)$

In diesen beiden Strophen sind folgende Elemente zusammengedrängt: irgendwelche Personen werden willkürlich ermordet; eine kulturelle Regression zum Anthropophagismus wird symbolisch dargestellt (das Motiv "Menschenblut trinken“ taucht mehrmals im Zyklus Lampiãos auf), und verschiedene sexuelle und sadistische Momente werden geschickt miteinander verkoppelt (das Brandmarken einer Person - ein häufiges Motiv bei Lampião - wird hier bei einer nackten Frau durchgeführt, vor deren Augen man auch noch ihren Bräutigam kastriert). Diese Häufung von Motiven, die starke sexuelle Emotionen hervor- 
rufen, ist relativ selten. Meist begnügt sich der Volksdichter mit einem einzigen Beispiel für die Perversität Lampiãos. Die bekannteste Episode ist die, in der der Cangaceiro mit seiner Gruppe auf einer Hochzeit erscheint und den Anwesenden befiehlt, sich nackt auszuziehen. Der unterbrochene Tanz muß fortgeführt werden. Zum Schluß ermorden die Banditen die von ihnen vergewaltigten Frauen. Mit wenigen Varianten wird diese Szene in Zé Vicentes Combate e morte de Lampião, in den Novos crimes de Lampiäo eines unbekannten Autors ${ }^{133}$ und in der Verdadeira bistória de Lampião e Maria Bonita von Manuel Pereira erzählt. Diese - authentische - Episode hatte in der epischen Volkspoesie einen so großen Erfolg, daß sie sogar in andere Zyklen überging, so zum Beispiel in den Zyklus der Valentes, wo sie in dem Folheto História do cangaceiro João Serra Negra von Minelvino Francisco Silva ${ }^{134}$ zehn Strophen lang beschrieben wird. Noch viele Jahre nach Lampiãos Tod schreiben die Volksdichter über dieses Ereignis. In dem ungefähr um 1955 verfaßten Folheto $A$ morte comanda o cangaço von Joaquim Batista de Sena wird Lampiãos Charakter einzig durch den "Tanz der Nackten" exemplifiziert. Keine andere Episode scheint dem Dichter typischer für den Cangaceirochef gewesen zu sein. Und auch in die gehobene Literatur fand sie Eingang. Sie wurde zum Beispiel von Jorge Amado in Seara vermelha ${ }^{135}$ aufgegriffen.

Aber obwohl Lampião durch sein brutales Vorgehen das genaue Gegenteil seines Vorgängers Silvino war, erliegen die Volksdichter nicht der Versuchung, in grober Schwarz-Weiß-Malerei dem "guten“ Antônio Silvino den „bösen“ Lampião entgegenzuhalten. Der Abscheu vor seinen Verbrechen geht auch nicht so weit, daß sie nun etwa durch ihre Verse die Polizeitruppen unterstützen. Ihr Solidaritätsgefühl gegenüber Lampião bleibt bestehen. Sie lehnen nicht seine gesamte Persönlichkeit ab, sondern verurteilen nur gewisse Züge an ihm.

Dieses Schwanken, diese Unsicherheit darüber, wie man sich ihm gegenüber einstellen soll, dieser Wunsch, ihn zu akzeptieren, und dieses Abgestoßensein von seinen Grausamkeiten veranlassen die Volksdichter zu seltsamen Kompromißlösungen. Ein gutes Beispiel dafür ist das Folheto des engagierten Lampião-Gegners João Martins de Ataíde Proezas de Lampião na cidade de Cajàzeiras. Dieser Dichter, der immer in besonders scharfer Form die Verbrechen des Cangaceiros geißelte, schrieb den Text um 1930, zu einer Zeit also, als Lampião in Bahia so tat, als habe er sich gebessert. Die vagen guten Nachrichten reichten aus, um Ataíde anzuregen, das Image Lampiãos reinzuwaschen, aus ihm einen zweiten Antônio Silvino zu machen. Es grenzt an Schizophrenie, 
wenn der Autor im ersten Teil des Folhetos von einem verabscheuungswürdigen Verbrechen Lampiãos berichtet und im zweiten versucht, seine Leser von der Harmlosigkeit des Cangaceiros zu überzeugen. Ataíde greift dabei ein Motiv aus dem Zyklus Silvinos auf ${ }^{136}$, läßt Lampião alle anderen Cangaceiros als Strauchdiebe verurteilen, läßt ihn als Verteidiger gerade der drei Dinge erscheinen, die Lampião nie geachtet hat, als Beschützer fremden Gutes, als Verteidiger des Lebens eines Unbekannten und als Bewahrer der sexuellen Ehre einer Frau. Nicht der wahre Lampião soll es sein, der den Sertão unsicher macht, sondern ein infamer Doppelgänger. Als die Bande dieses Gangsters ein Haus überfallen will, in dem sich der richtige Lampião gerade aufhält, wird er von seinem "Vorbild" erschossen, nachdem man ihm noch die folgenden Verse zugerufen hat:

Você é deshonrador

Segundo que me parece

Quem te mata é Lampião

Porém você não conhece

Assim eu mesmo assassino ${ }^{137}$

Môça, mulher e menino ${ }^{138}$

Aonde estou não padece. $\quad(65,254-280)$

Es scheint der Gipfel an Heuchelei zu sein, daß sich der berüchtigste Sittenverbrecher des Nordostens als Richter eines Gesinnungsgenossen aufspielt, zeigt aber doch, wie gern die Volksdichter in das Schema zurückfinden möchten, das zu Antônio Silvinos Zeiten galt. Lampiãos historische Handlungsweise wird als Abirrung vom echten Cangaceirotum angesehen, als sehr bedauernswerte Erschwerung für eine Identifizierung der Sertanejos mit ihm. Der Wunsch, diese enge Beziehung in dem Grade wiederherzustellen, wie sie in dem Zyklus Antônio Silvinos bestand, ist latent geblieben und versucht, sich bei dem leichtesten Anzeichen für eine Änderung des Vorgehens Lampiãos durchzusetzen ${ }^{139}$. 
Wir besitzen ein so reiches Material von Texten aus dem epischen Zyklus der Cangaceiros, daß wir, bei genügenden Kenntnissen von den historischen Fakten des Cangaços, in dieser speziellen Gattung der Volkspoesie Nordostbrasiliens eine eingehende Analyse des Prozesses durchführen können, durch den Realität in Dichtung umgesetzt wird. Die Betrachtung dieses volksliterarischen Phänomens wird noch interessanter dadurch, daß die beiden Protagonisten des Zyklus ein einander völlig entgegengesetztes Persönlichkeitsbild aufweisen.

Die individualisierenden Elemente des Images einer historischen Persönlichkeit werden bei ihrer Bearbeitung durch die Volksdichter fortwährend in ein bestimmtes Schema eingeordnet, bis sie sich schließlich $\mathrm{zu}$ einem Symbol verdichtet haben. Individualisierende Elemente sind die Daten, die eine Person definieren, die sie von allen anderen unterscheiden, Daten über die Einordnung eines Menschen in Raum und Zeit, Daten über seine Charakterzüge, über die wichtigsten Ereignisse in seinem Leben, über seine Beziehungen zu anderen Personen. Dieses Material unterwirft der Volksdichter einer Auswahl, in der er sich von seinem erwählten Thema verwandten Vorläufern und Modellen beeinflussen läßt. Das Wort „Cangaceiro“ ruft in ihm eine Reihe von Assoziationen hervor, die es ihm ermöglichen, ein Individuum, das sich in dieser Weise bezeichnen läßt, unter determinierten Gesichtspunkten zu betrachten.

Durch den Vergleich verschiedener Vertreter des Cangaceiroberufs haben sich bestimmte Aspekte herauskristallisiert, die man als "typisch“ bezeichnen könnte, als allen gemeinsam. Bei einer literarischen Darstellung des Lebens eines Cangaceiros wird der Volksdichter diejenigen individualisierenden Elemente besonders hervorheben, die er schon in älteren Gedichten vorfindet, vor allem in den Texten, die den unmittelbaren Vorgänger seines Protagonisten behandeln.

Er wird sich nicht auf eine bloße Schilderung objektiv vorhandener Fakten und Charakterzüge beschränken, sondern wird seine Geschichte so aufbauen, daß sie schließlich nur noch Motive enthält, die reine Wiederholungen schon bekannter, traditionell gewordener Daten sind. Um den symbolischen Aussagekern des Cangaceiros herum bildet sich 
eine Zone schematisierter Darstellung, die sich aus historischem Material speist, aber eine ganze Skala von Ubergängen zwischen dem Typischen und dem Realen aufweist. Aus der Vielzahl individueller Elemente wird ein verhältnismäßig starres schematisches System, das fast alles nicht durch Vorbilder Belegte aussortiert.

Neben der Verdichtung läuft eine Akzentverschiebung her, die sowohl in dem schematisierten als auch in dem nicht aufgenommenen Material die Bedeutung eines bestimmten Elementes jeweils nach den Forderungen der Tradition über- oder untertreibt. In der historischen Wirklichkeit wichtige Ereignisse werden $\mathrm{zu}$ belanglosen gemacht, die keiner Erwähnung bedürfen, oder Belanglosigkeiten werden zu überaus bedeutenden Ereignissen.

Aber immer noch nicht verschwinden sämtliche individualisierenden Elemente aus Texten, die sich im Bereich der Schematisierung befinden. Sowohl Einflüsse des persönlichen Images des Vorgängers des Protagonisten als auch die seines eigenen Bildes können festgestellt werden. Für diese Tatsache gibt es drei Gründe:

An erster Stelle wäre zu nennen, daß es aktuellen Daten eine Zeitlang gelingt, sich in dem schematisierten Bereich einer historischen Persönlichkeit zu halten. Erst wenn die Kraft ihrer Aktualität abgeschwächt ist, wenn sich gezeigt hat, daß sie die Sertanejos nur haben bewegen können, als sie neu und sensationell waren, verschwinden sie. Dieses Aufgehen individualisierender Elemente in einem Schema ähnelt dem psychischen Prozeß des Vergessens, bei dem sich mit der Zeit exakte Daten in umrißhafte Ideen verwandeln, die nur noch gefühlsmäßig die Realität wiedergeben können.

Der zweite Grund ist, daß zwar die Gestalt des Vorgängers des Protagonisten im allgemeinen die Kriterien dafür liefert, was in das schematisierte Image seines Nachfolgers aufgenommen werden darf und was mit eigenen Motiven übereinstimmt, daß aber in einigen Fällen etwas so Neues, noch nicht Dagewesenes geschieht, daß der Volksdichter unbedingt darüber berichten muß. Sein Wunsch jedoch, auch hierbei nach traditionellem Muster zu verfahren, verführt ihn dazu, im Leben des Vorgängers nach ähnlichen Motiven zu forschen, die, weil sie zu unbedeutend waren oder sehr rasch ihre Aktualität verloren, zu den aussortierten individualisierenden Elementen dieses Cangaceiros gehörten. Sie werden nun nachträglich schematisiert und als wichtiger Bestandteil des Images angesehen, so daß der Volksdichter in der Lebensgeschichte des nachfolgenden Cangaceiros diesem Modell folgen kann und den Bericht über das wichtige Ereignis dem Handlungsablauf seines Vorbildes anpaßt. So braucht das Beiseitelassen bestimmter Daten bei dem 
Aufbau einer schematisierten Gestalt nicht immer eine völlige Vernichtung dieser Elemente zu bedeuten.

An dritter Stelle müssen sekundäre Tendenzen erwähnt werden, die nicht notwendigerweise Bestandteil des Aussagekerns des Gedichtes sein müssen und die ihrerseits ein längeres Verweilen individualisierender Elemente in der Schematisierungszone herbeiführen. In einigen Fällen beschleunigen diese Tendenzen den Verdichtungsprozeß, im allgemeinen aber können sie sich von dieser Aufgabe befreien: sie beschränken sich auf die Durchführung ihrer eigenen Anliegen. So wird häufig die Behauptung, die Cangaceiros hätten diesen Beruf ergriffen, weil ihr Vater getötet worden sei, als unabtrennbarer Bestandteil des Images aller Cangaceiros gedeutet. In Wirklichkeit handelt es sich hier um individuelle Elemente der beiden letzten bedeutenden Cangaceiroführer, die nur in ihren jeweiligen Zyklen eine schematisierte Form gefunden haben. Ohne jeden $Z$ weifel entsprechen sie der allgemeinen Linie des Aussagekerns der Cangaceirogeschichten - das ist eine Grundvoraussetzung für die Wirksamkeit sekundärer Tendenzen —, ihre wichtige Position innerhalb der beiden Zyklen jedoch verdanken sie nicht dem Symbol des Cangaceiros, sondern ihrer Fähigkeit, Emotionen hervorzurufen, die durchaus unabhängig, vom Image eines Cangaceiros getrennt, wirken können. Ahnlich ist es mit Motiven, die versuchen, sadomasochistischen Tendenzen gerecht zu werden, und die ebenfalls eine wichtige Rolle in den Gedichten über Cangaceiros spielen, vor allem bei den Beschreibungen der Grausamkeiten Lampiãos. Auch Einschübe legendärer Episoden (Antônio Silvino als Ehestifter, z. B.) gehorchen weitgehend Kriterien, die nicht notwendigerweise dem Zyklus der Cangaceiros zuzuordnen sind. Die Folge ist, daß durch sie sich Ansatzpunkte zu anderen Zyklen der Volksliteratur Nordostbrasiliens finden ließen, daß durch ihre Vermittlung ursprünglich fremde Motive aufgenommen und umgeformt wurden.

Durch das Vorhandensein sekundärer Tendenzen, durch die Kraft einer schnell entschwindenden Aktualität lassen sich die großen Unterschiede der einzelnen Texte bei der Behandlung eines schon schematisierten Themas erklären. Dazu kommen die verschiedenen Möglichkeiten, ein Element zwischen den beiden extremen Polen des "Typischen“ und des "Realen" einzuordnen, es in verschiedenen Pliasen zu beobachten. Auch die Eigenart der Themenkreise beeinflußt den Grad der Schematisierung: je mehr sie mit dem typischen Leben im Cangaço zusammenhängen, desto einheitlicher wird ihre Beschreibung, wie man an den Szenen feststellen konnte, die die Kämpfe der Cangaceirochefs und das Verhältnis zu ihren Gefährten schildern. Schließlich wird aus dem Unter- 
schied der Persönlichkeit Antônio Silvinos und Lampiãos ein im psychologischen Sinne historischer; das heißt, jede der beiden Gestalten steht für eine bestimmte Phase in dem Prozeß der Verdichtung individueller Motive, wobei Silvino mehr von seinem historischen Charakter bewahrt und Lampião sich mehr der symbolischen Gestalt des Cangaceiros nähert. Kein Wunder, daß Lampião, unterstützt von der Aktualität seines Handelns, bei weitem die stärkere Persönlichkeit besitzt, der es gelingt, sich anderen, verwandten Gestalten gegenüber als Vorbild durchzusetzen. Aber weder das Schema Lampião noch das Schema Antônio Silvino ist in sich einheitlich abgeschlossen oder kann gar in seiner Gesamtheit gegen ein anderes ausgetauscht werden. Ihre Images folgen keiner ununterbrochenen, einzigen Linie; häufig überschneiden sie sich mit den Persönlichkeitsbildern anderer Menschen oder literarischer Gestalten, ohne aber auch mit ihnen deckungsgleich zu werden.

Die verschiedenen Stufen der Schematisierung entsprechen vier Grundphasen: Vergleich, Annäberung, Parallelisierung und Fusion.

Vergleiche zwischen den beiden berïhmten Cangaceiroführern stehen häufig zu Beginn eines Textes, als Einführung in das behandelte Thema. Die Unterschiede und Gemeinsamkeiten werden aufgezählt. Im allgemeinen führen diese Vergleiche zu einer Annäherung Silvinos und Lampiãos. In keinem Text behauptet ein Volksdichter, daß unüberwindbare Hindernisse für eine Nebeneinanderstellung der beiden Cangaceiros bestïnden. Betont wird stets, daß sie sich in wesentlichen Punkten nicht voneinander unterscheiden. Immer wird das beiden Gemeinsame hervorgehoben, unter Mißachtung der historischen Realität.

Die wichtigste Rolle im Zyklus der Cangaceiros spielt zweifellos die Parallelisierung, eine zwangsläufige Konsequenz der Annäherung. Die beiden Cangaceiros werden als fast identische Vertreter eines Berufes vorgestellt. So wird zum Beispiel ihr Kampf gegen die Polizei in beiden Zyklen auf eine ähnliche Weise beschrieben; eine Unterscheidung zwischen ihnen wird oft nur durch wenige Elemente gemacht, durch Hinweise auf die besondere Situation des Gefechtes, auf die Namen und die Amtsstellung der Gegner. Auch — nicht moralisierende - Schilderungen typischer Verbrechen, wie Mord und Raub, parallelisieren die Gestalten von Antônio Silvino und Lampião in vielen Fällen. Ein Detail im Zyklus Lampiãos läßt erkennen, wie die Parallelisierung dieses Cangaceiros mit seinem Vorgänger sich fortlaufend verengt, wie die individualisierenden Elemente immer mehr an Gewicht verlieren. Obwohl die Volksdichter den genauen Geburtsort Lampiãos nicht kannten, folgten sie den üblichen Zeitungsangaben und schrieben überwiegend, 
der Cangaceiro stamme aus Vila Bela. Ein Dichter aber legte den Geburtsort schon in das Gebiet des Pajeú, in die Gegend, die von alters her als Schlupfwinkel der berüchtigtsten Cangaceiros angesehen wurde und als die traditionelle Wiege des Cangaços ${ }^{140}$. Noch einen Schritt weiter ging der Verfasser, der Lampião aus der Umgebung von Afogados da Ingàzeira, dem Geburtsort Silvinos, stammen ließ ${ }^{141}$, und es fehlt auch nicht ein Text, demzufolge Virgulino Ferreira direkt in Afogados geboren wurde ${ }^{142}$. Und noch ein Volksdichter - und damit ist der äußerste Grad einer Parallelisierung erreicht - machte Lampião zu einem Verwandten von Antônio Silvino ${ }^{143}$, ein Vorgang, der auch schon in dem Zyklus Silvinos vorgebildet ist, und zwar insofern, als dieser in der História completa de Antônio Silvino als Neffe seines Vorgängers Silvino Aires vorgestellt wird.

Eine Fusion unterscheidet sich dadurch von einer Parallelisierung, daß keinerlei persönliche Unterscheidungsmerkmale mehr anzutreffen sind. Die Images sind einander vollkommen gleich geworden. Eine Fusion beider Gestalten nähert sich sehr ihrem Symbolgehalt, konzentriert sich aber im allgemeinen auf einen Aspekt, der nicht zum Wesentlichen des Symbols gehört. Eine genaue Abgrenzung ist nicht möglich, denn auch noch in der symbolischen Gestalt eines Cangaceiros können sich einige individuelle Züge erhalten haben; zumindest der Eigenname bleibt ja bestehen. Beispiele für die Fusion der Persönlichkeitsbilder Antônio Silvinos und Lampiãos sind in den Texten zu finden, die Kämpfe der Cangaceiros mit Jaguaren beschreiben, und in sehr eindringlicher, klarer Form in dem Folheto $\mathrm{O}$ encontro de Lampião com Antônio Silvino von José Costa Leite. Daß die Phase der Parallelisierung überschritten ist, wird deutlich daran, daß nicht einmal mehr moralische Unterschiede zwischen den beiden Cangaceiros bestehen. In diesem Text beschreibt der Autor einen Kampf Lampiãos mit Antônio Silvino - die zeitliche Fixierung wird also mißachtet - , der bezeichnenderweise unentschieden ausgeht. Jede Aktion Silvinos findet ihr Gegenstück in einer Reaktion Lampiãos, und umgekehrt.

Die Schematisierungsphasen der Parallelisierung und der Fusion können eine weitere Veränderung der historischen Gestalt der Cangaceiros in den Folhetos herbeiführen: da Teile von Images verschiedener Personen, die einander durch ein ganz bestimmtes Element - in diesem Falle durch den gemeinsamen Beruf - verbunden sind, in einigen wenigen determinierten Situationen untereinander ausgetauscht werden können, läßt sich auch eine Anzahl individueller Züge von einer Gestalt zur anderen verschieben. Je mehr die Persönlichkeitsbilder Lampiãos und 
Antônio Silvinos einander überlappen, desto mehr Möglichkeiten gibt es zur Verschiebung ursprünglich individualisierender Elemente, die nun ihre definierende Funktion verloren haben und zu schematisierten Ornamenten werden.

Im allgemeinen verschieben sich Motive in der Richtung von Lampião auf Antônio Silvino. Das Verhältnis Vorgänger-Nachfolger kehrt sich um: so überragend erschien die Persönlichkeit Lampiãos den Sertanejos, so berühmt wurde dieser Cangaceiro. Ein besonders beeindruckendes Beispiel für eine Verschiebung eines außergewöhnlichen individuellen Zuges von einem Cangaceirochef auf den anderen läßt sich im Zyklus Antônio Silvinos aufspüren: auch dieser Cangaceiro bekommt seine Maria Bonita.

Je unpersönlicher Lampião in seinen Folhetos vorgestellt, je schematisierter seine Gestalt wird, desto häufiger verbindet ihn - wenn auch nur in wenigen Worten - der Volksdichter mit Maria Bonita. Da sie ja nicht zum traditionellen Schema einer Cangaceirogeschichte gehört, kann sie zu Lampião erst dann in eine enge Beziehung gesetzt werden, wenn auch seine Gestalt einen Grad der Schematisierung erreicht hat, der dem ihrigen im Rahmen des Zyklus der Liebesgeschichten entspricht. Etwa zwanzig Jahre nach dem Tode Lampiãos ist es soweit gekommen, daß einige Volksdichter eine Geliebte als unerläßliche Ergänzung des Persönlichkeitsbildes eines Cangaceiros ansehen. Folgerichtig behauptet Manuel Pereira in seinem Romance da vida de Antônio Silvino, auch Silvino habe eine Geliebte gehabt, er, der in Wirklichkeit verheiratet war und von dem sonst kein einziges Folheto eine ihn betreffende Liebesgeschichte berichtete. In allen Einzelheiten - so soll auch die Geliebte Silvinos einen schwächlichen Ehemann gehabt haben -, übertrug Pereira das Maria-Bonita-Motiv auf den Zyklus Antônio Silvinos. Ein weiteres Beispiel für eine Verschiebung betrifft die Episode, die João Martins de Ataíde in Proezas de Lampião na cidade de Cajázeiras beschreibt und in der der Cangaceiro einen unliebsamen Doppelgänger bekämpft. Sie war typisch für das Persönlichkeitsbild Silvinos und ging auf Lampião über, um zu beweisen, daß auch dieser die moralisch konservative Haltung seines Vorgängers übernommen habe. Aus dem Zyklus Lampiãos wird sie nun ihrerseits, und zwar wieder in dem Romance da vida de Antônio Silvino, in den Zyklus Silvinos transponiert; sie kehrt in der von Ataíde ausgearbeiteten Form zu ihrem Ausgangspunkt zurück. 


\section{DAS SYMBOL DES CANGACEIROS}

Wenn die Figur des Cangaceiros zum Symbol wird, so stellt sich nicht mehr - wie in dem Bereich der verschiedenen Phasen der Schematisierung - das typische Persönlichkeitsbild eines Individuums dar, sondern das typische Abbild aller Personen, die als Cangaceiros bezeichnet werden können. Die Fusion zweier Images beschränkt sich auf eben diese beiden Menschen und auf nicht wesentliche Züge; eine symbolische Gestalt jedoch ist der kleinste gemeinsame Nenner aller Cangaceiros. Ihr Handeln und Denken läßt sich auf eine geringe Anzahl von Grundzügen zurückführen, deren Gesamtheit den Aussagekern der Cangaceirogedichte ausmacht. Trotz aller individuellen Unterschiede kann jeder Cangaceiro unter ein Symbol gestellt werden, das seine wichtigsten Handlungsweisen und Charaktereigenschaften umfaßt und genau festgelegte Grundschemata vertritt.

Das Symbol des Cangaceiros ist selbstverständlich nicht mehr abhängig von einer Position innerhalb bestimmter Zeit- und Raumkoordinaten; das starke Lokalkolorit des Nordostens verschwindet. Berühmte Erlebnisse eines Cangaceiros, sensationelle Ereignisse haben alles Interesse verloren und finden keinen Platz mehr in den Gedichten. Die Umgebung der symbolischen Gestalt des Cangaceiros hat nichts Reales an sich. Erhalten sich in einigen Texten einige wenige, unwesentliche Elemente aus dem Bereich der Schematisierung, schwankt der Volksdichter also noch, ob er nicht doch zur bloßen Lebensbeschreibung eines Individuums zurückkehren sollte, beeinflussen diese Passagen doch in keinem Falle den Aussagekern der Geschichte. Es sind Relikte einer übersprungenen literarischen Entwicklungsphase.

Nicht immer brauchen die Figuren der Cangaceiros Schritt für Schritt sämtliche Stufen der Schematisierung zu überwinden, bis sie zum Symbol geworden sind. In einigen Fällen werden sie schon in Gedichten, die während ihrer ersten Jahre im Cangaço geschrieben worden sind, als Symbole präsentiert. Im allgemeinen aber spielt der Zeitabstand zu den historischen Ereignissen eine große Rolle bei der endgültigen Beurteilung der Position eines Cangaceiros. Die meisten Texte, die Antônio Silvino und Lampião als Symbolfiguren behandeln, stammen aus den Jahren nach der Gefangennahme Silvinos und nach dem 
Tode Lampiãos. Durch das abrupte Ende der Karriere der beiden Cangaceiros wurde plötzlich aus einem aktuellen Phänomen, das man wie ein Journalist beschreiben wollte, ein historisches, abgeschlossenes, nicht wiederholbares, über das sich nun ausführlich reflektieren ließ und das in seinem gesamten Ausmaß abgeschätzt werden konnte. Die persönlichen Emotionen des Volksdichters gegenüber seinem Protagonisten verloren an Intensität; langsam begannen die Verfasser, das Wesentliche am Wirken der Cangaceiros zu sehen und alles zu vergessen, was nur schmückendes Beiwerk gewesen war. So wurden etwa zehn Jahre nach dem Tode Lampiãos weit mehr Folhetos geschrieben, in denen der Cangaceiro ein Symbol vertritt, als Texte, die in schematisierter Weise sein Leben behandeln.

Das Symbol des Cangaceiros durchschreitet in seiner Entwicklung zwei Phasen; es bietet sich unter zwei Aspekten dar, die einander gegenüberstehen und die aufeinander folgen: der Cangaceiro erobert eine bedeutende Position und der Cangaceiro genießt die Vorteile der von ibm eroberten bedeutenden Position.

Die Rebellion gegen die bestehende Autorität führt zu einer Absetzung der Autorität. Aus dem Rebell wird ein Herrschender. Das Mittel, um diesen Zweck zu erreichen, ist der Kampf, der ausgefochten wird auf der Basis der persönlichen Tapferkeit. In einigen wenigen Fällen kann der Kampf als etwas Absolutes, von jeder Funktionalität Unabhängiges angesehen werden, kann Selbstzweck sein.

Die erste Phase des Symbols des Cangaceiros ist gekennzeichnet durch den unbarmherzigen Angriff auf einen ganz bestimmten Feind, ein Individuum oder eine Institution, mit der Absicht, ihn zu vernichten. Die Zerstörung alles dessen, was den Cangaceiro umgibt, wird zu seinem Hauptziel. Widerstand findet er von seiten einer Person oder einer Gruppe von Personen, die eine höhere Position als er innehat, im allgemeinen die höchstmögliche Stellung auf diesem Gebiet. Ihre Kräfte sind den seinen überlegen, aber der Cangaceiro hat bewiesen, daß man ihn nicht mit gewöhnlichen Sertanejos vergleichen darf. Trotz seiner offensichtlichen Unterlegenheit nimmt er den Kampf gegen die Mächtigen auf. Er hat keinen Respekt vor ihrer Autorität; die Maxime seines Handelns ist uneingeschränkte Rebellion. „Eu estava insubordinado", läßt der Volksdichter Cícero Cidrono do Nascimento den Antônio Silvino sagen, als er sein Erfolgsgeheimnis offenbaren soll.

Die Auflehnung hat Erfolg, die bestehende Autorität wird zerstört, 
und der Cangaceiro nimmt ihren frei gewordenen Platz ein: aus einer Person, die gezwungen war zu gehorchen, wird ein freier Mensch, der nur sich selbst Rechenschaft schuldig ist und der den anderen seinen Willen aufzwingen kann. Seine passive Stellung verwandelt sich in eine aktive, aus einem "homem mandado" wird ein "homem de mando". Seitdem es Folhetos von Volksdichtern über einen berühmten Cangaceiro gibt, beschreiben und verherrlichen ihre Verse diesen Prozeß: die Respektlosigkeit gegenüber den Mächtigen und die ungehorsame Haltung des Protagonisten lassen ihn siegen, erlauben es ihm, auf der gesellschaftlichen Skala voranzukommen und die Barrieren zwischen den einzelnen Schichten zu durchbrechen. Auch die erste wichtige Episode im Leben der beiden letzten bedeutenden Cangaceiroführer, die Ermordung des Vaters, hat ihre Wurzeln in dieser rebellischen Haltung. Die Volksdichter wollen beweisen, daß Auflehnung der einzige Weg sei, das höchste Ziel, befehlen zu dürfen, zu erreichen. Und sie suggerieren den Sertanejos, daß jeder von ihnen fähig sei, das gleiche zu tun, denn alles sei auf der Grundlage der persönlichen Tapferkeit geschehen, einer Eigenschaft durchaus innerhalb ihrer Reichweite. So kann man selbst zu einem Mächtigen werden, kann die Autorität zerstören und sie seinerseits vertreten, ihre Wirksamkeit in bezug auf sich umkehren. Die Prinzipien der Autorität bleiben bestehen, ihr Objekt hat sich verändert. Durch die Identifizierung der Sertanejos mit den Cangaceiros während der Phase des Aufstiegs ist es ihnen möglich, zusammen mit den Protagonisten in den Genuß der eroberten Position zu kommen. Schlägt die Haltung der Cangaceiros um, wird aus einem Vertreter der Rebellion ein Vertreter der Autorität, so machen die Hörer und Leser der Verse den Umschwung mit und verlassen ihre ursprüngliche Position. Nun geht es ihnen darum, das Erlangte zu verteidigen und die bestehenden Zustände zu bewahren. Nun wenden sie sich gegen andere möglicherweise erscheinende Rebellen, verurteilen alles, was antiautoritär zu sein scheint. Zusammen mit den Cangaceiros, die ihresgleichen sind, nützen sie ihre Macht zu ihren Gunsten aus ${ }^{144}$.

Die Kenntnis der Sertanejos, der Leser der Folhetos, von der Zwangsläufigkeit des Umschwungs von der Rebellion der symbolischen Gestalt zu ihrer Herrschaft bringt es mit sich, daß sie, in Erwartung des sicheren Lohnes, die Karriere eines Cangaceiros von Anfang an sympathisierend mitverfolgen. Diese Tendenz besteht schon, wenn die Volksdichter noch versuchen, historische Daten in ein angemessenes Schema einzuordnen. Zeitweise kann der Abscheu gegenüber bestimmten Zügen eines Cangaceirochefs eine Identifizierung verhindern, aber die Sicherheit, daß auch dieser Bandit durch seine Machtstellung jeden Sertanejo an 
seiner Herrschaft wird teilnehmen lassen, ist stärker als jede rationalistische Verurteilung. So hat es kommen können, daß Lampião nach seinem Tode in wachsendem Maße vorteilhaft dargestellt worden ist, $\mathrm{da} ß$ er immer mehr von seiner ursprünglichen Scheußlichkeit verloren hat. Das ist verständlich, denn er war der mächtigste Cangaceiro, den es jemals gegeben hat. Er herrschte unangefochten, nicht nur in den Versen der Volksdichter, sondern auch in der historischen Realität. Kein anderer konnte so sehr wie er den Sertanejos das Gefühl persönlicher Machtfülle geben. Wenig bleibt da von moralischen Bedenken; sie entsprechen in ihrer Bedeutung nicht dem Grad der Wirksamkeit einer absolutistischen Herrschaft und werden fallengelassen.

Häufig wird von gebildeten brasilianischen Autoren, die über den Cangaço schreiben, die Rebellion des Cangaceiros als sozialrevolutionärer Protest gedeutet. Das ist aus den Texten der Volksdichter kaum herauszulesen. Zwar wird der Cangaceirochef als ein Mitglied der niedrigsten Schicht der Sociedade sertaneja vorgestellt, und der Wille, die herrschenden Zustände zu verändern, wird natürlich um so stärker, je mehr man unter ihnen zu leiden hat, und der Triumph über die Mächtigen um so größer, je weiter der Weg zu ihnen war; zweifellos ist in Nordostbrasilien der einzelne nicht zufrieden mit seiner Gesellschaft; aber er ist noch nicht soweit, ein Klassenbewußtsein auszubilden und gemeinsam mit seinen Leidensgenossen auf eine Veränderung der Verhältnisse hinzuarbeiten. So akzeptiert er die Sociedade sertaneja in der Form, in der er sie vorfindet, und sein ganzes Bestreben ist nur darauf gerichtet, seine eigene Position innerhalb ihres Rahmens zu verbessern. Ein objektiv als überwiegend sozial erscheinendes Problem wird vom Sertanejo fast ausschließlich unter persönlichen Gesichtspunkten betrachtet. Leicht läßt er sich vom gesellschaftlichen Aspekt ablenken und findet zu einer psychologischen Fragestellung zurück (wie kompensiere ich meine Abhängigkeit von anderen?). Der Nonkonformismus des Rebellen aus dem Sertão, auch der der Symbolgestalt des Cangaceiros, besteht in der Nichtanerkennung der Individuen, die die bedeutendsten Machtpositionen innehaben, keineswegs aber in einer Ablehnung der Gesellschaftsstruktur. Die bestehenden Verhältnisse werden dadurch verändert, daß existierende Positionen und Machtstrukturen durch neue Individuen ausgefüllt werden, die dann nach althergebrachten Normen das gleiche tun, was ihre Vorgänger getan haben. Nicht die gesamte Gesellschaft soll verändert werden, sondern die Umkehrung der Verhältnisse soll sich auf einzelne Personen beziehen. Da im Bewußtsein eines Individuums aus der Sociedade sertaneja in dieser Gesellschaft 
keine Spezialisierung einer einzigen Schicht oder bestimmter Einzelpersonen auf die Ausübung der Macht stattgefunden hat, kann jeder einzelne, unabhängig von seiner Klassenzugehörigkeit und deren sozialen und bildungsmäßigen Implikationen, höchste Funktionen einnehmen. Die Herrschaftsmethoden, so scheint es ihm, sind so fest eingeführt, so simpel und so wirksam, daß nicht Intelligenz oder Schläue, sondern einzig der Glückszufall, am Hebel der Macht zu stehen, von Wichtigkeit ist. Wie in orientalischen Märchen liegt der Schritt vom Eseltreiber zum Tyrannen jederzeit im - erträumten Bereich der Möglichkeiten. Eine Zerstörung des Bestehenden bringt ja weder eine Neuverteilung des Besitzes und eine neue Konzeption des Zusammenlebens mit sich, noch eine Synthese aus Altem und Neuem. These und Antithese sind deckungsgleich. Überwiegt eine der beiden Seiten, so verschluckt sie die andere, ohne Spuren übrigzulassen. Die Antithese zu ihr, die daraufhin neu ersteht, ist nur die Wiederholung ihrer Vorgängerin, auf keinen Fall aber auf einer entwickelteren Ebene postiert. Beklagt sich ein Cangaceiro darüber, daß wenige reich seien und die Mehrzahl der Bevölkerung arm, so will er nicht, daß dieser Unterschied aufgehoben wird, sondern er möchte unter den wenigen sein, die viel Geld besitzen. Beschwert sich ein Cangaceiro über die Ausbeutung der Landarbeiter, so will er nicht, daß diese Ausbeutung abgestellt wird, sondern er will statt eines Ausgebeuteten ein Ausbeuter sein. Hat er die von ihm erstrebte Machtstellung erreicht, dann benimmt er sich genauso niederträchtig gegenüber den Unterdrückten, wie sich die Unterdrücker einst ihm gegenüber verhielten.

In nur ganz wenigen Fällen setzt sich der zum Symbol gewordene Cangaceiro auch einmal für wirklichen sozialen Fortschritt, etwa für die Neuverteilung des Landes, ein, aber alle diese Versuche sind nicht konsequent zu Ende gedacht, und es wird ihnen in denselben Folhetos an anderer Stelle widersprochen ${ }^{145}$. Die Volksdichter beschränken sich somit darauf, das immer gleichbleibende Hin- und Herschwanken zwischen Aktion und Reaktion zu beschreiben, die Auseinandersetzungen zwischen Rebellion und Autorität, zwischen zur Autorität gewordener Rebellion und neuerstandener Rebellion. Der Rahmen verändert sich nicht, und die Umstände des Kampfes weisen nicht darauf hin, daß sich die Ziele der Kämpfenden verändern. Es wird von einer Kette von Ereignissen berichtet, die variiert, hin- und herpendelt, ohne Fortschritt zu bringen. Andere Darstellungsweisen entsprächen nicht der Kulturstufe, auf der sich die Sociedade sertaneja, eine aristokratische Hirtengesellschaft, befindet. 
Es gibt ein Motiv, das in dem Teil des Zyklus, in dem die symbolische Gestalt eines Cangaceiros im Mittelpunkt steht, eine überragende Bedeutung gewonnen hat, ein Motiv, um das sich ein neugeschaffener schematisierter Handlungsablauf gebildet hat: der Kampf gegen Himmel oder Hölle. Nach dem Tode sowohl Silvinos als auch Lampiãos begannen die Volksdichter, die Erlebnisse der beiden Cangaceiros nach ihrem Ableben mitzuteilen. Bis auf ganz wenige schematisierte Elemente handelt es sich hierbei um rein symbolische Gestalten. Sie versuchen, den Aussagekern einer Cangaceirogeschichte auf einer höheren Ebene aufzuzeigen. Sowohl die beiden Phasen des Symbols werden dargestellt, als auch die typische arrogante Haltung der Helden gegenüber jeder Autorität und ihr prahlerisches Selbstlob:

Cai uma banda do céu

Seca uma parte do mar

O purgatório resfria

Vê-se o inferno abalar

As almas deixam o degrêdo

Corre o Diabo com mêdo

O Céu Deus manda trancar. $(19,8-14)$

Nachdem der Cangaceiro auf der Erde die höchsten Positionen erfochten, nachdem er jeden ihm möglichen Erfolg gehabt hat, besitzt er eine so überzeugende Machtstellung, daß er es, in einer konsequenten Parallelisierung, wagen darf, die höchsten Autoritäten überhaupt, Gott und den Teufel, anzugreifen. Er befindet sich in einer guten Ausgangsposition, denn sein Erfolg auf der Erde kann ihm als Modell für seinen neuen Kampf dienen und macht seinen Sieg wahrscheinlich. Er fängt nicht von unten an, er kann auf vorhergegangene Triumphe aufbauen und sein Ansehen nur noch vermehren ${ }^{146}$.

Im allgemeinen befehden die Cangaceiros den Teufel. Es besteht eine gewisse Scheu der Volksdichter davor, Gott direkt angreifen zu lassen; an seine Stelle treten Heilige, die aber auch nicht völlig unterliegen. In einigen Fällen gelingt es sogar so tapferen Heiligen wie Paulus oder Georg, den Aggressor zu verprügeln oder ihn durch Schimpfwörter zu vertreiben. Solche Szenen sind bewußt blasphemisch, und auch die Berufung auf den parodistischen Ton dieser Verse und auf Vorbilder in der Volkspoesie Nordostbrasiliens (die wiederum ihre Pendants in der europäischen Volksliteratur finden) kann die Tatsache nicht verdecken, daß Zweifel an der Autorität Gottes geäußert werden. Nordostbrasilianische Folhetos über religiöse Themen zeigen, wie wenig gefestigt ein exakter Gottesbegriff im Bewußtsein der Sertanejos ist. Sehr häufig muß von den Volksdichtern überhaupt erst definiert und erläutert 
werden, woran man glaubt. In einer solchen Atmosphäre religiöser Unsicherheit können Parodien auf traditionell für heilig gehaltene Themen durchaus zersetzend wirken - oder wenigstens so gemeint sein. Man zieht sogar Parallelen zwischen der Feigheit der Heiligen und der Feigheit der traditionellen Feinde der Cangaceiros auf Erden, der Polizei. Meist jedoch brechen die Texte abrupt ab oder entfernen sich allmählich von diesem heiklen Thema, so daß der Leser im unklaren über den Ausgang der Auseinandersetzung bleibt.

Anders bei den Angriffen der Cangaceiros auf die Hölle: hier gelingt es ihnen, den Türhüter, den sie mit "moleque“, „Negerbengel“, beschimpfen, auszuschalten und in das Reich des Teufels einzudringen. Antônio Silvino oder Lampião schlägt sich sodann mit der „Negrada“ der Hölle und zerstört die gesamte Einrichtung ${ }^{147}$. Schließlich siegen sie und werden zu den Beherrschern der Unterwelt. Sie folgen genau dem Vorbild ihres Vorgängers Luzifer, machen sich dessen Programm $\mathrm{zu}$ eigen, tun seine Arbeit und bestimmen, welche Menschen als schlecht zu bezeichnen seien. Der Volksdichter Gonçalves Oliveira läßt den Cangaceiro die wichtigsten Punkte seines Programmes erläutern:

Vou fabricar êsse inferno

3 vêzes maior que o mundo

Para botar mulher ruim

Gente falso e vagabundo

Ateu, crente e amancebado

Sei que é superlotado

Em menos de um segundo.

Wüßte man nicht, daß es bei der Rebellion des Cangaceiros nur darum geht, in einer beherrschenden Position die Ablösung eines Individuums durch ein anderes herbeizuführen, müßte man sich fragen, warum Lampião - um ihn handelt es sich in diesem Text - bei einem solchen Programm Luzifer beseitigen wollte.

Als Herrscher der Hölle wird die symbolische Gestalt des Cangaceiros mit dem Symbol des Bösen, dem Teufel, gleichgesetzt. Alles, was ein Volksdichter - und Sertanejo - für schlecht hält, stellt er in Beziehung zu Lampião und Silvino, zum Cangaceirosymbol ${ }^{148}$.

Für den Sertanejo ist der Teufel als der unabhängige Herrscher über das Böse die Gegenkraft Gottes, eines Gottes, der in der Volksdichtung des Nordostens vor allem als ehrfurchterheischende Gestalt geschildert wird, die weit entfernt von den Menschen herrscht und deren Hauptzüge Würde und Unnachsichtigkeit sind. Es ist ein strafender Gott. Der Begriff der „Erlösung“, die Rolle des „verzeihenden Heilands“, die Figur Christi überhaupt und besonders das Symbol des Kreuzes sind 
Themen, die man nur sehr selten in den häufigen Versen über die Allmacht Gottes erwähnt. Die Nennung Jesu oder des Kreuzes hat fast ausschließlich magische Bedeutung, dient zur Beschwörung und zur Abwehr des Teufels (so schlägt Antônio Silvino in der História completa ein Kreuz, um bei einem Duell mit Satan den Gegner vertreiben zu können).

Gegen diesen alles beherrschenden Gott hat sich der Teufel aufgelehnt, und diese Rebellion ist es, die ihn dazu verurteilt hat, gemeinsam mit den Menschen stets das Bestehende zu bekämpfen. Auflehnung und der Begriff des Bösen werden miteinander gleichgesetzt: Teufel und Mensch gemeinsam versuchen, auf Erden ein Gegenreich Gottes aufzubauen. Stets ist die Gestalt des Teufels in den Folhetos personifiziert, stets versucht sie, den Menschen zu einer Mißachtung der Autorität anzustacheln. Autorität und Rebellion stehen sich als etwas "Gutes" und "Böses“ gegenüber. Das Gute macht das Wesen der Autorität aus, das Wesen einer etablierten Position. Gleich, wer diese Stellung einnimmt, er ist, definitionsgemäß, „gut“. Für den Sertanejo gibt es in diesem Falle keine Achtung des Usurpators: die Position ist das Wesentliche, nicht ihr Inhaber. Wer sie angreift, muß „schlecht“ sein. Da der Mensch für den Sertanejo von Natur aus weder gut noch schlecht ist, da eine Entscheidung für eine der beiden Möglichkeiten weder Lohn noch Strafe bringt, da ein Schuldbewußtsein der Bösen nicht besteht, da es keine Reue gibt, geht man bei der Beurteilung einer Person nicht von dem Wert ihrer guten Taten aus - auch Antônio Silvino wird mit dem Teufel identifiziert -, sondern von ihrer Haltung in dem Konflikt Rebellion-Autorität.

Im Zyklus des Teufels in der Volksdichtung Nordostbrasiliens zeigt sich der moralische Aspekt in der Bewertung von Auflehnung und Autorität darin, daß das Image des Teufels mit all den Attributen belegt ist, die dem Sertanejo verwerflich erscheinen: Luzifer flucht, läuft Frauen nach, lobt die Protestanten u. dergl. - eine endlose Reihe von Motiven, die in ihrer Gesamtheit jede Sympathie gegenüber dem Teufel im Keime ersticken. Kommt der Zyklus des Teufels mit Texten aus dem Zyklus der Cangaceiros in Berührung, so verändert sich die Figur des Satans, nähert sich der schematisierten Gestalt des Cangaceiros an ${ }^{149}$, wird sympathischer; die Volksdichter bereiten eine Identifizierung zwischen Teufel und Cangaceiro vor, die darauf abzielt, den der Rebellion innewohnenden Begriff des Bösen zu relativieren. Der Teufel verliert sein traditionelles Image und nimmt das den Sertanejos vertraute Persönlichkeitsbild der Cangaceiros an. Auch diese nähern sich dem Teufel und bereiten sich darauf vor, seine Stellung einzunehmen. In mancher 
Hinsicht übertrumpfen die Cangaceiros sogar den Luzifer. Ihr Kampfesmut wird von den Volksdichtern häufig dadurch exemplifiziert, daß der Teufel sich scheut, mit ihnen Streit anzufangen. Er läßt sich durch Unterteufel vertreten, in deutlicher Parallele zu den Kämpfen zwischen Cangaceiros und Heiligen, den Abgesandten Gottes.

Die gleichberechtigten Beziehungen zwischen dem Teufel und Gott wurden zu einem Begleitmotiv, das in einer symbolischen Darstellung des Cangaceiros nicht fehlen darf. Nachdem der Bandit auf der Erde alles erreicht hat, was er sich wünschen konnte, erreicht er auch im Jenseits alles. Die Volksdichter weisen in ihren Folhetos immer wieder auf die Unabhängigkeit des Teufels von den Weisungen Gottes hin. Die Befehlsfülle beider unterscheidet sich nicht voneinander (wie auch sonst kaum Unterschiede zwischen Himmel und Hölle festzustellen sind. Den Verdammten geht es nicht schlechter als den Seligen. Kein Volksdichter sagt innerhalb des Zyklus der Cangaceiros, was für Vorteile es hat, in den Himmel aufgenommen zu werden); die Position des Teufels erlangt zu haben, ist ebensoviel wert, wie die Gottes einzunehmen. So sieht sich zum Beispiel der Teufel in dem Folheto Luta do Diabo com Antônio Silvino von Leandro Gomes de Barros nicht gezwungen, eine vom Himmel abgelehnte Seele in die Hölle einzulassen. Er entscheidet frei, wen er aufnehmen will, und läßt sich dabei nicht von Beschlüssen beeinflussen, die andere vor ihm getroffen haben; der Teufel sagt:

... para êle entrar

O inferno está trancado

Eu cá estou bem descansado. (19, 129-134)

Auch in der letzten Strophe des Folhetos Chegada de Lampião no inferno werden die Wechselbeziehungen Himmel-Hölle abgestritten:

Leitores vou terminar

Tratando de Lampião

Muito embora que não possa

Vos dar a explicação ${ }^{150}$

No inferno não ficou

No céu também não chegou

Por certo está no sertão. (38, 175-180)

Diese Verse beweisen nicht nur die Autonomie der Hölle, sondern sie greifen auch einen weiteren Aspekt bei der Behandlung der symbolischen Gestalt des Cangaceiros durch die Volksdichter auf, den der ewigen Gültigkeit ihres Aussagekerns. Das Symbol des Cangaceiros war nicht 
nur das Abbild einer Gruppe historischer Figuren, die innerhalb einer bestimmten Zeit, in einer bestimmten Region, unter bestimmten Voraussetzungen eine wichtige Rolle spielten, sondern es ist der Ausdruck eines immer und allgemein gültigen Prinzips. Dadurch, daß die Volksdichter den Tod eines berühmten Cangaceiros als nicht erwiesen hinstellen, erreichen sie, daß man glaubt, alles das, was dieser Mann repräsentierte, sei noch lebendig und allgegenwärtig. Sogar in Folhetos, die in dokumentarischer Weise die Lebensgeschichte eines Cangaceiro aufzeichnen wollen, fehlt dieses Motiv nicht - in der Verdadeira bistória de Lampião e Maria Bonita zum Beispiel, von Manuel Pereira Sobrinho:

E quando surgiu a história

- Virgulino pereceu

Porém tem quem diga alto

Que Lampião não morreu

$\mathrm{O}$ que eu posso afirmar

É que desapareceu.

Não sei se for vivo ou morto

Porque há contradição

Tem gente que afirma sim

Porém tem quem diga não

$\mathrm{O}$ que sei é que o mesmo

Nunca mais veio ao sertão. $(67,883-894)$

Der Zweifel darüber, was aus einem berühmten Cangaceiro nach seinem vermeintlichen Tode geworden sei, ließ eine Reihe von Folhetos aufkommen, die ein neues Handlungsschema benutzten. Die Verfasser berichten von ihren Erlebnissen, als sie auszogen, um den Aufenthaltsort des Cangaceiros ausfindig zu machen oder um seinen Tod festzustellen.

Aber selbst wenn die Verfasser von dem Tode eines Cangaceiros berichten, der sich schon in der Phase des Symbols befindet, ist dieser Tod ein sehr relativer. Die Volksdichter kennen keine klare Trennungslinie zwischen dem Leben und dem Tode. Es gibt Zwischenwelten. Es gibt Orte, an denen die Lebenden mit den Toten Verbindung aufnehmen. Kein Wunder, daß sowohl Antônio Silvino als am Lampião häufig in spiritistischen Sitzungen erscheinen ${ }^{151}$, wo sie sich so benehmen, als lebten sie noch. In dem Folheto Chegada de Lampiäo von Silva Melo zum Beispiel beginnt der herabgestiegene Cangaceiro sofort eine Schlägerei mit den lebenden Anwesenden ${ }^{152}$. 
Auch die aus dem Bereich der Schematisierung stammenden Fusionen der Images verschiedener Cangaceiroführer helfen den Volksdichtern zu beweisen, daß der Tod eines berühmten Cangaceiros nicht die Kontinuität des Symbols des Cangaceiros beeinträchtigt. Auf Silvino Aires folgte Antônio Silvino, auf ihn Lampião. Von den ersten Texten eines neuentstehenden Zyklus an versuchen die Verfasser, den jungen Cangaceiro in eine Dynastie einzuordnen. Bis zu Lampião machte dies keine Schwierigkeiten; nach seinem Tode aber wurde es schwer, einen Nachfolger für ihn auszumachen. Corisco übernahm die Führung über den Cangaço für nur kurze Zeit, aber sofort wurde er von den Volksdichtern als blutiger König des Sertãos gefeiert. Und als Corisco getötet wurde und nicht die Hoffnungen erfüllte, die man in ihn gesetzt hatte, diente jeder, auch noch so unbedeutende Bandit dazu, zum Nachfolger Lampiãos ernannt zu werden. Das Symbol des Cangaceiros mußte unter allen Umständen seine Gültigkeit bewahren. So macht Rodolfo Cavalcante in dem Folheto Morte do bandido Guabiraba den unbedeutenden Verbrecher Guabiraba zu einem Nachfolger von Corisco, und schließlich muß sogar der völlig unbekannte Cordão de Ouro herhalten, damit die Kontinuität des Cangaços nicht abbricht.

Die hier herausgearbeiteten essentiellen Eigenschaften des Cangaceirosymbols: allgemeine und ewige Gültigkeit; zwei Phasen, die des Aufstiegs und die der Herrschaft, in ihrer Folge begründet durch den Kampfeswillen des Protagonisten, der daher in engster Beziehung zur symbolischen Gestalt des Bösen steht, leiten über zu einer Gruppe von Zyklen der Volkspoesie Nordostbrasiliens, die einen verwandten Aussagekern besitzen, und zu denjenigen Zyklen, die dem der Cangaceiros antinomistisch gegenüberstehen. 


\section{DIE POSITION DES EPISCHEN ZYKLUS \\ DER CANGACEIROS IN NERHALB \\ DER VOLKSPOESIE NORDOSTBRASILIENS}

Der Aussagekern des Zyklus der Cangaceiros läßt sich in drei Großen Zyklen der Volkspoesie wiedertreffen, jeweils mit nur unwesentlichen Veränderungen: in dem Großen Zyklus der Liebesgeschichten (Zyklus der Liebesgeschichten unverheirateter Partner), in dem Großen Zyklus der märchenhaften Geschichten (Zyklus der phantastischen Geschichten und Märchen) und in dem Großen Heroischen Zyklus. Die Abgrenzungen dieser Folhetogruppen zueinander ist sehr schwer durchzuführen: oft vereinigen die jeweiligen Protagonisten heroische und phantastische Elemente in sich oder sind Liebhaber auch in Texten, in denen das Heldische überwiegt. Die engsten Beziehungen bestehen zwischen märchenhaften und Liebesgeschichten. Beide Gruppen behandeln „typische" Ereignisse. Auch wenn bestimmte Orts- und Zeitangaben gemacht werden, so sind diese definierenden Elemente nur als Ausschmückungen aufzufassen, die keinen Einfluß auf die Aussage des Textes haben. Der Unterschied zwischen den beiden Zyklen liegt darin, daß in Folhetos über Liebesgeschichten das Vorhandensein wunderbarer Phänomene keine Rolle spielt, daß sich alles innerhalb der Grenzen des Wahrscheinlichen bewegt ${ }^{153}$.

Besonders typisch für solche Art von Geschichten ist das Folheto Chico Vira-Mundo, der zweite Band aus dem Sekundärzyklus „Romance Exagerado" (er beginnt mit der História de Vira Mundo), Teil des Großen Zyklus der märchenhaften Geschichten. Der Volksdichter beschreibt die Abenteuer heldenhafter Menschen und verstärkt - ein sehr häufiger Fall bei Handlungsschemata, die auf dem Gipfel ihrer Popularität stehen - die Grundstruktur seiner Gedichte durch eine Massierung seiner Mittel: ein einziger Protagonist spaltet sich in eine Dynastie von zehn Riesen. Was vom Verfasser für wichtig gehalten wird, wiederholt sich in jedem einzelnen der Heftchen, so daß es leichtfällt, den Aussagekern des Sekundärzyklus zu erkennen.

Allen Texten des märchenhaften Zyklus (und auch des Zyklus der Liebesgeschichten unverheirateter Partner) liegt folgendes Handlungsschema zugrunde: ein junger Prinz (hier: Chico Vira-Mundo) erobert nach vielen tapfer durchstandenen Kämpfen eine bedeutende Position, 
im allgemeinen eine Stellung, die der seines Vaters entspricht. Die häufigen Liebesintrigen oder Verzauberungen sind nur ein Vorwand, um die Phasen des Aufstiegs zur Macht und der Ausübung der Macht darstellen zu können.

Durch die Wahl eines Prinzen als Protagonisten fallen beide Aspekte des Wunsches, die eigene Stellung zu verbessern, zusammen: der psychologische - und wahrscheinlich primäre - Aspekt (ich möchte die Position meines Vaters haben) und der soziologische (ich möchte eine beherrschende Stellung in meiner Gesellschaft einnehmen).

Wie sehr der Aufstieg eines märchenhaften Helden eine Parallele darstellt zu dem Aufstieg eines Cangaceiros, zeigt sich, wenn der Leser in Chico Vira-Mundo nicht nur die zwei Lebensphasen des Protagonisten voneinander unterscheiden kann, sondern auch erfährt, daß der Held seinen Erfolg ausschließlich seiner Tapferkeit und seinem Widerspruchsgeist zu verdanken hat und daß er während seiner Jugendzeit mit dem Symbol des Bösen, dem Teufel, identifiziert wird. Die Volksdichter vergessen ebensowenig, die Allgemeingültigkeit dieser symbolischen Rebellengestalt herauszustreichen. Über den Tod hinweg wirkt ihr Werk weiter, denn sie sind ein Glied einer nicht endenden dynastischen Kette. Ein stilistischer Kunstgriff, bei vergleichbaren Situationen Verse aus vorhergegangenen Folhetos desselben Sekundärzyklus wiederaufzunehmen, verstärkt diesen Eindruck.

Im Großen Zyklus der Antihelden wird der schematisierte Handlungsablauf der Liebesgeschichten und Märchen nur unwesentlich verändert. An die Stelle der Tapferkeit tritt die Schläue; eine Eigenschaft, die die Sertanejos nach den gängigen Klischees in hohem Maße besitzen, wird durch eine andere ersetzt, die ebenfalls im Bereich ihrer Möglichkeiten liegt. Die Deckungsgleichheit mit dem Aussagekern von Folhetos aus anderen Zyklen beweist das kuriose Heftchen Visita de Cancão de Fogo ao inferno, in dem der Pícaro Cancão de Fogo Lampião die Herrschaft über die Hölle streitig macht.

Die erwähnten Handlungsschemata bildeten sich schon in einer Epoche heraus, die weit vor der Zusammenstellung des Cangaceirozyklus liegt, ja wahrscheinlich noch vor dem Erstehen der epischen Dichtung in Nordostbrasilien. Sie wurden in Prosa-, seltener in Romanzenform aus der Volksliteratur Portugals übernommen und gehörten von Anfang an zum Grundstock der Folklore Brasiliens. Die Zyklen der Liebesgeschichten und Märchen im 19. Jahrhundert waren sehr umfangreich, und es kann nicht erstaunen, daß die Volksdichter sich gerade 
ihrer Grundstrukturen bedienten, als sie es wagten, das Phänomen Cangaço literarisch zu bewältigen. Der Aussagekern dieser beiden Zyklen drängt sich auf durch seine Einfachheit und durch seine Geschlossenheit. Er gab den Volkspoeten die handwerklichen Mittel, die Realität, die sie umgab, darzustellen. Die Abenteuer der Cangaceiros in ihrem Sertão hatten vieles Grundsätzliche gemein mit den Abenteuern der Riesen und der liebestrunkenen Ritter aus den Volksgeschichten. Die Poeten variierten nun nicht mehr Vorhandenes, sondern fanden, von ihren literarischen Modellen ausgehend, zur Wirklichkeit zurück. Das ihnen so genau bekannte Skelett der Handlungsschemata wurde mit dem Fleisch und Blut realer Vorkommnisse ausgefüllt. Die Volksdichter erkannten, daß die Bewußtseinslage eines Riesen vom Type des Chico Vira-Mundo der eines Lampião entsprach, daß beide wiederum etwas taten, was sie, die Sertanejos, sich für sich selbst wünschten, und sie entdeckten die Deckungsgleichheit der Symbole ihrer traditionellen Helden mit denen der Cangaceiros. Durch Anwendung des literarischen Schemas auf wirkliche Ereignisse und gleichzeitige stufenmäßige Anpassung der Realität an diesen bekannten Aussagekern entstand der epische Zyklus der Cangaceiros in der Volkspoesie Nordostbrasiliens.

Die Vorliebe der Sertanejos im neunzehnten Jahrhundert für Liebesgeschichten und Märchen machte konsequenterweise im zwanzigsten der Vorliebe für Cangaceirofolhetos Platz. Die Geschichten über Antônio Silvino und Lampião verdrängten die Geschichten über mittelalterliche europäische Helden. Aus dem rein Imaginären wurde etwas Konkretes, aus Rittern vergangener Jahrhunderte und fremder Länder wurden zeitgenössische Sertanejos. Der Große Heroische Zyklus hatte sich um die Jahrhundertwende zu einer fast ausschließlichen Domäne der Cangaceirogedichte entwickelt. Die Auswechslung der Ritter durch die Banditen ist so gründlich durchgeführt worden, daß man sich heutzutage nur noch schlecht ein Bild von der Gesamtheit der heroischen Texte des letzten Jahrhunderts machen kann. In der Folhetoliteratur haben sich nur einige wenige Fragmente aus den europäischen Sagenkreisen erhalten: mit Vorrang wäre hier der Rolandzyklus zu nennen. Noch heute zirkulieren viele Gedichte, die Episoden aus dem Leben Rolands erzählen, die Karl den Großen porträtieren und die den Kampf gegen die Mauren in Nordspanien beschreiben. Die wichtigste Rolle spielen dabei Roldão und sein Freund Oliveiros ${ }^{154}$. Diese Texte sind zum größten Teil Nachdichtungen des berühmten Prosa-Volksbuches Carlos Magno, einer brasilianischen Fassung der Conquêtes du Grand Charlemagne (1485) und verschiedener spanischer Kompilationen ${ }^{155}$. Eine 
klare Struktur, einen definierbaren Aussagekern haben diese fragmentarischen Gedichte nicht: in ihrem Mittelpunkt stehen gewöhnlich Zweikämpfe, die die Christen zu gewinnen pflegen (das Motiv der Duelle ist in genau der gleichen Darstellungsweise in den Zyklus der Cangaceiros eingegangen). Das bekannteste Beispiel für diese Art von Texten ist das Folheto von Leandro Oliveiros e Ferrabrás. Ferrabrás, der Maurenkönig, ist der traditionelle Bösewicht der Volkspoesie Nordostbrasiliens und wird oft mit dem Teufel gleichgesetzt. (Wen wundert es, daß auch die Cangaceiros mit Ferrabrás verglichen werden!) Wie im 19. Jahrhundert die Gedichte aus dem Großen Heroischen Zyklus aussahen, wenn sie nicht nur Episoden berichteten, sondern eine zusammenhängende Geschichte erzählten, läßt sich heute nur noch aus den Nachdichtungen des Roberto do Diabo und an einem Text aus dem Rolandzyklus, dem Cavaleiro Roldão von Antônio Eugênio da Silva, 1958 in Campina Grande verlegt, erschließen. Beide Texte unterscheiden sich erwartungsgemäß von den Handlungsschemata und dem Aussagekern der märchenhaften und Liebesgeschichten nur durch eine stärkere Betonung des Kämpferischen.

Der epische Zyklus der Cangaceiros wirkte wie ein Ferment innerhalb der Gruppe heroischer Gedichte. Durch seinen Einfluß verschwanden alte Zyklen und entstanden neue. Der Aussagekern bleibt stets der gleiche, doch die Elemente aus dem Bereich schematisierter Darstellung folgen der neuerstandenen Tradition der Cangaceirogedichte. Nachdem es den Volksdichtern gelungen war, aus ihren Cangaceiros Protagonisten von epischen Gesängen zu machen, wagten sie sich auch an andere ähnliche Phänomene in der Sociedade nordestina heran. Man ging einen Schritt zurück in der historischen und soziologischen Entwicklung, verließ das Außergewöhnliche, das den Anstoß gegeben hatte, und wandte sich dem im fast normalen Leben stehenden, capangaähnlichen Valente $^{156}$ zu. Es entstand ein neuer Heldentypus innerhalb des Großen Heroischen Zyklus. Der Valente ist tapfer wie ein Cangaceiro, trägt dessen Kleidung, spricht dessen Sprache und kämptt wie er immer, wenn sich eine Gelegenheit dazu bietet. Der Zyklus der Valentes wurde zum bedeutendsten der Volkspoesie Nordostbrasiliens nach dem der Cangaceiros und dem des Padre Cícero.

Der Protagonist einer Valentegeschichte ist keine historische Persönlichkeit; er stellt unter immer neuen, meist exotisch klingenden Eigennamen einen Typus dar. Er ist ein Abenteurer, der durch den Sertão streift, um etwas zu erleben, der sein Glïck sucht. Er ist stets ein Angehöriger der untersten Klasse der Sociedade sertaneja. Er hat seine 
engere Heimat verlassen, um in anderen Gegenden seinen Lebensunterhalt auf angenehmere Weise zu suchen.

Es gibt zwei Handlungsschemata, nach denen die Gedichte im Zyklus der Valentes aufgebaut sind. Das erste läßt sich auf einen Protagonisten anwenden, der keinerlei moralische Bindungen anerkennt. Er kommt auf eine Fazenda oder auf eine Zuckerrohrplantage ${ }^{157}$. Schon an der Grenze seiner Besitztümer versucht der Fazendeiro oder Senhor de engenho, durch Capangas dem Neuankömmling den Eintritt zu verwehren, doch die Leute des Coronels werden besiegt. Weil sich der Valente als tapfer erwiesen hat, bekommt er eine Anstellung auf der Fazenda. Der Fazendeiro wird von den Volksdichtern im allgemeinen als ein sehr ruppiger Bursche dargestellt, als grausamer Tyrann, als Valentão. Er hat eine einzige Tochter, die er nach einem Entscheidungskampfe mit seinem angestellten Valente dem Sieger zur Frau geben muß. Die Fazenda geht in den Besitz des jungen Mannes über. Der Schwiegervater zieht sich zurück und hört auf, Valentão zu sein.

Der Valente trägt also den Sieg davon, weil er gegen die bestehende Autorität rebelliert. Die Leser erleben die Phase des Aufstiegs, sie erleben seinen Triumph. Sie sympathisieren mit dem tapferen jungen Mann, obwohl seine Handlungsweise „schlecht" ist, obwohl auch er wie die Cangaceiros mit dem Teufel identifiziert wird ${ }^{158}$. In einigen Fällen versuchen die Volksdichter, den Protagonisten den Sertanejos dadurch näherzubringen, daß sie eine Liebesgeschichte in ihren Text einflechten: der Valente bekämptt den Fazendeiro, weil er dessen Tochter liebt. Dieses Übergreifen auf Elemente aus dem Zyklus der Liebesgeschichten ist sehr geschickt: es sichert dem Protagonisten Sympathien, ohne die Bedeutung seiner Rebellion abzuschwächen. Die Person der Tochter die stets einziges Kind ist - läßt sich mit der Position des Vaters identifizieren und sichert so die Kontinuität der Stellung. Als personifiziertes Symbol des Besitzes ihres Vaters ist sie eine vermittelnde Figur zwischen der alten und der neuen Autorität. Die Beziehungen, die einst zwischen dem Valentão und seinem Kinde bestanden, werden nun ersetzt durch die Beziehungen zwischen dem Mädchen und dem neuen Besitzer der Fazenda: in jeder Hinsicht wird der Rebell der Nachfolger der entthronten Autorität ${ }^{159}$.

Ein weiterer Versuch der Volksdichter, davon abzulenken, daß das Handeln des Protagonisten in Valentegeschichten "schlecht" und ungesetzlich ist, besteht darin, den Gegner, den Valentão, zu verteufeln, ein Vorgehen, das schon aus dem Zyklus der Cangaceiros bekannt ist. Der Fazendeiro wird als so abscheulich geschildert, daß es nur gerecht erscheint, wenn er die Herrscherstellung verliert. So verletzte er die 
drei Tabus der Sertanejos, stahl, mordete und vergewaltigte. Er quälte seine Untergebenen auf die grausamste Weise. Alles Menschliche an sich verleugnet er; auch sein Außeres wird in den grellsten Farben geschildert ${ }^{160}$.

Wird der Fazendeiro auf diese Weise beschrieben, wird dem Leser der Folhetos klargemacht, daß nicht der verwerflich handelt, der die Autorität angreift, sondern derjenige, der nicht mit ihr umzugehen weiß, so ist die erste Stufe zu einer "Verbesserung" des Images der Valentes überschritten. In vielen Zwischenphasen wird aus dem "schlechten“ oder moralisch indifferenten Valente ein "guter" Valente, eine Person mit einwandfreiem Charakter, ein Beschützer der Unterdrückten.

Solche Protagonisten folgen dem zweiten wichtigen Handlungsschema innerhalb des Zyklus der Valentes. Die Rebellion wird bei ihnen nicht mehr als etwas Abzulehnendes angesehen, sondern als Pflicht. Der Valente zieht wie ein fahrender Ritter aus, um bestehendes Unrecht zu beseitigen, um Verbrecher zu bestrafen und um Ruhe in den Sertão zu bringen. Scheinbar verbündet er sich mit der bestehenden Autorität er schließt Verträge mit der Regierung, konspiriert mit Bürgermeistern, arbeitet mit der Polizei zusammen -, in Wirklichkeit aber geht es ihm nur darum, für sich selbst eine gute Position zu erlangen. Nun greift er den Fazendeiro nicht mehr ohne jeglichen Vorwand an, wie es der erste Typ der Valentes tat, sondern er wirft ihm vor, mit Cangaceiros zusammenzuarbeiten, so daß er bestraft werden müsse. Das Ergebnis ist dasselbe: der Valente heiratet die einzige Tochter des Coronels, übernimmt die Fazenda und schiebt seinen Schwiegervater aufs Altenteil ab.

Wie schon im Zyklus der Cangaceiros - und wie in allen Zyklen des Großen Heroischen Zyklus - schwanken die Sertanejos von einem Extrem zum anderen, von der sofortigen, rückhaltlosen Identifizierung mit den Protagonisten zu ihrer harten, unnachgiebigen Verurteilung. Sie sympathisieren mit dem Valente, der ohne Grund einen Haufen von gegnerischen Capangas totschlägt, und sie sympathisieren mit dem Valente, der wie ein Polizeioffizier Cangaceiros, den Inbegriff des Bösen, verfolgt. Die Ambivalenz der Gefühle gegenüber den typischen Vertretern des Heroischen im Sertão Nordostbrasiliens erlaubt es den Volksdichtern nicht, eine einzige Linie zu verfolgen und ihre Protagonisten wie aus einem Guß zu schaffen, aber bei allen Ausflüchten, bei den gewagtesten, alogischen Konstruktionen, bei allen Versuchen, sich von Vorwürfen beider Gruppen, der An- 
hänger der Autorität und der der Rebellion, zu befreien, vergessen sie nicht, daß im Grunde der Aussagekern all dieser Geschichten der gleiche ist, daß sie immer nur Variationen eines einzigen Themas schreiben. Treffen in ihren Gedichten "gute" Valentes mit einem der beiden berühmten Cangaceiroführer zusammen, bekämpfen sie sich (die in den Folhetos übliche Weise, zwei Personen zueinander in Beziehung zu setzen), so geht dieses Duell stets versöhnlich aus. Die Gegner wissen, daß sie sich nur durch unbedeutende Nuancen voneinander unterscheiden. Sie fühlen sich solidarisch. In vielem lassen sich ihre Persönlichkeitsbilder gegeneinander austauschen. Sie können auch parallel zueinander ihre Ziele verwirklichen und die von ihnen ersehnte hohe Position erkämpfen. So gehen zum Beispiel in dem Folheto O filho de Garcia der berühmte gute Valente und Lampião in Frieden und Freundschaft auseinander.

Diese scheinbare Konsequenzlosigkeit läßt sich aus der psychologischen Situation der Sertanejos erklären. Ihr stets prekäres Gleichgewicht läßt sich nur durch das exakt durchgeführte Ausbalancieren von einander widersprechenden Prinzipien und Strömungen bewahren. Wer eine grundlegende Behauptung ausspricht, muß gleichzeitig auch ihr Gegenteil vertreten. Keine Seite darf so sehr überwiegen, daß sie die andere überflüssig werden läßt. Aktive und passive Strömungen existieren zur selben Zeit am selben Ort, ebenso wie gleichzeitig das Prinzip der Rebellion neben dem der Autorität vertreten wird.

Die Volkspoesie ist ein Reflex dieses Wunsches der Sertanejos nach Ausgeglichenheit und Ruhe. Die Verfasser können nicht ausschließlich Geschichten erzählen, deren Aussagekern zur Rebellion aufruft. Dieselben Volksdichter, die mit Verve Cangaceiro- und Valente-Geschichten vortrugen, die Texte aus den traditionellen heroischen Zyklen verfaßten, verfechten in anderen Themenkreisen mit ebensolcher Begeisterung das Prinzip der Autorität. Gegensätze werden einander gegenübergestellt, ohne daß man auch nur den Versuch unternimmt, sie zu lösen oder gar mutig für nur eine Richtung zu plädieren. Die Poetas populares erweisen sich als echte Sertanejos, wenn sie jeder eindeutigen Entscheidung ausweichen. Sie wollen bestehende Tendenzen nur analysieren, von ihnen berichten, sie aber keineswegs beeinflussen. Die Registrierung des Bestehenden ist ihr Metier, nicht dessen Veränderung.

Das autoritäre Prinzip zeigt sich in den Folhetos unter zwei Aspekten: unter einem aktiven und einem passiven. Der Sertanejo kann sich mit einem autoritären Protagonisten identifizieren. Dann genießt er dessen 
Machtfülle, dann kann er gemeinsam mit ihm herrschen. Dies entspricht im Zyklus der Cangaceiros der zweiten Phase des Symbols, unterscheidet sich von ihr aber dadurch, daß der Leser dort den Aufstieg des Protagonisten miterlebt. Hier lernt er die autoritäre Persönlichkeit erst kennen, wenn sie die bedeutende Position schon innehat. Der Sertanejo kann sich aber auch mit den Personen aus dem Gedicht identifizieren, die sich dem Überlegenen zu unterwerfen haben. Er nimmt teil an der Macht des Autoritären, indem er sie an sich selbst spürt. Dieser deutlich masochistische Aspekt ist der weitaus häufigere; er ist der bestimmende in dem Großen Religiösen Zyklus. Der andere bietet sich schon in einigen Texten des Valentezyklus an, besonders deutlich aber zeichnet er sich in dem Zyklus der Geschichten über die Treue eines Ehepartners (Großer Zyklus der Liebesgeschichten) ab.

Wie das rebellische, so findet sich das autoritäre Prinzip in eindringlicher und klarer Form schon in den traditionellen, aus Europa importierten Stoffen. Sie bildeten auch hier die Plattform, von der aus die Volksdichter zu eigenen Variationen kommen konnten. Anders als bei den heroischen Gedichten waren die Themen, die dem autoritären Prinzip folgten, stark genug, um sich in zahllosen Versionen bis in unsere Tage $\mathrm{zu}$ erhalten (was nicht verwunderlich ist, denn auch das Gesellschaftssystem des Sertãos ist ja in seinen wesentlichen Zügen nach europäischen Denkmustern aufgebaut worden). Noch heute gehören zu der Volkspoesie Nordostbrasiliens die Geschichten der Imperatriz Porcina, der Genoveva. Man kann so erfolgreiche Folhetos kaufen wie die Martírios de Alcira und die Rosa de Milão. Bis auf unwesentliche brasilianische Zusätze (Palmenwälder und Jaguare in Venedig zum Beispiel) haben diese Gedichte ihre ursprüngliche Form, ihre Handlungsschemata, ihre Einordnung in den europäischen Raum und in die europäische Geschichte bewahrt. Das gibt ihnen ihren besonderen Reiz, denn Grafentitel, Königstöchter und die Namen der Städte Europas sind für den Brasilianer aus dem Sertão genauso exotisch, wie es die Erwähnungen von Kamelen und Wüstenreisen für die Moslems in Spanien waren.

Im Zyklus der Geschichten über die Treue eines Ehepartners verteidigt der Volksdichter rückhaltlos die Unantastbarkeit der Ehe und versucht, unter allen Umständen das Bestehende zu bewahren. In ihm siegt die Treue einer Ehefrau über die Kabalen eines jüngeren Verwandten oder eines vermeintlichen Vertrauten. Der Bösewicht, der durch den Ehebruch versucht (wieder durch einen Angriff auf die Frau, die dem Mächtigen gehört und als Symbol für seine Stellung und seinen Besitz gilt, wie in 
den Valente-Geschichten), eine höhere Position zu erringen, verliert sein Spiel. Das heroische Handlungsschema wird in diesem Zyklus in sein Gegenteil verkehrt. Nicht der Rebell siegt, sondern derjenige, der die erstrebte Stellung bereits innehat. Die Leser sympathisieren, durch den Volksdichter geführt, mit dem autoritären Protagonisten und wünschen, daß er die Macht, an der auch sie durch Identifizierung teilnehmen, behalten wird ${ }^{161}$.

Diese Texte sind für den Sertanejo, trotz aller vorhandenen Parallelen und eindeutigen Gegensätze, zu „wirklichkeitsfremd“, zu gleichnishaft, als daß er ihre Gegenposition zu Cangaceirogeschichten bewußt wahrnähme ${ }^{162}$. Der Volksdichter findet keinen brauchbaren Ansatzpunkt zu einem Vergleich der beiden Folhetogruppen, und so stehen sie in seiner Arbeit isoliert nebeneinander. Ahnlich ist es mit den Beziehungen heroischer Texte zu dem Großen Religiösen Zyklus, der in seiner Gesamtheit dem autoritären Prinzip verbunden ist. In ihm verlassen die Verfasser häufig eine epische Darstellung, versuchen gar nicht erst, etwas auszusagen durch künstlerische Exemplifizierung, sondern sie stoßen sofort zum Kern vor, sagen schlankweg, worum es ihnen geht und was sie von ihren Lesern erwarten. Die Zyklen der Geschichten über religiöse Ereignisse und Wunder, der Predigten und religiösen Betrachtungen zählen wohl einmal auch die Cangaceiros unter die Personengruppen, die bekämpft werden müssen, aber es fehlen Beispiele, es fehlen entsprechende Episoden, es fehlt eine traditionelle Handlung ${ }^{163}$.

Einen Übergang von didaktischen zu epischen Gedichten jedoch bilden die Folhetos aus dem Zyklus des Padre Cícero. In ihm gehen die Volksdichter wieder auf die Realität des Sertãos ein und behandeln ein geschichtliches Thema. Die Gedichte über diesen Padre haben in dem Großen Religiösen Zyklus eine Stellung, die ungefähr der des Cangaceirozyklus im Großen Heroischen entspricht, sowohl in ihrer Beziehung $\mathrm{zu}$ einem geschichtlichen Phänomen als auch in ihrer Bedeutung innerhalb der Volkspoesie Nordostbrasiliens. Der Zyklus des Padre Cícero ist an Umfang und Beliebtheit mit den Texten über Cangaceiros und Valentes zu vergleichen.

Der Padre Cícero (Cícero Romão Batista, 1844-1934) war der nach Antônio Conselheiro berühmteste und erfolgreichste Fanatikerführer des Nordostens. Als im Jahre 1890 eine Frau namens Maria de Araújo in einem damals unbekannten Dorf, Juàzeiro bei Crato im Staate Ceará, kommunizierte, schwamm ihr Mund in Blut. Dieses „Wunder“ wiederholte sich noch zweimal, und schlagartig wurde der Padre Cícero Idol des gesamten Nordostens. 
Meu padrinho no Juàzeiro ${ }^{164}$

Só tem feito caridade

É um cordeiro divino

É um anjo de bondade

Imitando as três pessoas

Da Santíssima Trindade.

É um pastor singular

Filho de Deus verdadeiro

Quando sai numa janela

Como um manso cordeiro

Fazendo então uma fala

$\mathrm{E}$ abençoa os romeiros.

Diese Verse aus dem Folheto Conselhos e trabalhos do Padre Cícero Romão Batista des Volksdichters Antônio Caetano (herausgegeben in Juàzeiro do Norte, 30/8/1944, V. 115-126) sind noch nicht einmal die überschwenglichsten. Ein immerwährender Pilgerstrom zog nach Juàzeiro, das mittlerweile zu einer Stadt von 70000 Einwohnern angewachsen ist. Mit dieser ihm völlig ergebenen Hausmacht rebellierte der Pfarrer 1913 gegen die Regierung seines Staates. Er wurde Vizepräsident des Ceará und sodann Abgeordneter im Parlament von Rio de Janeiro. Sein Ruf drang bis ins Amazonasgebiet, und er wurde als heiliger Nothelfer verehrt (ein ganzes Haus voller Exvotos zeugt vom offenbaren Erfolg dieser Gebete). Noch heute kriechen Pilger auf Knien durch die Straßen der Stadt und küssen die Türen, die der Padre berührt hat ${ }^{165}$.

Die Mehrzahl der Folhetos über den Padre Cícero gibt seine (fiktiven) Predigten wieder, in denen er sich für eine strikte Einhaltung der konservativen Moral einsetzt und gegen alles Moderne wettert. Die Volksdichter berichten über seine philosophischen Belehrungen und versuchen zu beweisen, daß er allmächtig und allwissend gewesen sei. Dutzende von Texten lassen den Padre die Zukunft vorhersagen (die stets sehr finster aussieht) und ihn Verborgenes erraten. Viele Folhetos demonstrieren, was mit den Sertanejos geschieht, die nicht auf ihn hören wollen: sie werden in wilde Tiere verwandelt (ein bekanntes Heftchen aus dem Zyklus des Padre Cícero heißt A môça que virou cobra), ein traditionelles Motiv, das sonst auf die Kinder angewandt wird, die ihre Eltern an einem Karfreitag verprügeln (so in dem Folheto $A$ môça que virou cachorra).

Interessanter als diese Texte, die immer die gleichen Lobeshymnen wie- 
derholen, sind die Folhetos, in denen die Volksdichter historische Ereignisse aus dem Leben des Padre Cícero erzählen wollen und in denen sie deshalb auch gezwungen sein müßten, über das berühmte Treffen des Fanatikers mit Lampião im Jahre 1926 zu schreiben, als der Padre den Cangaceiro zum Hauptmann der antirevolutionären patriotischen Truppen ernennen lie $\beta^{166}$. Wie gelingt es den Volksdichtern, in ihren Gedichten zwei Personen einander gegenübertreten zu lassen, die entgegengesetzte Symbole vertreten? Der Padre Cícero ist ein Vertreter Gottes auf Erden, die höchste Autorität, die der Sertanejo sich vorstellen kann; er verlangt absoluten Gehorsam, völlige Unterwerfung unter seinen Willen. Wer nicht an ihn glaubt, wird zerstört. Lampião wiederum wird in den Folhetos als ein Mann gezeigt, der nichts anerkennt und der keinen Respekt vor höhergestellten Personen hat.

Die überwiegende Anzahl der Volksdichter wählte bei der Behandlung des Juàzeiro-Themas, das Anlaß zu einer Stellungnahme in dem Konflikt zwischen Rebellion und Autorität hätte geben können, den am wenigsten kompromittierenden Weg. Die Verfasser lassen ihre eigene Ansicht nicht erkennen, verhalten sich neutral, überlassen dem Leser die Entscheidung, berichten betont objektiv und bewahren so die Gültigkeit beider antagonistischen Prinzipien. Noch vorsichtiger ist die Haltung des Dichters José Cordeiro, wenn er in einem Folheto, das er erstaunlicherweise programmatisch $A$ visita de Lampião em Juàzeiro nennt, kein einziges Mal das Treffen zwischen dem Padre und dem Cangaceiro erwähnt.

Bei einigen wenigen Verfassern treffen die Leser innerhalb des Zyklus der Cangaceiros auf den Hinweis, Antônio Silvino und Lampião hätten den Padre Cícero sehr verehrt. Diese Verse dürfen keineswegs als Unterwerfung unter den Fanatiker aufgefaßt werden; sie beweisen nur, wie groß das persönliche Prestige des Padre Cícero gewesen ist. Viele Beispiele in der Volkspoesie Nordostbrasiliens zeigen, daß gerade die Pfarrer, als Sinnbild autoritären Denkens, den Haß der Cangaceiros auf sich gezogen haben. In diese Abneigung gegen die Kleriker beziehen die Sertanejos die gesamte Institution der Katholischen Kirche ein. Es wäre völlig falsch zu behaupten, der Erfolg des Padre Cícero sei so groß gewesen, weil er Mitglied des Klerus war. Im Mittelpunkt des religiösen Interesses der Sertanejos steht die eigene magische Kommunikation mit dem Uberirdischen. Die Kirche und ihre Repräsentanten sind somit überflüssig. Wie die Cangaceiros zum Katholizismus standen, geht aus mehreren Folhetos ihres epischen Zyklus deutlich hervor. Ein spezielles priesterfeindliches Handlungsschema hat sich herausgebildet: vor allem die Volksdichter Leandro Gomes de Barros und Francisco 
das Chagas Batista geißeln in scharfer Form, unter Verwendung einer Reihe einschlägiger Schimpfwörter, die Habsucht, die Niedertracht und das Politisieren der Priester im Sertão. Selbst der Papst bleibt von ihren Angriffen nicht verschont, so in Leandros Folheto Antônio Silvino o rei dos cangaceiros. Der Padre Cícero ist zweifellos eine Ausnahmeerscheinung.

Aber wenn die Volksdichter die Katholische Kirche angreifen, so müssen sie zwangsläufig an anderer Stelle ihre Prinzipien verteidigen, damit das Gleichgewicht Autorität-Rebellion wiederhergestellt wird. Dies geschieht in dem Zyklus der Protestanten, einer Folhetogruppe, die vor etwa fünfundzwanzig Jahren entstand. Die Protestanten, vor allem die von Nordamerika unterstützten Baptisten, haben seit ungefähr 1930 versucht, den Nordosten zu missionieren, und brachten durch ihre Erfolge ein weiteres Element der Unruhe in die religiös nicht sehr krisenfeste Sociedade sertaneja. Aber während die Fanatiker, die vor ihnen religiösen Unfrieden im Sertão gestiftet hatten und die unter keinen Umständen bereit waren, die Autorität der Kirche anzuerkennen, von den Volksdichtern im allgemeinen als die Ihrigen angesehen werden und ihre Unterstützung finden, lehnen die Verfasser die Protestanten ab. Sie gehen gegen sie mit den Argumenten der Katholischen Kirche vor, verteidigen nun jedes noch so unwesentliche Detail des katholischen Glaubens. Sie legen den Protestanten genau die Anschuldigungen in den Mund, die die Volksdichter selbst in anderen Texten gegen die Priester vorbrachten: „Die Ketzer wagen es, die Pfarrer der Kirche habsüchtig zu nennen!“ Die Folhetos dieses Zyklus der Protestanten enden zumeist mit einer Bekehrung der Abtrünnigen.

Es läßt sich also die Wirksamkeit sowohl des rebellischen - heroischen - Prinzips als auch die des autoritären in der Volkspoesie Nordostbrasiliens feststellen. Beide Prinzipien bedienen sich traditioneller Strukturen aus der iberischen Volksliteratur.

So sind die beiden extremen Formen des Zusammenlebens, die sich innerhalb oder am Rande der Sociedade nordestina herausgebildet haben, Cangaço und Fanatismus, in der Volkspoesie eben wegen der hier zu beobachtenden Radikalität bestehender Tendenzen Grundlage der umfangreichsten und beliebtesten, das heißt erfolgreichsten, Gedichtzyklen geworden. 


\section{DER C A N G A CEIRO \\ ALS VOLKSHELD NORDOSTBRASILIENS}

Zweifellos hatten die Folhetos über Cangaceiros deshalb einen so großen Erfolg, weil sie in vorderster Linie an einer Modeströmung teilnahmen, die die Figur des Banditen zum Sinnbild eines heroischen Widerstandes der Sertanejos gegen die ökologischen und sozialen Gegebenheiten machte.

Durch die Offnung der Volkspoesie zur Realität war ihr Publikum, waren die unteren Klassen der Sociedade nordestina nicht mehr ausschließlich darauf angewiesen, in die Literatur zu "fliehen“, durch Identifizierung mit sagenhaften Protagonisten Befriedigung zu finden, sondern erstmals stand auch in den Gedichten im Hintergrund eine Möglichkeit, ihre gegenwärtige Situation zu verändern. Zwar begnügten sich auch in Anbetracht des Zyklus der Cangaceiros die meisten Sertanejos damit, sich weiterhin ohne jede Konsequenz mit dem Helden zu identifizieren, aber die innere Beteiligung war dennoch bei diesen Texten viel größer als bei anderen, denn man wußte, daß man im äußersten Notfalle die Cangaceiros wirklich würde nachahmen können.

Der Sertanejo sah rings um sich her nichts als Elend. Dürrezeiten töteten in unregelmäßigen Abständen die Rinderherden, vernichteten die wenigen Pflanzungen, die unter größter Mühe auf dem unfruchtbaren Boden angelegt worden waren. Zehntausende von Menschen kamen in den berüchtigten "Sêcas" des Nordostens um. Und dieses Land, in dem man stets Furcht vor kommenden Katastrophen, vor einer Wiederholung von Dürren wie der von 1877 haben mußte, war auch noch hoffnungslos übervölkert, verarmt und von Seuchen verheert ${ }^{167}$. Die patriarchalische Gesellschaft war unfähig, mit all diesen Problemen fertigzuwerden. So hatte sich der einfache Sertanejo jeden Tag allein mit einer unendlichen Vielzahl von Schwierigkeiten auseinanderzusetzen, wenn er überleben wollte. In welche Richtung er auch sah, von überall her erwartete ihn nur Unheil. Er fand keine Lösung für seine Konflikte; und so wurden eine offenbare Empfindungslosigkeit, eine unglaublich erscheinende Fähigkeit, zu leiden, und schließlich Fatalismus zu Kennzeichen des Nordestinos im Sertão. „Indolência“ gegenüber allem, was ihn umgab. Aber diese Dumpfheit des Empfindens läßt sich bei ihm nur so lange beobachten, wie sich sein Elend aus Gründen ab- 
leitet, die ihm unabänderlich erscheinen, die, wie das Wetter, von Gott kommen. Wird er von Menschen zur Verzweiflung getrieben, dann bricht sein Hang zum Gewalttätigen hervor, sein Wille, doch einmal zu versuchen, der Passivität zu entrinnen. Gerade aus der Empörung heraus, im normalen Leben, als Opfer von Mächten, die er nicht kennt, nichts verändern zu können, wendet sich der Sertanejo aus unreflektierten Beweggründen der Idee des Cangaços zu. Er droht seiner Umgebung, Cangaceiro zu werden, nur um sie zu erschrecken, um zu zeigen, daß er zu irgend etwas schon nütze sei. (So wie Fabiano in Vidas sêcas von Graciliano Ramos ${ }^{168}$, der aus Wut über die Ungerechtigkeit der Menschen und die Härte der Natur aufschreit, daß er in den Cangaço gehe, der dann aber wieder mutlos wird und seinen Plan aufgibt. Anders ausnahmsweise Volta Sêca, eines der herumstreunenden verlassenen Kinder der Capitães de areia Jorge Amados ${ }^{169}$ : als er nicht mit seiner Umwelt auskommt, als es ihm unmöglich wird, sie zu verstehen, entschließt er sich wirklich, in die Bande seines Paten Lampião einzutreten.) Allein das Wissen von einer Möglichkeit, zu entkommen, ist es, die dem einfachen Sertanejo erlaubt, sein gewohntes Leben weiterzuführen; die Drohung mit dem Cangaço ist ein Ventil für seinen Unmut.

Aber der Ruhm des Cangaceiros, die Anziehungskraft seines Bildes gehen weit über den Sertão hinaus, erreichen die Küste und die Hauptstädte, werden von den Sertanejos bis in den Süden Brasiliens getra$\operatorname{gen}^{170}$. Alle Schichten im Nordosten begeistern sich für ihn. Von der Volksdichtung geht der Cangaceiro in die übergeordnete gehobene Dichtung ein, in die Literatur der bei der Auseinandersetzung zwischen den Klassen faktisch auf der gegnerischen Seite stehenden hauptstädtischen Mittel- und Oberklasse, in die Literatur des gebildeten Brasiliens.

In den Werken des modernen "Romance nordestino“, des nordostbrasilianischen Regionalromans, steht ein "Zyklus der Cangaceiros" gleichberechtigt neben den Zyklen der Monokulturen, der "Retirantes" (Flüchtlinge vor den Dürren) und des Fanatismus. Es ist unmöglich geworden, ein literarisches Bild vom Nordosten zu geben, ohne die Figur des Cangaceiros zu behandeln. Zusammen mit ihr wird auch die Gestalt des Volksdichters in den Romance nordestino eingeführt: der Poeta popular ist es dort, der den Sertanejos die Taten der Cangaceiros erzählt, der ihr Ansehen mehrt, der durch seine Verse Sympathien für die Banditen erweckt. Die berühmteste literarische Figur eines Volksdichters ist der Dichter-Sänger Dioclécio aus José Lins do Rêgos Pedra Bonita und Cangaceiros ${ }^{171}$. Die Modernisten, und hier vor allem Mário de Andrade, der den Volksdichter João Martins de Ataíde „unser aller 
Meister" nannte, beginnen zur gleichen Zeit, etwa ab 1930, die Gedichte ihrer „Kollegen aus dem Sertão“ (Manuel Bandeira) zu untersuchen ${ }^{172}$, um bestimmte Motive und insbesondere ihre Ausdrucksweise in ihren eigenen Arbeiten verwenden zu können ${ }^{173}$.

Der Cangaceiro, von dem die Dichter Brasiliens erzählen, der das Vorbild des Nordestinos ist, der in Dutzenden von Filmen ${ }^{174}$ und in einer Flut von Trivialliteratur gefeiert wird, ist keine individuelle Gestalt, ist weder Antônio Silvino noch Lampião, er ist ein Typus, er hat die Züge, die sich im epischen Zyklus der Cangaceiros in der Volkspoesie als seine symbolischen herausarbeiten ließen. Das Bild des Cangaceiros in der Ơffentlichkeit hat einen ähnlichen Verdichtungsprozeß durchgemacht wie sein Image in der Volksliteratur, auch hier wurde aus dem Realen das Typische. Der Cangaceiro des Nordostens ist für den Brasilianer ein moralisch schlechter Mensch, kein edler Draufgänger wie ein Gaúcho oder ein nordamerikanischer Marshall, vertritt keine nationale Aufgabe wie der Cid, erobert und befriedet kein neues Land für seinen Staat wie die unerschrockenen Bandeirantes aus São Paulo oder die Siedler im Wilden Westen der USA. Ganz im Gegenteil: der Cangaceiro zerstört alles, was er antrifft. Und gerade dieser Punkt seines Persönlichkeitsbildes ist es, der ihn so berühmt und beliebt hat werden lassen. Der Cangaceiro ist ein anarchistischer Held ${ }^{175}$. Er kämpft nicht für einen neuen Anfang, begründet keine neue Gemeinschaft, keine neue Gesellschaftsform, keine neue Moral, sondern er zerschmettert den alten Staat, die alten Gemeinschaftsformen, die alte Moral. Er ist der aufflakkernde Endpunkt einer verhaßten Zeit, verhaßter Zustände. Obwohl es die Aufgabe der Oberschicht wäre, ihre Gesellschaft vor dem Untergang zu bewahren, hat auch sie die Hoffnung aufgegeben, die bestehenden Positionen halten zu können. Nach den exaltierten Lobpreisungen der Sociedade nordestina durch die Dichter des 19. Jahrhunderts und auch noch durch die Symbolisten ${ }^{176}$ breitet sich seit etwa 1920 in den Intellektuellenkreisen ein allgemeines Unbehagen an der Gesellschaft des Nordostens aus. Die immer noch zumeist "adeligen" Schriftsteller und Künstler sehen ein, daß das Ende kommen muß, daß der Niedergang schon zu weit fortgeschritten und daß alles so brüchig ist, daß sich nichts mehr retten läßt. José Lins do Rêgo, mit seinem Ciclo de cana de açúcar Chronist der letzten Augenblicke der dekadenten Sociedade açucareira, hat nicht ohne Grund in seinem letzten, im Nordosten spielenden Roman die Cangaceiros zu Protagonisten gemacht. Sie sind die Totengräber der alten Ordnung. Sie sind ihre Leichenfledderer, sie nützen noch einmal alles aus, was im Rahmen des Alten möglich gewe- 
sen ist. Eine Weltuntergangsstimmung begleitet sie: die Situation ist $\mathrm{zu}$ verfahren, es gibt keinen Ausweg ${ }^{177}$. Uberall bricht das Uberkommene zusammen, ist das Neue noch wenig erstrebenswert. Die Fackel des Aufruhrs im Nordosten wird nicht wieder erlöschen, denkt man ${ }^{178}$.

Aber nicht nur der apokalyptische Aspekt ist es, der den Cangaceiro zum typischen Helden des Nordostens hat werden lassen, es sind für den Gebildeten auch der Reiz des Archaischen, die Primitivität der Gedankenführung, die Einfachheit der Denkmodelle. Man wünscht sie für sich selbst auch, aber man denkt zu differenziert, zu qualvoll. Es ist eine Erleichterung, eine bewundernswerte Erleichterung, sich einmal mit dem Cangaceiro identifizieren zu können: es ist eine Flucht vor der Verpflichtung, weiter zu denken. Man verspürt den Wunsch, auf Verantwortung fordernden Fortschritt zu verzichten, auf den $\mathrm{Zwang}$, logische Schlüsse ziehen zu müssen. Der anarchistische, respektlose Wahlspruch des primitiven Helden „Deus mesmo, quando vier, que venha armado" 179 , diese Unbekümmertheit gegenüber den Folgen einer Haltung, die mutige Frechheit, die man selbst nicht hat, die „Bravura" “180, geben dem Menschen einer demokratisierten und technisierten Gesellschaft den Eindruck einer Energie, die ihm fehlt, lassen ihn spüren, daß diese Kraft verlorengegangen ist auf dem Wege, den er Fortschritt nennt.

Aus dieser Gefühlslage heraus dürfte man die Versuche interpretieren, die Euclídes da Cunha 1902 in Os sertões unternahm, gerade die Jagunços, diese Mischung aus Banditen und Vaqueiros, im Inneren Bahias als "rocha viva do povo brasileiro" hinzustellen, als die Essenz des nationalen Menschen. Die fatalistische Haltung gegenüber dem Zerstörungstrieb der Sertanejos, den die brasilianischen Schriftsteller festzustellen glaubten, schlägt nun um. Man entdeckt dynamische Eigenschaften an ihnen, die über den Untergang des Alten hinausweisen. Für die modernistischen Dichter ist der Cangaceiro auch ein Ausdruck echten Brasilianertums, ein positives, siegreiches Gegenbild zu dem nach dem Ersten Weltkrieg dahinsiechenden Europa, ein Menschentyp, der Modell sein kann und den zu verachten ein Brasilianer keinen Grund hat. Ein lebenskräftiger, unverdorbener Barbar, dem Germanen des Tacitus vergleich$\operatorname{bar}^{181}$.

Rückhaltloser Zerstörer und gleichzeitig Urquell aller aus dem Volke kommenden Kraft, diese beiden Aspekte des Cangaceiros sind die Gründe dafür, daß er zu einem Volkshelden Nordostbrasiliens geworden ist, auf den jeder Nordestino stolz ist und um dessentwillen er von 
den anderen Brasilianern beneidet wird. Der Cangaceiro wird heutzutage ohne $Z_{w}$ weifel als progressistische Figur verstanden, sowohl von den Gebildeten und ihrem Organ, der gehobenen Literatur, als auch in der Meinung des Volkes. Er wird durch die Beispielhaftigkeit seines Verhaltens zum Vorbild. Der Cangaceiro entspricht genau der Definition, die Ramón Menéndez Pidal von einem "Helden“ gibt und die er auf den Cid angewendet sehen möchte ${ }^{182}$ :

„El héroe lucha por realidades lejanas, rebeldes, en perenne reiteración de conflictos que él no deja resueltos para siempre, y debe ser medido únicamente por el valor energético de su esfuerzo y por el guionaje que ejerce sobre los que han de afrontar esos conflictos en su futuro reaparecer. Esa es la duración de su obra, la duración de su ejemplaridad ..."

Während die Erscheinung des Fanatismus im Interesse der Bevölkerung in den Hintergrund getreten ist, nahm das Ansehen des Cangaceiros (natürlich besonders nach seinem Verschwinden, zu einer Zeit, als er keine akute Gefahr mehr darstellte) immer mehr zu. Die bedeutendere Stellung, die er heute gegenüber dem Fanatiker einnimmt, entspricht nicht den historischen Relationen: als geschichtliches Phänomen waren die Fanatikeraufstände viel einschneidender in ihrer Wirkung. Man entsinne sich nur der Kampagne von Canudos, die vier Jahre dauerte und über 5000 Mann der brasilianischen Armee in Anspruch nahm. Als man die Festung des Antônio Conselheiro 1897 schließlich vernichtet hatte, waren etwa 10000 Menschen umgekommen. Dagegen nehmen sich die Verluste bei der Bekämpfung der Cangaçobanden und durch die Verbrechen der Cangaceiros unbedeutend aus. Aber der Gedanke an den Fanatismus wird verdrängt; er soll für den Nordestino nur noch eine Reminiszenz an eine wirkungslos gebliebene historische Episode, an eine überwundene reaktionäre Grundhaltung sein. Sie kann nicht vorbildhaft sein, denn sie stellt sich nicht der Realität, zeigt keine neuen Wege.

Die symbolische Gestalt des Cangaceiros jedoch tut dies; sie projiziert sich in die Zukunft. Auf den Trümmern des Alten läßt sich, so glaubt man, ein besserer Nordosten aufbauen. Wie dieses Neue aussehen wird, wissen die Nordestinos noch nicht, aber schlimmer, als es früher war, kann es nicht werden. Der Cangaceiro ist ein Symbol der Hoffnung: mit ihm soll der Nordosten wie ein Phönix aus der Asche steigen. Liest man, was Graciliano Ramos über die Rolle der Cangaceiros zu sagen hat, so bekommt man einen Eindruck von dem Ausmaß der ihnen zugeschriebenen utopischen Funktion ${ }^{183}$ : „Muitas vêzes sentimos vergonha da nossa decadência. Efectivamente 
valemos pouco. O que nos consola é a idéia de que no interior existem bandidos como Lampião. Quando descubrirmos o Brasil, êles serão aproveitados."

So wurde die Gestalt des miserablen Verbrechers, des Straßenräubers, der nur innerhalb seiner Gesellschaft für sich selbst seinen Anteil an Macht und Besitz, einen möglichst großen, erbeuten wollte, umgedeutet in die eines Helden, der neue Horizonte öffnet, der durch seine Eigenschaften das beste Versprechen für eine glückliche Zukunft ist.

Der Aufschwung des Cangaceiros zum Volkshelden nahm seinen Ausgang nicht von der historischen Wirklichkeit, sondern von ihrer Interpretation durch die Literatur (Volkspoesie, gefolgt von gehobener Dichtung). Das Klischee vom aufrührerischen Sertanejo, der jederzeit dazu bereit sei, mit der Waffe in der Hand sein Recht zu erfechten, wird nun, nachdem es sich jahrzehntelang verfestigt hat, für bare Münze genommen. Wer sich in Brasilien für fortschrittlich hält, rühmt den Nordosten als Region der Zukunft, als die Gegend, in der der revolutionäre Geist am ehesten Erfolge erringen könne. Dieses rhetorische Bekenntnis zum finstersten Elendsgebiet des Landes erspart soziale und politische Aktion in den anderen Regionen, denn die Gewißheit von dem angeblich unmittelbar bevorstehenden Aufstand in Nordostbrasilien und dessen Ubergreifen auf andere Teile des Landes macht eigene Vorarbeit unnötig. Der Unterschied zwischen literarischer Fiktion und tatsächlich existierenden Verhältnissen wird völlig mißachtet, wenn man wie der mit Vulgärmarxismen um sich werfende Rui Facó ${ }^{184}$ andeutet, daß die Cangaceiros nur hätten umfunktionalisiert werden müssen, um mit ihnen eine soziale Revolution herbeizuführen. Es wäre ihm sicher sehr schwer gefallen, diese plündernden Banditen nach der Vernichtung des Gegners zum tätigen Aufbau anzuhalten.

In den Städten des entwickelten Südens und Ostens Brasiliens erscheint eine Revolution immer noch wahrscheinlicher als im Nordosten. Dort brauchen sich die Armen nicht mehr ausschließlich verzweifelt darum zu bemühen, die primitivsten Bedürfnisse zu befriedigen und etwas Eßbares aufzutreiben. Ihnen dürtte an ihrer Arbeitsstelle zeitweise der Gedanke kommen, daß ihr Elend von Menschen herbeigeführt wurde und nicht von unkontrollierbaren unbekannten Mächten. In den großen Städten sind sie aus der patriarchalischen Tradition herausgerissen, und es fehlt ihnen in Notzeiten das besänftigende Gefühl, über sich vielleicht einen doch noch helfenden Herrn zu haben. Durch eine Berufsausbildung, durch den höheren technischen Wissensstand ist die Kaderbildung viel einfacher zu bewerkstelligen als im Nordosten. Und wäre - rein theo- 
retisch gesehen - ein etwa doch aufflackernder Unruheherd in Nordostbrasilien mit südbrasilianischer und möglicherweise auch ausländischer Hilfe infolge des höheren militärischen Potentials innerhalb kurzer Zeit auslöschbar, so wäre eine ähnliche Situation im Süden wesentlich schwieriger zu bereinigen.

Wie sehr die Erwartung baldiger Revolution im Nordosten eine Illusion sein dürfte, zeigt die Entwicklung der Volkspoesie in den letzten Jahren. Ihre Hauptaufgabe hatte sie ja während der gesamten ersten Hälfte unseres Jahrhunderts darin gesehen, ein Gleichgewicht zwischen der Neigung zur Rebellion und dem Hang zum Autoritären zu finden. 1930 bewies die von der Bundesregierung durchgeführte politische Entmachtung der Coronéis eindeutig, daß sich die ökonomischen Grundlagen der Sociedade sertaneja (Spitzenstellung der Viehzucht) verändert hatten, daß neue Machtverhältnisse, vor allem durch den Einzug des kapitalistisch betriebenen Plantagenanbaus und durch die Entdeckung riesiger, heute immer noch nicht ausgebeuteter Erzlager, im Begriff waren einzutreten. Aber über dreißig Jahre danach hatte sich im Bewußtsein der Sertanejos kaum eine Wandlung vollzogen; man hielt an den Riten der untergehenden Gesellschaft fest. Auch die Umgangsformen der Mitglieder der herrschenden Schicht sind sich gleichgeblieben: in den sechziger Jahren des 20. Jahrhunderts erschießen sich alagoanische Senatoren im Parlament von Brasília, bringen sich Bundestagskandidaten auf offener Straße in Maceió um, rotten sich zwei Familien in Custódia (Pernambuco) eigenhändig oder mit Hilfe von gedungenen Pistoleiros aus. In den letzten fünf Jahren aber haben die Volksdichter erkannt, daß das autoritär-rebellische, sado-masochistische psychologische Gleichgewicht in ihrer Gesellschaft zu verschwinden droht, und sie vollzogen eine Wendung zur reaktionären Seite. Ihre Gesellschaft ist bedroht, und sie verteidigen sie gegen alle Einflüsse von außen. Die Anzahl der moralisierenden Satiren wird immer größer; die Dichter beschimpfen alles Neue, alles Unbekannte und loben das Alte ${ }^{185}$. Diese Reaktion ist verständlich. Durch Erfahrung gewitzigt, befürchten die Autoren, daß sich bei Veränderungen ihrer Lebensformen die Situation im Sertão noch mehr verschlechtern könnte. Sie wollen wenigstens das halten, dessen sie sich sicher glauben. Die Flucht in den Konservatismus ist Ausdruck ihrer stärker werdenden Unsicherheit und das Ende der traditionellen epischen Dichtung.

So bietet sich das düstere Zukunftsbild einer in ihren unteren Schichten gelähmten Gesellschaft. Eine Frau, unfähig zum Protest, verdient im vergleichsweise blühenden Juàzeiro weiterhin wie 1965 für zehn Stunden Arbeit in einer Tabakfabrik umgerechnet nicht viel mehr als 
60 Pfennig, ernährt davon ihre Kinderschar und bringt ab und zu, weitere Schulden machend, in einem blauausgeschlagenen Sarg unter Freudenbezeugungen ein neues "Engelchen“ zum Friedhof. Der Ehemann kapituliert vor dem Schicksal und geht nach São Paulo. Die Bevölkerungszahl wird trotz schlechtester hygienischer Zustände weiterhin steigen, die Arbeitsmöglichkeiten mit Sicherheit nicht in gleichem Maße. Die Bevölkerung bleibt stumm, weil sie nicht weiß, wie sie reagieren soll, weil sie es für zwecklos hält, weil sie nicht weiß, was danach kommen soll.

Die brasilianische Regierung versucht, den Nordosten mit immer stärkeren Zuwendungen zu unterstützen, die Lebensbedingungen der Landarbeiter zu verbessern und so die auf die Dauer für sie gefährliche Situation auf evolutionärem Wege zu entschärfen. Erfolgsmeldungen aus Nordostbrasilien müssen jedoch mit äußerster Skepsis betrachtet werden, solange mit Vorrang den bereits Reichen geholfen wird, die Rede ist von Investitionssubventionen für südbrasilianische Unternehmer und pernambucanische Plantagenbesitzer, die dann ihre Industrieanlagen im sowieso schon reicheren Küstengebiet ansiedeln, nicht aber von Fortschritten in der Neuordnung der Besitzverhältnisse, der Einrichtung von arbeitsfähigen Genossenschaften im Sertão, geregelter Aussiedelungsplanung und Geburtenkontrolle.

Der Sertanejo kann erfahrungsgemäß plötzlich, nach vielen Jahren scheinbarer Gleichgültigkeit, von konservativer Verhärtung zu sinnloser Zerstörungswut überwechseln. Die Rebellion wird ihm aber wohl nichts einbringen. Er muß erst, vielleicht von außen angeleitet, auf eine Entwicklungsstufe gebracht werden, von der aus er einsieht, daß man nur durch gemeinschaftliche Aktion Erfolg haben kann, nicht durch individuellen Amoklauf nach dem Vorbild der Cangaceiros. Ja, und die Machthaber müßten bereit sein, den Forderungen der unteren Schichten zu entsprechen: der Nordestino hat allen Grund, pessimistisch in die Zukunft zu blicken. 
1 Diese Angaben stützen sich auf den vom brasilianischen Außenministerium herausgegebenen Band Brésil 1964, Rio de Janeiro 1964, S. 106 bzw. 142.

2 Eine semantische Differenzierung dieser drei Bezeichnungen besteht nicht. Man beachte bei dem Wort „Peleja“, wie wichtig das Moment des Kampfes in dieser Literaturgattung ist. Eines ihrer häufigsten Motive sind die prahlerische Übertreibung der eigenen kriegerischen Fähigkeiten und der Hinweis auf den bevorstehenden grausamen Tod des Gegners, eine Reminiszenz aus den Zeiten mittelalterlicher Kampfformen, als ein Dichter als der Vertreter seiner Partei oder seiner Truppe sprach.

3 Selbstverständlich ist der Desafio nicht auf Nordostbrasilien beschränkt, aber in den anderen Gebieten spielt er nicht die beherrschende Rolle. Es gibt eine Ausnahme: Rio Grande do Sul. Die dortigen Gaúcho-Desafios sind jedoch in Form und Inhalt weit mehr dem uruguayisch-argentinischen Kulturkreis zuzurechnen als dem brasilianischen. Die musikalische Begleitung ist völlig anders als im Nordosten: den vorherrschenden Quadras und Sextilhas (man vergleiche diese Formenarmut der Gaúcho-Dichtung mit den komplizierten Vers- und Strophenformen der Nordestinos, von denen auf den folgenden Seiten die Rede sein soll) wird Ziehharmonikaund Gitarrenmusik unterlegt, im Gegensatz zu der Verwendung von Rabeca (einer Violinenart) und Viola (einer Mandolaart) in Nordostbrasilien.

Wir können annehmen, daß die Cantoria repentista von Portugal nach Brasilien eingeführt worden ist, während die Desafios in Rio Grande do Sul von Spanien beeinflußt wurden (siehe hierzu: Câmara Cascudo, Dicionário do folclore brasileiro, S. 275).

Die ältesten uns bekannten Streitgesänge in Europa dürften von den griechischen Hirten stammen (siehe hierzu: Charles Barbier, „Une étude sur les idylles de Théocrite", Euvres complètes de Théocrite, Garnier, Paris 1899, S. 33-34). Deutliche Spuren davon sind in den Idyllen V, VIII und IX des Theokrit zu finden und in den Eklogen III, V und VII des Vergil. Im Mittelalter gibt es Streitgesänge in Frankreich ("Tensons", "Jeux-partis"), in Flandern und Deutschland (erinnern wir uns an den Sängerkrieg auf der Wartburg und an die späteren "Wettgesänge“ der Meistersinger! Bei beiden ist das Ziel allerdings nicht, den Gegner zum Schweigen zu bringen, sondern besonders schöne Lieder zu verfassen, ein Aspekt, der ausnahmsweise auch in der Cantoria repentista des nordostbrasilianischen Sertãos zur Geltung kommen kann). Die älteste erhaltene Erwähnung des Desafios in Portugal stammt aus dem 14. Jahrhundert, aus einer Poetik, die aus dem Provenzalischen übersetzt wurde. (Veröffentlicht von Teófilo Braga in "Cancioneiro português", in: Era Nova, Lissabon 1881, S. 414-420.) Verständlicherweise nennt man dort den Desafio 
mit dem provenzalischen, leicht portugisierten Terminus technicus "tensão". In alten spanischen Cancioneros heißen die Desafios „pallo", "payada" oder "payada-de-contrapunto". Sie verbreiteten sich über ganz Hispanoamerika, von Mexiko bis Argentinien. Uber einen eventuellen Einfluß arabischer Streitgesänge auf Portugal siehe Câmara Cascudo, Dicionário do folclore brasileiro, S. 275.

4 Zur Verwirrung des Gegners führen auch die vielen Rätselfragen, die die Repentistas (ein Wort, das sich von "repente" ableitet und ursprünglich eine Person bezeichnete, die "sofort“ auf einen gegebenen Vers einen neuen dichten kann) in ihre Strophen einflechten.

5 Ein "Mote“ von meist zwei sieben- oder zehnsilbigen Versen wird von den Volksdichtern "glossiert"; in meist zehn Verse umfassenden Strophen variieren sie das angedeutete Thema. Diese Glosas entsprechen genau den Vilancetes der portugiesischen Cancioneiros und den klassischen Glosas des Luís de Camões und des Bocage.

Die Angaben über die Anzahl der Silben in einem Vers sind dem portugiesischen Zählsystem entnommen. Die Silben werden also nur bis zu der letzten betonten Silbe im Vers durchgezählt. So sind die meisten Siebensilber, falls sie nicht mit einem oxytonen Worte enden, nach spanischer Zählmethode Achtsilber, die Zehnsilber sind Elfsilber usw. Die Diskrepanz zwischen dem portugiesischen und spanischen System kommt daher, daß Portugal dem französischen Vorbild folgte (das für eine Sprache wie das Portugiesische, in dem die paroxytonen Wörter überwiegen, allerdings nicht sehr praktisch ist). Es hat sich auch in Brasilien allgemein durchgesetzt.

6 Leonardo Mota, Violeiros do Norte, S. 42. Diese brasilianische Quadra leitet sich wahrscheinlich vom folgenden portugiesischen Vorbild ab:

Tudo que é triste ao mundo

Tomara que fôsse meu,

Para ver se tudo junto

Era mais triste do que eu!

Weitere brasilianische Quadras finden sich bei Gustavo Barroso, Ao som da viola, S. 486 ff.

7 Câmara Cascudo schreibt im Juni 1960 in dem Vorwort zu Leonardo Mota, Cantadores, S. 18: „A forma primitiva e legítima do desafio foi a quadra, simples, $\mathrm{ABCB}$, já popular nos finais do séc. XVIII, no sertão. As demais são posteriores a 1870." Damit korrigiert er seine Ansicht, die er 1952 in Literatura oral, S. 237, in folgende Worte faßte: „(... o modêlo para a poesia heróica)... dividiu-se nas quadras e pelos fins do século XVIII nas sextilhas de sete sílabas, o metro secular para os rimances e canções de gesta."

Tatsächlich scheinen sich Sextilhas und Setilhas erst Ende des 19. Jahrhunderts durchgesetzt zu haben, gehen von der Kunstpoesie wieder zurück in die brasilianische Volkspoesie und ersetzen die Quadra.

8 Leonardo Mota, Cantadores, S. 67.

Handelt es sich bei den Sextilhas wirklich um sechs Kurzzeilen oder eigentlich um drei Langzeilen nach dem 16-Silben-Muster der spanischen Romanzen? Die Tradition hat sich im Falle der brasilianischen Volkspoesie eindeutig auf die Seite der sechs Kurzzeilen gestellt. Die Bezeichnung „Sextilha“ ist allgemein gebräuchlich, und schreiben die Sänger ihre 
Verse einmal nieder, so stets als Strophen zu sechs Versen. Für die Kurzzeilen spricht außerdem die Tatsache, daß die Repentistas in vielen Fällen die Strophe in einen Dialog auflösen. Der erste Sänger übernimmt die erste Zeile, der Partner die zweite, usw., ein Verfahren, das bei Halbversen kaum angewandt werden würde. Dazu kommt, daß die Setilha zweifellos eine Weiterentwicklung der Sextilha ist, durch die Einführung eines zusätzlichen Reimes zwischen fünftem und sechstem Vers, zwischen zwei potentiellen Halbversen also.

9 Disco 88/B der Escola Nacional de Música, Rio de Janeiro, Aufnahme von Luís Heitor.

10 Eine "Gemedeira":

Meu caro amigo Azulão

Segura esta regra inteira,

Porque a hora é chegada

Nesta tarde alviçareira

Para trocarmos idéias,

Ai, ai, um...

No baião da gemedeira.

(Aus einem Desafio zwischen Azulão und Messias, Rio 1960, auf Tonband aufgenommen von M. Cavalcânti Proença. Diese Strophe stammt von Messias.)

11 Eine „Toada alagoana“:

$\mathrm{Na}$ profissão iludido

Estou metido,

Cantando tôda semana;

Mas a pedido do povo

Vou de nôvo,

Que a profissão me engana;

Vou ver, se são nestas dôres

Da toada alagoana.

(Gesungen von Jó Patriota, S. José do Egito, Pernambuco, Juli 1965.)

12 Ein "Gabinete":

Eu chegando na Central

Numa manhã bem cedinho,

Junto com um amiguinho

No meio do pessoal,

Perguntei ao policial:

Tem cartão?

Êle disse: tem.

Quem compra cartão, não embarca no trem,

Sem cartão ninguém vai, sem cartão ninguém vem,

Nem vem, nem vai, nem vai, nem vem,

Nem tem, nem dá, nem dá, nem tem,

Se tiver inveja, mande assim também;

Adiei logo o banquete,

Quem não canta gabinete,

Viu, Messias,

Não é cantor p'ra ninguém.

(Desafio zwischen Azulão und Messias, Rio 1960, auf Tonband aufgenommen von M. Cavalcânti Proença. Diese Strophe stammt von Azulão.) 
$\mathrm{Ai}$, tem que acertar

Os capins da garganta, Que o pinto sem manta

Agarrou a traição,

Ai, desata a mimosa,

Aonde anda a Betinha,

Me espantam a galinha,

Agarra bichano,

Leva êsse gato

Daqui, seu menino.

(Aus einem Desafio zwischen dem Cego Ferreirinha und Vicente Feitosa, Fortaleza 1943, gravação por Luiz Heitor, disco no. 62 da Escola Nacional de Música, Rio de Janeiro.)

14 Leonardo Mota, Cantadores, S. 33: „A ligeira é a quadra bipartida, de versos de sete sílabas, com a rima obrigatória em á e precedida do refrão ,Ai, d-a dá“." Aber schon damals, 1921, war die Ligeira altmodisch. Der Sänger Serrador sagte zu Mota: "Quem canta a Ligeira morre dela."

15 Weitere Einzelheiten über die Metrik der Volksdichter und ihre Nomenklatur, die von Staat zu Staat verschieden ist (hier wurde versucht, die allgemein akzeptierten Namen zu nennen), finden sich bei Leonardo Mota, Cantadores, S. 31-34, und in dem Vorwort zu DECA, Nr. 5, verfaßt von Ariano Suassuna, S. 11-27. Beide Autoren sind jedoch nicht vollständig. Genauer und umfassender ist der Aufsatz von Evelin Daus, "Análise estructural da cantoria trovadoresca popular do Nordeste" (hier auch eine gründliche Untersuchung der Begleitmusik).

16 So habe ich zum Beispiel von einem Mouräo cearense gehört, der im Süden des Staates Ceará entwickelt worden ist, den man mir in Nordpernambuco aber nicht vorsingen wollte, weil er zu schwierig sei.

17 Das sind die Namen der beiden berühmtesten Repentistas des Nordostens. Ihre Peleja ist auch heute noch im Munde der Sänger. Ich traf in Rio de Janeiro die 75jährige D. Ugulina Nunes Batista, die Passagen dieses Desafios auswendig kannte. Ihr Vater, der Volksdichter Ugolino aus Teixeira, hatte sie ihr übermittelt. Einige Strophen des vier Tage dauernden Kampfes finden sich bei Leonardo Mota, Violeiros do Norte, S. 86 .

Ariano Suassuna schreibt in seinem Vorwort zu DECA, Nr. 5, S. 26, daß er annehme, dieser Desafio habe nie stattgefunden und sei von einem Schüler des Romano, von Silvino Pirauá, verfaßt worden. Wir hätten es in diesem Fall mit einem überlegt angefertigten Text und nicht mit Improvisationen zu tun. Ich glaube, eine Diskussion über diese Frage ist müßig. $\mathrm{Da}$ es sich in jedem Falle um mündlich übertragene Literatur handelt, sind Veränderungen des ursprünglichen Textes unvermeidbar. Es dürfte unmöglich sein, nach über achtzig Jahren die Authentizität solcher Verse bestreiten oder nachweisen zu wollen.

18 Daß die epische Volksdichtung sich Jahrzehnte später herausbildete und etablierte als die lyrische oder Glosa-Poesie, findet sein Echo auch in dem zeitlichen Abstand zwischen dem Erscheinen der jeweiligen Sekundärliteratur. In beiden Fällen hinken die Werke über die nordostbrasilianische Volkspoesie den ältesten Quellen um rund fünfzig Jahre nach. Die erste 
bedeutende Sammlung von Gedichten aus dem Nordosten (im Rahmen der Folklore ganz Brasiliens) - meist handelt es sich um lyrische Lieder, teilweise auch um Romanzen -, Śllvio Romeros Cantos populares do Brasil, erschien 1883. In ihr wurden, wie bei Romeros Nachfolgern, Rodrigues de Carvalho (Cancioneiro do Norte, 1903) und Pereira da Costa (Folclore pernambucano, 1908), die Texte veröffentlicht, ohne daß man sie mit einer eingehenden Untersuchung oder Interpretation versah. Erst Gustavo Barroso (in den Ansätzen bereits in Terra de Sol, 1912, ausführlicher in Ao som da viola, 1921) und Leonardo Mota (Cantadores, 1921, Violeiros do Norte, 1925, Sertão alegre, 1928, und No tempo de Lampiäo, 1930) kommentieren die Cantoria repentista, die sie aufzeichneten, fachkundig, und sie waren auch die ersten, die sich intensiv den epischen Gedichten zuwandten. Die ersten kritischen Studien über die Poesia épica begannen um etwa 1930 und wurden dann erst wieder in den fünfziger Jahren fortgesetzt: es handelt sich dabei um Artikel oder Serien in Zeitungen und Zeitschriften. Zu nennen wären hier insbesondere Mário de Andrade, Romanceiro de Lampiäo, 1932, Orígenes Lessa, Literatura popular em verso, 1955, Eduardo Campos und Santa Cruz. Siehe auch die Sammlungen von Zeitungsausschnitten über dieses Thema in der Campanha para a Defesa do Folclore brasileiro, Rio de Janeiro. Gleichzeitig fing die brasilianische Volksdichtung an, im weiteren Rahmen einer Erforschung der brasilianischen volksliterarischen Quellen erwähnt zu werden (z. B. in den Werken von Câmara Cascudo, besonders in Cinco livros do povo und Literatura oral). 1937 erscheint die erste Anthologie von epischen Texten (O trovador do Nordeste, mit vermeintlichen Versen von João Martins de Ataíde, herausgegeben von Waldemar Valente; die meisten Gedichte dieses Bandes stammen von Leandro Gomes de Barros), 1959 die erste Studie über Poesia épica in Buchform (Ideologia dos poetas populares do Nordeste von Renato Carneiro Campos). Aber erst seit 1960 ist es möglich, gründliche Untersuchungen über die epische Volkspoesie im Nordosten zu schreiben: das Centro de Pesquisas da Casa de Rui Barbosa in Rio de Janeiro richtete unter Leitung von Thiers Martins Moreira und M. Cavalcânti Proença ein Zentrum für das Sammeln, Katalogisieren und Auswerten von Folhetos ein. 1961 erschien der erste Teil des Catálogo mit eintausend registrierten Gedichten, im gleichen Jahr die erste Antologia mit zweiundvierzig kommentierten Texten. Die Initiative des CPCRB kommt gerade noch rechtzeitig, denn die Tage der Folhetoliteratur sind gezählt, und in wenigen Jahren wird sie verschwunden sein. Heute schon ist es sehr schwierig geworden, Folhetos aufzutreiben, die älter als zwanzig Jahre sind.

"Episch" soll im Sinne von "erzählend" verstanden werden und als "Gegensatz zu „lyrisch“ oder "didaktisch“. Es gibt nämlich neben den beiden Hauptsparten der Cantoria, neben Desafiotexten und epischen Gedichten, Verse, die wohl auch Themen aus der Folhetoliteratur behandeln, aber mit lyrischen, didaktischen und manchmal rein panegyrischen Intentionen. Diese Art von Texten ist in dieser Arbeit ausgespart. So gehören zum „epischen" Zyklus der Cangaceiros z. B. keine „ABCs" (die Gedichte heißen so, weil jede Strophe, meist Quadra oder Sextilha, mit einem fortlaufenden Buchstaben des Alphabetes beginnt), die, schon ihrer Form wegen, zumeist keinen erzählerischen Charakter haben. (Ein Bei- 
spiel für das $\mathrm{ABC}$ eines Cangaceiro gibt Rodrigues de Carvalho, Cancioneiro do Norte, S. 294-300, "ABC de Jesuíno Brilhante").

20 Gustavo Barroso, Ao som da viola, S. $294 \mathrm{ff}$., zitiert einige Verse aus einem solchen Fragment, aus der "Canção dos Guabirabas“.

21 Ohne jeden Zweifel gab es schon vor diesem Text andere Folhetos, vielleicht schon ab 1889. Leandro Gomes de Barros, Autor von etwa eintausend Folhetos, erwähnt in dem 1907 erschienenen Text der „Mulher roubada", daß er schon seit achtzehn Jahren Volkspoesie schreibe.

In der Regel läßt sich sagen, daß sich die Folhetoliteratur auf die epischen Gedichte beschränkt. Es gibt jedoch eine beträchtliche Anzahl von Heftchen, die das Genre der Pelejas vertreten, die also zur Gruppe der Cantoria repentista gehören. Selbstverständlich kann es sich hierbei nicht mehr um improvisierte Verse handeln; der Verfasser beschreibt auch nicht einen wirklich stattgefundenen Desafio, sondern erfindet einen. Auch einige lyrische Texte wurden in Folhetos veröffentlicht. Das älteste erhaltene Heft, die Saudades..., ist ein Beispiel dafür. In diesen scharf zu umreißenden Fällen betritt also auch der epische Volksdichter das benachbarte Gebiet der Cantoria repentista: auf jeden Fall liegt die Beschäftigung mit ihr am Rande seiner Arbeit, fesselt nur einen geringen Teil seines Interesses.

22 Die Folge ist, daß Folhetos aus den ersten Jahren sehr selten geworden sind. Die Heftchen wurden von Insekten zerfressen oder sind durch häufiges Umblättern bis zur Unleserlichkeit zerfleddert.

23 Siehe: Ludwig Pfandl, Spanische Literaturgeschichte, Bd. I, LeipzigBerlin 1923, S. 20.

24 Die schon erwähnte "Canção dos Guabirabas" von Ugolino aus Teixeira z. B. ist in Quadras geschrieben. Sie beginnt laut Gustavo Barroso, Ao som da viola, S. 294 ff.:

Adjunte-se o povo todo,

Uma companhia inteira:

Vou contar uma desgraça

Que sucedeu no Teixeira.

25 Ob sie wirklich die ersten waren, die statt der Quadra die Sextilha benutzten, ist heute schwer festzustellen, weil vor ihnen die epischen Gedichte nicht schriftlich fixiert worden sind. Câmara Cascudo ist der Ansicht, daß es Silvino Pirauá Lima (1848-1913) aus Paraíba war (Câmara Cascudo, Cinco livros do povo, S. 12), der die städtischen Prosatexte in Sextilhaform brachte.

26 Die erste Zahl nach einem Folhetozitat bezieht sich auf die Nummer des betreffenden Textes im bibliographischen Teil dieser Arbeit, die darauffolgende auf die Position des Verses innerhalb des Gedichtes.

27 Bei der Infinitiv-Form "ver" statt der richtigen 3. P. Sing. "vê" handelt es sich um einen der häufigsten Fälle von Superkorrektion. Der Nordestino pflegt ein Schluß-r nicht auszusprechen.

28 Sicher war diese Tatsache neben anderen ein wichtiger Grund für das Auswechseln der Quadras durch Sextilhas. Es ist einfacher, einen Gedanken auszudrücken, ein Ereignis zu beschreiben, wenn man dazu sechs Verse zur Verfügung hat. Eine Folge von Sextilhas oder Setilhas wirkt weniger sprunghaft als eine Komposition aus Quadras, die jeden fünften Vers etwas Neues bringen muß. 
29 Eine Ausnahme bilden hier natürlich die Texte über aktuelle Ereignisse, bei denen der Autor nur Informationsmaterial über Personen oder Situationen liefert, die dem Leser bereits bekannt sind. Der Verfasser kann sofort seine Mitteilung „an den Mann bringen“, ohne sie einleiten zu müssen, er kann allzu Bekanntes überspringen, kann abrupt abbrechen.

30 Ramón Menéndez Pidal, Romancero bispánico, Madrid 1953, Bd. I, S. 63-65.

31 Uber weitere Formalaspekte siehe die ausgezeichneten Anmerkungen von M. Cavalcânti Proença in der Antologia der Literatura popular em verso. Hier erfährt man Einzelheiten über typische Metathesen, Ultrakorrektionen u. dergl. in der epischen Poesie Nordostbrasiliens.

32 Dieses System brachte eine Reihe von Verlegern dazu, sämtliche in ihrer Druckerei herausgekommenen Folhetos als von ihnen gedichtet auszugeben. Als Verfassernamen setzten sie ihren eigenen, mit der Begründung, die Rechte an dem Text gekauft zu haben. Berüchtigt für diese Art von Aneignung fremden geistigen Eigentums war João Martins de Ataíde, der lange Jahre hindurch als der Verfasser der von Leandro geschriebenen Gedichte galt. In dieser Arbeit werden bei Zitaten von Folhetos möglichst die wahren Autorennamen angegeben.

33 In São Paulo gibt es sogar einen Folheto-Verlag, die Prelúdio-Druckerei. Sie verkauft zwar bis Manaus, aber mit Volkspoesie hat sie nur noch sehr wenig zu tun, so sehr orientiert sie sich an amerikanischen Comic-strips. Sie beeinflußt die Dichter auch dadurch, daß sie Aufträge mit bindenden Auflagen vergibt.

34 Absoluter Bestseller ist nach Angaben von Orígenes Lessa der Pavão misterioso, der eine Gesamtauflage von 3000000 erreicht haben soll.

35 Diese Tatsachen stehen in einem krassen Gegensatz zu den Behauptungen von Robert Rowland, Cantadores del nordeste brasileño, die Anzahl der Volksdichter steige immer mehr an, und das sei so, weil die Bevölkerung Nordostbrasiliens immer mehr zunehme und nicht allen innerhalb ihrer ökonomischen Struktur einen Platz zuweisen könne (S.150). Rowland schätzt die Anzahl der Cantadores allein in Ceará, Rio Grande do Norte, Paraíba, Pernambuco und Alagoas auf 12000 . Das ist reine Phantasterei. Wahrscheinlich ist sogar noch ein Zehntel dieser Zahl zu hoch gegriffen.

36 Wie z. B. bei dem Sänger Azulão aus Rio, der ein Meister in allen Sparten der Volkspoesie des Nordostens ist.

37 Die epischen Gedichte, die von blinden Sängern auf den Straßen der großen Städte und auf Märkten vorgetragen werden, stammen fast nie von ihnen selbst, sondern sind auswendig gelernte Folhetotexte. Die Gestalt des Dioclécio aus José Lins do Rêgos Roman Pedra Bonita, Rio, 1938, eines Mannes, der die epischen Gesänge, die er selbst verfaßt, auch vorsingt, dürfte heutzutage kaum mehr anzutreffen sein. Sie war typisch für die Zeit vor dem Erscheinen der Folhetos.

38 Die Analogie Nordostbrasilien - europäisches Mittelalter ist seit Euclides da Cunhas berühmtem Buch Os sertôes, Rio 1902, zu einem oft angewandten Verfahren bei der Betrachtung geschichtlicher Ereignisse und Fakten geworden. Man geht davon aus, daß gleiche Situationen und Konstellationen gleiche Ergebnisse erzielen können, gleiche Funktionen haben. In diesem speziellen Falle, bei dem Cavalcante keineswegs allein dasteht, ist eine solche Gleichsetzung sicher nicht legitim, weil sie den 
überaus wichtigen soziologischen Aspekt völlig außer acht läßt. Der Unterschied Troubadour-Spielmann war in entscheidendem Maße ein Klassenunterschied, er ist es nicht bei Sänger-Volksdichter.

39 Der Prestigeverlust innerhalb des Sertãos ging parallel mit einer Aufwertung der volkstümlichen Poesia repentista durch die Intellektuellen und Literaten Brasiliens. Gerade das improvisierte Dichten erweckt am meisten Interesse. Von den ersten Büchern des Leonardo Mota an, dessen Hauptaugenmerk auf die Repentistas gerichtet war, bis zu dem Kongreß, den die improvisierenden Volksdichter 1960 in Rio de Janeiro abhielten, hielt die Sympathie für die „vates do sertão" unvermindert an. Wahrscheinlich ist es die Spontaneität dieser Sänger, die ihnen in den intellektuellen Kreisen so viele Freunde gewinnt, die Spontaneität, die den Kunstdichtern weitgehend fehlt, die Naivität, nach der man sich sehnt. Der Erfolg der Repentistas im Süden scheint jetzt auch im Nordosten wieder zu einem vermehrten Ansehen der Sänger zu führen, verstärkt durch ihre Mitarbeit an den Rundfunksendern. Fast jedes Funkhaus in Nordostbrasilien (und jede größere Stadt hat deren mehrere) sendet pro Tag etwa eine halbe Stunde Poesia repentista.

40 Auch die nordostbrasilianischen Volksdichter verwenden den Begriff „Romance" für ihre epischen Gedichte; er stellt in diesen Fällen aber nur ein Synonym dar zu "História“, Geschichte, Erzählung in Versen. Die eigentlichen Romanzen sind Gedichte mit siebensilbigen Versen, bei denen auf jeweils einen Blankvers ein einfacher Reim folgt; sie beschreiben eine kurze Szene, stellen eine Aktion oder dramatische Situation vor, in den wenigsten Fällen aber eine komplexe Handlung. Sehr häufig verwenden sie einen Refrain oder lassen den Hörer durch Dialoge, die nicht kommentiert werden, die Geschichte miterleben. Siehe hierzu die Definition von R. Menéndez Pidal, Romancero bispánico, Madrid 1953, Bd. I, S. $9-10$.

41 Uber die Volksbücher in Frankreich siehe Nizard, Histoire des livres populaires, Paris 1854.

Über deutsche Volksbücher vgl. Benz, Die deutschen Volksbücher, Jena 1913.

42 Siehe dazu Saraiva-Lopes, História da literatura portuguesa, 3. ${ }^{a}$ edição, Porto o. J., S. 168. Die Autoren nennen die Erstausgaben der Theaterstücke Gil Vicentes „folhetos de cordel“".

Uber die portugiesischen Folhetos der Volksliteratur siehe den Aufsatz von Pires de Lima "Literatura de cordel“, in: Actas do $10^{\circ}$ Congresso de Etnografia e Folclore, Lissabon 1963. Auch einige Fotos der Deckblätter portugiesischer Folhetos sind beigegeben. Wie ihre brasilianischen Nachfolger sind sie zumeist mit primitiv-naiven Holzschnitten geschmückt. Auf S. 106 hat Pires de Lima eine Liste von Heftchen (nach Teófilo Braga) geliefert, die im 18. Jahrhundert in Lissabon besonders beliebt waren. Weitere Arbeiten über die Folhetos in Portugal: Teófilo Braga, „Os livros populares portugueses“, in: Era Nova, Lissabon 1881, und "Literatura dos contos populares em Portugal", Einführung in den 2. Band der Contos tradicionais do povo português, Porto 1883.

43 Zitiert nach Câmara Cascudo, Cinco livros do povo, S. 16.

44 R. Menéndez Pidal, Romancero bispánico, Madrid 1953, Bd. II, S. 66 bis 69. „Entonces [im 16. Jahrhundert] se publicaban los romances en hojas 
sueltas, sin encuadernar ni coser, porque no ocupaban sino un pliego de papel que hacía 8 ó 16 páginas. Eran ,pliegos sueltos', editados para la lectura del momento, y no para ser conservados en los armarios de una biblioteca; asi que muy pocos sobrevivieron a la destrucción propria del uso negligente, de modo que los hoy conservados representan sólo una mínima parte de los que salieron a luz." (S.66) - Die ältesten dieser Pliegos scheinen aus dem Jahre 1506 oder nur etwas später zu stammen. Bezeichnenderweise gehört zu diesen ältesten Ausgaben auch ein Romance de los doce pares de Francia por muy gentil estilo fecho. Eine Liste der Pliegos sueltos vor 1550 (sie kann natürlich nicht vollständig sein, Milá y Fontanals kannte noch nicht alle Editionen) gibt Milá y Fontanals in De la poesia beroico-popular castellana, Barcelona 1959, S. 526 ff.

45 Siehe hierzu: Câmara Cascudo, Literatura oral.

46 Das besonders hohe Alter dieses Zyklus und seine stark akzentuierte Abhängigkeit von den europäischen Modellen werden durch die Tatsache bewiesen, daß viele der nordostbrasilianischen Folhetos über Karl den Großen und seine Vasallen in Décimas espinelas geschrieben sind, in einer Strophen- und Versform also, die wohl in der spanischen epischen und dramatischen Kunstdichtung sehr häufig war, nicht aber in der epischen Dichtung des Nordostens.

47 Die Entwicklung dieser Geschichte und ihr Schicksal in Brasilien beschreibt Câmara Cascudo in Cinco livros do povo, S. 169-221.

48 Durch diese und viele andere Geschichten auch stellen die Volksdichter eine Verbindung mit der orientalischen Erzählkunst her. Sie übernehmen Themen, die von ihren iberischen Vorbildern arabischen Quellen entnommen wurden. Die "Imperatriz Porcina“ z. B. taucht schon in 1001 Nacbt auf, kursiert dann in Europa seit dem 11. Jahrhundert in lateinischen Fassungen, in den Gesta Romanorum z. B. unter den Namen „Crescentia" und "Florencia de Roma“, in einigen Miracles de la Vierge (das besagte Manuskript findet sich in der Nationalbibliothek in Paris) wird diese Geschichte unter dem Titel „De pudicitia et tolerantia cuiusdam imperatricis" erzählt. Siehe auch Câmara Cascudo, Cinco livros do povo, S. $283-349$.

49 Dieser Stoff hat in der epischen Volkspoesie Nordostbrasiliens sogar einen kleinen Sekundärzyklus hervorgebracht. Die Geschichte wird bis zu einer Enkelin der Heldin fortgeführt. Das Folheto über die „Donzela Teodora" dürfte eines der meistverkautten im Sertão sein. Câmara Cascudo widmete sich sehr eingehend dem Quellenstudium dieser Erzählung, er geht dabei besonders auf die orientalischen Quellen ein. Siehe dazu seine Werke: Dicionário do folclore brasileiro, S. 283; Vaqueiros e cantadores, S. 17-29, und in besonders ausführlicher Form in Cinco livros do povo, S. 35-168. Wie bekannt das Thema der "Donzela Teodora“ auch in Spanien war, geht aus der Tatsache hervor, daß Lope de Vega darüber ein Stück schrieb, die Doncella Teodor. Uber spanische Ausgaben dieser volkstümlichen Erzählung siehe Walter Mettmann, La bistória de la Donzella Teodor, Mainz 1962.

50 Siehe hierzu Câmara Cascudo, Cinco livros do povo, S. 353-437. In dem Aufsatz von Pires de Lima "Literatura de cordel“, Actas do $10^{\circ}$ Congresso de Etnografia e Folclore, Lissabon 1963, ist gegenüber S. 97 das Foto des Deckblattes einer portugiesischen Edition dieser Geschichte aus dem Jahre 
1859 abgebildet. Auch Beispiele von Ausgaben der „Imperatriz Porcina“ und der "Donzela Teodora" sind auf diesen Fotos vertreten.

51 Siehe dazu Câmara Cascudo, Dicionário do folclore brasileiro, S. 445, mit genauer Untersuchung der Quellen. Die älteste portugiesische Erwähnung stammt aus dem 16. Jahrhundert.

52 Die ersten Folkloristen Brasiliens, die kurz vor und nach 1900 begannen, Volkspoesie aufzuzeichnen, interessierten sich, der damaligen Mode in Portugal entsprechend, ganz besonders für Romanzen. So haben wir einige sehr zufriedenstellende Sammlungen von Texten, die um diese Zeit noch aufzufinden waren. Zu nennen sind hier vor allem Sílvio Romero, Cantos populares do Brasil, Pereira da Costa, Folclore pernambucano, und - später herausgegeben - Câmara Cascudo, Vaqueiros e cantadores. Siehe auch Câmara Cascudo, Dicionário do folclore brasileiro, S. 665-666.

53 Uber Musik, Text und Choreographie des Côco siehe die Monographie von Altimar de Pimentel, O côco praieiro, João Pessoa 1964.

54 Eine Abkapselung, die nicht nur von politischem Separatismus begleitet wurde (besonders in Pernambuco), sondern auch von isolationistischen Strömungen in der gehobenen Literatur. Franklin Távora fordert in seinem Vorwort zu Cabeleira, einem Roman, der die Geschichte eines cangaceiro-ähnlichen Verbrechers erzählt, die Schaffung einer „Literatura do norte", einer von Südbrasilien (und vor allem von Rio) unabhängigen Literatur Nordbrasiliens. In einer gegen José de Alencar gerichteten Polemik begründet Távora seinen Vorschlag damit, daß der Nordosten kaum etwas gemein habe mit dem übrigen Brasilien und daß die Literatur der Cariocas und Gaúchos schon wegen ihrer Themenwahl einem Nordestino nicht zusagen könne.

55 Einige wenige Nordestinos nahmen - gezwungenermaßen - an diesem Kriege teil. Uber die Auswirkungen im Sertão siehe die Memoiren des Ulysses Lins de Albuquerque, Um sertanejo e o sertão.

56 Diese Zahlen stammen von Rui Facó, Cangaceiros e fanáticos, S. 29-31.

57 Die Definitionen für die Begriffe „Literatura oral, popular und tradicional ${ }^{\star}$ - alle drei bilden die "Literatura do Povo“, die Volksliteratur gibt Câmara Cascudo in Cinco livros do povo, S. 10-13: „A Literatura Oral possui a caraterística de sua transmissão verbal. Consta dos contos de fadas, facécias, anedotas, adivinhas, casos, autos cantados e declamados, desafios. É anônima. Os seus elementos de formação constituem multidão, vindos dos horizontes mais distantes e das fontes mais variadas. A oralidade modifica, determinando versões locais, adaptações psicológicas e ambientais. Concorre incessantemente a fôrça viva e nova trazida pelos viajantes, notícias vagas, cousas lidas, tudo amalgamado e conduzido na memória popular, vivendo sempre. A Literatura Popular, típica, é impressa, tendo ou não autores sabidos, identificáveis... O poeta popular transforma o livro da cidade, do autor letrado, em romance, romance na acepção clássica da adaptação e assimilação destinada a um certo ambiente social... Literatura Tradicional é a que recebemos impressa há séculos e é mantida pelas reimpressões brasileiras depois de 1840 ... (As novelas) Tiveram origem erudita, estudada na novelística francêsa, espanhola, italiana e portuguêsa. Vieram dos séculos XV ao XVIII, com formação diversa..." 
58 Luís da Câmara Cascudo, Vaqueiros e cantadores, S. 189.

59 Uber die Beziehungen zwischen den Weißen und den Indianern von 1500 bis 1560 siehe Alexander Marchant, Do escambro à escravidão, São Paulo 1943 (trad. de Carlos Lacerda).

60 Diese sehr kurze Übersicht stützt sich auf Capistrano de Abreu, Capítulos de História Colonial (1500-1800), Rio 1934, S. 68-69. Seine drei mittleren Bevölkerungsschichten sind hier zu einer einzigen zusammengefaßt.

61 Uber die Grausamkeiten der Portugiesen bei der Unterwerfung des Ceará siehe die farbige Schilderung von Djacir Menezes, O outro Nordeste, S. 68.

62 Djacir Menezes, op. cit., S. 80-81, berichtet von Ereignissen um 1700, bei denen der Antagonismus Eroberer - Eingeborener nicht mehr der beherrschende zu sein scheint.

63 Kriterium für die Adelszugehörigkeit ist der Reichtum. Meist sind Geldadel und Blutadel identisch, müssen es aber nicht sein. Jeder, der reich genug war, um sich ein Zuckerrohr-Engenho oder eine Fazenda zu kaufen, und dies spätestens im 19. Jahrhundert tat, wird zur Oberschicht gerechnet.

64 Über Aspekte der Fixierung der unteren Schichten in der Sociedade sertaneja siehe: Costa Porto, O pastoreio na formação do Nordeste, S. 32-34.

65 Nur wenige, sehr begabte Volksdichter konnten es sich leisten, einen eigenen Stil herauszubilden, und auch das erst, nachdem sie berühmt geworden waren. $\mathrm{Zu}$ nennen sind hier vorzugsweise Francisco das Chagas Batista und Leandro Gomes de Barros zu Beginn unseres Jahrhunderts. Von der nachfolgenden Generation verdient José Pacheco, erwähnt zu werden.

66 Das Folheto war jahrzehntelang (vor dem Erscheinen des Rundfunks) das einzige Massenmedium im Sertão und bot somit die Möglichkeit, die öffentliche Meinung zu beeinflussen. Nicht wenige Lokal- und Landespolitiker baten die Volksdichter, gegen entsprechende Bezahlung Panegyriken über sie zu verfassen und die Heftchen kostenlos zu verteilen. Folhetos über Wahlkämpfe sind Legion. Uber einen Gouverneur in einem Folheto lesen zu können, sollte nach Ansicht der Auftraggeber bedeuten, daß die gesellschaftliche und kulturelle Kluft zwischen dem Politiker und dem Volk durch die Vermittlung des Dichters überwunden war. Wer für irgend etwas Propaganda machen wollte, wandte sich an die Poetas populares. So gibt es ein Heftchen von João José da Silva, A fera invisivel, in dem der Autor als Auftragsleistung für die Schutzimpfung gegen die Tuberkulose eintritt. Auftragsarbeiten der Volksdichter lassen sich jedoch sehr genau, schon wegen der aufgezwungenen Themenwahl, von ihrer übrigen Produktion unterscheiden.

Wie genau ein Volksdichter weiß, daß er Sprachrohr einer ganz bestimmten Schicht ist, wie sein Publikum nur eines von vielen möglichen ist, zeigt sein Wunsch, in die übergeordnete "Kunstdichtung" vorzustoßen, wenn er in der Volksdichtung arriviert ist. So schreibt Rodolfo Cavalcante Sonette und João Martins de Ataíde Lobgesänge auf die Frauen. Beide wollen vom "Handwerk" zur "Kunst" vorstoßen. Die Glosas, die sie dichten, sehen sie als nicht ausreichend an. Bezeichnend ist, daß Volkspoeten, wenn sie gehobene Literatur machen wollen, immer Verse schreiben, von ihrem - volksliterarischen - Standpunkt aus die Prosa nicht 
als künstlerisches Mittel anerkennen. Der Aufstieg von einer Literaturstufe zur anderen ist in ihrem Bewußtsein nur ein Wechsel von einer Gedichtform zu einer anderen, zu einer, die höheres Prestige besitzt.

67 Cangaçoähnliche Zustände in anderen Regionen Brasiliens sind erst einige Jahrzehnte später als im Nordosten festzustellen. Besonders zu nennen wären hier Goiás, Mato Grosso und der Sertão von Minas Gerais.

68 Es soll dabei nicht immer auf vergleichbare volksliterarische Phänomene in der Folklore anderer Länder hingewiesen werden. Ubereinstimmungen gibt es in großer Anzahl, doch es wird schwierig werden, eventuelle gegenseitige Beeinflussungen nachweisen zu wollen. Beim epischen Zyklus der Cangaceiros scheint die polygenetische Theorie die wahrscheinlichste zu sein. Eine gleiche psychologische Basis, ähnliche soziologische Bedingungen, vergleichbare ökologische und kulturelle Konditionen ließen parallele Strukturen und ähnliche Motive entstehen. Das gilt besonders für die in dieser Arbeit beschriebene Form des Cangaceiro-Symbols.

69 Luís da Câmara Cascudo, Dicionário do folclore brasileiro, S. 417. Cascudo sagte mir, diese Zahl sei geschätzt. Der größte Teil der Folhetos ging verloren, weil er nicht in den großen Typographien der Küste oder des südlichen Ceará gedruckt worden ist. Man kann damit rechnen, daß von den aktuellen Themen bis 1940 rund 70 Prozent aller Folhetos nicht mehr erhalten sind. Der Rest ist durch Zufall gerettet worden oder durch Neuauflagen bekannt geblieben.

70 Gustavo Barroso, Ao som da viola, S. $283 \mathrm{ff}$.

71 Über die Identifizierung siehe Sigmund Freud, Massenpsychologie und Ich-Analyse, VII, Die Identifizierung, Bd. XIII der Ges. Werke, Imago, London 1940, S. 115-121.

72 Ariano Suassuna in: DECA, No. 5, S. 28. Die Zyklen sind folgende:

1. Ciclo heróico,

2. Ciclo maravilhoso,

3. Ciclo religioso e de moralidades,

4. Ciclo cómico, satírico e picaresco,

5. Ciclo histórico e circunstancial,

6. Ciclo de amor e fidelidade.

73 Centro de Pesquisas da Casa de Rui Barbosa, Literatura popular em verso, Catálago, Tomo I, S. 394.

74 Unbrauchbar ist die von Waldemar Valente in seinem Ataíde-Band Trovador do Nordeste angewandte Klassifizierung. Der Autor stützt sich auf Gustavo Barroso, der in Ao som da viola eine Einteilung der gesamten Volksdichtung Brasiliens versuchte, ohne dabei auf die spezifischen Probleme der Literatura de cordel eingehen zu können. Auch die Klassifizierung von Câmara Cascudo in seinen Vaqueiros e cantadores umfaßt die gesamte Volksdichtung und ist in bezug auf die Folhetoliteratur in einem nur sehr beschränkten Umfang anwendbar.

75 In zwei schwerwiegenden Punkten weiche ich von Suassuna ab. Das Kriterium für die Zuordnung eines Folhetos zu dem Heroischen Zyklus ist für mich nicht das „tragische Geschick“ (das z. B. ein Cangaceiro gar nicht hat), sondern die rebellische Grundhaltung des Protagonisten. Zum Ciclo cómico, satírico e picaresco zählt Suassuna sodann all die Texte, die ihr Thema humoristisch behandeln. Humor ist jedoch für die Volksdichter nur eines von vielen stilistischen Mitteln und nur selten Selbstzweck. 
Dieser Zyklus muß also auf andere Zyklen aufgeteilt werden, wobei sich als resistenter Kern die Figur des Antihelden herausschält.

76 Der Zyklus der sozialen und wirtschaftichen Satiren muß von dem der moralisierenden Satiren (aus dem Großen Religiösen Zyklus - E -) unterschieden werden. In ihm herrscht das rebellische Prinzip gegenüber dem autoritären vor. Das Handlungsschema seiner Episoden ist im allgemeinen mit den Grundlinien der Valente-Geschichten identisch. Eine Satire kann innerhalb desselben Folhetos zuerst moralisierend-autoritär, dann rebellisch und sozialkritisch sein, wie O sacrifício do povo von João Vicente da Silva. Musterbeispiel für eine soziale Satire mit deutlich rebellischen und antikirchlichen Zügen ist die Discussão dum fiscal com uma fateira von Manuel A. Campina.

77 Nicht-pikaresk sind diejenigen Antihelden, die nicht durch schelmische Schläue, natürlich auch nicht durch die heroische Tapferkeit, sondern durch eine andere Eigenschaft - durch eine hervorragende Kombinationsgabe etwa - ihr Ziel erreichen.

Der weitaus größte Teil des Großen Zyklus der Antihelden jedoch besteht aus Pícaro-Geschichten. Die „einheimischen“ nordostbrasilianischen, nicht aus Europa überführten Pícaros heißen wegen ihrer erbärmlichen Gestalt und ihrer ungesunden Gesichtsfarbe „amarelinhos“. Renato Campos, Ideologia dos poetas populares do Nordeste, S. 89-103, macht in dem Kapitel über den Amarelinho eine Unterscheidung von Folheto-Lesern im Sertão und in der Zuckerrohrzone, ein recht unverständliches Vorgehen, das vom Verfasser nicht mit einem Wort begründet wird. Carneiro behauptet, Anregungen Gilberto Freyres folgend, die Arbeiter in den Zuckerrohrplantagen bewunderten vor allem die Antihelden, weil sie wüßten, daß die Sertanejos in Wirklichkeit gar nicht so tapfer seien wie in den Folhetos. Ein Vergleich zwischen existierenden und fiktiven Personen dürfte kaum dazu ausreichen, beim Leser den Effekt einer symbolischen literarischen Gestalt auszulöschen.

78 Das beste Schlaraffenland-Folheto ist Viagem a S. Saruê von Manuel Camilo dos Santos.

79 In diesem Großen Zyklus finden sich einige nicht-epische Texte oder Textteile.

80 Hier wird das Wort "Cangaço" nicht verwendet in seiner ursprünglichen Bedeutung als „reunião de objetos caraterísticos do ,cangaceiro', fuzil ou mosquetão (...), revólver ,para-bellum', grande punhal atravessado na cartucheira dupla da cintura, cartucheiras cruzadas no peito, bornais de algodão, com munição, medicamentos, muda de roupa, fumo, fósforos, varetas para limpiar as armas, etc." (Câmara Cascudo, Dicionário do folclore brasileiro, S. 176), sondern im Sinne der "Gesamtheit aller Phänomene, die mit den Cangaceiros in Zusammenhang stehen". Außerdem bedeutet Cangaço „die von den Cangaceiros gegründete Gemeinschaft und ihre spezifischen Lebensgewohnheiten“. Ein Beispiel für die Anwendung des Wortes "Cangaço" in dem zuerst genannten Sinne: „Muito se tem dito ... no intuito de identificar as causas responsáveis pelo cangaço nos sertões do Nordeste brasileiro" (Rodrigues de Carvalho, Serrote Prêto, S. 57). Ein Beispiel für die zweite Bedeutung: „Sebastião Pereira deixou o cangaço e se retirou para e Estado de Mato Grosso" (Luís Luna, Lampião e seus cabras, S. 47). 
81 Ein Vorgang, der sich später in allen anderen Gebieten Brasiliens mit Indianerkriegen wiederholen sollte.

82 Die so berühmten "Questões de honra“, „Ehrenangelegenheiten“, unterscheiden sich im Sertão nicht wesentlich von den üblichen Konflikten um Besitztumsfragen. Der Clan-Führer empfindet die Beleidigung eines Verwandten als Angriff auf seinen Besitzstand; denn er betrachtet alles, was sich innerhalb seines Autoritätskreises befindet, als sein Eigentum.

83 Typische Beispiele dafür liefern die sehr bekannten Familienfehden der Mourões und Moquecas (Gustavo Barroso, Heróis e bandidos, S. 127134) und der "Caboclinhos" und des Clans Antônio Tomás (Rodrigues de Carvalho, Serrote Prêto, S. 142-147).

84 Für den Sertanejo ist es selbstverständlich, daß eine Landesregierung es als ihre Pflicht ansieht, ihren Parteifreunden bei der Erhaltung der Macht dadurch behilflich zu sein, daß sie nur die Verbrecher verfolgt, die von den Gegnern bezahlt werden. Historische Beispiele dafür sind überaus häufig. Djacir Menezes, O outro Nordeste, zitiert den Fall des Cangaceiros "Cansação": Der (Landes-)Präsident Moreira da Rocha (vom Ceará), den man stets anklagte wegen „excessiva tolerância para com os bandoleiros, devido às suas afinidades com certos políticos“, läßt im Munizipium Barbalha ein halbes Dutzend von "cangaceiros desprotegidos“ erschießen, als „prova da imparcialidade do govêrno, porque no caso tratava-se de miseráveis malfeitores sem ligação com os chefes da politicagem da zona".

85 Fazendeiros, die sich als Coiteiros betätigten, werden von vielen Autoren, die über den Cangaço geschrieben haben, als eine der Ursachen für die Ausbreitung der Cangaceiros über den ganzen Nordosten angesehen (z. B. in: Rodrigues de Carvalho, Serrote Prêto, S. 57-86).

86 Ubten Capangas Funktionen aus, die nicht als direkte Teilnahme an einer Familienfehde interpretiert werden können, so nennt man sie häufig schon "Cangaceiros". Ich bleibe in einem solchen Falle bei der Bezeichnung "Capanga". Capanga bedeutet "Valentão assalariado para proteger uma pessoa ou para tropelias, assim chamado porque usa a tiracolo em capangas (sacos ou bolsas, de pano, prêsos por alças ao ombro oposto) as munições de bôca e de fogo" (Antônio de Morais Silva, Grande Dicionário da Língua Portuguêsa, vol. III, 10. ${ }^{a}$ edição, Confluência, S. 865). Capangas werden auch "Cangaceiros mansos" genannt, im Gegensatz zu den "Cangaceiros independentes". Capangas sind demnach in den Dienst einer Person gestellt, die völlig innerhalb des normalen Rahmens der Sociedade sertaneja steht, während Cangaceiros sich jeder Bevormundung entziehen.

87 In bestimmten Konflikten kann die erforderliche Anzahl von Capangas in die Hunderte gehen. Man stelle sich die Höhe der Ausgaben des Fazendeiros vor.. Rui Facó, Cangaceiros e fanáticos, S. 61-63, zitiert einige Beispiele von Privatfehden zwischen mächtigen Sertanejos. Die von ihm berichteten Ereignisse spielten sich zwar nicht im Kernbereich des Nordostens ab, finden ihre Parallelen aber auch in Paraíba und Pernambuco: „Num conflito político no interior da Bahia, na segunda década do século atual, entre os coronéis Militão e Horácio de Matos, êstes e seus respetivos aliados ... enfrentam-se durante cinco mêses com mais de 600 homens..." (Facó zitiert hier Américo Chagas, O chefe Horácio de Matos, São Paulo, 
1961, S. 64.) „Numa disputa havida nas Lavras Diamantinas, em 1919/ 1920, o coronel Horácio de Matos, dono de vastos garimpos, mobiliza uns mil homens, ocupando a cidade de Lençóis ..." "Na mesma época, outros coronéis ... ameaçam ocupar a cidade de Juàzeiro (Bahia) com mais de 1000 homens. Marcionílio (Sousa) movimenta-se em direção à cidade de Nazaré com mais de 500 capangas seus."

88 Ein Verhältnis, das es einem Capanga ermöglichte, selbst zu herrschen, wenn der Fazendeiro eine schwache Persönlichkeit war. Siehe dazu: Rodrigues de Carvalho, Serrote Prêto, S. 356-357.

89 Vgl. den Aufsatz von Graciliano Ramos "Dois cangaços“ in: Viventes das Alagoas, S. 147-152: „Os instrumentos libertaram-se, entraram a mover-se por conta própria."

90 Gustavo Barroso, Terra de Sol, S. 98, definiert das Wort „Cangaceiro“ folgendermaßen: „O têrmo cangaceiro se estende a tôdas as modalidades do criminoso nos sertões: é o salteador, o sequaz de atrabiliário e cruel dono de fazenda, de ignorante e perverso chefete político; um criminoso perseguido pela Justiça, muitas vezes vítima da exacerbação de ódios políticos, que vive pelos matos às ocultas, exercendo vinganças, cometendo desatinos, matando inimigos descuidosos nas largas estradas solitárias; ou ainda os criminosos degenerados, tarados pelo atavismo, com nevrose de tôdas as espécies. "In dieser Definition geht Barroso nicht auf die Unterschiede zwischen einzelgängerischem Verbrecher, Cangaceiro und Capanga ein, erwähnt auch nicht den Typ des grausamen Fazendeiros, der ebenfalls häufig Cangaceiro genannt wird. Luís da Câmara Cascudo, Dicionário do folclore brasileiro, S. 175, schreibt: „Diz-se, no Nordeste, do criminoso errante, isolado ou em grupo, vivendo de assaltos e saques, perseguido, perseguindo..."

Die beiden Definitionen entsprechen nicht dem, was man sich heutzutage, vor allem im Süden Brasiliens, unter einem Cangaceiro vorstellt. Es ist ein Mann, der in einer Bande lebt und mit ihr mordet, raubt und vergewaltigt. Der Cangaceiro unterscheidet sich deutlich von Verbrechern, die allein handeln, und von Capangas.

91 Die höchsten Kommandoposten allerdings bleiben bei der Polizei Vertretern der herrschenden Schicht vorbehalten. Der einfache Sertanejo kann nur zu mittleren Befehlspositionen vordringen.

In der Praxis scheint aber schon ein Sargento außergewöhnliche Macht gehabt zu haben, wie aus vielen Berichten hervorgeht. Siehe hierzu die Schilderungen von Verbrechen, die von Polizisten verübt wurden, bei Rodrigues de Carvalho, Serrote Prêto, S. 73-77.

Uber die Willkür der Offiziere siehe die Beschreibung des (historischen) Tenente Maurício in José Lins do Rêgos Fogo Morto, Rio 1943, und Pedra Bonita, Rio 1938.

92 So gab er sich und seinen Unterführern Offiziersgrade, wie „Capitão“ und "Tenente". Dadurch setzte er sich auch in Beziehung zu den reichen Fazendeiros, deren Adelsprädikate seit der Gründung der Guarda Nacional (siehe: Vítor Nunes Leal, Coronelismo, enxada e voto, Rio de Janeiro 1948, S. 153-157) Offiziersgrade waren, wie "Coronel“, "Major" und "Capitão". Sowohl in der Sociedade sertaneja als auch in der Sociedade açucareira zeugen diese Bezeichnungen für die starke militaristische Komponente in autoritären Gesellschaftsformen. 
93 Lampião hatte bereits 1930 den Zenit seiner Karriere überschritten. Danach sorgte nur noch sein Prestige dafür, daß der Cangaço nicht ausstarb. Lampião versäumte es, seine Operationsweise zu modernisieren. Er nützte nicht die strategischen Möglichkeiten von Eisenbahn und Straße aus, bewaffnete sich nicht mit Maschinengewehren, knüpfte keine politischen Beziehungen zu den Parteiführern in den Hauptstädten an, kurz: er war weit von der Raffinesse sizilianischer Banditen entfernt. Innerhalb seiner sich wandelnden Gesellschaft stellte der Cangaceiro einen Anachronismus dar (eine Tatsache, die die Rolle Lampiãos von der Antônio Silvinos sehr unterscheidet).

94 Uber soziologische Gründe, die Corisco bewogen haben mögen, Cangaceiro zu werden, siehe den Aufsatz "Corisco" von Graciliano Ramos, in: Viventes das Alagoas, S. 144-146.

$95 \mathrm{Um}$ zu einer so großen Uniformität zu kommen, war es nötig, die Kulturunterschiede, die zwischen den einzelnen Komponenten der Sociedade sertaneja bestanden, weitgehend zu eliminieren. Die Gesellschaft hatte es fertiggebracht, einzelne Sertanejos (die Indianer z. B. und zum Teil die wenigen Neger, die bei der Besiedelung des Sertãos mitwirkten) auf eine höhere Kulturstufe zu heben, während z. B. die Portugiesen aus der Metropole eine kulturelle Regression durchmachten, die der ökonomischen entsprach (sie stammten aus einer frühkapitalistischen Gesellschaft und lebten nun in einem Gebiet, das mit primitiven Mitteln Viehzucht trieb). Das ursprünglich bestehende Bildungsgefälle wurde ebenfalls beseitigt, zuungunsten der eingewanderten Portugiesen.

96 Uber den Begriff "patriarchalische Gesellschaft" siehe die Definition Freuds, die er in Totem und Tabu, Bd. IX der Ges. Werke, Imago, London 1940, gab. Vgl. auch seine Darlegungen in Der Mann Moses, 2. Aufl., Frankfurt 1961, besonders auf S. 185-194 (Bd. XVI der Ges. Werke).

97 Diese Willkür findet ihre Begrenzung, wenn sie in zu übertriebener Weise dem Ehrbegriff des Unterdrückten zuwiderhandelt. Ein Mann, der sich als Mitglied der Sociedade sertaneja innerhalb ihres normalen Rahmens fühlt, nimmt ohne weiteres eine Reihe von Restriktionen seiner persönlichen Freiheit in Kauf, läßt sich auch ausbeuten und demütigen. Wird jedoch seine Ehre in einem entscheidenden Punkte verletzt, wägt er nicht mehr die Tragweite seines Handelns ab, sondern wendet sich von jeder logischen und realistischen Betrachtung der Situation ab, um die Person zu bestrafen, die ihn beleidigt hat. Wo diese Schwelle des Reagierens zu lokalisieren ist, hängt von der persönlichen Konstitution der Sertanejos ab. Sie liegt zum Teil sehr hoch; und in einigen Fällen gelingt es dem Ehrenkodex überhaupt nicht, jemanden zur Reaktion anzustacheln. Vgl. hierzu die Gestalt des Fabiano in Vidas sêcas von Graciliano Ramos (Rio 1938).

98 In der Darstellung des Patrick Mullahy (Édipo: mito e complexo, Rio 1962, trad. de Álvaro Cabral, S. 66) ist für Sigmund Freud der Sadismus „uma fusão dos instintos eróticos e dos instintos destrutivos dirigidos para fora, na qual a destrutividade tem o caráter de agressividade. O masoquismo representa a fusão dos instintos eróticos e dos instintos destrutivos, voltada para a própria pessoa, sendo sua finalidade a autodestrução". In einer Anmerkung seines Aufsatzes Die sexuellen Abirrungen, Bd. V der Ges. Werke, Imago, London 1942, S. 57, nennt Freud diese 
Abart des Masochismus den „sekundären Masochismus“, als ein vom "primären (erogenen) Masochismus" zu unterscheidendes Phänomen. Der sekundäre Masochismus stellt eine Umkehr des im Leben nicht verwandten Sadismus zu der eigenen Person dar. Eingehender behandelt Freud dieses Problem (vor allem die ökonomische Frage) in Bd. XII der Ges. Werke, S. 369-383. Wie sich schon aus der Definition des Ursprungs von Sadismus und Masochismus schließen läßt, bilden beide Formen stets ein gleichzeitig vorhandenes Gegensatzpaar (Die sexuellen Abirrungen, S. 59). Vielleicht besteht eine Beziehung zwischen ihnen und der Bisexualität des Menschen. Erich Fromm sagt, daß Personen, die stark von diesem Gegensatzpaar beeinflußt seien, einen „sadomasochistischen Charakter" (einen „symbiotischen Charakter") hätten, der im allgemeinen als „autoritärer Charakter" zu erkennen sei (Fromm nennt denjenigen Sadomasochisten "autoritär", den man als normal - d. h. nicht neurotisch - ansehen könnte). Siehe über diese Theorie das Kapitel „Autoritarismo“ in Édipo: mito e complexo, S. 291-292, von Patrick Mullahy. Auf Ausbrüche des Sadismus in den beiden Gesellschaften Nordostbrasiliens ist schon häufig hingewiesen worden (siehe dazu die Ausführungen Gilberto Freyres in Casa grande E senzala, Vol. II, bes. S. 469-472, und die in der Literatur über den Nordosten üblichen Beschreibungen der „Brigas de feira“). Wie stark die masochistischen Tendenzen sind, können wir auf geistigem Gebiet aus der ewigen Wiederholung von Floskeln wie „o nosso Nordeste desprezado e bom“ ersehen, die voller Koketterie vorgebracht werden. Man denke auch an die große Anzahl von Volksgeschichten über das Elend, an die vielen "Lamúrias", die genußvoll die Erniedrigungen der Sertanejos beschreiben.

99 Moralische Begriffe im Sertão werden je nach der politischen Opportunität relativiert. Was der Autorität nützt, ist „gut“. (Siehe über die soziologische Relevanz von Begriffen wie Gut und Böse: Emílio Willems, Uma vila brasileira, São Paulo 1961, S. 48, eine Studie, die sich auf ein Landstädtchen im Staate São Paulo bezieht.)

100 Rui Facó, Cangaceiros e fanáticos, S. 9-10, schreibt: "Se o têrmo ,Cangaceiro' é usado comumente nos sertões para designar os participantes dos bandos de insubmissos que pegam em armas para viver de assaltos, e os próprios componentes dêstes bandos se identificam como cangaceiros, o mesmo já não ocorre com o têrmo ,fanático'. Esste veio de fora, dos meios cultos para o sertão..." "Mas o têrmo tem sido amplamente adotado para designar os participantes daquêles núcleos de insubmissos do campo [der Autor bezieht sich auf die Conselheiristas von Canudos und auf die Gläubigen des Padre Cícero und des Beato Lourenço] generalizando-se nacionalmente. É com estas restrições que o empregamos aqui."

101 Sehr viele Cangaceiros - insbesondere, wenn sie nicht selbst eine Bande leiten - sind dem normalen psychologischen System im Sertão noch so sehr verbunden, daß ihr Eintritt in den Cangaço nicht zur bedingungslosen Rebellion führt. Sie ersetzen ihren ehemaligen Herrn durch einen neuen, durch ihren Führer. Es bleibt ihnen die Möglichkeit, sadistischen Tendenzen freien Lauf zu lassen. Niemand wird ihnen (zumindest nicht zu Zeiten Lampiãos) verbieten, grausam zu morden und zu vergewaltigen.

102 Die Passivität der Fanatiker gegenüber ihren Führern geht so weit, daß 
sie völlig auf die aktive Realisierung des Ideals der Sertanejos verzichten. Der Ehrenkodex des Sertãos, der ein Minimum an persönlicher Handlungsfreiheit sichert, existiert für sie nicht mehr. Selbst in sexuellen Fragen, in denen der Ehrbegriff die wichtigste Rolle spielt, verzichten die Sertanejos, die sich einer Fanatikergruppe angeschlossen haben, auf ihre Rechte und vernachlässigen ihre Pflichten. Waldemar Valente, Misticismo e região (eine Arbeit über den Sebastianismo in Brasilien), S. 81, berichtet von dem Fall des João Antonio Santos, des Sebastianistenführers von Pedra Bonita, der innerhalb von vierundzwanzig Stunden nach der (von ihm durchgeführten) Eheschließung die Bräute der Mitglieder seiner Gruppe entjungferte. Nach Luís da Câmara Cascudo, Dicionário do folclore brasileiro, S. 688, besaß er außerdem mehrere Frauen. Mauro Mota, Paisagem das sêcas, S. 109-110, erzählt von dem Beato Lourenço, daß er geschlechtlichen Verkehr mit zwanzig jungen Mädchen aus seiner Gruppe hatte, die extra für ihn ausgewählt worden waren. „Os pais consideraram privilégio a ,doação' das filhas na puberdade e o revezamento delas no refúgio aparelhado exclusivamente para recebê-las." Weder in Pedra Bonita noch bei Lourenço versuchten die betreffenden Ehemänner und Väter, ihre nach dem Ehrenkodex des Sertãos besudelte Ehre wiederherzustellen.

103 Siehe die Gestalt des Domício in Pedra Bonita, Rio 1938, und Cangaceiros, Rio 1953, von José Lins do Rêgo (ähnlich die Jagunços in Os sertões, Rio 1902, von Euclides da Cunha).

104 Häufig berufen sich die Volksdichter ausdrücklich auf ihre Zeitungslektüre, ihre einzige Quelle neben eventuellen persönlichen Kenntnissen von der behandelten Materie. Sie wollen die Genauigkeit des Textes in ihrem Folheto unterstreichen, wie z. B. João José da Silva in A morte de Marreco:

Afirma o Diário da Noite... (112, 25)

Die Zeitung als Quelle zu nennen, ist zur Tradition geworden.

105 Einen Beweis für die Eigenständigkeit des Motivs "Jugend des Protagonisten " liefern die beiden Varianten des Valente-Folhetos História do valente Vilela. Genau derselbe Text erscheint einmal mit, einmal ohne Zusatz über die Jugend des Helden. Das eine Mal schildert der Verfasser den Kampf des Valente mit der Polizei, nachdem er seine Leser mit dem Charakter des Vilela bekannt gemacht hat, nachdem er die Jugendverbrechen erzählte, das andere Mal (in der Ausgabe von 1944) steht ausschließlich die Kampfepisode im Mittelpunkt. Einzige Bedingung für die Aufnahme einer Jugendepisode ist, daß in ihr genau die Eigenschaften eine große Rolle spielen, die später die Basis der Persönlichkeit des Protagonisten ausmachen. Im Falle der Cangaceiros handelt es sich dabei stets um die Tapferkeit.

106 In den beiden Folhetos, die Chagas Batista 1904 und 1907 schrieb, also vor dem Text, aus dem diese Strophe stammt, steht noch nichts vom 2. November als Geburtstag des Cangaceiros. Dieses Datum tauchte erst auf, als Silvinos Karriere schon abgeschlossen war, als man seine Bedeutung für den Cangaço abschließend betrachten konnte, im Jahre 1915.

107 Diese Begebenheiten schildert Leandro Gomes de Barros in O nascimento de Antônio Silvino. 
108 Der Volksdichter selbst zieht in der folgenden Strophe diese Parallele, erläutert, warum er die Szene beschrieben hat:

Devido a êsse exercício

Que em pequeno eu tinha tido

Uma onça me emboscou

$\mathrm{E}$ deu o bote perdido

Se não fosse meu manejo

Ela tinha-me comido. (22, 133-138)

109 Vgl. das ABC do Nicandro, Letra C:

Com dois mêses, já falava

Demonstrando inteligência...

(Gustavo Barroso, Ao som da viola, S. 378). Barroso bemerkt dazu: „Os meninos prodígios, que falam, lêem, escrevem, doutrinam ou profetizam na mais tenra idade são comuns em todos os folclores do mundo. Segundo Plínio, por exemplo, um filho de Creso... vaticinou aos seis mêses de nascido. A Vida de Santo Antônio refere-se a outro que falou no bêrço. $\mathrm{O}$ Visconde de Puymaigre faz notar traços idênticos nos antigos cantos catalães e provençais." In den Folhetos des Sertãos sind die frühreifen Kinder jedoch zumeist keine Wunder an Intelligenz, sondern an „Valentia".

110 A vida de Antônio Silvino, Ausgabe von 1904, Verse 9-18.

111 Darüber, daß seine Eltern ihn Arzt oder Advokat werden lassen wollten, berichtet Manuel Pereira Sobrinho in seiner História completa de Lampião e Maria Bonita, Verse 73-76; über Virgulinos Aufenthalt im Priesterseminar schreibt der anonyme Autor der História do Capitão Lampião, Mario de Andrade, Romanceiro de Lampião, S. 89.

112 Antônio Silvino hatte wahrscheinlich drei Brüder (Rodrigues de Carvalho, Serrote Prêto, S. 340), Lampião vier Brüder und vier Schwestern (Rodrigues de Carvalho, Serrote Prêto, S. 90).

113 Über den ganzen Fragenkomplex der Ambivalenz der Gefühle gegenüber Verwandten siehe: Sigmund Freud, Totem und Tabu, Bd. IX der Ges. Werke, Imago, London 1940, S. 26-92.

114 So in dem Folheto As aventuras do valente Josué, wo der Verfasser in einem "Argumento", das er nach Art der europäischen Renaissance- und Barockdichter und nach dem Vorbild iberischer Volksbücher seinem Gedicht vorwegstellt, erklärt, er wolle die Geschichte eines jungen Mannes erzählen, der "por morte de seu pai tornou-se cangaceiro".

115 Texte über Duelle parallelisieren die Kämpfenden miteinander. Strophenlang wird beschrieben, wie die Kontrahenten gleichzeitig hochspringen, wie sie gute Chancen vergeben, wie sie einen Kugelregen auf sich herabfallen sehen, wie sie gleich stark zu sein scheinen und wie dann schließlich der Cangaceiro Sieger bleibt, wie es ihm gelingt, den Gegner zu töten. Diese Schilderungen sind völlig unrealistisch, solche Szenen dürften im üblichen Cangaçoleben kaum vorgekommen sein. Mit Sicherheit sahen die Cangaceiros nicht ruhig zu, wenn ihr Chef an einen gleich tapferen und gewandten Gegner geriet, sie griffen ein und brachten den Übermütigen um. Das berühmteste Duell im Zyklus der Cangaceiros ist der historische - Kampf zwischen Antônio Silvino und Nicácio aus Trapiá. Er wurde von Francisco das Chagas Batista, Leandro Gomes de Barros und noch vierzig Jahre nach dem Ereignis von Cesário beschrieben 
(in: O encontro de Antônio Silvino com o valente Nicácio na vila de Trapiá).

116 Berühmte Beispiele solcher summarischen Gefechtsbeschreibungen sind die Verse Leandro Gomes de Barros' (Cálculos de Antônio Silvino) und Francisco das Chagas Batistas (História completa de Antônio Silvino) über den Kampf vom Surrão, den Antônio Silvino gegen eine zahlenmäßig weit überlegene Polizeitruppe durchzustehen hatte.

117 Diese Episode steht in der História completa Chagas Batistas. Der Cangaceiro hatte die Truppe des Tenente Maurício geschlagen - es ist übrigens derselbe Maurício, dessen willkürliches Betragen José Lins do Rêgo in den Romanen Fogo Morto, Rio 1943, und Pedra Bonita, Rio 1938, schildert -, als folgendes geschah:

Seis minutos mais ou menos

Depois que os tiros cessaram

Dois soldados corajosos

Do alferes* se aproximaram

Do dinheiro que êle conduzia

Então êles se apossaram. $\quad(12,1333-1338)$

118 Ahnliche Verse finden sich auch in von Mário de Andrade, Romanceiro de Lampiäo, S. 94-95, zitierten Passagen über Lampião. Die Gefährten werden mit Phantasienamen vorgestellt, mit symbolisch gemeinten Namen, wie Onça Brava und Dragão. Genau die gleichen Verse, mit nur wenigen Varianten, zitiert übrigens schon Gustavo Barroso, Ao som da viola, S. 326-328. Wie üblich, gibt er seine Quelle nicht an. Es handelt sich bei den Strophen wohl um ein Gedicht über Antônio Silvino, denn es ist von Tempestade als "mein Gevatter" die Rede. Wahrscheinlicher Autor beider Textversionen ist Leandro Gomes de Barros.

119 Gustavo Barroso, Heróis e bandidos, S. 259.

120 Man beachte hier die Identifizierung der Gefährten Antônio Silvinos mit ihrem Chef. Sie müssen sein Schicksal teilen. Das Motiv des verwunschenen Ochsen, das Francisco das Chagas Batista in diesen Versen aufgreift, stammt aus der Tradition der epischen Volksdichtung Nordostbrasiliens. Geschichten über „bois misteriosos“ sind in der Folhetoliteratur häufig, genau wie in Emboladas (am bekanntesten hier der „Boi Surubim").

121 Auch andere Volksdichter, die über die Gefangennahme Antônio Silvinos schrieben, lassen den Cangaceiro durch ominöse Vorzeichen von seinem unabwendbaren Geschick wissen. In dem Folheto Prisäo de Antônio Silvino von einem unbekannten Verfasser erzählt Silvino, wie er sieben Tage vor dem 28.11. - sieben ist eine unheilvolle Zahl - von einem Haus geträumt habe, das wahrscheinlich ein Gefängnis sein sollte. Dasselbe Motiv findet sich bei Leandro in O leão na jaula, einem Folheto übrigens, das den Untertitel trägt "Antônio Silvino capturado pelo valente oficial da polícia pernambucana, tenente Teófanes", ohne daß auch nur ein einziges Mal von dem Offizier die Rede wäre. Wieder eine völlige Ignorierung der Rolle, die die Gegner der Cangaceiros spielten.

122 Dieser Vers bezieht sich auf die vorher beschriebenen bösen Vorzeichen.

* Maurício war nicht „alferes“, Fähnrich, sondern „tenente“, Leutnant. 
Er unterstreicht die Entschlossenheit Antônio Silvinos, gegen das Schicksal anzukämpfen.

123 Joaquim Moura ist der einzige Gefährte, der bei dieser Episode mit Namen genannt wird. Der Verräter bleibt anonym.

124 Die Bezeichnung "Freund" bindet Joaquim Moura noch enger an seinen Chef.

125 Manuel Pereira Sobrinho beschreibt auch die äußere Erscheinung Maria Bonitas genau nach den im Zyklus der Liebesgeschichten herrschenden Traditionen:

Lampião era de aço

Porém diante a beleza

Daquela mulher mimosa

Com um porte de princesa

Cabelos e olhos grandes

Parecendo uma duquesa

Morena côr de canela

Dessas que o vento palpita

Muito bem feita de corpo

Lábios da côr de uma fita

Disse Lampião: - Te levo

Minha "Maria Bonita“. (67, 611-672)

Maria Bonitas Schönheit ist so unwiderstehlich, daß Lampião sich sofort in sie verliebt. Auch dieses Motiv stammt aus dem Großen Zyklus der Liebesgeschichten. Die Liebe stellt sich stets sofort ein und wird erwidert, wie z. B. in dem Folheto Julita e Galdino von Apolinário:

Galdino avistou Julita

Ficou impressionado

Julita do mesmo jeito

Ficou com o ar mudado

Ninguém sabia dos dois

Qual o mais apaixonado. (105a, 25-30)

126 Optato Gueiros, Lampião, S. 258-260, veröffentlichte neun Strophen zu je sieben Versen, die von Lampião selbst gedichtet sind. Pereira Sobrinho zitiert folgende Strophe:

Tive também meus amores

Cultivei minha paixão

Amei uma flor mimosa

Filha lá do meu sertão

Sonhei de gozar a vida

Bem perto à prenda querida

A quem dei meu coração. $(67,935-941)$

127 So bei Beschreibungen von Streitigkeiten zwischen verfeindeten Personen und bei Gefechten, die sehr bekanntgeworden sind. Wie genau sich in diesen Fällen die Volksdichter an die geschichtlichen Ereignisse halten, geht aus einer Untersuchung von Veríssimo de Melo, $\mathrm{O}$ ataque de Lampiăo a Mossoró através do romanceiro popular, hervor. Der Verfasser verglich Zeitungsmeldungen und Augenzeugenberichte über den Angriff Lampiãos auf Mossoró im Jahre 1927 mit Folhetos von Volksdichtern. 
Die Arbeit Melos verliert viel von ihrem Wert dadurch, daß der Verfasser nicht erläutert, was er unter "romanceiro popular" versteht; auch Texte von Intellektuellen nahm er in seine Untersuchung auf, eine Ausweitung des Begriffes Volkspoesie, die sicher zu weit geht. Volksdichter ist man nicht dadurch, daß man in Sextilhas oder Setilhas schreibt.

128 Sie stehen in der História completa de Antônio Silvino von Francisco das Chagas Batista und in Tôdas as lutas de Antônio Silvino von Leandro Gomes de Barros. Über einen Kampf zwischen Lampião und einem Jaguar schrieb ein unbekannter Verfasser, der von Mário de Andrade zitiert wird (Romanceiro de Lampiäo, S. 98-99) und dessen Text im Verlag des Chagas Batista veröffentlicht wurde. Die weitgehende Übereinstimmung mit den Versen aus der História completa dürfte auf eine nachträgliche Anpassung des Chagas-Batista-Textes an die Lebensgeschichte Lampiãos zurückzuführen sein.

Eine Variante eines Kampfes zwischen einem Cangaceiro und einem gefährlichen Tier bietet das Folheto Antônio Silvino abençoado pelo Padre Cícero... Der Gegner ist eine giftige Schlange.

129 Als Beispiel für die Unbekümmertheit der Volksdichter gegenüber dem Delikt Mord mögen folgende Verse gelten, die geschrieben wurden, als Lampião vom Padre Cícero zum Hauptmann ernannt worden war:

Não serei mais Lampião

Sou capitão Virgulino

Nem também sou ladrão

Só fico sendo assassino

Troquei velhas profissões

Por tres bonitas galões

Da polícia que destino! $\quad(70,427-432)$

Der Cangaceiro ist "nur" noch Mörder, das Räuberhandwerk hat er aufgegeben!

130 Es gibt mehrere Folhetos, die den stolzen Ausspruch Antônio Silvinos: ...E até me glorio em ser

Da honra um defensor, (32,101-102)

an einem Beispiel aufzeigen wollen. Solche völlig imaginären Episoden stehen, breit dargestellt, in Texten wie As bravuras de Antônio Silvino em honra de um velho amigo von Luís Rodrigues Lira (es gibt von diesem Folheto eine ältere Variante, As bravuras de Antônio Silvino e um casamento trágico. Die Verse stimmen bis auf wenige stilistische Abweichungen miteinander überein. Die ältere Ausgabe hat einen mehr dokumentarischen Charakter; so werden die Namen zweier Gefährten Silvinos genannt, Rio Prêto und Criança), Uma das maiores proezas que Antônio Silvino fêz no sertão pernambucano von José Camelo und Manuel Pereiras Romance da vida de Antônio Silvino. Der Name Silvinos in diesen Geschichtchen ist kaum mehr als ein Anreißer für die Käufer der Folhetos, denn der Cangaceiro steht nur am Rande des Geschehens und könnte durch jeden Valente ersetzt werden. Das Hauptinteresse der Dichter richtet sich auf die Liebesintrige, die durch Silvinos Erscheinen als strafender Gerechtigkeitsfanatiker gelöst wird.

131 Mário de Andrade schreibt in seiner Untersuchung Romanceiro de Lampião, S. 103, daß Verse über sexuelle Verbrechen nur sehr selten in Folhetos zu finden seien. Es fragt sich, was Andrade unter "sehr selten" 
versteht. Es gibt kaum einen Autor, der nicht solche Verse gedichtet hat, wenn er ein Folheto über Lampião schrieb. Wie sehr die Volksdichter diesen Cangaceiro mit Sexualverbrechen assoziieren, beweist die Tatsache, daß nach seinem Tode vorwiegend von solchen Episoden die Rede ist.

132 Das Fehlen exakter, dokumentarischer Angaben über die erzählte Episode, des Namens der Stadt z. B., unterstreicht die Absicht des Autors, ein „typisches“ Ereignis zu erzählen.

133 Mário de Andrade, Romanceiro de Lampião, S. 103.

134 Bei dem Protagonisten dieses Folhetos handelt es sich keineswegs um einen Cangaceiro, sondern um einen Valente.

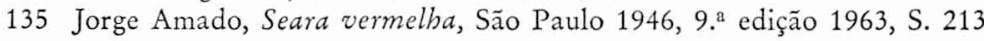
$-216$.

136 Es erscheint zum erstenmal in Chagas Batistas História completa de Antônio Silvino:

Valendo-se do meu nome

Estão hoje os cangaceiros

Que matam para roubar

Viajantes e fazendeiros

Eu tenho por inimigos

Todos êsses desordeiros. $\quad(12,121-126)$

137 Man bemerke wieder einmal, mit welcher Nonchalance Lampião, der in diesem Text ja einen "guten" Sertanejo darstellt, darüber spricht, daß er ein Mörder sei!

138 Dieser Vers spielt auf die sehr bekannte, häufig zitierte Strophe eines Volksliedes über den Verbrecher Cabeleira an. In Presença do Nordeste na literatura von José Lins do Rêgo lautet sie folgendermaßen: Feche a porta, gente/Cabeleira aí vem/Vem matando menino/E velho também. In anderen Versionen wird das Wort „velho" durch "môça" oder "mulher" ersetzt.

139 Oft wird Lampião konsequenterweise von den Volksdichtern schon gelobt, wenn er nichts tut, wenn man also auch nicht über ein weiteres Verbrechen berichten muß:

$\mathrm{Na}$ cidade de Capela

Entrou não matou ninguém ... (67, 685-686)

Diese Tatsache ist so außergewöhnlich, daß der Verfasser glaubt, besonders auf sie hinweisen zu müssen.

140 Diesen Autor zitiert Mário de Andrade, Romanceiro de Lampião, S. 89. Wie berüchtigt die Gegend des Pajeú war, geht aus den beiden ersten Versen des Folhetos O monstro do Pajeú von Manuel Camilo dos Santos hervor:

No tempo que o Pajeú

Era o pai do banditismo... (111, 1-2)

Siehe auch Rodrigues de Carvalho, Serrote Prêto, S. 79.

141 História do Capitão Lampião, von einem anonymen Autor, zitiert bei Mário de Andrade, Romanceiro de Lampiäo, S. 89:

Dos sertões de Pernambuco

É natural Virgulino,

Nasceu no mesmo torrão

Em que vivera Silvino,

Nas margens do Moxotó 
Onde o homem vive, só

Pensando em ser assassino.

Auch hier wieder die Assoziation Moxotó - Mördergrube!

142 Im Folheto Lampião arrependido da vida de cangaceiro von Laurindo Gomes Maciel (die Begründung dafür, warum der Autor Lampião zus Ingàzeira stammen läßt, fehlt auch diesmal nicht):

Lampião é natural

Da cidade de Ingàzeira

Foi criado em Pernambuco

Naquelas zonas guerreiras

De cacête e canivete... $(48,15-19)$

143 Ein anonymer Autor, zitiert von Mário de Andrade, schreibt (Romanceiro de Lampião, S. 89):

Lampião era parente

Do grande Antônio Silvino...

144 Bei der Beschreibung der Machtfülle eines Cangaceirochefs geraten die Volksdichter bisweilen in wahre Ekstase. In O silêncio de Antônio Silvino schildert Leandro Gomes de Barros, wie sich sogar die Natur der Herrschaft Silvinos beugt:

Admira todo o mundo

Quando eu passo em um lugar

Os matos afastam os ramos

Deixa o vento de soprar

Se perfilam os passarinhos

Os montes dizem aos caminhos:

- Deixai Silvino passar $(28,15-21)$

Die Autorität Silvinos und Lampiãos fordert Unterwerfung auch von ihren weniger mächtigen Cangaçokollegen. Der Herrscher Antônio Silvino verurteilt alle die, die es noch nicht so weit gebracht haben wie er. Die Dialektik des Symbols der Cangaceiros wird deutlich durch Verse wie diese, aus Leandros As proezas de Antônio Silvino:

Quando eu pego um cangaceiro

Tiro-lhe o nó da goela

O fígado sai pelas costas

O bofe pela canela

As tripas pelo pescoço

A sangue que sai é grosso

Que parece cabidela.* $\quad(26,64-70)$

und auch durch diese Strophe aus dem Silêncio ...:

Esses cangaceiros grandes

Que existem no sertão

Em qualquer parte que me vêem

Falam com o chapéu na mão

Se precisam me falar

Perguntam antes de chegar:

- Dá licença, capitão? (28, 22-28)

Man sieht, in welch hohem Maße die Sertanejos durch eine Identifizie-

* Diese Strophe zeigt übrigens deutlich stilistische Einflüsse aus der Cantoria repentista. 
rung mit dem Cangaceiro die Bedeutungslosigkeit ihrer eigenen Position kompensieren können. Die ihnen täglich auferlegte Geste der Demütigung, die Pflicht, Höhergestellte um Erlaubnis zu fragen, wenn man etwas sagen möchte, muß nun von den anderen ausgeübt werden. Jetzt sind es die armen Sertanejos, vor denen man sich verneigt.

145 In A política de Antônio Silvino berichtet Francisco das Chagas Batista von den Projekten des Cangaceiros für den Augenblick, da er die Macht über den Nordosten besitzen werde. Hier werden Pläne verkündet, die über den üblichen Austausch von Persönlichkeiten hinausweisen:

\footnotetext{
A terra será em comum

Todos se aposserão

Ninguém pagará mais foro

Para fazer plantação

Não haverá nêsse tempo

Nem criado nem patrão.
}

Será geral igualdade

Todos hão de ter direito

O que foi rico terá

Ao que foi pobre respeito

O graúdo senhor de engenho

Irá trabalhar no eito. $(23,241-252)$

Aber der Leser darf nicht vergessen, daß das nur Wahlversprechen sind, Utopien, aufgestellt, als Silvino eben noch nicht der Beherrscher des Sertãos war. Und so mischen sich in dieses revolutionäre Sozialprogramm auch Forderungen wie die Rückverschiffung der Neger nach Afrika. Wenn später Szenen beschrieben werden, in denen Silvino sein Ziel schon erreicht hat, ist von diesem Programm nicht mehr die Rede. Auch bei Francisco das Chagas Batista ist seine Herrschaft keine Stufe einer fortschrittlichen Entwicklung.

146 Bemerkenswert ist, daß die Volksdichter nach dem Tode der Cangaceiros bei der Beschreibung des Kampfes gegen Himmel und Hölle kein einziges Mal davon berichten, daß über Lampião und Silvino zu Gericht gesessen wurde. Zu Gott und zum Teufel gehen sie, um einen Gegner zu suchen, nicht, um sich zu verantworten. Keiner von ihnen unterwirft sich, seinen Prinzipien getreu, einer fremden Gerichtsbarkeit.

147 Diese Kämpfe werden so beschrieben, wie es den jeweiligen Schemata in dem Zyklus der Cangaceiros entspricht. Kämpfe zwischen dem Cangaceiro und einem einzelnen Teufel folgen dem Schema der Duelle. Gefechte gegen eine Gruppe von Teufeln weisen eine Anzahl von Elementen auf, die aus dem Bereich der Schematisierung im Zyklus des Teufels stammen; so besteht z. B. die Truppe der Hölle aus Negern, die Teufel verbrennen sich an den großen Kochtöpfen, usw.

Die Beschreibung des Konfliktes zwischen Höllenwächter und Cangaceiro orientiert sich an einem Handlungsschema aus dem Zyklus der Valentes. In Valente-Geschichten muß der Protagonist einen "Vigia“ besiegen, ehe er die Fazenda seines Gegners betreten kann. Der Wächter wird stets zuerst geschmäht und dann niedergeschlagen oder getötet. 
148 Die Verfasser lassen ihrer Phantasie freien Lauf, wenn sie darüber nachdenken, was schlecht ist. Es läßt sich kein einheitliches Kriterium feststellen, wenn es um konkrete Dinge geht. Manchmal scheinen die Verse Sozialkritik zu enthalten, aber es ist schwierig zu sagen, mit welcher Seite der Volksdichter sympathisiert. Oft weiß man auch nicht, ob seine Aussagen ironisch gemeint sind, wie z. B. in den folgenden Versen aus dem Folheto $A$ eleição no inferno von Gonçalves Oliveira:

... Só tem vaga no inferno

Pra homem capitalista

Como bem pra doutor

Mecânico e aviador

Engenheiro e motorista.

Mas dêsse pessoal

Não agüento desafôro

Trabalhador de alugudo

Mulher que possui namôro

Eu já tirei do caderno

Só entra no meu inferno

Quem tiver dente de ouro. (42, 192-203)

Abneigung gegen den technischen Fortschritt, Beschimpfung des angestellten Arbeiters (ein übliches Motiv in der Volkspoesie Nordostbrasiliens: wer für einen anderen arbeitet, taugt nichts. Diesen Vorwurf macht Lampião sogar dem H1. Petrus) und daneben Verse, die die traditionelle Moral verteidigen.

Ein anderer Autor, Francisco Guerra Vascurado, der unter dem Pseudonym Chico Goiano schreibt und der (laut Orígenes Lessa) von sich sagt, er sei Kommunist und Spiritist, hat etwas genauere Vorstellungen von dem, was scblecht bedeutet. Er bringt Lampião mit ihm als böse erscheinenden Personen aus der Zeitgeschichte zusammen und dehnt den Begriff des Bösen auch auf einige Phänomene der Wirtschaft aus:

Disse Lampião: - Sou chefe

Sou o grande maioral

Destronei o Satanás

Meu poder é sem igual

Sou eu o chefe supremo

De tudo que é infernal.

Hitler é meu general

Por ser o pai do Nazismo

E Mussuline* também

O general do Facismo

Somos os braços fortes

Do mundo, capitalismo. $\quad(40,97-108)$

* Ein auslautendes unbetontes „e“ wird im Brasilianischen wie „“ ausgesprochen. 

Sou chefe de todos trustes
Sou o rei dos armamentos
Tenho milhares de emprêsas
Dando monstros rendimentos
O câmbio negro é meu filho
Para cumprir meus intentos. (40,151-156)

149 Eine kurze Abhandlung über den Zyklus des Teufels ist der Aufsatz „O diabo na literatura de cordel“ von Luís Santa Cruz. Der Autor zählt auch Beispiele auf für die Annäherung zwischen Teufel und Cangaceiro.

150 Die Erklärung, ob Lampião tot sei oder nicht.

151 João José da Silva, ein bekannter Volksdichter und einer der größten Verleger von Folhetos, sagte mir, daß die Mehrzahl der von ihm verlegten Autoren Spiritisten sei. Die Volksdichter führen spiritistische Sitzungen also nicht nur in ihre Folhetos ein, um durch einen literarischen Kunstgriff die immerwährende Gültigkeit eines Symbols zu beweisen, sondern weil sie wirklich der Meinung sind, daß die Grenzen zwischen Leben und Tod nicht exakt zu ziehen seien. In einem anderen Zyklus, in dem des Padre Cícero, verzichten sie allerdings auf die Hilfe des Spiritismus, um die Macht des vom Protagonisten vertretenen Symbols zu demonstrieren. Innerhalb des Großen Religiösen Zyklus, bei einer Figur, die eng mit der Katholischen Kirche assoziiert wird, beschränken die Verfasser sich darauf, den Padre in Träumen weiterleben zu lassen.

152 Und selbst wenn der Sertanejo die absolute Gewißheit haben kann, daß der Cangaceiro gestorben ist, so mißt er dem Tode wenig Bedeutung zu. In den Folhetos sterben die Teufel zu Dutzenden. In vielen Fällen läßt sich der Tod mit Niederlage gleichsetzen, vor allem, wenn die Protagonisten Symbolkraft besitzen.

153 Für den Sertanejo ist selbstverständlich alles das wahrscheinlich, was für ihn persönlich denkbar ist. Der Kontrast zwischen seiner und unserer Vorstellungswelt ist es, der uns seine Werke trotz all ihrer schon ausgiebig vorhandenen Reflexion "naiv“ erscheinen läßt.

154 Siehe hierzu den Aufsatz "Roland no Brasil" von Câmara Cascudo, in: Motivos da literatura oral da França no Brasil.

155 Eine genaue Aufführung dieser Editionen findet sich bei Câmara Cascudo, Dicionário do folclore brasileiro, S. 185.

156 Oft werden die Valentes in ihrem Zyklus "Cangaceiros“ genannt, ohne jede Berechtigung. Die meisten Dichter differenzieren jedoch sehr genau.

157 Die Figur des Valente ist im ganzen landwirtschaftreibenden Nordosten heimisch; es wird kein Unterschied zwischen dem Sertão und der „Zona de mata" gemacht. In einigen Folhetos wird auch das Amazonasgebiet miteinbezogen. Nur in den Hauptstädten ist der Valente kaum zu finden. Über weitere Einzelheiten des Begriffes „Valente“ siehe den Aufsatz "Heróis e valentes no conceito do povo", in: Estudos de folclore cearense, S. 67-76, von Eduardo Campos.

158 Ein Vorgang, der sich sehr eindringlich in einem weiteren heroischen Zyklus, in dem der berühmten Verbrecher, wiederholt. Es lohnt sich hier nicht, diese Folhetogruppe eingehender zu untersuchen, weil sie in allen Einzelheiten den Normen des Zyklus der Cangaceiros folgt und kaum eigene Elemente ausgebildet hat. 
Besonders interessant in dem Zyklus der berühmten Verbrecher ist die Trilogie João José da Silvas über den pernambucanischen Räuber und Mörder Marreco. In ihr bekämpt der Protagonist den Chef der Hölle, Lampião. Er schafft es, ihn zu entmachten, wird dann aber in dem Heft A volta de Lampião e a brigada de Marreco wieder von dem Cangaceiro abgesetzt. Die Fusion Marreco-Lampião ist vollständig durchgeführt. In allen Einzelheiten folgt der Verbrecher bei seinem Versuch, in die Unterwelt einzudringen, dem Handlungsschema, das die Leser aus dem Folheto A chegada de Lampiäo no inferno kennen. Die Dialektik von Rebellion und Ausübung der Macht wird in dieser Trilogie gleich zweimal vorexerziert.

Daß als Identifikations-Ersatz für den Teufel gleich von Anfang an die Gestalt des Cangaceiros genommen werden kann, um zu beweisen, daß ein rebellischer Protagonist schlecht ist, zeigt auch ein Text aus dem Zyklus der pikaresken Antihelden, das Folheto Visita de Cancão de Fogo ao inferno. Wieder tritt Lampião an die Stelle des Satans.

159 Der Valentão weiß, daß er mit seiner Tochter auch seine Stellung verlieren wird. So bricht in vielen Folhetos der Konflikt zwischen ihm und dem Valente aus, weil er seiner Tochter verbietet, Männer anzuschauen, aus Angst, sie könne sich verheiraten. In O beroísmo de Petronilha $e$ as bravuras de João de Deus von Luís de Lira zwingt der Fazendeiro seine Tochter, stets mit einer Maske umherzulaufen.

160 So heißt der gute Valente in O beroismo de Petronilha e as bravuras de João de Deus sinnfällig João de Deus und sein Antagonist, der Fazendeiro, Dr. Chico do Diabo.

In dem Folheto $\mathrm{O}$ encontro de dois errados braucht der Verfasser 23 Strophen, um die Bosheit eines Zuckerrohrpflanzers und seine Häßlichkeit zu beschreiben (zu allem Überfluß ist der Coronel auch noch Portugiese!).

161 Ein Überblick über das in den Geschichten über die Treue einer Ehefrau regelmäßig angewandte Handlungsschema findet sich in der Arbeit von A. Wallensköld, Le conte de la femme chaste convoitée par son beaufrère, Helsingfors 1907. Der Verfasser geht dabei auch auf die Verbreitung dieses Themas in den verschiedenen Literaturen ein. Wie konsequent die Sertanejos für die These eintreten, die Ehe sei heilig und müsse bedingungslos geschützt werden, zeigt die erstaunliche Tatsache, daß ich in der Flut von Liebesgeschichten nur zwei Folhetos kenne, die einen Ehebruch zu akzeptieren scheinen (es handelt sich um Mariana e o capitão de navio von João Bernardo da Silva und um Óscar e Aurora von einem unbekannten Autor). Aber auch hier geben sich die beiden Frauen ihren Liebhabern völlig erst dann hin, als - plötzlich und unerwartet - ihre Ehemänner gestorben sind.

162 Eine Ausnahme macht die Figur der Maria Bonita. Sie ist völlig nach dem Vorbild der Liebesgeschichten dargestellt worden und bildet so einen schwer zu assimilierenden Fremdkörper in dem Zyklus der Cangaceiros.

163 Es ist interessant zu sehen, wie konsequent die Volksdichter sein können, wenn sie sich in einem Text auf die Seite des autoritären Prinzips gestellt haben. Dann verurteilen sie als Rebellen sogar den brasilianischen Freiheitshelden Tiradentes, wie in dem Folheto Conselhos e opiniôes von Sousa Lima.

164 Mit "Padrinho", Pate, wird der Padre Cícero üblicherweise angeredet. 
Diese Bezeichnung betont das familiäre Abhängigkeitsverhältnis zwischen Sertanejos und diesem Priester.

165 Uber den Padre Cícero existiert eine reichhaltige Literatur. Siehe die Liste der wichtigsten Bücher bei Câmara Cascudo, Dicionário do folclore brasileiro, S. 550. Am besten orientiert sind folgende Werke: Xavier de Oliveira, Beatos e cangaceiros; Floro Bartolomeu (der Freund und Stellvertreter des Padre Cícero), O Juàzeiro do Padre Cícero; Lourenço Filho, Juàzeiro do Padre Cícero; Abelardo F. Montenegro, História do fanatismo religioso no Ceará.

166 Über den Besuch Lampiãos in Juàzeiro siehe: Luís Luna, Lampião e seus cabras, S. 61 (hier wird der Wortlaut des Offizierspatentes zitiert); Nertan Macêdo, Capitão Virgulino Ferreira Lampião, S. 109-111,191-192, 197-201; Edmar Morel, Padre Cícero o santo do Juàzeiro, S. 123-137.

167 Ein Panorama der Situation Nordostbrasiliens vom Jahre 1958 von Mauro Mota in Paisagem das Sêcas zeigt, daß sich im Inneren des Sertãos in den letzten fünfzig Jahren die Grundprobleme kaum verändert haben.

168 Graciliano Ramos, Vidas sêcas, Rio 1938.

169 Jorge Amado, Capitães da areia, Rio 1937.

170 In der südbrasilianischen Literatur findet sich in dem Roman $A$ viagem maravilhosa von Graça Aranha, Rio 1930, schon eine Szene, in der die Nordestinos auf den Kaffeeplantagen São Paulos sich von den anderen vor allem dadurch unterscheiden wollen, daß sie sich der Taten ihrer Cangaceiros (und besonders Lampiãos) brüsten.

171 José Lins do Rêgo, Pedra Bonita, Rio 1938, Cangaceiros, Rio 1953.

172 Mário de Andrade war der erste, der eine Abhandlung über den Zyklus des Lampião schrieb, "Romanceiro de Lampião“, in: O baile das quatro artes.

173 Das bekannteste Werk der brasilianischen modernistischen Literatur, das weitgehend auf Folklorematerial basiert - Material aus ganz Brasilien und nicht nur aus dem Nordosten -, ist neben Raul Bopps Cobra Norato, Rio 1931, der „Roman“ Macunaíma von Mário de Andrade, São Paulo 1928. Ausschließlich der nordostbrasilianischen Volksliteratur verbunden sind José Lins do Rêgo und Jorge Amado. Über die Auswirkungen seiner Beschäftigung mit der epischen Dichtung des Nordostens auf den Stil und die Romantechnik José Lins' schreibt der Literaturkritiker José Aderaldo Castello in "Memória e regionalismo" (Einführung in das Werk des José Lins do Rêgo, Erster Band der Gesammelten Romane, Menino de engenbo, etc. . . 7.a edição, Rio de Janeiro 1960): "Talvez o equilíbrio e a espontaneidade do romancista devam muito à naturalidade e à riqueza das narrativas folclóricas do Nordeste, ao seu processo expressivo. Há, de fato, em 'Menino de engenho', um capítulo sem dúvida fundamental para o estudo do processo de expressão do romancista, o capítulo XXI, em que fala de Trancoso e de Totonha, contadora de histórias. O tipo desta velha, tão frequente no Nordeste, e a reprodução do seu processo narrativo, sugere o próprio processo narrativo de José Lins do Rêgo. Isto nos lembra observação que êle mesmo fêz, ao falar sôbre aspectos da técnica do romance, quando afirmou, que, ao desejar um modêlo, buscava o exemplo nos processos de narrativa oral dos contadores e cantadores populares, do folclore nordestino. A leitura de 'Menino de engenho' 
dá-nos, assim, a idéia de quem pensa numa situação naturalmente evocada e consegue fixá-la na escrita com a mesma espontaneidade de uma exposição oral, isto é, de sua versão oral, que é quase uma confidência. Daí, entre outras coisas, a escassez de diálogo, que só é reconhecível no seu processo indireto. É mais um recurso da evocação que parte de dentro do romancista, de seu mundo íntimo, de sua vida emotiva, e se transfere para o leitor, confidente. Daí também outro aspecto já ressaltado, a ausência de argumento centralizador." (Menino de engenbo, S. XXIVXXV.)

José Lins do Rêgo schrieb den Stil der Volksdichter Nordostbrasiliens, weil er einen in jeder Einzelheit zutreffenden Eindruck seiner Heimat geben wollte, weil er nicht nur exakt die Gesellschaft der Region beschreiben wollte, weil er nicht nur die verschiedenen Zuckerrohrarten, die verschiedenen Arbeitsgänge eines Engenhos schildern wollte, sondern weil bei ihm auch der Ton stimmen mußte, weil er Prozesse und Situationen in der Sprache ausdrücken wollte, die im Leben des Nordostens verwandt wird.

Jorge Amado ahmte die Ausdrucksweise der Volksdichter aus anderen Gründen nach. Sie diente ihm als Mittel dazu, ein Publikum zu erreichen, das bisher nur von Repentistas und Poetas populares erfaßt wurde. Er machte sich durch seinen volkstümlichen Stil verständlich. Seine wichtigsten Quellen sind die ABCs (man beachte nur den Titel seiner CastroAlves-Biographie: $A B C$ de Castro Alves, São Paulo 1941) und die zumeist lyrischen Passagen von Desafios, wohl auch einmal Romanzen, und hier vor allem die „Nau Caterineta“. Von ihrer Technik übernahm er den Refrain, das laufende Wiederholen gleichlautender Sätze, stets als Abschluß eines Absatzes.

Wie genau die nordostbrasilianischen Autoren ihre Volksdichter kennen, läßt sich daraus schließen, wie häufig sie sie zitieren, wie oft sie eine Darstellung historischer Phänomene des Nordostens mit Versen von Poetas populares belegen. Besonders beeindruckend auch hier ist die Abhängigkeit José Lins do Rêgos von seinen volksliterarischen Quellen, so in dem Aufsatz $A$ presença do Nordeste na literatura. Ein ähnlicher Fall ist der des Polyhistors Gustavo Barroso. Bei einer Darstellung der Gründe für den Cangaço bezieht er sich überhaupt nur auf - meist falsche - Daten, die er Folhetos entnommen hat (siehe Heróis e bandidos).

174 Den Anfang machte der berühmte Film von Luís Barreto, O Cangaceiro, der auf Episoden aus dem Leben Lampiãos basierte.

175 Die konsequente radikale Übertreibung des Heroischen bis zum Anarchismus ist ein in der Volkspoesie Nordostbrasiliens häufig anzutreffender Prozeß. Auch die Bezeichnung „anárquico“ gehört zum festen Vokabular einer Cangaceirogeschichte. Das Wort ist ebenfalls sehr häufig anzutreffen in dem Zyklus der Valentes und in dem der moralisierenden Satiren. Es wird stets in einem verurteilenden Sinne benutzt.

176 Das eklatanteste Beispiel für die Unterstützung der Gesellschaft Nordostbrasiliens durch einen Symbolisten ist der schwülstige "Retirantes"Roman Luzia-Homem von Domingos Olímpio, Rio 1902.

177 Der kurz bevorstehende Weltuntergang ist eines der wichtigsten Motive des Großen Religiösen Zyklus in der Volkspoesie. Alles wird in den 
schwärzesten Farben gezeichnet. Dadurch sind manche Texte, vor allem aus dem Zyklus des Padre Cícero, sehr eindrucksvoll, weil man spürt, daß dies nicht nur bloße Fiktion ist, sondern daß der ehrliche Glaube des Volksdichters dahinter steht.

178 Zur Blütezeit des Cangaços und auch noch Jahre danach glaubte man fest daran, daß es den Cangaceiros wirklich gelingen werde, die Sociedade nordestina $\mathrm{zu}$ vernichten. Der Cangaço wurde zu einer fixen Komponente, wie Dürrezeit und Verelendung. Noch wenige Monate vor dem Tode Lampiãos schrieb Graciliano Ramos in seinem Aufsatz „Virgulino“, Viventes das Alagoas, S. 137-140: „Resta-nos Lampião, que viverá longos anos e provàvelmente vai ficar pior. De quando em quando noticia-se a morte dêle com espalhafato. Como se noticiasse a morte da sêca e da miséria. Ingenuidade."

179 Dieses Motto stammt aus Grande sertão - Veredas, 3. ${ }^{\mathrm{a}} \mathrm{ed}$. Rio 1963, von J. Guimarães Rosa, S. 20. In diesem. Werk wird das Symbol des Cangaceiros auf den Jagunço des mittleren Westens transponiert.

180 Die Bravura des Cangaceiros wurde sprichwörtlich. In Presença do Nordeste na literatura schreibt José Lins do Rêgo über den Literaturkritiker Sílvio Romero: „Âs vêzes fracassou ... mas sempre conservou ... a bravura de uma espécie de cangaceiro de letras." (S. 13)

181 Dieser Aspekt wird so sehr überbetont, daß Gilberto Freyre in seinem Standardwerk über den zuckerrohranbauenden Nordosten, in Casa grande E senzala, die Cangaceiros nur erwähnt, um auf ihre gesunde afrikanische Ernährung hinzuweisen (Bd. I, S. 60). Daß viele der Cangaceiros durch ihre Diät ein Beispiel für "vigor ou . . . beleza física" gewesen sein sollen, dies zu glauben, wird einem objektiven Menschen, der die Fotografien der Cangaceiros kennt, sehr schwerfallen.

182 Ramón Menéndez Pidal, El Cid Campeador, ed. Austral, Madrid o. J., S. 276.

183 Graciliano Ramos, Viventes das Alagoas, „Lampião“, S. 132. Die Sekundärliteratur über den Cangaço durchlief drei Phasen: die erste Gruppe von Büchern widmete sich den abenteuerlichen Biographien von berühmten Cangaceiros (so Xavier de Oliveira, Beatos e cangaceiros, und Gustavo Barroso, Heróis e bandidos); die zweite behandelte das Leben Lampiãos und versuchte dabei schon, nach dem Warum des Cangaços zu fragen (so z. B. Rodrigues de Carvalho, Serrote Prêto); die dritte und letzte schließlich konnte den Cangaço in seiner Gesamtheit erfassen, konnte nach seinem Verschwinden seine Ursachen und seine Manifestationen zu erklären versuchen. Aus der Vielzahl dieser interpretativen Werke, die in den letzten fünfzehn Jahren erschienen, seien nur Estácio de Lima, O mundo estranbo dos cangaceiros, und Rui Facó, Cangaceiros und fanáticos, genannt.

184 Rui Facó, Cangaceiros e fanáticos. Facó hält die Gelegenheit für eine Revolution im Nordosten für gekommen, weil um 1930 der Kapitalismus seinen Siegeszug im Sertão angetreten habe. Das beweise die Gründung einer Bank im Cariri-Gebiet!

185 Bezeichnenderweise geißeln die Volksdichter dabei mit Nachdruck die neuen Umgangsformen zwischen Söhnen und Vätern. Bei ihrer immer noch herrschenden Vorliebe für psychologische Probleme haben sie sehr richtig die Keimsituation späterer Rebellion erkannt. 


\section{B I B L IOG RA PH IE}

\section{A. FOLHETOS}

Bei der Reproduktion der Texte der Folhetos stützte ich mich auf das Vorbild M. Cavalcânti Proenças in Literatura popular em verso, Antologia, Tomo I, herausgegeben vom Centro de Pesquisas da Casa de Rui Barbosa. In den folgenden Fällen wich ich von den dort angewandten Kriterien ab:

1. Die Interpunktion der Originale wurde nicht beibehalten. Kommata, Ausrufungs- und Fragezeichen wurden nur gesetzt, wenn anderenfalls der Text mißverstanden werden könnte. Am Schluß jeder Strophe steht ein Punkt.

2. Vor jede direkte Rede wurde ein Doppelpunkt und Bindestrich gesetzt.

3. Die Anfangsbuchstaben eines jeden Verses wurden großgeschrieben.

4. Die Anführungsstriche, die einige Volksdichter setzen, um Regionalismen zu kennzeichnen, wurden weggelassen.

5. In allen Fällen wurde der - phonetisch nicht vorhandene - orthographische Unterschied zwischen "mal" und "mau" wiederhergestellt.

6. Unbetontes "O " und „ $\mathrm{e}^{\text {, }}$, die von den Volksdichtern häufig als "u“ und „i“ geschrieben wurden, habe ich, den Regeln der Orthographie folgend, wieder als "O" und "e" kopiert. Eine Ausnahme macht hier das Wort "se" (wenn, falls), das einige Male in der volkstümlichen Form "si“ (als Unterscheidung zum Personalpronomen) belassen worden ist.

In jedem Falle wurde die zur Zeit in Brasilien gültige Orthographie als Grundlage genommen.

Fünf Arten verschiedener Folhetogruppen sind in diese Bibliographie aufgenommen worden:

1. Folhetos aus dem Zyklus der Cangaceiros (Sekundärzyklus Antônio Silvinos);

2. Folhetos aus dem Zyklus der Cangaceiros (Sekundärzyklus Lampiãos);

3. Folhetos aus dem Zyklus der Cangaceiros (Texte, in denen Antônio Silvino und Lampião gemeinsam erscheinen);

4. Folhetos aus dem Zyklus der Cangaceiros (Texte, die weder Antônio Silvino noch Lampião behandeln);

5. Folhetos aus den anderen Zyklen der Volksliteratur Nordostbrasiliens.

Bei den ersten drei Gruppen führe ich sämtliche Texte an, die mir zur Verfügung standen, bei den beiden letzten nur die, die in dieser Arbeit erwähnt worden sind.

Die Titel der Folhetos sind nach dem Alphabet geordnet. Bei den näheren Angaben über die Texte wurden folgende Abkürzungen benutzt:
A Autor
E Verleger
L Verlagsort
D Datum der vorliegenden Auflage 
S. Anzahl der Seiten des Folhetos

Str. Anzahl der Strophen des Gedichtes

V. Anzahl der Verse in einer Strophe

Bem. Bemerkungen

Ein Strich bedeutet, daß keine Angaben vorlagen.

Als letztes wurde vermerkt, aus welcher Sammlung (COL) das betreffende Folheto stammt. Folgende Abkürzungen wurden für die Sammlungen, aus denen ich Texte verwerten konnte, verwandt:

BN Biblioteca Nacional, Rio de Janeiro

CFB Campanha para a Defesa do Folclore Brasileiro, Rio de Janeiro

CP Cavalcânti Proença, Rio de Janeiro

CPCRB Centro de Pesquisas da Casa de Rui Barbosa, Rio de Janeiro

DECA Departamento de Extensão Cultural e Artística, Recife

DMSP Discoteca Municipal, São Paulo

LEANDRO Sammlung Leandro Gomes de Barros im Centro de Pesquisas da Casa de Rui Barbosa, Rio de Janeiro

MDJr. Manuel Diégues Junior, Rio de Janeiro

OL Orígenes Lessa, Rio de Janeiro

RD Ronald Daus

SNB Sebastião Nunes Batista, Rio de Janeiro

Wurde das Folheto schon vom Centro de Pesquisas da Casa de Rui Barbosa katalogisiert, so gebe ich hinter der Bezeichnung der Sammlung, aus der es stammt, die Katalognummer an (CPCRB CAT NO ...).

1. Folhetos aus dem Zyklus der Cangaceiros (Sekundärzyklus Antônio Silvinos)

1. Antônio Silvino abençoado pelo Padre Cícero e arrependido da vida de cangaceiro. A: Cícero Cidrono de Nascimento; E: Tipografia Lima; L: Maceió; D: -; 15 S. 63 Str. zu 6 V.; Bem.: Mit Tinte geschriebene Notiz: Henrique Brandão Martins, 30/10/1915; COL BN.

2. Antônio Silvino e o negro Currupião. A: Francisco Alves Martins; E: Severino Semeão (sic!); L: -; D: —; 16 S. 79 Str. zu 6 V.; Bem.: -; COL RD.

3. Antônio Silvino no júri - debate de seu advogado. A: Leandro Gomes de Barros; E: Editôra Guajarina; L: Belém; D: 19/5/1938; 16 S. 67 Str. zu 6 V.; Bem.: -; COL OL CPCRB CAT NO. 314.

4. Antônio Silvino, o rei dos cangaceiros. A: Leandro Gomes de Barros; E: -; L: Recife; D: —; 15 S. 68 Str. zu 6 V.; Bem.: —; COL LEANDRO CPCRB.

5. Antônio Silvino se despedindo do campo. A: -; E: -; L: -; D: -; 4 S. 14 Str. zu 6 V.; Bem.: Es ist die zweite von zwei in diesem Folheto enthaltenen Geschichten; der Text ist lyrisch, nicht episch; das Folheto hat kein Deckblatt; die andere im Folheto enthaltene Geschichte ist „Prisão de Antônio Silvino na cadeia“ (No. 25) (vgl. auch die Bem. zu No. 9); COL LEANDRO CPCRB.

6. As bravuras de Antônio Silvino em bonra de wm velho amigo. A: - ; E: João José da Silva; L: -; D: -; 16 S. 77 Str. zu 6 V., 1 Str. zu 10 V.; Bem.: In der letzten Strophe findet sich das Akrostichon LUISDELIRA; Autor des Textes ist Luís Rodrigues Lira; die Geschichte ist eine Variante von "As bravuras de Antônio Silvino e um casamento 
trágico" (No. 7); Verlagsort ist Recife; COL MDJr. CPCRB CAT NO. 832.

7. As bravuras de Antônio Silvino e um casamento trágico. A: Luís Rodrigues Lira; E: -; L: -; D: -; 16 S. 77 Str. zu 6 V., 1 Str. zu 10 V.; Bem.: Die Geschichte ist eine Variante von „As bravuras de Antônio Silvino em honra de um velho amigo" (No. 6); COL OL.

8. Os cálculos de Antônio Silvino. A: Leandro Gomes de Barros; E: -; L: Recife; D: -; 9 S. 31 Str. zu 7 V.; Bem.: Es ist die zweite von zwei in diesem Folheto enthaltenen Geschichten; die andere ist „As proezas de Antônio Silvino" (No. 26); COL LEANDRO CPCRB.

9. (Chegada) de Antônio Silvino na cadeia. A: -; E: -; L: -; D: -; $12 \mathrm{~S} .47$ Str. zu 6 V.; Bem.: Es ist die erste von zwei in diesem Folheto enthaltenen Geschichten; die andere ist „Antônio Silvino se despedindo do campo" (No. 5); das erste Wort des Titels fehlt — deshalb wurde dieser Text sowohl als No. 9 nach einer Notiz (Chegada) als auch als No. 25 (Prisão) registriert; das Folheto hat kein Deckblatt; COL LEANDRO CPCRB.

10. Como Antônio Silvino fêz o Diabo chocar. A: João Martins de Ataíde; E: -; L: Recife; D: 3/6/1947; 8 S. 47 Str. zu 6 V.; Bem.: —; COL CP CPCRB CAT No. 260.

11. O encontro de Antônio Silvino com o valente Nicácio na vila de Trapiá. A: Severino Cesário; E: Severino Cesário; L: —; D: —; 16 S. 78 Str. zu 6 V., 1 Str. zu 7 V.; Bem.: Akrostichon CESARIO in der letzten Strophe; Bleistiftanmerkung: R. 7/9/62; COL RD.

12. História completa de Antônio Silvino (sua vida de crimes e seu julgamento). A: Francisco das Chagas Batista; E: Livraria H. Antunes Ltda.; L: Rio de Janeiro; D: 20/9/1960; 394 Str. zu 6 V.; Bem.: Im Anschluß an diesen Text folgen Verse von Sebastião Nunes Batista - sie wurden als Auftragsarbeit nicht registriert; COL RD.

13. A história de Antônio Silvino (contendo o retrato de tôda a vida de crimes do célebre cangaceiro desde o seu primeiro crime até a data presente - setembro de 1907). A: Francisco das Chagas Batista; E: Imprensa Industrial; L: Recife; D: 1907; 47 S. 200 Str. zu 6 V.; Bem.:-; COL LEANDRO CPCRB.

14. A história de Antônio Silvino (Novos crimes). A: Francisco das Chagas Batista; E: Imprensa Industrial; L: Recife; D: 1908; 13 S. 55 Str. zu 6 V.; Bem.: Es ist die erste von zwei in diesem Folheto enthaltenen Geschichten; die andere ist "A famosa Guiomar"; COL LEANDRO CPCRB.

15. O interrogatório de Antônio Silvino (suas declaracões ao chefe de polícia do Recife). A: Francisco das Chagas Batista; E: João Bernardo da Silva; L: Juàzeiro do Norte; D: 1/6/1954; 15 S. 63 Str. zu 6 V.; Bem.: Teile dieses Folhetos sind identisch mit Versen aus der „História completa de Antônio Silvino" (No. 12); COL RD.

16. A ira e a vida de Antônio Silvino. A: Leandro Gomes de Barros; E: Leandro Gomes de Barros; L: Recife; D: -; 8 S. 31 Str. zu 6 V.; Bem.: Es ist die erste von zwei Geschichten; die andere ist „O boi misterioso", deren Seiten in diesem Folheto herausgeschnitten sind; COL LEANDRO CPCRB.

17. As lágrimas de Antônio Silvino por Tempestade. A: -; E: —; L: -; 
D: -; 10 S. 34 Str. zu 7 V.; Bem.: Es ist die erste von zwei in diesem Folheto enthaltenen Geschichten; die andere ist "O sorteio militar"; COL LEANDRO CPCRB.

18. O leão na jaula (Antônio Silvino capturado pelo valente oficial da polícia pernambucana, tenente Teófanes). A: -; E: -; L: -; D: -; 16 S. 61 Str. zu 6 V.; Bem.: A. ist wahrscheinlich Leandro Gomes de Barros; COL OL.

19. Luta do Diabo com Antônio Silvino. A: Leandro Gomes de Barros; E: Leandro Gomes de Barros; L: Recife; D: -; 9 S. 40 Str. zu 6 V.; Bem.: Es ist die erste von zwei in dem Folheto enthaltenen Geschichten; die andere ist "Vingança dum filho"; COL LEANDRO CPCRB.

20. A morte de Cocada e a prisão de suas orelhas. A: Francisco das Chagas Batista; E: Imprensa Industrial; L: Recife; D: 1908; 5 S. 20 Str. zu 6 V.; Bem.: Es ist die erste von zwei in dem Folheto enthaltenen Geschichten; die andere ist "A política de Antônio Silvino“ (No. 23); COL LEANDRO CPCRB.

21. A morte de Tempestade. A: Leandro Gomes de Barros (Antônio Félix); E: Leandro Gomes de Barros; L: Recife; D: 1909; 9 S. 33 Str. zu 6 V.; Bem.: Es ist die erste von drei Geschichten; die beiden anderen sind „O homem que virou urubu" und „O reino da pedra fina"; das Deckblatt gibt Leandro als Autor an, auf der ersten Seite steht in Klammern unter dem Titel der Geschichte „Antônio Félix", möglicherweise handelt es sich dabei um den wirklichen Namen des Cangaceiro Tempestade, wahrscheinlich nicht um das Pseudonym eines Volksdichters; COL LEANDRO CPCRB.

22. O nascimento de Antônio Silvino. A: Leandro Gomes de Barros; E: Leandro Gomes de Barros; L: Recife; D: -; 9 S. 33 Str. zu 6 V.; Bem.: Es ist die erste von zwei in dem Folheto enthaltenen Geschichten; die andere ist "Histórias das Índias", ihre Seiten fehlen; COL LEANDRO CPCRB.

23. A politica de Antônio Silvino. A: Francisco das Chagas Batista; E: Imprensa Industrial; L: Recife; D: 1908; 11 S. 49 Str. zu 6 V.; Bem.: Es ist die zweite in diesem Folheto enthaltene Geschichte; die andere ist "A morte de Cocada e a prisão de suas orelhas" (No. 20); COL LEANDRO CPCRB.

24. A prisão de Antônio Silvino (auf der 1. Seite:... do célebre Antônio Silvino). A: João Martins de Ataíde; E: -; L: Recife; D: -; 11 S. 36 Str. zu 7 V.; Bem.: -; COL CP CPCRB CAT No. 882.

25. (Prisão) de Antônio Silvino na cadeia. A: -; E: -; L: -; D: -; $12 \mathrm{~S}$. 47 Str. zu 6 V.; Bem.: Es ist die erste von zwei in diesem Folheto enthaltenen Geschichten; die andere ist "Antônio Silvino se despedindo do campo" (No. 15); das erste Wort des Titels fehlt - deshalb wurde dieser Text sowohl als No. 9 (Chegada) als auch als No. 25 (Prisão) registriert; das Folheto hat kein Deckblatt; COL LEANDRO CPCRB.

26. As proezas de Antônio Silvino. A: Leandro Gomes de Barros; E: Leandro Gomes de Barros; L: Recife; D: -; 7 S. 21 Str. zu 7 V.; Bem.: Es ist die erste von zwei Geschichten; die andere ist „Os cálculos de Antônio Silvino" (No. 8); COL LEANDRO CPCRB.

27. O romance da vida de Antônio Silvino, $2^{\circ}$ volume (conclusão). A: 
Manuel Pereira; E: Manuel Camilo dos Santos; L: Campina Grande; D: 23/6/1955; 32 S. 157 Str. zu 6 V.; 1 Str. zu 7 V.; Bem.: Akrostichon PEREIRA; COL RD.

28. O silêncio de Antônio Silvino. A: Leandro Gomes de Barros; E: Leandro Gomes de Barros; L: Recife; D: 1910; 6 S. 20 Str. zu 7 V.; Bem.: Es ist die erste von zwei in dem Folheto enthaltenen Geschichten; die andere ist „Suspiros de um sertanejo“ (die Seiten dieses Textes fehlen); der Text dieses Folhetos erscheint in dem Buch Trovador do Nordeste als von João Martins de Ataíde geschrieben, unter dem Titel von "Confissões de Antônio Silvino"; COL LEANDRO CPCRB.

29. O sonbo de Antônio Silvino na cadeia (em que lhe apareceram as almas de todos os que êle matou). A: Leandro Gomes de Barros; E: Pedro Batista; L: Guarabira/Paraíba do Norte; D: 1918; 15 S. 63 Str. zu 6 V.; Bem.: Die Kernepisode ist mit der aus dem Folheto „A visão de Antônio Silvino" (No. 33) identisch; am Schluß des Textes folgt eine "Lamentação"; COL LEANDRO CPCRB.

30. Tôdas as lutas de Antônio Silvino. A: Leandro Gomes de Barros; E: Leandro Gomes de Barros; L: Recife; D: -; 14 S. 59 Str. zu 6 V.; Bem.: Bleistiftanmerkung: Rachel Aleixo 14/11/1912; COL LEANDRO CPCRB.

31. Uma das maiores proezas que Antônio Silvino fêz no sertão pernambucano. A: José Camelo; E: João José da Silva; L: -; D: -; 24 S. 95 Str. zu 6 V., 1 Str. zu 10 V.; Bem.: Verlagsort ist Recife; Akrostichon JOSECAMELO in der letzten Strophe; COL RD.

32. A vida de Antônio Silvino. A: Francisco das Chagas Batista; E: Imprensa Industrial; L: Recife; D: 1904; 14 S. 54 Str. zu 6 V.; Bem.: -; COL LEANDRO CPCRB.

33. A visão de Antônio Silvino. A: Leandro Gomes de Barros; E: Leandro Gomes de Barros; L: Recife; D: -; 16 S. 60 Str. zu 6 V.; Bem.: Die Kernepisode ist mit der aus dem Folheto "O sonho de Antônio Silvino" (No. 29) identisch; COL LEANDRO CPCRB.

\section{Folhetos aus dem Zyklus der Cangaceiros (Sekundärzyklus Lampiãos)}

34. O ataque de Lampiäo a Mossoró. A: João Martins de Ataíde; 61 Str. zu 7 V.; der Text ist veröffentlicht in "O trovador do Nordeste“, S. $145-160$.

35. O ataque a Mossoró e a vitória desta cidade. A: José Lima de Oliveira; E: -; L: Areia Branca; D: Juni 1927; 96 Str. zu 7 V., 2 Str. zu 10 V.; der Text ist veröffentlicht in Raimundo Nonato da Silva, „Lampião em Mossoró".

36. A chegada de Lampiäo no céu. A: Rodolfo Coelho Cavalcante; E: -; L: Salvador; D: Juni 1948; 8 S. 32 Str. zu 7 V.; Bem.: Das Folheto zeigt an: 4. Auflage; COL CP CPCRB CAT No. 442.

37. Chegada de Lampião no espiritismo e o samba de Maria Bonita. A: Silva Melo; E: -; L: Juàzeiro do Norte; D: 1941; 8 S. 29 Str. zu 6 V.; 1 Str. zu 4 V.; Bem.: Der Text des „Samba de Maria Bonita“, der sich an den erzählenden Teil anschließt, wurde nicht registriert; COL CP CPCRB No. 138.

38. Chegada de Lampião no inferno. A: José Pacheco; E: -; L: Juàzeiro 
do Norte; D: 2/6/1949; 8 S. 31 Str. zu 7 V.; Bem.: Es gibt eine Reihe von Varianten dieses Textes; COL CP CPCRB CAT No. 941.

39. Combate e morte de Lampião. A: Zé Vicente (Lindolfo Mesquita); E: Ed. Guajarina; L: Belém/Pará; D: 10/12/1938; 16 S. 63 Str. zu 6 V.; Bem.: Auf dem Deckblatt steht: 4. Auflage, auf der ersten Seite: 3. Auflage; COL OL CPCRB CAT No. 612.

40. Comunicação de Lampião. A: Chico Goiano (Francisco Guerra Vazcurado); E: Tip. da „Luta“; L: Anápolis; D: -; 8 S. 31 Str. zu 6 V.; Bem.: Bleistiftnotiz: 13/10/53; COL OL.

41. Debate de Lampião com São Miguel. A: Minelvino F. Silva; E: Minelvino F. Silva; L: Itabuna/Bahia; D: —; 8 S. 31 Str. zu 7 V.; Bem.: -; COL OL CPCRB CAT No. 807.

42. A eleição do Diabo e posse de Lampião no inferno. A: Severino Gonçalves de Oliveira; E: João José da Silva; L: -; D: —; 8 S. 32 Str. zu 7 V.; Bem.: Verlagsort ist Recife; es gibt Varianten dieses Textes unter dem Titel „A eleição no inferno"; COL CPCRB.

43. O encontro de Guabiraba com Lampião. A: Rodolfo Coelho Cavalcante; E: - ; L: Salvador; D: Januar 1947; 8 S. 30 Str. zu 7 V.; Bem.: Das Folheto zeigt an: 1. Auflage; COL CP CPCRB CAT No. 308.

44. O encontro de Marreco com Lampião no inferno. A: -; E: João José da Silva; L: -; D: -; 8 S. 40 Str. zu 6 V.; Bem.: Autor ist João José da Silva; Verlagsort ist Recife; COL RD.

45. A grande briga de Lampião com a môça que virou cachorra. A: José Pacheco; E: -; L: -; D: -; 8 S. 31 Str. zu 6 V.; Bem.: -; COL DMSP.

46. A grande briga de Lampião com o homem que virou bode. A: Manuel de Almeida Filho; E: -; L: -; D: -; 8 S. 31 Str. zu 7 V.; Bem.: -; COL OL CPCRB CAT No. 646.

47. Grande debate que teve Lampiäo com S. Pedro. A: José Pacheco; E: -; L: Juàzeiro do Norte; D: -; 8 S. 22 Str. zu 10 V.; Bem.: -; COL CP CPCRB CAT No. 792.

48. Lampiäo arrependido da vida de cangaceiro. A: Laurindo Gomes Maciel; E: -; L: Viçoso/Alagoas; D: -; 8 S. 32 Str. zu 7 V.; Bem.: -; COL MDJr CPCRB CAT No. 76.

49. Lampiäo e a velha feiticeira. A: Manuel Tomás de Assis; E: -; L: Juàzeiro do Norte; D: 7/7/1942; 8 S. 32 Str. zu 7 V.; Bem.: Es ist der erste von zwei in diesem Folheto enthaltenen Texten; der andere ist "Os sêlos de hoje em dia"; COL OL CPCRB CAT No. 505.

50. Lampião em Vila Bela. A: João Martins de Ataíde; E: -; L: Recife; D: 26/9/1946; 16 S. 61 Str. zu 7 V.; Bem.: -; COL CP CPCRB CAT No. 286.

51. Lampião foi cercado. A: João Martins de Ataíde; E: -; L: Recife; D: 25/8/1928; 16 S. 46 Str. zu 7 V.; Bem.: -; COL BN.

52. Lampião na Babia. A: José Bernardo da Silva; E: -; L: Juàzeiro do Norte; D: 11/11/1947; 16 S. 64 Str. zu 6 V.; Bem.: -; COL OL CPCRB CAT No. 503.

53. Lampião no tiroteio de Guaribas. A: João Martins de Ataíde; 59 Str. zu 7 V.; der Text ist veröffentlicht in "O trovador do Nordeste", S. $181-196$.

54. Lampião - sua vida - seus crimes - sua morte. A: Arinos de Belém; 
E: Ed. Guajarina; L: Belém/Pará; D: 17/3/1939; 48 S. 237 Str. zu 6 V.; Bem.: auf dem Deckblatt steht: Narração completa (ebenso auf der ersten Seite); COL CP CPCRB CAT No. 285.

55. A liberdade de Volta Sêca. A: Rodolfo Coelho Cavalcante; E: -; L: Salvador; D: -; 8 S. 30 Str. zu 7 V.; Bem.: auf dem Rückblatt steht: Salve! 1949; COL CP CPCRB CAT No. 969.

56. A morte de Lampião. A: João Martins de Ataíde; E: -; L: Recife; D: 31/8/1938; 16 S. 63 Str. zu 7 V.; Bem.: -; COL MDJr CPCRB CAT No. 355.

57. A morte de Lampião (A chegada de Lampião e Maria Bonita a Maceió e Corisco vingando o chefe). A: João Martins de Ataíde; E: -; L: Recife; D: 4/4/1948; 16 S. 63 Str. zu 7 V.; Bem.: -; COL CP CPCRB CAT No. 209.

58. A morte de Lampião e de seus companheiros (... na fazenda Angico no Estado de Alagoas 12 kilómetro para Sergipe). A: -; E: -; L: Juàzeiro do Norte; D: -; 11 S. 42 Str. zu 7 V.; Bem.: Es gibt eine Variante aus der COL OL mit dem Titel „A morte de Lampião, Maria Bonita e 10 companheiros", Autor ist José Bernardo da Silva, das Folheto hat 12 S. 45 Str. zu 7 V.; COL CP CPCRB CAT No. 777.

59. Nôvo encontro de Lampião com a polícia - tiroteio e morte. A: José Ferreira Lima; E: -; L: -; D: -; 16 S. 63 Str. zu 6 V.; Bem.: -; COL BN.

60. O que me disse um soldado que milagrosamente escapou da unha de Lampião. A: João Martins de Ataíde; 63 Str. zu 7 V.; der Text wird veröffentlicht in Nertan Macêdo, "Capitão Virgulino Ferreira Lampião“, S. 96-109; Bem.: Möglicherweise fehlt in Macêdos Buch die Einleitung des Folhetos; die erste zitierte Strophe beginnt zu abrupt mit der Erzählung.

61. Perseguições de Lampião pelas fôrças legais. A: José Cordeiro; E: -; L: Juàzeiro do Norte; D: 15/6/1951; 32 S. 94 Str. zu 7 V.; Bem.: In den 'Text eingefügt ist eine „Polca de Lampião" mit 3 Str. zu 4 V. und einem Refrain zu 4 V.; COL CP CPCRB CAT No. 636.

62. A primeira entrevista de Lampiäo na Babia. A: João Martins de Ataíde; E: —; L: Recife; D: 26/2/1929; 16 S. 62 Str. zu 7 V.; Bem.:-; COL BN.

63. A prisão de Volta Sêca (o bandido de 16 anos no grupo de Lampião). A: Pedro Herta Batista; E: Tip. Popular Editora; L: João Pessoa; D: -; 12 S. 44 Str. zu 6 V.; COL SNB.

64. As proezas de Lampião (Novas proezas ...). A: João Martins de Ataíde; E: -; L: Recife; D: 22/9/1946; 16 S. 62 Str. zu 7 V.; Bem.: -; COL CP CPCRB CAT No. 233.

65. Proezas de Lampião na cidade de Cajàzeiras. A: João Martins de Ataíde; E: -; L: Recife; D: 20/9/1946; 16 S. 45 Str. zu 7 V.; Bem.: -; COL CP CPCRB CAT No. 667.

66. Os projetos de Lampião. A: João Martins de Ataíde; 61 Str. zu 7 V.; der Text wurde veröffentlicht in "O trovador do Nordeste“, S. 213-228.

67. A verdadeira bistória de Lampião e Maria Bonita. A: Manuel Pereira Sobrinho; E: João José da Silva; L: Recife; D: -; 32 S. 151 Str. zu 6 V., 7 Str. zu 7 V.; COL MDJr CPCRB CAT No. 372.

68. A vida do cangaceiro Lampião. A: Pau de Arara Poeta (João Rodrigues da Silva); E: Graf. Minas Gerais; L: Rio de Janeiro; D: -; $30 \mathrm{~S}$. 
90 Str. zu 6 V., 19 Str. zu 7 V., 5 Str. zu 8 V.; Bem.: Bleistiftnotiz: Rio 31/3/55; COL OL.

69. Virgulino Ferreira da Silva (Lampião). A: José Cordeiro; E: -; L: Juàzeiro do Norte; D: -; 24 S. 76 Str. zu 7 V.; Bem.: Das Folheto ist eine Variante von „Visita de Lampião em Juàzeiro“ (No. 70); COL CP CPCRB CAT No. 484.

70. Visita de Lampião em Juàzeiro (Encontro que êle teve com os revoltosos, sua visita a Juàzeiro e sua elevação a capitão de polícia a 4 de março de 1926). A: José Cordeiro; E: José Bernardo da Silva; L: Juàzeiro do Norte; D: 5/2/1953; 24 S. 76 Str. zu 7 V.; 1 Str. zu 4 V., 1 Str. zu $8 \mathrm{~V}$; Bem.: Das Folheto ist eine Variante von „Virgulino Ferreira da Silva (Lampião)“ (No. 69); die beiden letzten Strophen formen das Akrostichon JOSE CORDEIRO; COL RD.

71. A volta de Lampião e a brigada de Marreco. A: -; E: -; L: - ; D: -; 8 S. 32 Str. zu 7 V.; Bem.: Autor ist João José da Silva, Verlagsort Recife; COL RD.

3. Folhetos aus dem Zyklus der Cangaceiros (Texte, in denen Antônio Silvino und Lampião gemeinsam erscheinen)

72. Antônio Silvino contra Lampião pela posse no inferno. A: Antônio Alves da Silva; E: -; L: -; D: -; 8 S. 39 Str. 6 V.; Bem.: Anmerkung der CFB: 1961; COL CFB.

73. O encontro de Lampião com Antônio Silvino. A: José Costa Leite; E: José Alves Pontes; L: Guarabira; D: 2/10/1963; 16 S. 80 Str. zu 6 V.; Bem.: -; COL CPCRB.

4. Folhetos aus dem Zyklus der Cangaceiros (Texte, die weder Antônio Silvino noch Lampião behandeln)

74. O cangaceiro. A: Minelvino F. Silva; E: Minelvino F. Silva; L: Itabuna/ Bahia; D: -; 24 S. 116 Str. zu 6 V.; Bem.: Das Folheto beschreibt den Film "O cangaceiro" von Lima Barreto; COL RD.

75. „O cangaceiro" baseado na vida de Lampião. A: João José da Silva; E: João José da Silva; L: -; D: -; 32 S. 154 Str. zu 6 V., 2 Str. zu 7 V., 3 Str. zu 4 V.; Bem.: Das Folheto beschreibt den Film „O cangaceiro" von Lima Barreto; Verlagsort ist Recife; COL CPCRB.

76. A morte comanda o cangaço. A: Joaquim Batista de Sena; E: Joaquim Batista de Sena; L: Fortaleza; D: -; 32 S. 158 Str. zu 6 V.; Bem.: Mit Tinte geschriebene Notiz: enviado pelo autor em 26-set.-63 (nota do Cpcrb); COL CPCRB.

5. Folhetos aus den anderen Zyklen der Volksliteratur Nordostbrasiliens

77. Aladim e a princessa de Bagdá. A: João José da Silva; E: -; L: Recife; D: -; 32 S. 158 Str. zu 6 V.; Bem.: es fehlen auf S. 27 drei Verse; COL CP CPCRB CAT No. 870.

78. Ali-Babá e os 40 ladrões (O romance de...). A: Severino Borges; E: João José da Silva; L: Recife; D: —; 32 S. 158 Str. zu 6 V.; Bem.: -; COL OL CPCRB CAT No. 201. 
79. Amor de perdição, vol. I. A: João Martins de Ataíde; E: —; L: Recife; D: 21/5/1947; 32 S. 159 Str. zu 6 V.; Bem.: -; COL CP CPCRB CAT No. 315.

80. Amor de perdição, vol. II. A: João Martins de Ataíde; E: José Bernardo da Silva; L: Juàzeiro do Norte; D: 17/5/1951; 32 S. 158 Str. zu 6 V.; Bem.: -; COL CP CPCRB CAT No. 269.

81. Batalba de Carlos Magno com Malaco, Rei de Fez (... Magno e os 12 Pares de França com ...). A: José Bernardo da Silva; E: -; L: Juàzeiro do Norte; D: 15/7/1942; 40 S. 119 Str. zu 10 V.; Bem.: -; COL CP CPCRB CAT No. 473.

82. O cavaleiro Roldão (História completa do...). A: Antônio Eugênio da Silva; E: Manuel Camilo dos Santos; L: Campina Grande; D: 14/2/1958; 32 S. 159 Str. zu 6 V.; Bem.: -; COL CP CPCRB CAT No. 141.

83. Conselhos e opiniões. A: Augusto de Sousa Lima (ou Limeira Baiano, o violeiro das rádios); E: Augusto de Sousa Lima; L: -; D: -; $8 \mathrm{~S}$. 32 Str. zu 6 V.; Bem.: -; COL CPCRB.

84. O Corcunda de Notre Dame. A: Altino Alagoano; E: Guajarina; L: Belém/Pará; D: August 1947; 100 Str. zu 6 V.; Bem.: Es ist die erste Geschichte des Folhetos, die andere heißt "As mocinhas de hoje“; COL OL CPCRB CAT No. 50.

85. A Dama das Camélias (Romance da ... [ou os sofrimentos de Margarida]). A: João Martins de Ataíde; E: -; L: Recife; D: 24/4/1941; 16 S. 62 Str. zu 7 V.; Bem.: -; COL CP CPCRB CAT No. 1.

86. Discussão dum fiscal com uma fateira. A: Manuel A. Campina; E: - ; L: -; D: -; 8 S. 31 Str. zu 6 V.; Bem.: Akrostichon: CAMPINA; COL CP CPCRB CAT No. 775.

87. O encontro de dois errados. A: -; E: João José da Silva; L: Recife; D: -; 16 S. 79 Str. zu 6 V.; Bem.: -; COL CP CPCRB CAT No. 143

88. A fera invisível (ou o triste fim de uma trapezista que sofria do pulmão) A: João José da Silva; E: —; L: —; D: -; 16 S. 74 Str. zu 6 V.; Bem.: Verlagsort ist Recife; COL RD.

89. O filbo de Garcia (... do valente Zé Garcia). A: Manuel Camilo dos Santos; E: Manuel Camilo dos Santos; L: Campina Grande; D: 21/1/ 1958; 32 S. 128 Str. zu 6 V.; Bem.: -; COL CP CPCRB CAT No. 194.

90. Fugida da Princesa Beatriz com o Conde Pierre. A: João Martins de Ataíde; E: -; L: Recife; D: 26/12/1946; 32 S. 141 Str. zu 6 V.; Bem.: Akrostichon: ATAIDE; COL CP CPCRB CAT No. 122.

91. Helena a deusa de Tróia. A: -; E: João José da Silva; L: Recife; D: 一; 32 S. 159 Str. zu 6 V., 1 Str. zu 7 V.; Bem.: Akrostichon: CAETANO, Autor ist Antônio Caetano; COL OL CPCRB CAT No. 55.

92. O heroísmo de Petronilha e as bravuras de João de Deus. A: -; E: João José da Silva; L: Recife; D: -; 16 S. 77 Str. zu 6 V., 1 Str. zu 10 V.; Bem.: Autor ist Luís de Lira, da Akrostichon: LUISDELIRA; COL CPCRB.

93. História da Donzela Teodora. A: João Martins de Ataíde; E: João Bernardo da Silva; L: Juàzeiro do Norte; D: -; 32 S. 142 Str. zu 6 V.; Bem.: Der tatsächliche Autor ist Leandro Gomes de Barros; COL CP CPCRB CAT No. 265.

94. História da Imperatriz Porcina (Romance da ....). A: João Martins de Ataíde; E: -; L: Recife; D: 3/12/1946; 63 S. 246 Str. zu 7 V.; Bem.: 
Der tatsächliche Autor ist möglicherweise Francisco das Chagas Batista; COL CP CPCRB CAT No. 665.

95. História de Aladin ou a lâmpada maravilhosa. A: Firmino Teixeira do Amaral; E: -; L: Juàzeiro do Norte; D: -; 42 S. 206 Str. zu 6 V., 1 Str. zu 7 V.; Bem.: Akrostichon: FIRMINO; COL CP CPCRB CAT No. 571 .

96. História de João de Calais, vol. I. A: José Bernardo da Silva; E: -; L: Juàzeiro do Norte; D: 21/7/1941; 38 S. 168 Str. zu 6 V.; Bem.: -; COL CP CPCRB CAT No. 560.

97. História de João de Calais (Continuação da ... ou os últimos sucessos de sua vida), vol. II. A: Damásio Paulo da Silva; E: Damásio Paulo da Silva; L: Juàzeiro do Norte; D: -; 38 S. 188 Str. zu 6 V., 1 Str. zu 7 V.; Bem.: Akrostichon: DAMASIO; COL CP CPCRB CAT No. 712.

98. História de Roberto do Diabo. A: João Martins de Ataíde; E: -; L: Recife; D: 28/8/1947; 48 S. 238 Str. zu 6 V.; Bem.: -; COL CP CPCRB CAT No. 648.

99. A bistória de Vira-Mundo. A: João José da Silva; E: João José da Silva; L: Recife; D: -; 16 S. 80 Str. zu 6 V.; Bem.: Es handelt sich um den ersten Band des Sekundarzyklus „Romance Exagerado"; die weiteren Bände: 2. "Chico Vira-Mundo“; 3. "Gonçalinho Vira-Mundo“; 4. „O valente Corta-Mundo“; 5. "Lasca-Mundo“; 6. "Arrebenta-Mundo“; 7. „Bisneta de Vira-Mundo"; 8. "Cava-Mundo"; 9. „Bate-Mundo"; 10. "Fura-Mundo"; COL CPCRB.

100. História do boi mandigueiro e o cavalo misterioso, vol. I. A: José Bernardo da Silva; E: -; L: Juàzeiro do Norte; D: 18/5/1951; 32 S. 122 Str. zu 7 V.; Bem.: -; COL CP CPCRB CAT No. 625.

101. História do capitão do navio. A: -; E: -; L: Recife; D: 26/2/1946; 16 S. 75 Str. zu 6 V.; Bem.: -; COL CP CPCRB CAT No. 950.

102a. História do valente Vilela. A: João Martins de Ataíde; E: João Martins de Ataíde; L: Recife; D: 12/9/1944; 8 S. 33 Str. zu 6 V.; Bem.: -; COL CP CPCRB CAT No. 898.

102b. História do valente Vilela. A: João Martins de Ataíde; E: José Bernardo da Silva; L: Juàzeiro do Norte; D: 1/10/1961; 16 S. 78 Str. zu 6 V.; Bem.: -; COL CFB.

103. Joana d'Arc (A virgem de Lorena). A: Rodolfo Coelho Cavalcante; E: -; L: Salvador; D: -; 24 S. 120 Str. zu 6 V.; Bem.: -; COL OL CPCRB CAT No. 188.

104. Joana d'Arc (... [A heroína da França]). A: Delarme Monteiro Silva; E: -; L: Recife; D: -; 56 S. 278 Str. zu 6 V., 1 Str. zu 7 V.; Bem.: Akrostichon: DELARME; COL OL CPCRB CAT No. 199.

105. Joana d'Arc. A: -; E: -; L: Recife; D: -; 32 S. 156 Str. zu 6 V.; Bem.: -; COL CP CPCRB CAT No. 290.

105a. Julita e Galdino. A : -; E: João José da Silva; L: -; D: —; 16 S. 77 Str. zu 6 V., 1 Str. zu 10 V.; Bem.: Akrostichon mit dem wahrscheinlichen Autorennamen: APOLINARIO (Manuel Apolinário Pereira?), Verlagsort ist Recife; COL RD.

106. Mariana e o capitão do navio. A: José Bernardo da Silva; E: -; L: Juàzeiro do Norte; D: 7/4/1951; 32 S. 169 Str. zu 6 V., 1 Str. zu 4 V.; Bem.: -; COL CP CPCRB CAT No. 379.

107. Os martírios de Genoveva. A: João Martins de Ataíde; E: -; L: Recife; 
D: 9/11/1943; 47 S. 231 Str. zu 6 V.; Bem.: Der tatsächliche Autor ist Leandro Gomes de Barros; COL CP CPCRB CAT No. 54.

108. Os Martírios de Rosa de Miläo. A: Teodoro Ferraz da Câmara; E: - ; L: -; D: -; 40 S. 196 Str. zu 6 V.; Bem.: -; COL CP CPCRB CAT No. 618 .

109. A môça que virou cachorra. A: Rodolfo Coelho Cavalcante; E: -; L: Salvador; D: August 1948; 8 S. 31 Str. zu 7 V.; Bem.: Der Text zeigt an: 4. Auflage; COL CP CPCRB CAT No. 959.

110. A môça que virou cobra (O exemplo da...). A: Severino Gonçalves Oliveira; E: -; L: -; D: -; 8 S. 32 Str. zu 7 V.; Bem.: —; COL OL CPCRB CAT No. 435.

111. O monstro do Pajeú. A: Manuel Camilo dos Santos; E: Manuel Camilo dos Santos; L: Campina Grande; D: 23/2/1957; 16 S. 63 Str. zu 6 V.; Bem.: -; COL CP CPCRB CAT No. 189.

112. A morte de Marreco. A: João José da Silva; E: -; L: -; D: -; 8 S. 32 Str. zu 6 V.; Bem.: Verlagsort ist Recife; COL DECA.

113. A mulher que pediu um filho ao diabo. A: Galdino Silva; E: -; L: Bahia; D: -; 8 S. 30 Str. zu 7 V.; Bem.: -; COL CP CPCRB CAT No. 527.

114. A mulber roubada. A: João Martins de Ataíde; E: João Martins de Ataíde; L: Recife; D: 10/5/1947; 48 S. 218 Str. zu 6 V., 1 Str. zu 7 V.; Bem.: Tatsächlicher Autor ist Leandro Gomes de Barros; COL CP CPCRB CAT No. 488.

115. O Nero do Amazonas. A: -; E: João José da Silva; L: -; D: -; 16 S. 79 Str. zu 6 V., 1 Str. zu 7 V.; Bem.: Verlagsort ist Recife; COL RD.

116. Oscar e Aurora. A: -; E: João José da Silva; L: -; D: -; 32 S. 154 Str. zu 6 V.; Bem.: Verlagsort ist Recife; COL RD.

117. O Príncipe e o monstro - Teseu, o berói do labirinto. A: Olímpio Cruz (José Bernardo da Silva); E: —; L: Juàzeiro do Norte; D: 16/7/1947; 24 S. 101 Str. zu 6 V.; Bem.: -; COL CP CPCRB CAT No. 487.

118. A prisão de Oliveiros (... e dos seus companheiros). A: João Martins de Ataíde; E: -; L: Recife; D: 28/8/1948; 46 S. 137 Str. zu 10 V.; Bem.: -; COL CP CPCRB CAT No. 837.

119. Roldão no leão de ouro. A: João Martins de Ataíde; E: José Bernardo da Silva; L: Juàzeiro do Norte; D: 23/1/1951; 40 S. 190 Str. zu 6 V.; Bem.: Tatsächlicher Autor ist João Melquíades Ferreira; COL CP CPCRB CAT No. 509.

120. Romance de Iracema a virgem dos lábios de mel. A: João Martins de Ataíde; E: -; L: Recife; D: 24/4/1948; 48 S. 191 Str. zu 7 V.; Bem.: -; COL CP CPCRB CAT No. 759.

121. Romance do pavão misterioso (História do...). A: -; E: -; L: Juàzeiro do Norte; D: 30/8/1951; 32 S.; 141 Str. zu 6 V.; Bem.: Der Autor ist João Melquíades Ferreira da Silva, er folgt einem Text von José Damelo de Melo Resende; COL CP CPCRB CAT No. 278.

122. Sacco e Vanzetti aos olhos do mundo. A: João Martins de Ataíde; E: -; L: -; D: -; 16 S. 60 Str. zu 7 V.; Bem.: -; COL MDJr CPCRB CAT No. 152.

123. O sacrifício do povo. A: João Vicente da Silva; E: -; L: -; D: -; 8 S. 39 Str. zu 6 V.; Bem.: Der Text wurde RD vom Autor in Teresina/ Piauí geschenkt (23/6/1965). COL RD. 
124. Sansão e Dalila. A: Cuíca de Santo Amaro; E: -; L: Salvador; D: - ; 8 S. 32 Str. zu 6 V.; Bem.: -; COL OL CPCRB CAT No. 109.

125. Sansão e Dalila (A verdadeira história de ...). A: J. L. Junior; E: João José da Silva; L: -; D: -; 32 S. 127 Str. zu 6 V.; Bem.: Akrostichon: ZELUIS; COL OL CPCRB CAT No. 404.

126. Sansão e Dalila. A: Antônio Alves dos Santos; E: Rodolfo Coelho Cavalcante; L: Salvador; D: -; 32 S. 159 Str. zu 6 V.; Bem.: -; COL OL CPCRB CAT No. 549.

127. Os sofrimentos de Alzira. A: João Martins de Ataíde; E: José Bernardo da Silva; L: Juàzeiro do Norte; D: 16/8/1951; 46 S. 227 Str. zu 6 V., 1 Str. zu 7 V.; Bem.: Tatsächlicher Autor ist Leandro Gomes de Barros; COL CP CPCRB CAT No. 47.

128. Traições de Galalão e a morte dos 12 pares de França. A: Marcos Sampaio (Moisés Matias de Moura); E: -; L: Juàzeiro; D: 13/1/1941; 32 S. 138 Str. zu 6 V., 1 Str. zu 7 V.; Bem.: Akrostichon in den letzten beiden Strophen: MARCOS SAMPAIO; COL CP CPCRB CAT No. 18.

129. Viagem a São Saruê. A: Manuel Camilo dos Santos; E: Manuel Camilo dos Santos; L: Campina Grande; D: 7/5/1956; 32 Str. zu 6 V., 2 Str. zu 10 V.; Bem.: Die Strophen zu 6 V. haben siebensilbige Verse, die zu 10 V. zehnsilbige; COL MDJr CPCRB CAT No. 213.

130. Visita de Cancão de Fogo ao inferno. A: -; E: -; L: Salvador; D: -; 8 S. 32 Str. zu 7 V.; Bem.: -; COL CPCRB.

B. SEKUNDÄRITERATUR (eine Auswahl von Arbeiten, die sich mit nordostbrasilianischen, und speziell volksliterarischen, Problemen beschäftigen)

Diese Bibliographie ist nach der alphabetischen Reihenfolge der Autorennamen geordnet (bei Portugiesen und Brasilianern zählt stets zuerst der letzte Nachname). Dem Titel des Werkes folgt (falls zu ermitteln) der Name des Verlages, sodann der Verlagsort und das Erscheinungsjahr.

Wurden Zitate aus Arbeiten, die vor 1945 erschienen, verwandt, so wurden sie, den Normen des „Vocabulário Ortográfico Resumido da Língua Portuguêsa" (1947) folgend, verändert. So erscheint "Lampião" stets in dieser Schreibweise, und nicht als "Lampeão“; das gleiche gilt für "Virgulino“ statt "Virgolino“, etc.

Abreu, João Capistrano de: Capítulos de história colonial (1500-1800), Edição da Sociedade Capistrano de Abreu, Briguiet, Rio de Janeiro, 1934. Abreu, Pedro Vergne de: Os dramas dolorosos do Nordeste à luz crua da verdade, Tip. do Jornal do Comércio, Rio de Janeiro, 1930.

- O flagelo de Lampião (Relação documentada de suas hediondas façanhas no Nordeste, durante os primeiros 4 mêses de 1931, editada pelo Dr. Pedro Vergne de Abreu com o concurso dos grandes jornais do Rio e da Bahia), Tip. do Jornal do Comércio, Rio de Janeiro, 1931.

Albuquerque, Ulysses Lins de: Moxotó brabo (Aspectos histórico-sociológicos de uma região sertaneja - Pernambuco), Simões, Rio de Janeiro, 1960.

- Um sertanejo e o sertão (Memórias), José Olympio, Rio de Janeiro, 1957.

Andrade, Mário de: Danças dramáticas do Brasil, 3 Vol., Martins, São Paulo, 1959. 
- Ensaio sôbre a música brasileira, Martins, São Paulo, 1962.

- Romanceiro de Lampião, in: O baile das quatro artes, Martins, São Paulo, 1963. (Dieser Aufsatz wurde zuerst 1932 in der "Revista Nova“, São Paulo, veröffentlicht, unter dem Pseudonym Leocádio Pereira.)

Ataíde, João Martins de (Athayde): O trovador do Nordeste (herausgegeben von Waldemar Valente), 1. ${ }^{a}$ série, 1937.

Barroso, Gustavo: Almas de lama e de aço (Lampião e outros cangaceiros) Melhoramentos, São Paulo, 1930.

- Ao som da viola (Folclore), 2. ${ }^{a}$ edição?, Imprensa Nacional, Rio de Janeiro, 1949.

- Heróis e bandidos, Francisco Alves, Rio de Janeiro, 1917.

- Terra de Sol (Natureza e costumes do Norte), 6. ${ }^{a}$ edição, Imprensa Universitária do Ceará, Fortaleza, 1962.

Bartolomeu, Floro: Juàzeiro e o Padre Cícero (Depoimento para a história), Imprensa Nacional, Rio de Janeiro, 1923.

Batista, Francisco das Chagas: Cantadores e poetas populares, F. C. Batista Irmão, Paraíba (João Pessoa), 1929.

Batista, Pedro: Cangaceiros do Nordeste, Livraria São Paulo, Paraíba (João Pessoa), 1929.

Bezerra, João: Como dei cabo de Lampião, Rio de Janeiro, 1940.

Camelo, Neri: Alma do Nordeste, $3 .^{\mathrm{a}}$ edição, B. de Sousa, 1941.

Campos, Eduardo: Estudos de Folclore Cearense, Imprensa Universitária do Ceará, Fortaleza, 1960.

Campos, Renato Carneiro: Folhetos populares na zona dos engenhos de Pernambuco, in: Boletim do Instituto Joaquim Nabuco, Recife, Vol. 4, 1955.

- Ideologia dos poetas populares do Nordeste, MEC-INEP, Centro Regional de Pesquisas Educacionais do Recife, 1959.

Carvalho, Cícero Rodrigues de: Serrote Prêto (Lampião e seus sequazes), Sociedade Editora e Gráfica, Rio de Janeiro, 1961.

Carvalho, José Rodrigues de: Cancioneiro do Norte, 2. ${ }^{a}$ edição, Livraria São Paulo, Paraíba (João Pessoa), 1928.

Cascudo, Luís da Câmara: Cinco livros do povo (Introdução ao estudo da novelística no Brasil), José Olympio, Coleção Documentos Brasileiros v. 72, Rio de Janeiro, 1953.

- Dicionário do Folclore Brasileiro (2 Vol.), 2. edição - revista e aumentada, Ministério da Educação e Cultura, Instituto Nacional do Livro, Enciclopédia Brasileira, Biblioteca de Obras Subsidiárias Série A. Assuntos Brasileiros, Rio de Janeiro, 1962.

- Literatura oral, v. VI da História da Literatura Brasileira, José Olympio, Coleção Documentos Brasileiros v. 63-A, Rio de Janeiro, 1952.

- Motivos da literatura oral da França no Brasil, Recife, 1964.

- Vaqueiros e cantadores (Folclore poético do sertão de Pernambuco, Paraíba, Rio Grande do Norte e Ceará), Livraria do Globo, Pôrto Alegre, 1939.

Centro de Pesquisas da Casa de Rui Barbosa (Herausgeber: Thiers Martins Moreira; Leitung: M. Cavalcânti Proença): Literatura popular em verso, Antologia (Tomo I), Catálogo (Tomo I), Ministério da Educação e Cultura, Casa de Rui Barbosa, Coleção de Textos da Língua Portuguêsa Moderna 4, Rio de Janeiro, 1961.

Costa, Francisco Augusto Pereira da: Folclore pernambucano, Revista do 
Instituto Histórico e Geográfico Brasileiro, Tomo LXX Parte II; Imprensa Nacional, Rio de Janeiro, 1908.

Cunha, Euclides da: Os sertões (Campanha de Canudos), 25. ${ }^{a}$ edicão, Francisco Alves, Rio de Janeiro, 1957.

Daus, Evelin: Análise estructural da cantoria trovadoresca popular do Nordeste (noch unveröffentlicht).

DECA (Revista do Departamento de Extensão Cultural e Artística): Ano IV, No. 5 (1962), Recife, Ano V, No. 6 (1963), Recife.

Diégues Jr., Manuel: Formação das populações nordestinas, in: Cultural, Ano IV, No. 6, Rio de Janeiro, 1954.

Facó, Rui: Cangaceiros e fanáticos (Gênese e lutas), $2 .^{a}$ edicão, Civilizacão Brasileira, Rio de Janeiro, 1965.

Freyre, Gilberto: Casa grande \& senzala, 2 Vol., 10. ${ }^{a}$ edicão, José Olympio, Rio de Janeiro, 1961.

Gueiros, Optato: Lampião (Memórias de um oficial ex-comandante de fôrças volantes), $4 .^{\text {a }}$ edição, Livraria Progresso, Salvador, 1956.

Instituto Brasileiro de Geografia e Estatística: Enciclopédia dos Municípios Brasileiros, volume XVIII.: Pernambuco (1958), volume XIX.: Alagoas/ Sergipe (1959), volume XVII.: Paraíba/Rio Grande do Norte (1960), Rio de Janeiro.

- Grandes Regiões Meio-Norte e Nordeste (Geografia do Brasil), Volume III, série A, publicação no. 17; Biblioteca Geográfica Brasileira, Conselho Nacional de Geografia, Rio de Janeiro, 1962.

Lessa, Orígenes: Literatura popular em versos, in: Anhembi, Ano VI, número 61, vol. XXI, São Paulo, Dezembro 1955.

Lima, Estácio de: O mundo estranho dos cangaceiros (Ensaio bio-sociológico), Hapoa, Salvador, 1965.

Lourenço Filho: Juàzeiro do Padre Cícero, 9. ${ }^{a}$ edição (6. Tausend), Comp. Melhoramentos, São Paulo, Caieiras, Rio de Janeiro, o. J.

Luna, Luís: Lampião e seus cabras, Leitura, Rio de Janeiro, 1963.

Macêdo, Nertan: Capitão Virgulino Ferreira Lampião, Leitura, Rio de Janeiro, o. J.

Marroquim, Mário: A língua do Nordeste, São Paulo, 1934.

Melo, Veríssimo de: $\mathrm{O}$ ataque de Lampião a Mossoró através do romanceiro popular, Ofic. d. Dep. de Imprensa, Natal, 1953.

- Cantador de viola, Coleção Concórdia, Recife, 1961.

Menezes, Djacir: O outro Nordeste (Formação social do Nordeste), José Olympio, Coleção Documentos Brasileiros vol. 5, Rio de Janeiro, 1937.

Montenegro, Abelardo F.: História do fanatismo religioso no Ceará, Batista Fontenele, Fortaleza, 1959.

Morel, Edmar: Padre Cícero, o santo do Juàzeiro, Emprêsa Gráfica „O Cruzeiro“, Coleção „Grandes Vidas“, Vol. 8, Rio de Janeiro, 1946.

Mota, Leonardo: Cantadores (poesia e linguagem do sertão cearense), 3.a edição, Imprensa Universitária do Ceará, Fortaleza, 1961.

- No tempo de Lampião, Of. industrial gráf., Rio de Janeiro, 1930.

- Sertão alegre (poesia e linguagem do sertão nordestino), 2. ${ }^{a}$ edição, Imprensa Universitária do Ceará, Fortaleza, 1965.

- Violeiros do Norte, 2. ${ }^{a}$ edição, A Noite, Rio de Janeiro, 1955.

Mota, Mauro: Paisagem das sêcas, Ministério da Educação e Cultura, Instituto Joaquim Nabuco de Pesquisas Sociais, Recife, 1958. 
Nóbrega, Francisco Pereira da: Vingança, não (Depoimente sobre Chico Pereira e cangaceiros do Nordeste), 2. ${ }^{a}$ edição, Freitas Bastos, Rio de Janeiro, 1961.

Oliveira, Xavier de: Beatos e cangaceiros (História real, observação pessoal e impressão psicológica de alguns dos mais célebres cangaceiros do Nordeste), Rio de Janeiro, 1920.

Parreira, Abelardo: Sertanejos e cangaceiros, 1. a série, Ed. Paulista, São Paulo, 1934.

Porto, Costa: O pastoreio na formação do Nordeste, Ministério da Educação e Cultura, Serviço de Documentação, Os Cadernos de Cultura (série) 121 -; Imprensa Nacional, Rio de Janeiro, 1959.

Prata, Ranulfo: Lampião, Ariel, Rio de Janeiro, 1934.

Ramos, Graciliano: Viventes das Alagoas (Quadros e costumes do Nordesteobra póstuma), Martins, São Paulo, 1962.

Rêgo, José Lins do: Presença do Nordeste na literatura, Ministério da Educação e Cultura, Serviço de Documentação, Os Cadernos de Cultura (série) - 104 -; Imprensa Nacional, Rio de Janeiro, 1957.

Rocha, Melquíades da: Bandoleiros das caatingas, A Noite, Rio de Janeiro, 1942(?).

Romero, Sílvio: Cantos populares do Brasil, 2 Vol., Lissabon, 1883.

Rowland, Robert: "Cantadores" del nordeste brasileño (Estructura y cambio social en el nordeste del Brasil), in: Aportes, No. 3, enero 1967, Paris.

Santa Cruz, Luís: O Diabo na literatura de cordel, in: Cadernos Brasileiros; Ano V, No. 5, 1964, Rio de Janeiro.

Silva, Antônio Carlos Simões da: O Padre Cícero e a população do Nordeste (Elementos de defesa, história, "folklore" e propaganda), Imprensa Nacional, Rio de Janeiro, 1927.

Silva, Raimundo Nonato da: Lampião em Mossoró, 2. ${ }^{a}$ edição, Pongetti (Col. Mossoroense, série G, v. XVI), Rio de Janeiro, 1956.

Vidal, Ademar: Terra de homems, „O Cruzeiro“, Rio de Janeiro, 1944. 
Aktualität 29, 42, 114, 120

Anarchismus $97 \mathrm{f}$.

Antiautoritärer Kampf 73 ff., 83 ff., 101, 130, 133

Antiklerikalismus $93 \mathrm{ff}$.

Autorität 73, 76 ff., 83 ff., 101, 119, 126 f., 130

Bildungswille 24

Cantoria repentista $6 \mathrm{ff}$., 13 f., 18 , 24, $103 \mathrm{f}$., $107 \mathrm{f}$.

Capangas 27, $31 \mathrm{f}$., 40, 101, $116 \mathrm{f}$.

Desafios 6 f., 9, 103 f., 107 f., 110, 132

Ehrenkodex 34 f., 45 f., 116, 118 ff.

Enzyklopädismus 24

Epische Gedichte Nordostbrasiliens, allgemein $9 \mathrm{ff} ., 17,22 \mathrm{ff} ., 26 \mathrm{ff}$., $106 \mathrm{ff} ., 131$

Ermordung des Vaters 45 ff., 68, 121

Fabeln 28

Familienfehden $30 \mathrm{ff} ., 116 \mathrm{f}$.

Fanatiker 35 f., 91 ff., 99, 119 f., $130 \mathrm{f}$.

Folhetos

- allgemein 15, $110 \mathrm{f}$.

- Nordostbrasilien, allgemein (Literatura de Cordel) 9 ff., 107 ff., $113 \mathrm{f}$.

- Stil 10 ff., 23, 113, $131 \mathrm{f}$.

- Verbreitung 13, 26, 109, $113 \mathrm{f}$.

- Verkaufssystem 13, 23

Folhetins 17

Geographie Nordostbrasiliens 6, 17 f., 22, $125 \mathrm{f}$.

Gesellschaft Nordostbrasiliens $19 \mathrm{ff}$., 21 ff., 30 ff., 34 ff., 75 f., 101 ff., 113,133
Glosas 7, 106, 113

Himmel (das „Gute“) 77 ff., 127

Identifizierungsprozeß 26, 50, $52 \mathrm{ff}$., $74 \mathrm{f}$., 88 f., 118, 122, $126 \mathrm{f}$.

Image-Parallelisierung $69 \mathrm{f}$.

Image-Schematisierung $67 \mathrm{ff}$.

Indianerkriege $21 \mathrm{f} ., 30,113,116$

Isolation Nordostbrasiliens 17 f., 112

Katholizismus 28, 77 ff., 91 ff., 129

Kollektivideologie 23 f., 42, 88 f.

Konservatismus 90 ff., 101, 128

Liebesgeschichten 28, 60, 71, $83 \mathrm{ff}$., $123 \mathrm{f}$., 130

Magie 28, 43, 54 f., 81 f., 129, 92, 122

Märchen 27, 83 ff., 114

Metrik 7 ff., 103 ff., 110

Militarismus $32 \mathrm{f}$., $117 \mathrm{f}$.

Morde $61 \mathrm{ff} ., 125 \mathrm{f}$.

Patriarchalismus 34 f., 118

Pícaro-Geschichten 16, 27, 43, 84, $114 \mathrm{f}$.

Polizei (Bekämpfung der Cangaceiros und soziale Stellung) $32 \mathrm{f}$., $38,44,47$ f., 51 ff., 78, 117, 122 f.

Professionalisierung des Cangaços $32 \mathrm{f}$.

Protestantismus 28, 94

Revolution $100 \mathrm{f}$.

Ritterlichkeit $61 \mathrm{f}$, , 68, 124

Romanzen 12, 15 f., 84, 104, 110 ff., 132

Roland-Zyklus 16, 27, $85 \mathrm{f}$.

Satiren 27 f., 115, 132 
Sadismus, Sadomasochismus 35, 63, Utopismus 28, 99 f., 102 $90,101,118 \mathrm{f}$.

Schläue 121

Sertão-Gesellschaft $22 \mathrm{ff}$., $30 \mathrm{ff}$., 34 ff., $101 \mathrm{ff}$., 113

Sexualverbrechen $34,63 \mathrm{ff} ., 120$, $124 \mathrm{f}$.

Strophenformen $7 \mathrm{ff}$., 103 ff., 108, 110

Valentes 27, 64, 86 ff., 125, 127, $129 \mathrm{f}$.

Verbrecher $116 \mathrm{f} ., 129 \mathrm{f}$.

Verwendung nicht-brasilianischer Stoffe 19, $84 \mathrm{ff}$., $111 \mathrm{f}$.

Vitalität $98 \mathrm{ff}$.

Volksbücher 9, 15, 18, 110

Tapferkeit 61, 73, 120, 133

Teufel (das „Böse“) 28, 77 ff., 84, 87, $127 \mathrm{ff}$.

Troja-Zyklus 16

Unsterblichkeit $80 \mathrm{f}$.

Weltuntergang $97 \mathrm{ff} ., 131 \mathrm{ff}$.

Zuckerrohr-Gesellschaft 21 ff., 30, 113,133

Zweikämpfe 43 f., 47 f., 69 ff., 121 f., 127 
Abreu, Capistrano de 113

Aires, Silvino 38

Albuquerque, Ulysses Lins de 39, 112

Alencar, José de 19, 112

Amado, Jorge 96, 125, 131, 132

Andrade, Mário de 41, 96, 107, 121 f., 124 ff., 131

Aranha, Graça 131

Ataíde, João Martins de 19, 47 f., 64, 71, 96, 107, 109, $113 \mathrm{f}$.

Azulão 105, 109

Bandeira, Manuel 97

Barbier, Charles 103

Barreto, Luís 132

Barros, Leandro Gomes de 10, 13, 16, 43 f., 49, 58 f., 61, 80, 93 f., 107 f., 109, 113, 120, 121 f., 124, 126

Barroso, Gustavo 26, 39, 104, 107 f., 114, $116 \mathrm{f} ., 122,132 \mathrm{f}$.

Bartolomeu, Floro 131

Batista, Francisco das Chagas 9, 10, 13, 38, 44, 50 f., 52 ff., 61, 93 f., 113, $120 \mathrm{ff} ., 124$ f., 127

Bezerra, João 41, 52

Bocage, Manuel Maria Barbosa du 8, 104

Boccaccio, Giovanni 19

Bopp, Raul 131

Braga, Teófilo 103, 110

Caetano, Antônio 92

Camelo, José 124

Camões, Luís de 7, 15 f., 27, 104

Campina, Manuel A. 115

Campos, Eduardo 107, 129

Campos, Renato Carneiro 107, 115

Carvalho, Cícero Rodrigues de 39, 41, 115 ff., 121, 125, 133

Carvalho, José Rodrigues de 107 f.
Cascudo, Luís da Câmara 26, 41, 103 f., 107 f., 110 ff., 117, 120, 129,131

Castello, José Aderaldo $131 \mathrm{f}$.

Castelo Branco, Camilo 19

Catingueira, Inácio da 9

Cavalcante, Rodolfo 14, 22, 113

Cesário (Severino?) 121

Cícero, Padre (Cícero Romão Batista) $28,40 \mathrm{f.,} 86,91 \mathrm{ff} ., 119$, 124, 129, 130 f., 133

Conselheiro, Antônio 91, 99

Cordeiro, José 39, 93

Corisco 33, 41, 82, 118

Costa, Francisco Augusto Pereira da 107, 112

Cunha, Euclides da 98, 109, 120

Dias, Baltasar 15, 18

Duda, José Galdino da Silva 19

Facó, Rui 100, 112, 116 f., 119, 133

Feitosa, Vicente 106

Ferreirinha 106

Freyre, Gilberto 115, 119, 133

Freud, Sigmund 114, 118 f., 121

Fromm, Erich 119

Garrett, Almeida 16

Gueiros, Optato 41

Heitor, Luís $105 \mathrm{f}$.

Leal, Vítor Nunes 117

Lessa, Orígenes 107, 109, 128

Lima, Augusto Sousa 130

Lima, Estácio de 133

Lima, Pires de 110, $111 \mathrm{f}$.

Lima, Silvino Pirauá 108

Lira, Luís Rodrigues 124, 130

Lope de Vega 8, 111

Lourenço (Beato Lourenço) 119, 120 
Lourenço Filho 131

Luna, Luís 41, 115, 131

Macêdo, Nertan 41, 131

Maciel, Laurindo Gomes 126

Mãe d'Água, Romano da 9

Marchant, Alexander 113

Maria Bonita (Maria Déa) 40, 130

Matos, Horácio de $116 \mathrm{f}$.

Maurício (Tenente Maurício) 117, 122

Melo, Silva 81

Melo, Veríssimo de $123 \mathrm{f}$.

Menéndez Pidal, Ramón 12, 99, $109 \mathrm{ff} ., 133$

Menezes, Djacir 113, 116

Messias 105

Mettmann, Walter 111

Montenegro, Abelardo F. 131

Moreira, Thiers Martins 107

Morel, Edmar 131

Mota, Leonardo 8, 104 f., 106 f., 110

Mota, Mauro 120, 131

Mullahy, Patrick $118 \mathrm{f}$.

Nascimento, Cícero Cidrono do 73

Olímpio, Domingos 132

Oliveira, Severino Gonçalves de 78, 128

Oliveira, Xavier de 131, 133

Pacheco, José 10, 113

Patriota, Jó 105

Pereira, Sebastião 40, 115

Pereira Sobrinho, Manuel 59 f., 64, $71,81,121,123 \mathrm{f}$.

Pfandl, Ludwig 108

Pimentel, Altimar de 112

Prestes, Luís Carlos 40

Proença, M. Cavalcânti 105, 107, 109
Queiroz, Rachel de 40

Ramos, Graciliano 96, 99 f., 117 f., 131,133

Rêgo, José Lins do 96 f., 109, 117, $120,122,131 \mathrm{ff}$.

Rocha, Moreira da 116

Rodríguez Marín, Francisco 15

Romeiro, Sílvio 107, 112, 133

Rosa, João Guimarães 133

Rowland, Robert 109

Sá, Mem de 21

Santa Cruz, Luís 107, 129

Santos, João Antônio 120

Santos, Manuel Camilo dos 24, 115, 125

Sena, Joaquim Batista de 64

Silva, Antônio de Morais 116

Silva, João Bernardo da 52, 130

Silva, João José da 14, 113, 120, 129,130

Silva, João Vicente da 115

Silva, Minelvino Francisco 64

Suassuna, Ariano 27, 106, 114

Távora, Franklin 112

Teófanes (Tenente Teófanes) 39, 53, 122

Ugolino (Ugolino da Teixeira) 106, 108

Valente, Waldemar 107, 114, 120

Vargas, Getúlio 29

Vascurado, Francisco Guerra 128

Vicente, Gil 15, 110

Vicente, Zé 64

Volta Sêca 50

Wallensköld, A. 130

Willems, Emílio 119 
TEIL I: DIE VOLKSPOESIE NORDOSTBRASILIENS UND DER EPISCHE ZYKLUS DER CANGACEIROS $\ldots . . .5$

Streitgesang und epische Gedichte ................. 6

Ursprünge der epischen Gedichte in Nordostbrasilien ..... 15

Die soziale Stellung der Volksdichter und ihres Publikums .. 21

Der Zyklus der Cangaceiros und die Klassifizierung

der epischen Volksgedichte Nordostbrasiliens ........... 25

Die historische und soziologische Entwicklung des Cangaços .. 30

Die psychologische Basis der Sertanejos ............... 34

TEIL II: DAS BILD DER CANGACEIROS

IN IHREM EPISCHEN ZYKLUS $\ldots \ldots \ldots \ldots \ldots \ldots, 37$

Antônio Silvinos und Lampiãos Leben und Taten

im epischen Zyklus der Cangaceiros $\ldots \ldots \ldots \ldots \ldots \ldots . . \ldots$

Antônio Silvinos und Lampiãos Eigenschaften und Charaktere

im epischen Zyklus der Cangaceiros ................. 61

Phasen der Schematisierung

im epischen Zyklus der Cangaceiros ................. 66

Das Symbol des Cangaceiros ................... 72

Die Position des epischen Zyklus der Cangaceiros
innerhalb der Volkspoesie Nordostbrasiliens .......... 83

SCHLUSSBETRACHTUNG $\ldots \ldots \ldots \ldots \ldots \ldots \ldots \ldots \ldots \ldots \ldots$

Der Cangaceiro als Volksheld Nordostbrasiliens $\ldots . \ldots . .95$

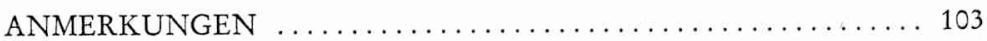

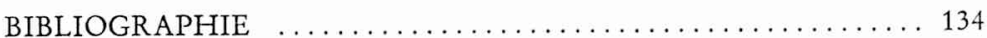

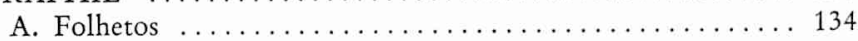

B. Sekundärliteratur $\ldots \ldots \ldots \ldots \ldots \ldots \ldots \ldots \ldots \ldots \ldots \ldots \ldots$

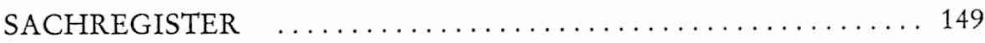

PERSONENREGISTER $\quad \ldots \ldots \ldots \ldots \ldots \ldots \ldots \ldots \ldots \ldots \ldots \ldots \ldots \ldots \ldots \ldots \ldots$ 


\section{BIBLIOTHECA IBERO - AMERICANA}

Veröffentlichungen des Ibero-Amerikanischen Instituts

Preußischer Kulturbesitz

Herausgegeben von Hans-Joachim Bock

Band 1 . Max Uhle

Wesen und Ordnung der altperuanischen Kulturen

Aus dem Nachlaß herausgegeben von Gerdt Kutscher

132 Seiten, 2 Tafeln, 7 Abbildungen, engl. Broschur DM 14,-

Band 2 . Hans Horkheimer

Nahrung und Nahrungsgewinnung im

vorspanischen Peru

160 Seiten, 8 Tafeln, 7 Abbildungen, engl. Broschur DM 14,-

Band 3 . Miguel de Ferdinandy

En torno al pensar mítico

264 Seiten, 5 Tafeln, 2 Abbildungen, engl. Broschur DM 24,-

Band 4 - Peter A. Schmitt

Paraguay und Europa

Die diplomatischen Beziehungen unter Carlos Antonio López und Francisco Solano López 1841-1870

368 Seiten engl. Broschur DM 24,-

Band 5 . Rudolf Geske

Góngoras Warnrede im Zeichen der Hekate

Ein Deutungsversuch

zu den Versen 366-502 der Soledad Primera

136 Seiten engl. Broschur DM 14,-

Band 6 . Cary Hector

Der Staatsstreich als Mittel der politischen Entwicklung in Südamerika

226 Seiten engl. Broschur DM 19,-

COLLOQUIUM VERLAG BERLIN 


\section{BIBLIOTHECA IBERO-AMERICANA}

Veröffentlichungen des Ibero-Amerikanischen Instituts

Preußischer Kulturbesitz

Herausgegeben von Hans-Joachim Bock

Band 7 - Fritz Hoppe

Portugiesisch-Ostafrika

in der Zeit des Marquês de Pombal (1750-1777)

360 Seiten engl. Broschur DM 24,-

Band 8 . Juan Carlos Agulla

Soziale Strukturen und soziale Wandlungen in Argentinien

278 Seiten engl. Broschur DM 19,-

Band 9 - Friedel Maurer-Rothenberger

Die Mitteilungen des Guzmán de Alfarache

132 Seiten engl. Broschur DM 14,-

Band 10 . Georg Thomas

Die portugiesische Indianerpolitik in Brasilien

1500-1640

244 Seiten engl. Broschur DM 19,-

Band 11 . Ulrich Fleischmann

Ideologie und Wirklichkeit in der Literatur Haitis

312 Seiten engl. Broschur DM 24,-

Band 12 . Ronald Daus

Der epische Zyklus der Cangaceiros in der Volkspoesie

Nordostbrasiliens

156 Seiten engl. Broschur DM 14,-

COLLOQUIUM VERLAG BERLIN 



der unantastbaren „Autorität", gegenübersteht. Durch eine undialektische, entwicklungslose Antithetik versuchten die Volksdichter, das psychische und soziale Gleichgewicht in ihrer Gesellschaft zu erhalten und ihren Mitbürgern das Gefühl ständiger Sicherheit zu suggerieren. Der tatsächliche Beginn einer dynamischen geschichtlichen Entwicklung wird in der Volkspoesie (literarisch erfolgreich) $\mathrm{zu}$ einer Bestätigung der alten Immobilität umgedeutet.

In einem Anhang stellt Ronald Daus den Übergang der volkstümlichen CangaceiroKlischees in die "gehobene" brasilianische Literatur dar und macht darauf aufmerksam, daß sich hier durch die willkürliche Trennung des Symbols von seiner ursprünglichen Antithese kurioserweise bei den betreffenden Autoren die Überzeugung durchgesetzt hat, gerade die Cangaceiro-Literatur in der Volkspoesie sei Beweis für die eminent revolutionäre Gesinnung der nordostbrasilianischen Volksmassen. 
